\title{
Poster Session Abstracts
}

\section{3rd Annual International Conference of the}

\author{
American Society for Horticultural Science
}

New Orleans, Louisiana

\begin{abstract}
All posters are displayed in the Poster Hall-Napoleon Ballroom on the third floor of the Sheraton New Orleans Hotel.
\end{abstract}

The number (in parentheses) preceeding the poster title corresponds to the location of the poster within the Poster Hall.

Presenting authors are denoted by an astrisk (*).

Poster Session 1-Herbs, Spices, and Medicinals

27 July 2006, 12:00-12:45 p.m.

(132) Study on Morphological Characteristics and Essential Oil Constituents Bulgarian Oil-bearing Rose

Natasha Kovacheva ${ }^{1}$, Krasimir Rusanov ${ }^{2}$,

Valtcho Jeliazkov (Zheljazkov)*3, Nedko Nedkov ${ }^{1}$

${ }^{1}$ Institute of Rose and Aromatic Plants, Institute of Rose and Aromatic Plants, Kazanlak, Bulgaria; ${ }^{2}$ AgroBioInstitute, Bulgaria, So, AgroBioInstitute, Dragan Tsankov 8, Sofia, Bulgaria, Sofia, Bulgaria; ${ }^{3}$ Mississippi State, North Mississippi Reserch and Ext. Center, Verona, MS, 38879

Bulgaria is famous for its 330-year-old-tradition in rose oil production, which is based on the Kazanluk rose (Rosa damascena Mill. $f$. trigintipetala Dieck.). The Bulgarian rose oil (otto) is recognized as the ultimate rose oil. For successful selection and breeding work of oil-bearing roses, information is needed on the variation of morphological and phenological characteristics and essential oil composition of locally available genotypes. We estimated the correlation coefficients between yields and morphological characteristics of 15 genotypes of Bulgarian oil-bearing rose. It was found that rose yields depended mostly on the number of flowers, the number of flower branches per bush, and the weight of individual flowers $(r=0.99,0.88$, and 0.84 , respectively). Also, we established correlations between the concentrations of various essential oil constituents of the Bulgarian rose oil. Generally, higher concentration of citronellol + nerol was associated with lower concentration of geraniol and stereo-terpens $(r=-0.76$ and -0.59 , respectively). Also, higher concentration of citronellol + nerol was positively correlated to increased concentration of terpene aldehydes $(r$ $=0.63)$ and esters $(r=0.48)$. The geraniol concentration was positively correlated to stearoptenes $(r=0.57)$. Both morphological characteristics and essential oil constituents should be used for further selection of high-yielding cultivars with desirable essential oil composition.

\section{(133) Growth and Development of Introduced Leuzea in the Rose Valley, Bulgaria}

Anatoli Dzhurmanski ${ }^{1}$, Georgi Dzhurmanski ${ }^{1}$, Valtcho Jeliazkov (Zheljazkov)*2

${ }^{1}$ Institute of Rose and Aromatic Plants, Institute of Rose and Aromatic Plants, Kazanlak, Bulgaria; ${ }^{2}$ Mississippi State, North Mississippi Research and Extension Center, Verona, MS, 38879

Leuzea, or Maralroot, is a perennial medicinal plant originating from Siberia, and is characterized with significant metabolic and tonic effects. A 3-year study was conducted at the Research Institute for Roses, Aromatic and Medicinal Plants Kazanluk, Bulgaria, on the introduction of various genotypes of Leuzea (Rhaponticum carthamoides Willd/Iljin.) from the Altai region, Russia. Phenological observations, and up to 11 morphological indices were characterized for 1-, 2-, and 3-year-old plants. Generally, it was found that the climatic and soil conditions in the region were not very favorable for the growth and development of Leuzea. Also, for the tested region, Leuzea should be grown only under irrigation. Yields of Leuzea roots and rhizomes reached $7.19 \mathrm{t} / \mathrm{ha}$ in the 2nd year, and up to $8.62 \mathrm{t} / \mathrm{ha}$ in the $3 \mathrm{rd}$ year. Yields of aboveground herbage were up to $8.73 \mathrm{t} / \mathrm{ha}$ when plants were harvested at the beginning of blossoming. Second cut of the above-ground herbage of Leuzea was not satisfactory under the climatic conditions of the region. When grown for seed production, seed yields during the 3 rd year were up to $128 \mathrm{~kg} / \mathrm{ha}$. Leuzea may have a potential as a cash crop for the region if grown for seed production.

\section{(134) Effect of Seed Source and Organic Management on Agronomic Performance of Three Species of Echinacea}

Fredy R. Romero*, Kathleen Delate, David Hannapel

Iowa State University, Horticulture, Ames, IA, 50011

Consumption of Echinacea, one of the most popular botanical supplements, continues to expand in the United States. In addition, organic herbal products have captured a large share of the botanical supplement market. We evaluated commercial organic production of the three most-important medicinal species of Echinacea, E. angustifolia DC, E. purpurea (L) Moench., and E. pallida (Nutt.) from two seed sources. Plants were grown in the field for 3 consecutive years. We found that, during the first year, screen cages were associated with enhanced post-transplanting establishment. Growth of E. angustifolia was not affected by either production system or seed source after 3 years, and yields were equivalent for years 2 and 3 for this species. Growth of E. purpurea was affected by production system, but not by seed source, during the first 2 years. In year 3 , neither seed source nor production system affected growth of E. purpurea. Yield of E. pallida was greater in the open field the first year; no difference between production systems was found during the second; and, by the third year, plants growing in screened cages produced more than plants growing in the open field. Production system affected yield of E. purpurea only during year 2, and yield was greater in the open field than in screened cages. Echinacea plants in the open field, however, were more affected by aster yellows disease, with an infection rate of $17 \%$ for E. purpurea in the open field compared to $3 \%$ under screen cages. Based on these results, in areas of aster yellows incidence, excellent Echinacea root yields can be obtained under screen cages using organic seeds.

\section{(135) Study on the Seed Progeny of Echinacea purpurea Mench.}

Anatoli Dzhurmanski ${ }^{1}$, Kana Varbanova ${ }^{2}$, Valtcho Zheljazkov*3

${ }^{1}$ Research Institute for Roses, Aromatic and Medicinal Crops, Kazanluk, 6100, Bulgaria; ${ }^{2}$ Institute of Plant Genetic Resources, Sadovo, 4122, Bulgaria; ${ }^{3}$ Mississippi State, North Mississippi Research and Ext. Center, Verona, MS, 38879

Common coneflower (Echinacea purpurea) is used as medicinal, cutflower, or ornamental plant. There is significant diversity and chemotypes within the species. Flower morphology and shape has been shown to affect fertilization and, subsequently, seed formation and yields, and seed germination. The aim of this study was to describe morphological and biological characteristics of locally available Echninacea seed progeny and evaluate segregating populations in $\mathrm{F}_{1}$. Overall, the $\mathrm{F}_{1}$ seed progeny of Echinacea purpurea was clustered into three different groups 
with distinct morphological characteristics and ornamental qualities: 1) plants having tubular type of flowers, $38.9 \%$ of all plants; 2 ) plants with flat flowers; and 3) plants with cone-shaped flowers. The latter is the most commonly found type. We found that $11 \%$ of all Echninacea plants would fail to have seed set. However, $55 \%$ of Echninacea plants with tubular (spherical) flowers would be without seeds. Of the plants with tubular flowers, $40 \%$ were with tubules longer than $10 \mathrm{~mm}$. The plants from the $\mathrm{F}_{2}$ and $\mathrm{F}_{3}$ progenies were with very low seed productivity, with greater variation of morphological characteristics, and some of them with characteristics not found in $\mathrm{F}_{1}$. Several promising forms with potentially high ornamental value were identified.

\section{(136) Effects of Healthy and Natural Ingredients in Various Beverage Lines: A Practical Approach for Small Businesses by Offering Healthy Products}

\section{Usha Palaniswamy*1, Zafar Bokhari ${ }^{2}$}

${ }^{1}$ University of Connecticut, Asian American Studies, Storrs, CT, 06268; ${ }^{2}$ Chicago State University, Marketing, Chicago, IL, 60628-1598

Zafi Beverages, Inc., envisioned energy drinks, mineral natural water, healthy drinks for kids, exotic drinks, flavored drinks, and cholesterolreducing tea. Emphasis is on non-carbonation and the use of herbal extracts. Consumption of carbonated drinks can lead to reflux, ulcer, and other stomach problems. Zafi Beverages is also developing a unique marketing approach for its products, offering a niche for small businesses and entrepreneurs. Zafi's educational process of entrepreneurship also covers the steps on the road to success: innovative, value-creating, and growth-oriented. Emphasis is also placed on ethical marketing. Small businesses employ $53 \%$ of the total private nonfarm work force, contribute to $47 \%$ of all sales in the country, are responsible for $51 \%$ of the gross domestic product (GDP), produce about two out of every three new jobs each year, and account for over half of United States GDP. Studies report that $40 \%$ of the top $1 \%$ of the wealthiest Americans got there by building a small business. Interest in small business is increasing, because many Americans believe this is one of the best paths to riches in the United States. About 16 million Americans are in some type of part- or full-time entrepreneurial activity. Entrepreneurship is attractive to people of all ages. Some unique contributions of small business concepts promoted by Zafi Beverages are to encourage innovation and flexibility, maintain close relationships with customers and community, and provide employees with comprehensive learning experience, develop risk-takers, generate new employment, and provide greater job satisfaction. Zafi Beverages is 2 years old; its growth and challenges in the development of herbal drinks for health and new entrepreneurs are described.

\section{Poster Session 2-}

Vegetable Crops Management-Cropping Systems 1

27 July 2006, 12:00-12:45 p.m.

\section{(1) Influence of Storage Temperature and Time in Storage on Pigment Content of Potato (Solanum tuberosum L.)}

Mekhled M. Alenazi ${ }^{1}$, Harrison G. Hughes ${ }^{* 1}$, Cecil Stushnoff ${ }^{1}$, David G. Holm²

${ }^{1}$ Colorado State University, Department of Horticulture \& Landscape Architecture, Colorado Fort Collins, Colorado, 80523-1173; ${ }^{2}$ Colorado State University, San Luis Valley Research Center, Center, Colorado, 81125

The influence of storage temperature and length of time in storage on anthocyanin tuber concentration were investigated in seven potato genotypes. These genotypes were cultivars 'All Blue' and 'Yukon Gold' plus five selections that were various skin/flesh color types of red/red, purple/purple, white/yellow, and two red/yellow types. The red, blue, and purple colors are the result of various anthocyanin compounds. Tubers of the seven genotypes were stored at 4.4 or $10{ }^{\circ} \mathrm{C}$ for $0,4,6,8,10,12,16,20$, or 24 weeks. Both fresh and freeze-dried samples of the tubers were evaluated for each temperature and time treatment combination. Extractable anthocyanins were found in only the three pigmented genotypes red/red, purple/purple, and 'All Blue'. Anthocyanin concentrations were estimated spectrophotometrically with a Molecular Devices Spectramax 384, based upon extinction coefficients reported in the literature for purple and red pigmented potatoes. Anthocyanin concentration increased in storage as time in storage increased for both fresh and freeze-dried samples. Tubers stored at the cooler temperature $\left(4.4^{\circ} \mathrm{C}\right)$ had higher levels of anthocyanin than those tubers stored at the higher temperature $\left(10^{\circ} \mathrm{C}\right)$. Increased levels of anthocyanins in cold-stored tubers may be linked to the conversion of starch to sugar (so called cold sweetening) known to occur at cold storage temperatures. Pigment extraction was more efficient from freeze-dried tuber samples compared to fresh tuber samples. There was, however, a similar increasing trend in both freeze-dried and fresh tuber sources with storage duration.

\section{(2) Icebox Watermelon Variety Trial in Western Washington}

Carol A. Miles*1, Kathryn Kolker², Tracy Smith ${ }^{2}$, Jenn Reed ${ }^{2}$, Gail Becker $^{2}$, Carolyn Adams ${ }^{2}$

${ }^{1}$ Washington State University, Horticulture and Landscape Architecture, Vancouver, WA, 98665; ${ }^{2}$ Washington State University, Extension

Icebox watermelons first appeared in the United States about 50 years ago. They weigh between 6 and 12 pounds and come in a variety of shapes and colors. With a rising interest in local production, organic produce, and direct marketing, farmers in Washington are looking to diversify crop varieties to meet these demands. Icebox watermelons offer a means of locally producing high-quality watermelons. In 2004 and 2005, we evaluated icebox watermelon varieties to determine which are most suitable for production in our region. In 2004, we evaluated 44 varieties of icebox watermelon and in 2005 we evaluated 100 varieties at WSU Vancouver REU. Varieties were seeded in the greenhouse midApril and transplanted to the field by mid-June. The greenhouse and field were managed organically. The study design was a randomized complete-block with three replications. Plots were single rows, 6.1 $\mathrm{m}$ long, with seven plants per plot. Spacing was $1 \mathrm{~m}$ between plants and $3 \mathrm{~m}$ between rows. Plants were mulched with black plastic and drip-irrigated $2.5 \mathrm{~cm}$ per week. Melons were harvested twice weekly, from mid-August through mid-October. Fruit weight, number, and size were measured, and percentage of soluble solids was measured using a ${ }^{\circ}$ Brix meter. General eating quality was also evaluated. Summaries of selected varieties will be presented here. To view other varieties included in the trial, see our website, http://agsyst.wsu.edu. Results of this study show significant differences among icebox watermelon varieties in total yield, number of fruit per plot, average fruit weight, number of days to harvest, and percentage of soluble solids. These preliminary findings indicate that more than 80 varieties of icebox watermelon can be grown productively in our region.

\section{(3) Comparability of Nutrient and Water Management Strategies for Seepage-irrigated Watermelon in South Florida}

Kent Cushman*1, Sanjay Shukla², Gregory Hendricks², Thomas Obreza $^{3}$, Fritz Roka ${ }^{4}$, Eugene McAvoy

${ }^{1}$ University of Florida, Horticultural Sciences Department, Immokalee, FL, 34142; ${ }^{2}$ University of Florida, Agricultural and Biological Engineering, Immokalee, FL, 34142; ${ }^{3}$ University of Florida, Soil and Water Science Department; ${ }^{4}$ University of Florida, Food and Resource Economics; ${ }^{5}$ University of Florida, Hendry County Extension

Florida is one of the leading states in the United States in watermelon production, and on-farm management of nutrients and water is an important issue in the state. A management strategy using higher-thanrecommended rates was compared to two strategies using recommended rates. A systems approach was used to define treatments: (HR) high rate of 265 pounds per acre $(\mathrm{lb} / \mathrm{ac}) \mathrm{N}, 170 \mathrm{lb} / \mathrm{ac} \mathrm{P}_{2} \mathrm{O}_{5}, 459 \mathrm{lb} / \mathrm{ac} \mathrm{K}_{2} \mathrm{O}$, and soil moisture content of $16 \%$ to $20 \%$ via seepage irrigation, (RR) 
recommended rate of $150 \mathrm{lb} / \mathrm{ac} \mathrm{N}, 100 \mathrm{lb} / \mathrm{ac} \mathrm{P}_{2} \mathrm{O}_{5}, 150 \mathrm{lb} / \mathrm{ac} \mathrm{K}_{2} \mathrm{O}$, and soil moisture content of $8 \%$ to $12 \%$ via seepage irrigation, and (RR-S) equal to RR but irrigation provided by subsurface drip tubing. Large quarter-acre plots were used for each experimental unit. 'Tri-X 313' was interplanted with 'Mardi Gras' during Spring 2004 and with 'SP-1' during Spring 2005 in a RCB design with two replications at the SWFREC in Immokalee. Leaf tissue analyses, petiole sap, and biomass accumulation were recorded each season. Watermelons were harvested at least twice each year and fruit were counted and weighed individually from three subplots within each plot. At least five fruit from each subplot were cut open for internal evaluation. Leaf nitrogen and potassium content for HR was consistently greater than that of RR or RR-S. Yields of HR were $41 \%$ to $50 \%$ greater than the two RR treatments. Yield was 1089, 704, and 775 hundred-pound units per acre (cwt/ac) in 2004 and 801, 541, and $533 \mathrm{cwt} / \mathrm{ac}$ in 2005 for HR, RR, and RR-S, respectively. Soluble solids content and hollowheart incidence were not affected by treatment. Our results indicate HR was more productive than RR or RR-S and may justify the higher inputs associated with this management strategy.

\section{(4) 1-MCP Preharvest Spray Application to Synchronize Harvest and Improve Fruit Quality of Cantaloupe}

Daniel Leskovar*1, Shinsuke Agehara*1, Smiljana Goreta ${ }^{2}$

${ }^{1}$ TAES, Texas A\&M University, Horticulture, Uvalde, TX, 78801; ${ }^{2}$ Institute for Adriatic Crops, Vegetable Crops, Put duilova 11, Split, 21000, Croatia

The objective of this study was to determine the effects of 1-MCP preharvest spray application on harvest synchrony, maturity, fruit quality, and marketable yield of cantaloupe. Seeds were planted in a commercial field on 16 Mar. (early planting, cv. Caravelle) and 4 Apr. (late planting, cv. Mission) 2005. Standard plant population, fertilization, irrigation, and pest control practices were followed. We evaluated three $1-\mathrm{MCP}$ rates $\left(5,10\right.$, or $25 \mathrm{~g} \cdot \mathrm{ha}^{-1}$ a.i. $)$ at three preharvest spraying times for the early $(22,15$, and 7 days before harvest, $\mathrm{DBH})$ or once for the late planting experiment (4 DBH). An additional test (late planting) compared fruit quality after storage for melons dipped with 1 -MCP ( 0 or $\left.10 \mathrm{mg} \cdot \mathrm{L}^{-1}\right)$. Fruits were harvested six times during June 2005 (early planting) and once on 19 July 2005 (late planting) and fruit quality parameters were measured at harvest and after storage. The preharvest 1-MCP application slightly delayed maturity and improved early harvest synchrony, but did not affect total marketable or yield by fruit size regardless of timing or rate of application. There was no effect of 1-MCP rate or application timing on fruit quality at harvest or after cold storage, except for an increased in fruit firmness $(10 \%)$ in one of the six harvests. However, fruits treated with 1-MCP spray at $25 \mathrm{~g} \cdot \mathrm{ha}^{-1}$ a.i. (late planting) had higher firmness than those treated with lower rates after 9 days of storage. In addition, 1-MCP postharvest dipping significantly improved fruit firmness; however, a 'greening' was evident in the fruit surface. Our results suggest that cantaloupe fruit quality was less affected by early preharvest spray application of 1-MCP applied at less than $25 \mathrm{~g} \cdot \mathrm{ha}^{-1}$ a.i. as compared to postharvest applications.

\section{(5) Cucumber Cultivars and Cultural Practices for Patio Gardening}

Melisa Crane, Todd Wehner*

North Carolina State University, Horticultural Science, Raleigh, NC, 27695-7609

Cucumber (Cucumis sativus L.) is one of the most popular vegetables grown in U.S. home gardens. The objectives of this study were to identify suitable cultivars and proper plant density for use with container-grown cucumber. Additional objectives were to determine the value of field trials for predicting cucumber performance in containers, and to evaluate different plant types (dwarf vs. tall, gynoecious vs. monoecious, pickling vs. slicing) for container use. Fourteen cultivars and breeding lines were tested at three densities in two seasons using a randomized complete-block design with six replications. Pickling cucumbers were M 21, M 27, NC-74, 'NC-Danbury', 'NC-Dixon', 'Sumter', 'Vlaspik', and 'Picklebush'. Slicing cucumbers were 'Bush Whopper II', 'Spacemaster 80', 'Bush Champion', 'Marketmore 76', 'Dasher II', and 'Cherokee 7'. Plant densities were one, two, or three plants per container. For both the spring and summer container trials, there were corresponding field trials run at the same time for comparison. Best performance was obtained using three plants per container, or 4 $\mathrm{L}$ of soil volume per plant. There was a strong, significant correlation between patio and field trials, permitting gardeners to choose cucumber cultivars with high yield, high quality, and disease resistance using data from field trials. Pickling-type cucumbers have thinner skin than slicing-type cucumbers that were bred for shipping. Gynoecious types must be planted with monoecious cultivars to assure fruit set. Monoecious types can self-pollinate, and have the additional advantage of longer harvest period. Thus, home gardeners may want dwarf, monoecious, pickling types for best performance in containers. The best cultivar of that type was 'NC-Danbury'.

\section{(6) Sucker Removal and Pruning Affect on Heirloom Tomato Yield and Fruit Size}

Wesley L. Kline*1, Stephen A. Garrison ${ }^{2}$, June F. Sudal ${ }^{3}$

${ }^{1}$ Rutgers University, Agricultural and Resource Management Agents, Millville, NJ, 08332; ${ }^{2}$ Rutgers University, Extensioin Specialists, Rutgers Agricultural Research and Extension Center, Bridgeton, NJ, 08302; ${ }^{3}$ Rugers University, Agricultural Specialist, Rutgers Agricultural Research and Extension, Bridgeton, NJ, 08302

Heirloom tomato production is increasing in the Eastern United states as consumer demand increases. Pruning and suckering heirloom tomatoes have not been studied to see if there is any need for this labor-intensive activity. A 2-year study was undertaken to evaluate whether pruning or suckering would affect yield or fruit size for two heirloom cultivars ('Mortgage Lifter' and 'Prudens Purple'). The treatments imposed on the cultivars were 1) removing all suckers from the second or third stem down after the flower cluster; 2) removing the bottom two suckers, or 3 ) removing no suckers. Pruning had no effect on early yield or fruit size (harvests 1-4). Mid-season (harvests 5-7) total and marketable yields were significantly higher for removing two suckers or not suckering over the other two treatments for year 1 , but not year 2 . The tomato fruit size was only reduced for the non-suckering treatment. There were no statistical differences among the pruning treatments for yield or fruit size for late season harvests (8-10) for both years. Marketable yields were statistically higher for no suckering over the two- and three-stem treatments, but not different from two suckers when all harvests were combined for the season for year 1 . No statistical differences were observed in year 2. However, fruit size was reduced when not suckering compared to the other treatments. The cultivar 'Prudens Purple' did have higher total and marketable yield than 'Mortgage Lifter' for both early and total combined harvests, but not for mid- or late-season harvests in year 1 . There were no statistical differences between the two cultivars for year 2 .

\section{(7) Effect of Leaf Removal on Beef Tomato Cultivated under Greenhouse Conditions}

Rubén Macias-Duarte ${ }^{1}$, Raul Leonel Grijalva-Contreras*2, Fabián Robles-Contreras ${ }^{3}$, Manuel de Jesus Valenzuela-Ruiz ${ }^{4}$ ${ }^{1}$ INIFAP-Caborca, Soli \& Horticultural, Caborca, Sonora, 83600, México; ${ }^{2}$ INIFAPCaborca, Protected Horticulture, Caborca, Sonora, 83600, México; ${ }^{3}$ INIFAP-Caborca, Agroclimatology, Caborca, Sonora, 83600, México; ${ }^{4}$ INIFAP-Caborca, Viticulture, Caborca, Sonora, 83600, México

The tomato (Lycopersicon esculentum Mill.) is the most important crop under greenhouse conditions and covers $73 \%$ of the area under that system in Mexico. To increase fruit quality and yield, leaf removal is necessary to produce a balance between the vegetative and generative growth of tomato production. The objective of this experiment was to determine the effect of leaf removal on the tomato quality and production under greenhouse conditions. The evaluation was carried out in the Experimental Station INIFAP-CIRNO inside a polyethylene greenhouse. The date of seedling establishment was 28 Sept. 2003. In this trial, we used the Beatrice variety and a plant density of 3.78 
plants $/ \mathrm{m}^{2}$. We compared four treatments of leaf removal: 1) two leaves below the cluster; 2) two leaves below the cluster and later to remove those leaves when fruit reaches commercial size; 3) severe leaf removal; and 4) the control with no leaf removal. The results show significant differences between the intensively of leaf removal. The highest yield values corresponded to the treatment 2) with a yield of $281 \mathrm{t} \cdot \mathrm{ha}^{-1}$ and fruit weight of $153 \mathrm{~g}$ vs. $202 \mathrm{t} \cdot \mathrm{ha}^{-1}$ and $137.7 \mathrm{~g}$ of fruit weight for the control treatment.

\section{(8) Supplemental Potassium Source and Processing Tomato Quality}

Christopher Gunter*1, David Francis ${ }^{2}$, Alba Clivati McIntyre ${ }^{2}$

${ }^{1}$ Purdue University, Horticulture and Landscape Architecture, Southwest Purdue Ag. Program, Vincennes, IN , 47501; ${ }^{2}$ The Ohio State University, Horticulture and Crop Sciences, OARDC, Wooster, OH, 44691

Yellow shoulder disorder (YSD) is a physiological disorder of processing tomato that affects both the appearance and nutritional quality of the fruit. This disorder reduces the suitability of fruit intended for the whole-peeled and diced product markets. The YSD involves an interaction between plant genotype and the environment. A number of soil factors have been related to the incidence of YSD, including organic matter, phosphorous, $\mathrm{K} / \mathrm{Mg}$ ratios, and soil $\mathrm{K}$. Varieties of tomatoes differ in their susceptibility to color disorders, thus variety selection offers growers one strategy to manage this color disorder. The use of supplemental $\mathrm{K}$ application at a time when plants are blooming and actively growing offers a second strategy for management of YSD. To this end, a field study was conducted at the Southwest Purdue Agricultural Program in southwestern Indiana to study the effects of different sources of $\mathrm{K}$ on the color and quality of tomato fruit. Potassium chloride, potassium nitrate, and potassium sulfate were applied at first flowering in a solid, broadcast application. Appropriate controls were used to balance the nutrients supplied in addition to K. Supplemental $\mathrm{K}$, regardless of source, improved fruit hue, though the trend was not always statistically significant between treatments. Variety specific effects were observed. This is a complex disorder and its management will entail minimizing risk of incidence through careful selection of variety and field location.

\section{(9) Cucurbitaceous Crops in Asia}

\section{Prem Nath*1, Sundari Velu*2}

${ }^{1}$ Dr. P.N. Agricultural Science Foundation (PNASF), Chairman, \#9, 1st Cross, 1st Main, 1 st Block, Rajmahal Vilas Extension, 2nd Stage, Bangalore, Karnataka, 560094, India; ${ }^{2}$ Dr. P.N Agricultural Science Foundation (PNASF), Technical Advisor, Irvine, CA, 92620-2717

Among the vegetables, the cucurbitaceous crops form one of the largest groups with their wide adaptation from arid climates to the humid tropics. In Asia, about 23 edible major and minor cucurbits are grown and consumed. Though the data on cucurbits alone are not easily available, the production of watermelon was reported to be 69.7 million tons in Asia, 9.0 million tons in the Near East, 2.7 million tons in North and Central America, and 2.4 million tons in Latin America and the Caribbean (2003). Cucurbits demonstrate wide adaptability, which allows the crops to grow in varied agroclimatic conditions. Among food crops, cucurbits are the largest producers of biological water and are easily digestible. The cucurbits contain $80 \%$ to $95 \%$ water and also contain nutritive elements, such as carbohydrates, protein, vitamins A and C, calcium, lycopene, phosphorus, potassium, and other properties, in addition to medicinal values. They are common crops in rural, urban, and peri-urban areas, and are accessible to both rich and poor. Even with the gradual increase in production and consumption, the production of cucurbits is plagued by the occurrence of diseases and insect pests, inadequate availability of quality seeds, lack of maintenance of genetic varieties and of naturally occurring biodiversities, and the lack of knowledge on the international standard of quality production and postharvest handling. The thrust areas of development, as identified, are: harnessing new sciences; diversification in cropping patterns; utilization of available genetic diversities; reversal of postharvest losses; and value addition in food products. Cucurbits hold promise as supplementary food for the common masses.

\section{(10) Effect of the Floating Cover on Cucumber (Cucumis sativus L.) Yield}

Marcelino Bazán Tene*, Javier Farías Larios, José Gerardo López Aguirre, Francisco Radillo Juárez, Jorge Rogelio Flores Sánchez

Universidad De Colima, Facultad De Ciencias Biológicas y Agropecuarias, Km. 40 Autopista Colima Manzanillo, Tecomán, Colima, 28100, México;

Production of horticultural crops is important throughout the world, with high consumption mainly in Europe and the United States of America. Cucumber is consumed both fresh and processed. This vegetable generates important profits for producing countries such as Mexico, which, in 2003, produced 435,897 tons of fresh fruit with a value of 1.190 million Mexican pesos (around USD \$109 million). The objective of this work was to evaluate the effect of the floating cover on the yield of fresh cucumbers. Four treatments and five repetitions were imposed in a randomized distribution: covered 20 days (C20) post-emergence, covered until beginning of flowering (CF), covered until beginning of harvest (CIC), and without cover (SC). Data at the first and fourth harvest were analyzed. Results showed that, in the first harvest, treatment C20 days was highest in fruit yield (3.11 ton/ha); Treatment CIC had 2.47 ton/ha, and SC produced 1.66 ton/ha. Data obtained in the fourth harvest, treatment $\mathrm{C} 20$, had the highest yield, with 24.12 ton/ha, and treatment CF had a yield of 21.11 ton/ha, but there was not significant difference (Tukey's $P<0.05$ ).

\section{Poster Session 3-Postharvest}

\section{July 2006, 12:00-12:45 p.m.}

\section{(179) Using Quantitative Real Time PCR to Predict Levels of Botrytis allii in Stored Onion}

Timothy Coolong*1, William Randle ${ }^{1}$, Ronald Walcott ${ }^{2}$

${ }^{1}$ University of Georgia, Horticulture, Athens, GA, 30602; ${ }^{2}$ University of Georgia, Plant Pathology, Athens, GA, 30602

Onion (Allium cepa L.) is an economically important vegetable in the United States. Though considered a minor crop in terms of total acreage, onions have high value when compared to other crops and, nationally, their value approaches $\$ 800$ million. Because harvested onions are routinely stored for long periods, disease can be a major obstacle to the industry. The primary disease reported in stored onions is botrytis neck rot caused by the fungus Botrytis allii (syn. B. aclada). Losses from neck rot can approach $35 \%$ of the stored crop. In order to accurately quantify the level of $B$. allii inoculum in bulbs at harvest to be able to predict potential botrytis neck rot in storage, a quantitative real-time PCR test to quantify levels of $B$. allii DNA present in onion bulb tissue has been developed. We have employed the TaqMan real time PCR assay and report log-linear $\left(R^{2}=0.9915\right)$ relationship between $B$. allii DNA concentration and cycle threshold $(\mathrm{Ct})$ value with a detection limit of 5 pico gram/microliter DNA. In addition, a log-linear standard curve plotting mycelial dry weight against $\mathrm{Ct}$ value has been developed to allow prediction of mycelial weight in onion tissue at harvest. Currently, the ability of this test to predict botrytis neck rot during storage is being tested.

\section{(180) Postharvest Calcium Chloride Dips of Whole Tomato Fruit Reduce Postharvest Decay under Commercial Conditions}

Mark A. Ritenour*1, Peter J. Stoffella ${ }^{1}$, Zhenli $\mathrm{He}^{1}$, Jan A. Narciso², James J. Salvatore ${ }^{1}$

${ }^{1}$ University of Florida, Indian River Research and Education Center, Fort Pierce, FL, 34945-3138; ${ }^{2}$ USDA-ARS, Citrus \& Subtropical Products Laboratory, Winter Haven, FL, 33881

Previous research showed that mature green tomato fruit dipped 1 to $4 \mathrm{~min}$ in a $1 \% \mathrm{CaCl}_{2}$ solutions before storage had significantly increased peel calcium content and reduced postharvest decay. The present experiments, conducted over 3-day periods (reps), evaluate 
treatment effectiveness under commercial packinghouse conditions. Three cartons of $5 \times 6$ sized mature green 'FL 47' tomatoes were collected from the line (control). $\mathrm{CaCl}_{2}$ was then added to the packinghouse 15,142 -L dump tank to a concentration of $1 \%$ before more fruit were run through the line and three additional cartons collected. The cycle was repeated after bringing the concentration in the dump tank up to $2 \% \mathrm{CaCl}_{2}$. After storage for $\leq 24$ days at $20^{\circ} \mathrm{C}$, postharvest decay was significantly reduced in fruit receiving the $2 \% \mathrm{CaCl}_{2}$ treatment. Calcium content in the tomato peel tended to increase with each successively higher $\mathrm{CaCl}_{2}$ treatment, but differences were nonsignificant. Laboratory tests showed Rhizopus more affected by $3 \% \mathrm{CaCl}_{2}$, while Alternaria was affected by $2 \%$ and $3 \% \mathrm{CaCl}_{2}$ solutions. Results were recorded as colony diameter, but colony morphology and sporulation were also affected. Inoculation studies of tomatoes dipped in $1 \% \mathrm{CaCl}_{2}$ after wounding with Rhizopus or Alternaria showed better decay control when compared to treating before wounding.

\section{(181) 1-Methylcyclopropene Pretreatment of Roma- Type Tomato Ameliorates Effects of Physical Impact}

Eunkyung Lee*, Steven A. Sargent, Donald J. Huber

University of Florida, Horticultural Science, Gainesville, FL, 32611

Roma tomatoes ('Sunoma') were hand-harvested at the mature-green color stage and treated with $100 \mu \mathrm{L} \cdot \mathrm{L}^{-1}$ ethylene for $60 \mathrm{~h}$ at $20^{\circ} \mathrm{C}$ and $90 \% \mathrm{RH}$. Tomatoes at breaker ripeness stage $(<10 \%$ red coloration) were sorted by weight (about $100 \mathrm{~g}$ ) and half of the fruits were treated with 1-methylcyclopropene (1-MCP; $1 \mu \mathrm{L} \cdot \mathrm{L}^{-1}$ for $24 \mathrm{~h}$ at $\left.22^{\circ} \mathrm{C}\right)$. After $1-\mathrm{MCP}$ treatment, individual fruits were subjected to double impacts over the marked locular surface with force equivalent to a $40-\mathrm{cm}$ height drop using a pendulum impactor. In non-1-MCP treated fruit, impacts increased the maximum respiration rate by $27 \%$ (to $39.1 \mathrm{~mL} \cdot \mathrm{kg}^{-1}$ per h) and ethylene production by $24 \%$ (to $5.5 \mu \mathrm{L} \cdot \mathrm{kg}^{-1}$ per h). Treatment with $1-\mathrm{MCP}$ decreased relative production of both $\mathrm{CO}_{2}(56 \%)$ and ethylene (54\%) over non-1-MCP treated fruit, while the ripening period (as measured by softening and color development) was extended 2.5 times, to about $8 \mathrm{~d}$. Fruits treated with 1-MCP had increased TTA (about $40 \%$; $0.58 \%$ citric acid equivalent), decreased $\mathrm{pH}(5 \%)$, and no difference in soluble solids content $\left(3.7^{\circ} \mathrm{Brix}\right)$; double impacts did not affect these values. Double impacts accelerated the onset of polygalacturonase (PG) activity by about $100 \%$ (to $99.8 \mathrm{~mol} \cdot \mathrm{kg}^{-1}$ per min* $10^{-5} \mathrm{D}$-galacturonic acid) at day 6 over non-impacted control fruit. 1-MCP treatment delayed the onset of increased PG activity by $10 \mathrm{~d}$ over non-1-MCP treated fruit. Although 1-MCP alleviated the impact-induced increase in PG activity, PG activity recovered to rates similar to those of non-1-MCP treated fruit during the final $4 \mathrm{~d}$ of ripening.

\section{(182) Comparison of Aqueous and Gaseous Application of 1-Methylcyclopropene on Ripening of Tomato Fruit Harvested at Two Stages of Maturation}

Jiwon Jeong, James Lee, Donald J. Huber*

Institute of Food and Agricultural Sciences, Horticultural Sciences Department, Gainesville, FL, 32611

This study was performed to characterize the physiological responses of tomato (Lycopersicon esculentum L.) fruit harvested at either $10 \%$ to $30 \%$ or $30 \%$ to $60 \%$ color change and treated with two forms of 1-methylcyclopropene (1-MCP). Tomato fruit were treated either by submersion for $1 \mathrm{~min}$ in 1-MCP aqueous solution at the ambient temperature or by exposure for $12 \mathrm{~h}$ at $20^{\circ} \mathrm{C}$ in air with $1-\mathrm{MCP}$ gas, then stored at $20^{\circ} \mathrm{C}$. The concentrations $\left(1.0,5.0\right.$, or $\left.10.0 \mu \mathrm{L} \cdot \mathrm{L}^{-1}\right)$ in $1-\mathrm{MCP}$ aqueous solution were achieved through addition of $0.5,2.5$, or $5.0 \mathrm{~g}$ of AFxRD-300 powder (2.0\% formulation, Agro-Fresh, Inc.) to $10 \mathrm{~L}$ of the de-ionized water, following manufacturer's instructions. 1-MCP $\left(0.5 \mu \mathrm{L} \cdot \mathrm{L}^{-1}\right)$ gas in a $174-\mathrm{L}$ container was achieved through addition of $0.22 \mathrm{~g}$ of SmartFresh ${ }^{\circledR}$ powder $(0.14 \%$ formulation, Agro-Fresh, Inc.) to $100 \mathrm{~mL}$ of tap water. Both forms of 1-MCP significantly delayed ripening of fruit at the two initial ripeness stages, as noted by a significant delay in fruit softening and peel color change. The firmness of $30 \%$ to
$60 \%$ color change tomatoes was significantly retained in response to gaseous or aqueous 1-MCP. Control fruit softened rapidly and reached the minimum marketable firmness value (about $5 \mathrm{~N}$ ) within 8 days of storage at $20^{\circ} \mathrm{C}$, whereas fruit treated with gaseous $1-\mathrm{MCP}\left(0.5 \mu \mathrm{L} \cdot \mathrm{L}^{-}\right.$ $\left.{ }^{1}\right)$ or aqueous 1 -MCP $\left(1.0\right.$ or $\left.5.0 \mu \mathrm{L} \cdot \mathrm{L}^{-1}\right)$ reached the same stage after 16,20 , or 24 days, respectively. Firmness retention was also highly significant for $10 \%$ to $30 \%$ color change tomatoes treated with both forms of 1-MCP. The highest concentration of aqueous 1-MCP (10.0 $\left.\mu \mathrm{L} \cdot \mathrm{L}^{-1}\right)$ did not result in a further delay in ripening compared with treatment at 5.0 or $1.0 \mu \mathrm{L} \cdot \mathrm{L}^{-1} 1-\mathrm{MCP}$.

\section{(183) Quality and Shelf Life of Greenhouse Tomatoes Exposed to 1-Methylcyclopropene}

Sarah Stephenson*1, Jennifer DeEll ${ }^{2}$, Dennis Murr ${ }^{1}$, Rickey Yada ${ }^{3}$

${ }^{1}$ University of Guelph, Plant Agriculture, Guelph, Ontario, N1G 2W1, Canada; ${ }^{2}$ Ontario Ministry of Agriculture Food and Rural Affairs, Crop Technology 2, Simcoe, Ontario, N3Y 4N5, Canada; ${ }^{3}$ University of Guelph, Department of Food Science

The objectives of this research were to determine if 1-methylcyclopropene (1-MCP) improves fruit quality and extends shelf life of Ontario greenhouse tomatoes. 'Beefsteak' tomatoes between breaker and turning maturity stages were harvested from commercial growers in Leamington, Ontario, and randomly sorted into uniform lots for 1-MCP treatment. Application of 1-MCP concentrations from 0 to $1200 \mathrm{~nL} / \mathrm{L}$ was done at $22{ }^{\circ} \mathrm{C}$ for 12 hours in sealed bags. After treatment, fruit were held at $22{ }^{\circ} \mathrm{C}$. Color change, fruit firmness, and production rates of $\mathrm{CO}_{2}$ and ethylene were followed for a period of 2 weeks. Significant differences $(P \leq 0.05)$ were found in color, ethylene, and $\mathrm{CO}_{2}$ production rates between treatments. However, there were few significant differences among cultivars and growers. This suggests that different tomato cultivars respond similarly to 1-MCP, and that commercial growing conditions and practices may not affect its efficacy. Over the 2-week ripening period, fruit from treatments of less than $300 \mathrm{~nL} / \mathrm{L} 1-\mathrm{MCP}$ exhibited similar color changes while treatments of more than $600 \mathrm{~nL} / \mathrm{L}$ resulted in blotchy ripening, causing fruit to be unmarketable. 1-MCP treatment led to an increase in the rates of ethylene and $\mathrm{CO}_{2}$ production, two processes correlated with the onset of fruit ripening. This increase was unexpected and other studies showed that 1-MCP delayed the onset of these processes in tomatoes, and inhibited them in other fruits. Tomatoes treated at a maturity between breaker and turning did not respond well to 1-MCP, perhaps due to the ripening process having already begun. This implies that maturity stages earlier than breaker to turning may respond better to 1-MCP, and it may be more beneficial to target greenhouse tomatoes at an earlier maturity.

\section{(184) Phenolic Composition and Antioxidant Activity of Sweetpotato Cultivars Marketed in the European Union}

Malkeet S. Padda*, David H. Picha

Louisiana State University, Horticulture

Phenolic compounds and antioxidant activity were quantified in the principal sweetpotato cultivars marketed in the European Union. Total phenolic content, individual phenolic acids, and antioxidant activity in each cultivar were determined using Folin-Denis reagent, reversed-phase HPLC, and 1,1-diphenyl-2-picrylhydrazyl (DPPH) methods, respectively. Significant differences in phenolic composition and antioxidant activity were found between cultivars. AJamaican-grown, white-fleshed cultivar had the highest total phenolic content $\left[4.11 \mathrm{mg} \cdot \mathrm{g}^{-1}\right.$ chlorogenic acid (dry tissue weight)], while the highest antioxidant activity [3.60 $\mathrm{mg} \cdot \mathrm{g}^{-1}$ Trolox (dry tissue weight)] was observed in the orange-fleshed California-grown cultivar Diane. Chlorogenic acid and 3,5-dicaffeoylquinic acid were the predominant phenolic acids, while caffeic acid was the least abundant in most cultivars. The highest content of chlorogenic acid $\left(0.42 \mathrm{mg} \cdot \mathrm{g}^{-1}\right.$ dry tissue weight); 3,5-dicaffeoylquinic acid ( $0.43 \mathrm{mg} \cdot \mathrm{g}^{-1}$ dry tissue weight); and 3,4-dicaffeoylquinic acid $(0.25$ $\mathrm{mg} \cdot \mathrm{g}^{-1}$ dry tissue weight) was present in the white-fleshed Jamaican cultivar. The orange-fleshed cultivars Diane and Beauregard had the 
highest content of caffeic acid $\left(0.13 \mathrm{mg} \cdot \mathrm{g}^{-1}\right.$ dry tissue weight $)$ and 4,5 dicaffeoylquinic acid $\left(0.32 \mathrm{mg} \cdot \mathrm{g}^{-1}\right.$ dry tissue weight $)$, respectively.

\section{(185) Genetic Resistance to Crack Development in Processed "Baby" Carrots}

\section{Phillip Joy*1, Rajasekaran Lada ${ }^{1}$, Angus Ells ${ }^{2}$, Brian Williams ${ }^{2}$}

${ }^{1}$ Nova Scotia Agricultural College, Plant and Animal Sciences, Truro, Nova Scotia, B2N 5E3; ${ }^{2}$ Oxford Frozen Foods Ltd., Hillaton Foods

The individually quick frozen "baby" carrot industry is growing. Crack development during freezing (CDF) has recently become a quality issue. There is little scientific information available on the causes of CDF. Studies were initiated to determine genetic resistance for CDF and to identify crack-resistant varieties. Ten varieties and breeding lines (Columbia, HMX-0331, Sugarsnax, Sweet Bites, Tasty Peel, Top Cut, Trinity, XCR-0124, XCR-9650, and XCR-9840) were grown under the same field conditions, harvested identically, and processed. Samples were removed after a quick freeze tunnel and tested immediately for membrane stability using electrical conductivity $(\mathrm{EC} / \mathrm{g})$ and a membrane injury index. Percentage cracked, the length, width, and depth of cracks were also measured. Another set of samples were placed in freezer storage at $-10{ }^{\circ} \mathrm{C}$ for 8 weeks and tested again for the same parameters. EC/g and membrane injury indexes showed significant interactions between variety and length of storage time. Crack length, width, and depth were significantly higher in XCR-9650 and XCR-9840, while Trinity had the smallest dimensions. Crack depths after week 8 in freezer storage were also significantly higher $(0.30 \mathrm{~cm})$ than those at week $0(0.21$ $\mathrm{cm})$. Finally, percent cracked was also dependent on the variety and length of storage time. Trinity had the lowest percentage of cracked pieces (16\%), whereas XCR-9650 (70\%) had the highest percentage of visible cracking. Freezer storage time also played a role in CDF, since cracked percent significantly increased by $4 \%$ over the 8 weeks. Our results clearly reveal that there are differences in CDF among varieties. Among all, Trinity had the highest resistance to cracking, comparable to all the varieties except XCR-9650 and XCR-9840.

\section{(186) Fresh-cut Chunks of a New Orange- fleshed Melon Genotype: Analytical and Sensory Comparisons to Its Inbred Parents, and to Commercial Cantaloupe and Green-fleshed Honeydew Harvested in Winter}

Robert Saftner*1, Gene Lester $^{2}$, Judith A. Abbott ${ }^{1}$

${ }^{1}$ Agricultural Research Service, United States Department of Agriculture, Produce Quality and Safety Laboratory, Beltsville, MD, 20705; ${ }^{2}$ Agricultural Research Service, United States Department of Agriculture, Crop Quality \& Fruit Insects Research Unit, Weslaco, TX, 78596

Anew hybrid orange-fleshed netted melon has been bred specifically for use by the fresh-cut industry in winter. Quality characteristics of freshcut chunks from the hybrid were compared to those of its parental lines and to commercial cantaloupe and honeydew fruits available in winter. Female parent and hybrid chunks had higher soluble solids content (SSC) and firmness, and lower aromatic volatile concentrations versus that of the male parent. Hybrid chunks also had higher SSC (>3\%) and were firmer $(>5 \mathrm{~N})$ than commercial fruit, and showed no appreciable differences in aromatic volatile concentrations to commercial honeydew or in surface color to commercial cantaloupe. Consumers liked the flavor, texture, sweetness, and overall eating quality of the hybrid chunks better than those of its inbred parents and winter honeydew and as well as or better than that of winter cantaloupe. Hybrid fruit stored 5 weeks at $1^{\circ} \mathrm{C}$ under modified atmospheric conditions, then fresh-cut and stored $14 \mathrm{~d}$ in air at $5{ }^{\circ} \mathrm{C}$ maintained good quality (firmness $=51$ $\mathrm{N}, \mathrm{SSC}=12.2 \%$, surface $\mathrm{pH}=6.0$, beta-carotene and ascorbic acid concentrations $=14$ and $182 \mathrm{mg} \cdot \mathrm{kg}^{-1}$, respectively), and showed no signs of tissue translucency or surface pitting despite microbial populations approaching $8 \log \mathrm{cfu} \cdot \mathrm{g}^{-1}$. The results indicate that the orange-fleshed hybrid melon is a promising new melon type for fresh-cut processing, especially during the winter.
Poster Session 4-Floriculture Nutrition and Substrates

27 July 2006, 12:00-12:45 p.m.

(67) Effect of Two Types of Fertilizers on the Growth and Development of Tissue-cultured Daylilies Transferred to the Greenhouse

Johnny Carter*, Diondre Palmer, Lianghong Chen, Surinder Gulia

Fort Valley State University, Agricultural Research Fort Valley, GA, 31030-4313

During Summer 2005, a study similar to that of Summer 2004 was conducted to determine the effect of two type of fertilizers on the growth and development of tissue-cultured daylilies transferred to the greenhouse. Peters 20-20-20 water-soluble fertilizer and a slow-release fertilizer were the two fertilizers evaluated. Peters 20-20-20 fertilizer was used at 0 (control), 50, 100, $200 \mathrm{mg} / \mathrm{L}$ rates. The slow-release fertilizer was used at $2.5 \mathrm{~g}$ per $10.2-\mathrm{cm}$ pot. Each treatment was replicated four times in randomized complete-block design. After 6 weeks of growth, the results showed that when compared to the control, all treatments except for $200 \mathrm{mg} / \mathrm{L}$ caused a significant increase in root growth. Shoot growth was significantly increased by the $100 \mathrm{mg} / \mathrm{L}$ treatment, while the $200 \mathrm{mg} / \mathrm{L}$ and the slow-release treatments suppressed shoot growth. Similar to the growth of roots and shoots, the $100 \mathrm{mg} / \mathrm{L}$ treatment caused significant increase in fresh weight, while both the $200 \mathrm{mg} / \mathrm{L}$ and slow-release treatments caused a reduction. Results obtained for Summer 2005 were similar to that of Summer 2004. These results imply that the $100 \mathrm{mg} /$ L Peters 20-20-20 fertilizers treatment is the best treatment for maximum growth and development of tissue-cultured daylilies transferred to the greenhouse.

\section{(68) The Role of Proteins in Leaf Re-greening}

Ellen T. Paparozzi*, Joshua R. Widhalm, M. Elizabeth Conley University of Nebraska, Agronomy and Horticulture, Lincoln, NE, 68583-0724

Common swedish ivy plants when exposed to nitrogen $(\mathrm{N})$ stress display typical nitrogen deficiency symptoms such as reddening of stems and petioles and yellowing of leaves. When $\mathrm{N}$ levels are restored, leaves of swedish ivy plants will re-green without leaf loss. An experiment was conducted to determine how proteins change when leaves were re-greened after $\mathrm{N}$ deficiency. Cuttings of Plectranthus australis were rooted under mist and allowed to yellow. Plants were then potted up and fertilized with one of two treatments: complete nutrients with $\mathrm{N}$ at $150 \mathrm{ppm}$ or complete nutrients with $0.8 \mathrm{ppm} \mathrm{N}$. The experimental design was a randomized complete-block design with six blocks. Each block had the two $\mathrm{N}$ treatments and six plants per treatment. After 3-4 weeks, all plants in the 150-ppm $\mathrm{N}$ treatment had re-greened and leaf samples for protein analysis were taken. Plants in four of the six blocks were then switched to the other treatment. After leaves had re-greened once again, leaf samples were taken and the experiment was terminated. Two-dimensional polyacrylamide gel electrophoresis was used to compare the treatments. No obvious differences in protein absence or presence were noted. However, Rubisco appeared to be differentially expressed between the two treatments. 2-D gel analysis with subsequent Western blots showed that for most of the leaf samples, the large subunit of Rubisco $(56 \mathrm{kD})$ was quantitatively about 1.3 times more concentrated in the $\mathrm{N}$-deficient plants and possibly modified. The small subunit $(12 \mathrm{kD})$ was not reliably detectable. Additional protein results for repeated leaf re-greening and the role Rubsico may play in leaf re-greening will be discussed.

\section{(69) Use of Hypochlorous Acid for Treatment of Greenhouse Irrigation Water}

Steven E. Newman*

Colorado State University, Horticulture and Landscape Architecture, Fort Collins, CO, 80523-1173

Scaling from dissolved and suspended solids in irrigation water reduces the efficiency of greenhouse irrigation systems. Water deposits inside 
pipes reduce water flow and deposits may reduce the flow through irrigation emitters, often clogging them. If not properly maintained, the clogging of emitters requires constant maintenance. This results in considerable labor expense and/or emitter replacement. Scaling inside irrigation system pipes also has the potential to harbor plant pathogens from the resulting biofilms. Oxcide, a novel hypochlorous acid $(\mathrm{HOCl})$ compound, is produced electrochemically by removing sodium and hydroxide from sodium hypochlorite. The elimination of sodium hydroxide from the product creates a nontoxic oxidizer. A system to inject Oxcide into irrigation water at a commercial Colorado greenhouse was installed to maintain irrigation efficiency of emitters and irrigation lines during Winter 2003. The oxidation reduction potential (ORP) was monitored and visual evaluations of irrigation equipment in the Oxcide treated zones compared to those zones not treated with Oxcide was conducted. During January through March, geranium stock plants were irrigated with water that maintained ORP levels at around $600 \mathrm{mV}$. Visual ratings of the irrigation emitters revealed that the injection of Oxcide in the irrigation water did reduce the level of deposition. Deposition on the main feed lines was so thick that they hindered the complete closure of existing valves. Treatment of the irrigation water Oxcide injection for six months successfully removed of the scale and deposits from the water line.

\section{(70) Improved Reactivity Indices for Horticultural \\ Limes}

Jinsheng Huang*1, Paul R. Fisher ${ }^{1}$, William R. Argo ${ }^{2}$

${ }^{1}$ University of New Hampshire, Plant Biology, Durham, NH, 03824; ${ }^{2}$ Blackmore Co, Blackmore Co, Belleville, MI, 48111

The objective was to develop indices to describe reactivity of different lime particle size fractions with respect to $\mathrm{pH}$ change in horticultural substrates. Particle size efficiency (PSE) was calibrated from $\mathrm{pH}$ responses for separated six lime particle size fractions $(>850,850$ to 250,250 to 150,150 to 75,75 to 45 , and $<45 \mu \mathrm{m}$ ) from three calcitic limes, and seven dolomitic limes, based on their increase in substrate $\mathrm{pH}$ relative to reagent grade $\mathrm{CaCO}_{3}$ when mixed in a sphagnum peat substrate at $5 \mathrm{~g} \mathrm{CaCO}_{3}$ equivalents per liter of peat. The fineness factor (FF) was calculated for a liming material by summing the percentages by weight in each of the six size fractions multiplied by the appropriate PSE. The effective calcium carbonate equivalence (ECC) of a limestone was the product of the FF and the acid neutralizing value (NV) in $\mathrm{CaCO}_{3}$ equivalents. Reliability of the parameters for FF and $\mathrm{ECC}$ were then validated in two experiments, using 29 unscreened carbonate and hydrated lime sources, including the 10 calibration limes. In one experiment, $1 \mathrm{~L}$ of peat was blended at $5 \mathrm{~g}$ of lime (i.e., not corrected for differences in NV between limes). In the second experiment, $5 \mathrm{~g}$ $\mathrm{CaCO}_{3}$ equivalents for each lime, corrected for $\mathrm{NV}$, were blended with $1 \mathrm{~L}$ of peat (a different peat source), using the same 29 lime sources. Both FF and ECC were positively correlated with the corresponding substrate-pH changes, with $P<0.001$ and $r^{2}$ from 0.87 to 0.93 . This calibration of PSE, FF, and ECC can improve limestone selection and application rate for the short term response and fine limestone sources used in horticulture.

\section{(71) Comparison of Phytophthora Disease Incidence in Composted Pine Bark Mixes to Chemical and Biological Controls}

\author{
Jennifer Green*1, Derald A. Harp ${ }^{1}$, Kevin L. Ong ${ }^{2}$ \\ ${ }^{1}$ Texas A\&M University-Commerce, Agricultural Sciences, Commerce, TX, 75429; ${ }^{2}$ Texas
} A\&M University-Dallas, Texas Cooperative Extension, Dallas, TX, 75252

Phytophthora diseases are economically important, requiring the use of chemical fungicides and, more recently, biological controls. Recent research suggests that composted bark products may lessen the impact of the disease, even in the absence of these chemicals. An experiment was conducted to compare chemical and biological fungicides to untreated pine bark compost. Impatiens wallerana plugs were transplanted from 288 trays into 1801 trays. All plants were planted into Berger BM-7, $35 \%$ composted bark mix (Berger Horticulture, Quebec, Canada).
Media was prepared by premixing one of the five following fungicide treatments: 1) Control, 2) Banrot at $0.6 \mathrm{~g} / \mathrm{L}, 3$ ) Root Shield at $1.6 \mathrm{~g} / \mathrm{L}$, 4) Actino-Fe at $5.1 \mathrm{~g} / \mathrm{Ll}$, or 5) SoilGard at $1.6 \mathrm{~g} / \mathrm{L}$. Plants received no fertilizer. Three strains of Phytophthora were grown in $25^{\circ} \mathrm{C}$ on clarified V8 media. Pathogenic inoculum was made by macerating the growth media and fungi in $100 \mathrm{ml} \mathrm{H}_{2} \mathrm{O}$. Mixture was pulse-blended for $1 \mathrm{~min}$, and an additional $200 \mathrm{~mL} \mathrm{dH}_{2} \mathrm{O}$ was added. Inoculation was $5 \mathrm{ml}$ per plant. Flats were kept on a misting bench, and misted twice daily for $15 \mathrm{~min}$. The experiment was set up using a RBD repeated six times with three plants per rep. Plants were rated weekly for 5 weeks using a damage scale of 0 to 5 , with 0 indicating no sign of disease and 5 being dead. Statistical analysis was conducted using a Chi-Square. Disease incidence between the biological, chemical, and composted bark treatments did not differ, with all treatments providing complete control. At least in this study, the use of composted pine bark media provided Phytophthora control equivalent to current chemical and biological fungicides.

\section{(72) Effects of Clay-amended Substrates on Production of Nursery and Greenhouse Crops}

\section{Catanzaro*1, S. Bhatti ${ }^{1}$, B.T. Jordan $\mathrm{III}^{2}$}

${ }^{1}$ Tennessee State University, Institute of Agricultural \& Environmental Research, Nashville, TN, 37209; ${ }^{2}$ Tennessee State University, Department of Agricultural Sciences, Nashville, TN, 37209

The U.S. Environmental Protection Agency limits the amount of nitrate and phosphate, yet these nutrients are applied in relatively large amounts during crop production. The objective of greenhouse studies conducted in 2002-05 was to determine the effects of calcined, attapulgite-type clays used as substrate amendments during production of containerized poinsettias, chrysanthemums, and ornamental grasses. Crops were grown with recommended rates of controlled-release fertilizers and irrigation volumes set to achieve a leaching fraction around 0.2 . Results with poinsettias grown in substrates amended with clays were as follows: EC of leachate from poinsettia was reduced by up to $39 \%$ in the first few weeks after potting; orthophosphate concentration in leachate was reduced by up to $74 \%$ in peat-based substrate; cumulative irrigation volume required to produce plants in 16.5 -cm containers was reduced by $11 \%$. With two chrysanthemum cultivars, clays reduced $\mathrm{EC}$ of leachate and increased plant growth. A non-calcined clay reduced growth of poinsettia and 'Oborozuki' Japanese sweetflag grass, but not 'Karl Foerster' feather reed grass. Results from these studies suggest that, with controlled irrigation volumes, calcined clays added to a peat-based substrate can reduce leachate nutrient concentrations and reduce crop water requirements without negatively affecting crop growth or quality.

\section{(73) Effect of Media on Growth of Euphorbia pulcherima 'White Star'}

\section{Ajay Nair, Donglin Zhang, Stephanie Burnett*}

University of Maine, Plant Soil and Environmental Sciences, Orono, ME, 04469

Euphorbia pulcherima Willd. ex Klotzsch (poinsettia) are grown commercially in all 50 states. This experiment was conducted to find a suitable media for cultivating 'White Star' poinsettia under natural day-length conditions in Orono, Maine. The growth, morphology, and foliar and substrate nutrient concentration of 'White Star' poinsettia was evaluated in three different media formulations (Promix ${ }^{\circledR}, \mathrm{Me}-$ tromix $-560^{\circledR}$, and a 1:1 v/v mixture of Promix ${ }^{\circledR}$ and Metromix- $560^{\circledR}$ ). Results indicated minimal variability in overall plant height, but there were significant differences in the canopy area. Canopy area was greatest for plants grown in Promix ${ }^{\circledR}$ followed by a combination of Promix ${ }^{\circledR}$ and Metromix-560 ${ }^{\circledR}$. Plants grown in Promix ${ }^{\circledR}$ recorded the highest fresh weight $(170.6 \mathrm{~g})$. Bract area was statistically insignificant among the three treatments. Nutrient status of the media varied widely and was significant for nitrate-nitrogen, phosphorus, soluble salts, iron, calcium, magnesium, manganese, sodium, sulfur, and zinc. Foliar analysis revealed that nutrient concentrations also significantly differed across treatment media. Optimum media $\mathrm{pH}$ 
for growing poinsettia ranges from 6.0 to 7.5. Media $\mathrm{pH}$ for Promix ${ }^{\circledR}$ was 5.9, which was significantly higher than Metromix $-560^{\circledR}(4.65)$

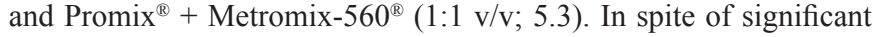
differences in foliar and substrate nutrient concentrations, overall plant growth remained the same.

\section{Poster Session 5-Ornamental Plant Breeding 1}

\section{July 2006, 12:00-12:45 p.m.}

\section{(232) Production of an Intergeneric Hydrangeaceae Hybrid}

Keri D. Jones*1, Sandra M. Reed ${ }^{1}$, Timothy Rinehart ${ }^{2}$

${ }^{1}$ USDA-ARS, Floral and Nursery Plants Research Unit, McMinnville, TN, 37110; ${ }^{2}$ USDA-ARS, Southern Horticultural Laboratory, Poplarville, MS, 39470

Dichroafebrifuga (Hydrangeaceae) is an evergreen shrub with metallic blue fruit that persists throughout winter. Phylogenetic studies have indicated that $D$. febrifuga is closely related to Hydrangea macrophylla. The objective of this study was to produce hybrids between these two ornamental species. Reciprocal crosses were made between $D$. febrifuga and both diploid and triploid cultivars of H. macrophylla. Two-thirds of the seed capsules produced from these hybridizations were allowed to mature on the plant, after which time seed were collected and sown in a greenhouse. Embryo rescue was used with the remaining seed capsules. Ovules were excised from ovaries about 9 weeks after pollination and plated on Gamborg's B-5 media with 2\% sucrose. Both germination techniques resulted in vigorous seedlings. Hybridity was verified in plants obtained from ovule culture using simple sequence repeat (SSR) markers. Reciprocal hybrids were obtained using both diploid and triploid forms of $H$. macrophylla. This study confirms the close relationship between D. febrifuga and H. macrophylla and provides valuable material for future breeding efforts.

\section{(233) Comparison of Inflorescence Morphology, Anthesis and Floral Sex Expression in Bottlebrush and Red Buckeye}

Ann M. Chanon ${ }^{1}$, Pablo S. Jourdan², Joseph C. Scheerens*1

${ }^{1}$ The Ohio State University, Horticulture and Crop Science, Ohio Agricultural Research and Development Center, Wooster, OH, 44691; ${ }^{2}$ The Ohio State University, Horticulture and Crop Science, Columbus, OH, 43210

As a prelude to interspecific hybridization, we compared the floral biology of bottlebrush buckeye (Aesculus parviflora) and red buckeye (A. pavia) by examining inflorescence morphology, pattern of floral anthesis, sex expression, and the effects of panicle decapitation on complete flower development. Inflorescences of both species $(n=$ 1606) were randomly selected and analyzed for length, total number of flowers and complete flower number and location. The pattern of anthesis was observed in four genotypes using 10-30 inflorescences per plant. For each flower, its date of anthesis, position on both the rachis and cincinnus, and sex were recorded. For studies of panicle decapitation, sets of panicles were selected and one member was severed in half early in development in an attempt to increase the number of complete flowers. More than one-fourth of all panicles observed were completely staminate. For both species, the ratio of complete flowers to male flowers $(\mathrm{C}: \mathrm{M})$ within mixed panicles was about $5 \%$. Complete flowers were observed in the basal portion of $A$. pavia inflorescences and in the apical portion of A. parviflora inflorescences. Anthesis progressed from base to tip over a period of 6-11 days. Complete flowers are present in A. pavia from the beginning of anthesis but do not appear in A. parviflora until the fifth day of anthesis. Staminate flowers are present throughout anthesis in both species. Severing panicles in half increased the potential for differentiating complete flowers. In conclusion, the frequency of complete flowers in both species was quite low, but could be increased by panicle decapitation to increase opportunities for controlled hybridization.
(234) Aesculus Pollen Viability and Longevity under

\section{Frozen Storage}

Ann M. Chanon ${ }^{1}$, Pablo S. Jourdan ${ }^{2}$, Joseph C. Scheerens*1

${ }^{1}$ The Ohio State University, Horticulture and Crop Science, Ohio Agricultural Research and Development Center, Wooster, OH, 44691; ${ }^{2}$ The Ohio State University, Horticulture and Crop Science, Columbus, OH, 43210

The genus Aesculus (buckeyes and/or horsechestnuts) is composed of 13 species and a number of interspecific hybrids. Pollen from 11 genotypes from five Aesculus species and the hybrid Aesculus $\times$ carnea were used to develop an in-vitro germination test to evaluate pollen viability under various storage treatments. This test was optimized using samples of both fresh pollen and pollen that had been stored up to 1 year. The most effective medium contained $20 \%$ sucrose, $100 \mathrm{mg} \cdot \mathrm{L}^{-1}$ $\mathrm{H}_{2} \mathrm{BO}_{3}, 150 \mathrm{mg} \cdot \mathrm{L}^{-1} \mathrm{Ca}\left(\mathrm{NO}_{3}\right)_{2}$, and $1 \%$ agar. The highest germination percentage was observed at $15^{\circ} \mathrm{C}$ across all storage treatments. Fresh pollen germinated in excess of $80 \%$ over a wide range of germination temperatures. Based on this, all specimens studied would be good pollen parents. The differences in pollen germination between storage at -20 and $-80^{\circ} \mathrm{C}$ were nonsignificant, but the duration of the storage period was highly significant. At 3 months, viability remained above $60 \%$ for four of the six species/hybrid tested. However, at 12 months, all pollen tested dropped below the threshold for good fruit set based on in-vitro pollen germination. Based on these observations, short-term pollen storage may permit crosses between parents with temporally separate flowering phenologies. However, conventional storage procedures are inadequate to maintain pollen collected from a male parent for crosses in subsequent growing seasons.

\section{(235) 'Raspberry Profusion' and 'Lavender Mist': New Abelia Cultivars for the Landscape}

Carol D. Robacker*1, Sloane M. Scheiber ${ }^{2}$

${ }^{1}$ University of Georgia, Horticulture, Griffin, GA, 30223; ${ }^{2}$ University of Florida, Environmental Horticulture, Mid-Florida Research \& Education Center, Apopka, FL, 32703

Abelia $\times$ grandiflora is a drought-tolerant, pest-resistant, flowering shrub that has long been used as a foundation plant. Interspecific hybridization has produced seedlings with an assortment of morphological traits, allowing for development of new cultivars with unique or improved qualities. 'Raspberry Profusion' and 'Lavender Mist', developed at the University of Georgia, are seedling selections of 'Edward Goucher' $\times$ Abelia chinensis. 'Raspberry Profusion' is a very heavy and very early bloomer. Panicles are large and showy with fragrant pink flowers and raspberry-colored sepals. Flowering begins in early May and becomes very heavy by early June. The bright-colored sepals remain on the plant throughout the summer. Summer foliage is a medium to dark green color. In a pot, 'Raspberry Profusion' blooms early and heavily. 'Lavender Mist' is a heavy bloomer, with clusters of fragrant lavender flowers beginning in mid-June, and continuing into autumn. Sepals are a straw-green color at the base, becoming rose at the tips. Summer foliage is gray-green. 'Lavender Mist' performs well in a pot, forming a gray-green mound contrasting with the lavender blossoms scattered around the plant. Leaves on both cultivars are glossy, particularly from mid-summer through autumn. Both plants tend to be mostly deciduous in the winter. Laboratory evaluations of cold hardiness in Griffin, Ga., during Winter 2003-04 revealed a mid-winter hardiness of $-18^{\circ} \mathrm{C}$ to $-21^{\circ} \mathrm{C}$ for 'Raspberry Profusion' and $-15^{\circ} \mathrm{C}$ to $-17^{\circ} \mathrm{C}$ for 'Lavender Mist'. These plants develop into dense compact shrubs following pruning and establishment in the landscape.

\section{(236) 'Plum Surprise': A New Heat- and Drought- tolerant Evergreen Abelia}

Carol D. Robacker*1, Sloane M. Scheiber ${ }^{2}$

${ }^{1}$ University of Georgia, Horticulture, Griffin, GA, 30223; ${ }^{2}$ University of Florida, Environmental Horticulture, Apopka, FL, 32703

Abelia $\times$ grandiflora is a hardy shrub in the landscape, surviving heat and drought with few pest problems. However, improved cultivars with better form, the ability to retain foliage during drought, and unique flowering and foliage characteristics are in demand. 'Plum Surprise' is a 
new cultivar of Abelia that was developed at the University of Georgia in response to these needs. 'Plum Surprise' is a seedling selection from the cross 'Edward Goucher' $\times$ 'Francis Mason'. It forms an unusual weeping, spreading mound with fine-textured foliage. In March and April, foliage is yellow-green with scattered red/purple leaves. In late spring, the foliage becomes emerald green, changing to a lighter green throughout the summer. New stem growth is red. The most striking features of 'Plum Surprise' are the fall and winter foliage color and the evergreen habit of the cultivar. As autumn progresses, the outer shoots and leaves transform to red/purple or crimson, while the inner foliage is bright emerald green. Foliage is glossy in the winter, and a deep purple or burgundy color. 'Plum Surprise' is a relatively light bloomer, with flowers scattered individually or in pairs. The flowers appear white, but on close examination have a purple blush with a pale yellow throat. 'Plum Surprise' is noteworthy for its heat and drought tolerance. In both the summers of 2002 and 2005, when check cultivars had lost $50 \%$ to $80 \%$ of their foliage, 'Plum Surprise' exhibited little leaf drop. 'Plum Surprise' performs well in a pot under nursery conditions. The foliage cascades down over the pot, making an attractive appearance in both form and color.

\section{(237) Chemical Mutagenesis in Snapdragon (Antirrhinum majus)}

Leslie Heffron*1, Alan Blowers², Schuyler Korban ${ }^{1}$

${ }^{1}$ University of Illinois, Department of Natural Resources and Environmental Sciences, Urbana, IL, 61801; ${ }^{2}$ Ball Horticultural Company, Ball Helix, West Chicago, IL, 60185

Seeds of Antirrhinum majus (snapdragon), proprietary line OAK564, were treated with $0 \%, 0.10 \%, 0.25 \%, 0.5 \%, 0.75 \%$, and $1.0 \%$ ethyl methanesulfonate (EMS) for 8,10 , and $12 \mathrm{~h}$ at room temperature. The experiment was replicated three times over time. Data were collected on percent seed germination, seedling survivability, and pollen viability to determine optimal conditions for induced mutagenesis in OAK564 seeds. In the pilot experiment, $\mathrm{M}_{1}$ seeds treated with 1.0\% EMS for $12 \mathrm{~h}$ had the lowest seed germination rate among all 18 treatments. Based on this pilot experiment, a large-scale mutagenesis experiment was performed using three levels of EMS $(0.5 \%, 0.75 \%$, and $1.0 \%)$ for 10-h exposure period. Mutants were induced on all these treatments, and morphological changes in the $\mathrm{M}_{1}$ population were detected. These included dwarfism, chlorophyll deficiency, and leaf morphology abnormality. This indicated that the EMS treatments were successful in inducing mutations, and mutants were further characterized for morphological traits.

\section{(238) Ethylene Screening using 1- aminocyclopropane-1-carboxylic acid (ACC) in Both Nonmutagenized and Mutagenized Snapdragon Lines}

Leslie Heffron*1, Alan Blowers², Michael Uchneat ${ }^{3}$, Schuyler Korban ${ }^{1}$

${ }^{1}$ University of Illinois, Department of Natural Resources and Environmental Sciences, Urbana, IL, 61801; ${ }^{2}$ Ball Horticultural Company, Ball Helix, West Chicago, IL, 60185; ${ }^{3}$ Ball Horticultural Company, PanAmerican Seed Company, West Chicago, IL, 60185

A tissue culture screen for ethylene tolerance using 1-aminocyclopropane-1-carboxylic acid (ACC) was optimized for a snapdragon (Antirrhinum majus) inbred line, OAK564. Two experiments were conducted using various concentrations of ACC (ranging from 0 to $100 \mu \mathrm{M})$. Presence of $5 \mu \mathrm{M}$ ACC in the tissue culture medium elucidated biological activity in snapdragon seeds. This screen was used to determine relative sensitivity to ethylene in 48 hybrid lines. Different levels of sensitivity to ethylene were observed among the various hybrid lines. Moreover, 40,000 mutagenized seeds from three $\mathrm{M}_{2}$ populations, derived from different levels of EMS $(0.5 \%, 0.75 \%$, and $1.0 \%)$ treatments, were screened for ethylene sensitivity. A total of 231 putative mutants were recovered spanning eight distinct phenotypes based on the 'triple response' assay. Of these putative mutants, 16 mutants were selected for further analysis, including at least one and up to three lines from each of the eight phenotypic classes. Plants were established in the greenhouse, and allowed to grow to maturity to collect selfed seeds.
These seeds were once again screened with $5 \mu \mathrm{MACC}$ to determine the level of ethylene sensitivity present within each of the eight phenotypic classes. Responses in the $\mathrm{M}_{3}$ populations varied from complete ethylene tolerance to ethylene sensitivity. Implications of these results on the recovery of ethylene tolerant mutants will be discussed.

\section{Poster Session 6-Citrus}

27 July 2006, 12:00-12:45 p.m.

\section{(85) Determination of D-Glucarate Content in Grapefruit Varieties}

Jose L. Perez*, G.K. Jayaprakasha, Bhimanagouda S. Patil

Texas A\&M University, Department of Horticulture, College Station, TX, 77845

Grapefruithas potential health-promoting properties due to the presence of multitude bioactive compounds. Ongoing cell culture and animal studies in our lab using limonoids and flavonoids have provided strong evidence of their protective properties for preventing chronic diseases. Studies related to D-glucarate, a natural, nontoxic bioactive compound found in grapefruit, has not been explored. One of the derivatives, such as D-glucaro-1,4-lactone, is reported to be a potent $\beta$-glucuronidase inhibitor. With the inhibition of $\beta$-glucuronidase enzyme, glucuronidation will be favored. Glucuronidation is a conjugation process through which potentially carcinogenic environmental toxins can be neutralized. In this context, quantification of glucarate using HPLC was developed. Samples from grapefruits were prepared by heating fruit extract with distilled water. Further, the extract was homogenized and centrifuged. The supernatant was treated with petroleum ether to remove non-polar substances. Then the extract was subject to ion exchange chromatography. Fractions were collected and analyzed by analytical HPLC for the quantification of D-glucarate content and its lactone. This project was supported by the USDA-CSREES grant for Designing Foods for Health through the Vegetable and Fruit Improvement Center.

\section{(86) Isolation and Molecular Characterization of Putative Ascorbate Peroxidase from Citrus}

Madhurababu Kunta, H. Sonia del Rio, Eliezer Louzada

Texas A\&M University-Kingsville, Pathology, Weslaco, TX, 78596

[Note: This poster will be presented by Claudine Bona,

Texas A\&M University-Kingsville.]

Reactive oxygen species (ROS) are continuously produced during the normal aerobic metabolism and also under environmental stress conditions. They are the major damaging factors to the photosynthetic machinery under stress conditions and need to be scavenged for the normal growth of the plant. Ascorbate peroxidase (APX) is the key enzyme in detoxifying $\mathrm{H}_{2} \mathrm{O}_{2}$, one of ROS from chloroplast and cytosol. A cDNA encoding a putative APXcit was isolated from mature 'Dancy' tangerine (Citrus reticulata Blanco) juice vesicles using differential display reverse transcription-polymerase chain reaction (RT-PCR). Subsequently, full-length APXcit cDNA clone and genomic clone were obtained and sequenced. The full-length APXcit sequence is composed by 1082-bp nucleotides, including an open reading frame (ORF) of $753 \mathrm{bp}$, encoding a protein of 250 amino acids $(27 \mathrm{kDa})$. The 5 ' un-translated region (UTR) of the APXcit gene consisted of 91 nucleotides and the 3' UTR consisted of 238 nucleotides. Homology search for APXcit at GenBank database showed high similarity to APX from several plant species.

\section{(87) Molecular Characterization of Cold Acclimation in Poncirus and Citrus}

Ping Lang ${ }^{1}$, Can-kui Zhang ${ }^{1}$, Fenny Dane ${ }^{1}$, Shasha Meng ${ }^{1}$, Robert Ebel*1, Narendra Singh ${ }^{2}$

${ }^{1}$ Auburn University, Horticulture, Auburn, AL, 36849; ${ }^{1}$ Auburn University, Horticulture, Auburn, AL, 36849; ${ }^{2}$ Auburn University, Biological Sciences, Auburn, AL, 36849

Commercial citrus species, some of the most important fruit crops 
worldwide, are sensitive to sub-freezing temperatures. Poncirus trifoliata, a species closely related to commercial citrus and tolerant to $-30{ }^{\circ} \mathrm{C}$, has been used in breeding programs or as a rootstock to impart greater freeze tolerance. Gene expression of $P$. trifoliata and C. unshiu (Satsuma mandarin) were investigated and compared under slow and fast cold-acclimation regimes. The mRNA differential display-polymerase chain reaction (DDRT-PCR) and cDNA-AFLP, coupled with quantitative relative RT-PCR or real-time PCR were used. Many unique gene fragments were isolated and found to be upor down-regulated as a result of exposure to low temperature. The up-regulated fragments in Poncirus show high similarities to genes involved in osmotic regulation (betaine/proline transporter, water channel protein, and nitrate transporter), oxidative stress (aldoketo reductase, early light induced protein), and protein interaction (tetratricopeptide-repeat protein, F-box protein, and ribosomal protein L15). In C. unshiu the up-regulated genes show high similarities to genes involved in transcription (zinc finger and GTP-binding protein-related), signal transduction (14-3-3 protein and extension-like protein), protein synthesis and amino acid translocation (permease and ribosomal proteins), chromosome folding (chromosome condensation, structural maintenance of chromosomes-like protein), and carbohydrate metabolism (glycosyl transferase). Several genes involved in photosynthesis, defense and cell wall metabolism were down regulated. Characterization of cold responsive genes will be discussed.

\section{(88) Sour Orange: A Source of Unique Bioactive Limonoid Glucosides}

Amit Vikram*, G.K. Jayaprakasha, Bhimanagouda S. Patil

Texas A\&M University, Vegetable and Fruit Improvement Center, Department of Horticulture, College Station, TX, 77845

Our recent studies have shown that certain citrus limonoids protect from colon cancer based on cell and animal studies. Animal studies also suggest that citrus juice protects from osteoporosis. To understand the structure-function relationship through animal studies requires a large amount of purified limonoids. Since certain limonoids are present in low concentration, it is a challenge to obtain the required quantity of different limonoids. In this context, we report the purification of limonin 17- $-\mathrm{D}$ glucopyranosides (LG), and deacetylnomilinic acid 17-ß-D glucopyranoside (DNAG). However, DNAG was isolated in relatively large amount from sour orange (Citrus aurantium L.) seeds. Defatted seed powder was extracted with methanol and purified using column chromatography to obtain multigrams of DNAG. While LG was found in lower concentration, a large concentration of hesperidin was also purified in this process. This project is based upon work supported by the USDA-CSREES under Agreement USDA IFAFS \#2001 5210202294 and USDA\#200534402-14401 "Designing Foods for Health" through the Vegetable \& Fruit Improvement Center.

\section{(89) Abiotic Factors Possibly Contributing to Reset Failure of Citrus Trees in a Commercial Grove in Florida}

Joseph Albano*1, Shivendra Sahi ${ }^{2}$, Chris Wilson ${ }^{3}$, Kim Bowman ${ }^{1}$

${ }^{1}$ USDA-ARS-U.S. Horticultural Research Laboratory, Fort Pierce, FL, 34945-3030; ${ }^{2}$ Western Kentucky University, Department of Biology, Bowling Green, KY, 42101-1080; ${ }^{3}$ University of Florida, Department of Soil and Water Science, Indian River Research \& Education Center, Fort Pierce, FL, 34945-3030

Reset/replant problems and/or failure are recognized as a problem in fruit tree production throughout the world. Problems in establishing or reestablishing fruit trees have been documented in apple, peach, grape, and citrus. Research to date has not identified a single casual agent responsible for reset failure, but rather there is evidence that such problems are related to a complex interaction of biotic and abiotic factors. In this study, we compared abiotic factors related to soil texture and soil nutrients in healthy and reset failure areas of a commercial citrus grove in Florida. A significant difference in soil texture was found in healthy sand, silt, and clay $(94 \%, 4 \%$, and $2 \%$, respectively) vs. failed ( $99 \%$ sand and $<1 \%$ silt and clay) reset areas in the citrus grove block. Mehlich III extractions were performed on soil samples and levels of $\mathrm{Ca}, \mathrm{Cu}, \mathrm{Fe}, \mathrm{K}, \mathrm{Mg}, \mathrm{Mn}, \mathrm{P}$, and $\mathrm{Zn}$ in the extract solution were significantly higher in healthy compared to failed reset areas of the citrus grove block. These data are consistent with what has been observed in other fruit crops where soil texture, which directly relates to soil hydrologic conditions, and soil nutrient levels have been identified as contributing factors related reset/replant failure in fruit tree crops.

\section{(90) Young Tree Growth and Leaf Function of Citrus Seedlings under Colored Shade Netting}

Kuo-Tan Li*, Jim Syvertsen

University of Florida, IFAS, Citrus Research and Education Center, Lake Alfred, FL, 33850

Young citrus trees and seedlings in Florida's commercial nurseries are often grown under shade cloth netting to avoid high light and temperature. To investigate the potential benefit of altering radiation by colored shade nets, 'Cleopatra' mandarin (Cleo, C. reticulata Blanco) seedlings and potted 'Valencia' trees [Citrus sinensis (L.) Osbeck] on Cleo or Carrizo [Carr, C. sinensis $\times$ Poncirus trifoliate (L.) Raf.] rootstocks were grown in full sun or under $50 \%$ shade from blue, black, silver, grey, and red colored shade nets. Changes in photosynthetically active radiation (PAR) and temperatures under the shade were monitored. Leaf function and leaf chlorophyll contents were measured, and plants were harvested by the end of the experiment for shoot and root growth measurements. Plants under the shade received an average of $45 \%$ PAR and had lower mid-day leaf temperature than plants in full sun. Plants under blue nets had greatest leaf chlorophyll a, b, and total chlorophyll content, whereas those under red nets had the lowest. However, shading improved photosystem II efficiency from measurements of leaf chlorophyll fluorescence $(\mathrm{Fv} / \mathrm{Fm})$ regardless of the color of shade nets. Shading increased shoot growth, shoot to root ratio, and total plant dry weight of Cleo seedlings, especially those under silver nets.

\section{(91) Yield Recovery of Commercial Citrus Trees Im- pacted by the 2004 and 2005 Florida Hurricanes}

James J. Salvatore*1, Mark A. Ritenour ${ }^{1}$, Brian T. Scully ${ }^{1}$, L. Gene Albrigo ${ }^{2}$

${ }^{1}$ University of Florida, Indian River Research and Education Center, Fort Pierce, FL, 34945-3138; ${ }^{2}$ University of Florida, Citrus Research and Education Center, Lake Alfred, FL, 33850-2299

Up to three hurricanes (Charley, Frances, and Jeanne) passed over the same citrus-producing areas of Florida in August and September 2004. In October 2005, hurricane Wilma also passed over South Florida. We began evaluating citrus tree recovery in four commercial groves (red and white grapefruit, and 'Murcott' tangerine) following the 2004 hurricanes to determine how quickly commercial groves recover following such catastrophic events. We previously reported that, among other things, even branches formed after the last 2004 hurricane matured sufficiently to flower the following spring, but to a lesser extent than older shoots. Here, we report hurricane effects on tree yield, fruit quality, and shelf life. Fruit loss was dramatic following the 2004 hurricanes ( $>90 \%$ ). Fruit loss was also substantial following hurricane Wilma, with 'Murcott' yields reduced $18 \%$ and grapefruit yields reduced $58 \%-65 \%$. However, in comparison to 2003 pre-hurricane yields, yields following hurricane Wilma declined only $9 \%$ for 'Murcott,' and 26\%-40\% for grapefruit. These yield reductions are less than the fruit lost due to the present year's hurricane. Therefore, the citrus trees studied demonstrated tremendous resilience and, if not for another hurricane the following year, would have likely exceeded pre-hurricane yields only 1 year after the devastating 2004 hurricanes. Effects of the hurricanes on harvested fruit quality and shelf life will also be discussed. 


\section{Poster Session 7-}

Waste and Water Utilization in Horticulture

27 July 2006, 1:15-2:00 p.m.

\section{(298) Harvest Yields of Greenhouse Tomatoes} Grown in Pine Bark-amended Cotton Gin Compost

Brian E. Jackson*1, Joe M. Kemble ${ }^{2}$, Amy N. Wright ${ }^{2}$, Jeff L. Sibley $^{2}$

${ }^{1}$ Virginia Polytechnic Institute and State University, Horticulture, Blacksburg, VA, 24061; ${ }^{2}$ Auburn University, Horticulture, Auburn, AL, 36849

Tomatoes are the most abundantly produced greenhouse vegetable crop in the United States. The use of compost substrates has increased in recent years for the greenhouse production of many vegetables, bedding plants, and nursery crops. 'Blitz' tomatoes were grown during the spring and fall growing seasons in 2004 in six substrate blends of pine bark (PB), a traditional production substrate in the Southeastern U.S., and cotton gin compost (CGC), an agricultural by-product, to assess the potential use of CGC as a viable replacement for PB for the production of greenhouse tomatoes. Treatments ranged from $100 \%$ PB to $100 \%$ CGC. During both growing seasons, plants grown in substrates containing CGC produced similar total, marketable, and cull yields compared to plants grown in $100 \% \mathrm{~PB}$. Substrates containing $40 \%$ or more CGC had significantly higher EC levels both initially and throughout both growing seasons than did $20 \% \mathrm{CGC}$ and $100 \% \mathrm{~PB}$ blends. Initial and final $\mathrm{pH}$ of all substrates was similar during both studies and remained within recommended ranges for greenhouse tomato production. Water-holding capacity increased as the percent CGC increased in each substrate blend, indicating the need for less irrigation volume for substrates containing CGC compared to the $100 \%$ PB control. Results indicate that CGC can be used as an amendment to or replacement for PB in greenhouse tomato production.

\section{(299) The Use of Worm Castings As an Alternative to Sphagnum Peat Moss in Tomato (Lycopersicon esculentum Mill.) Transplant Production in Chile}

\section{Monica Ozores-Hampton*1, Brain Mardones ${ }^{2}$}

${ }^{1}$ University of Florida/SWFREC, Horticulture, Immokalee, FL, 34142; ${ }^{2}$ Universidad de Mar, Horticulture, Valparaiso, Chile

Intensive peat mining in Chile and worldwide produces a significant increase in production costs and less market availability. Alternative systems to promote peat mining sustainability are an immediate necessity. A viable alternative for replacing peat in tomato transplant production is to use worm castings or vermicompost. Vermicomposting is a biological process that relies on the action of earthworms (Eisenia sp.) to stabilize waste organic materials. The objective of this study was to evaluate the use of Ecobol- $S^{\circledR}$ worm castings as a replacement for peat in tomato transplant production. Three experiments were designed using a randomized complete-block design containing two factors (planting date and worm casting rate). Tomatoes were seeded in a growth chamber using five growth media made up of the different ratios of worm castings, peat, and rice hulls [0:70:30 (control) 18:52:30; 35:35:30; 52:18:30; and 70:0:30], respectively. It was determined that Ecobol- $S^{\circledR}$ worm castings have an adequate $\mathrm{C}: \mathrm{N}$ and particle size for tomato transplant production. However, limitations were observed due to its high $\mathrm{EC}$ and low $\mathrm{C}$ content. During early fall, with high temperature in the growth chamber, it is not recommended to use worm castings in transplant production due to nutrient leaching caused by frequent irrigation. In mid-fall, it is recommended to use a rate of $35 \%$ worm castings, while in early winter it is recommended to use a rate of $52 \%$ to obtain strong and healthy transplants. Therefore, worm castings can be used as a viable alternative in the tomato transplant industry in Chile and possibly worldwide.
(300) Safety and Productivity of Cool-season Salad Greens Grown in Soils Amended with Composts

Lurline Marsh*, Corrie Cotton, Elizabeth Philip, Salina Parveen, Fawzy Hashem

University of Maryland Eastern Shore, Agriculture, Princess Anne, Maryland, 21853

Excessive amounts of poultry waste on the Delmarva Peninsula of the United States, coupled with the availability of yard waste, may be potential inexpensive nutrient sources for growing vegetables. However, these composts may contain unsafe microorganisms. This study, therefore, was conducted to determine the presence and persistence of biological agents in soil treated with poultry compost and yard waste. Tatsoi [Brassica rapa (Narinosa Group)] and spinach (Spinacia oleracea L. 'F415' and 'Seven R') were planted under a high tunnel to extend their fall growing season. Samples of soil-compost mixture and original poultry compost were collected once a month for 4 months. Escherichia coli $\mathrm{O} 157: \mathrm{H} 7$ in the samples was determined by enrichment and immunomagnetic separation, and was not detected in any of the soil-mixtures. However, this bacterium was detected in the original poultry compost in very low numbers. Plant leaves were harvested periodically. Results showed that tatsoi plants significantly produced larger leaves and higher fresh weight in soils amended with organic compost with the tendency for yield to increase with the increase in harvest date. Generally, the organic amendments did not influence size and total fresh weight of spinach leaves, although earlier harvests tended to produce significantly larger leaves and higher fresh weight.

\section{(301) Bioavailability of Dairy Manure Compost Nutrients to Urban Landscape Plants}

John Sloan*1, Cynthia McKenney ${ }^{1}$, James McAfee ${ }^{2}$, Wayne Mackay ${ }^{1}$ ${ }^{1}$ Texas Agricultural Experiment Station, Dallas Center, Dallas, TX, 75252; ${ }^{2}$ Texas Cooperative Extension, Dallas Center, Dallas, TX, 75252

Dairy manure compost (DMC) may be an effective soil amendment when establishing new urban landscapes. The objective of this study was to evaluate the bioavailability of DMC nutrients to typical urban landscape plants. In March 2003, DMC rates of 0, 9, 18, and $27 \mathrm{~kg} / \mathrm{m}^{2}$ $(0,1.25,2.5,5 \mathrm{~cm})$ were incorporated into the top 10 to $15 \mathrm{~cm}$ of Austin silty clay soil. Half of each 6 x 6-m plot was established with bermudagrass sod and the other half with six types of ornamental plants consisting of annual, perennial, and woody species. During the third 2005 growing season, plant tissue was harvested from selected landscape plants to measure biomass production and nutrient uptake. Plant growth and nutrient contents were compared to plant available soil nutrients that were measured during fall 2004 and 2005. Plant available $P$ in the upper $7.5 \mathrm{~cm}$ of soil ranged from 89 to $170 \mathrm{mg} / \mathrm{kg}$ in September 2004 and from 31.3 to $105.5 \mathrm{mg} / \mathrm{kg}$ in August 2004 . Potassium and trace elements $(\mathrm{Fe}, \mathrm{Cu}$, and $\mathrm{Zn}$ ) were also increased in the upper $7.5 \mathrm{~cm}$ by DMC applications. Increased concentrations of plant available soil nutrients in DMC-amended plots were correlated to overall increases in plant growth and nutrient uptake. Bermuda grass exhibited increased growth and increased tissue concentrations of $\mathrm{N}, \mathrm{P}$, $\mathrm{K}$, and $\mathrm{Zn}$. Penta biomass and nutrient uptake were also increased by DMC applications. Lantana stem weights significantly increased with DMC application rate up to $18 \mathrm{~kg} / \mathrm{m}^{2}$, but no additional increases were obtained with the $27 \mathrm{~kg} / \mathrm{m}^{2}$ rate. Results of this study show that, after three growing seasons with no additional fertilization, a $1-$ to $2-\mathrm{cm}$ application of dairy manure compost is sufficient to provide continued fertility to landscape plants.

\section{(302) Physical and Chemical Properties of Energized Water and Its Effects on the Germination, Growth, and Development of Sprouting Vegetable Plants}

Wol-Soo Kim*

Chonnam National University, Dept. of Horiculture, 300 Yongbong-dong, Gwangju, 500-757, Korea

Energized water production: Underground water, which was not con- 
taminated with heavy metal ions, chemicals, and much nitrate, etc. $\Rightarrow$ 1) filtering through reversed osmosis pressure filter, 2) nano-sized mineral system with specific stone powder, 3) far red light expositing system, 4) magnetic field treatment, 5) oxygen supply system $=>$ energized water (EW). Physical and chemical properties: EW showed higher $\mathrm{pH}$ level, electrical conductivity (EC), energy levels by Killian camera and oxygen concentration; however, lower ORP, cluster size as much as $79 \mathrm{~Hz}$ by NMR in comparison to underground water, as control. Bioassay of sprouting vegetable plants: In barley germination test, EW showed higher germination rate, strong top/root growth, especially outstanding differentiation of roots in comparison to control. After 2 weeks, the control barley seedlings showed significant symptoms of senescence in root tissue. Also, bean sprouts greatly increased growth in epicotyls and hypocotyls, and development under EW conditions. The roots of control plants showed discolored and mal flavors and gradually decayed in room temperature. With EW supply, vegetable seeds and sprouting plants showed better growth and development of top and root parts. In conclusion, EW influenced the plants to have higher biodynamic potentials for seed germination and growth and development of new plant tissues.

\section{(303) Performance of a New, Low-cost Soil Moisture, Temperature, and Electrical Conductivity Sensor}

Colin S. Campbell*, Gaylon S. Campbell, Douglas R. Cobos, Brody Teare

Decagon Devices, Inc., Research and Development, Pullman, WA, 99163

Knowledge of soil water, fertilizer, and temperature is important when growing plants in any type of growing media. Although instruments to measure these properties have been available for several years, they are often expensive, failure-prone, and require different calibration for individual soil types. Recently, a low-cost sensor (Trade name: ECH2O-TE) was released that measures volumetric water content, electrical conductivity (EC), and temperature. The objective of this study was to determine how the probe performed in various soil and soilless media, as well as various salinities. We found the probe performed very well over a wide range of soil types and salinities. From the data, it appears that a single calibration can be used for all mineral soils and organic potting soils. A second calibration equation may be required for substrates such as rockwool. The output of the probe was not affected by the salinity (EC) of the soil from 0.1 to greater than $10 \mathrm{dS} / \mathrm{m}$ and showed considerable improvement in temperature sensitivity compared to existing technology. These results suggest the sensor provides a low-cost, reliable, easier-to-use alternative to other sensors of its kind.

\section{Poster Session 8-Propagation 1}

27 July 2006, 1:15-2:00 p.m.

\section{(225) Effects of Nutrient Salt Formulations and PGRs on Axillary Shoot Proliferation of Tropical Hibiscus}

Rebecca E. Scoville*, Todd P. West

West Virginia University, Division of Plant and Soil Sciences, Morgantown, WV, 265066108

The objective of this study was to investigate the effects of multiple nutrient salt formulations and different plant growth regulator concentrations on initiation and proliferation of axillary shoot culture of tropical hibiscus (Hibiscus rosa-sinensis L.). Combinations of five thidiazuron (TDZ) concentrations $\left(0,10^{-6}, 10^{-7}, 10^{-8}\right.$, or $\left.10^{-9} \mathrm{M}\right)$ in conjunction with two 6-benzylaminopurine (BA) concentrations $\left(0,10^{-5} \mathrm{M}\right)$ and two indole-3-butryic acid (IBA) concentrations $(0$, $\left.10^{-5} \mathrm{M}\right)$ were compared to determine which plant growth regulator combination(s) would stimulate the proliferation of the most viable axillary shoots. Also, five nutrient salt formulations (MS, 1/2 MS; Macro MS, WPM, LP, or DKW) ranging from high to low salt formulations were studied to determine a suitable nutrient medium formulation for axillary shoot proliferation. Nodal explants that were $2 \mathrm{~cm}$ in length were used to initiate cultures and were maintained on the various medium treatments plus $30 \mathrm{~g} \cdot \mathrm{L}^{-1}$ sucrose and $7 \mathrm{~g} \cdot \mathrm{L}^{-1}$ agar at a $\mathrm{pH}$ of 5.8. Explants were incubated about $30 \mathrm{~cm}$ beneath cool-white fluorescent lamps that provide a photon flux of about $40 \mu \mathrm{M} \cdot \mathrm{m}^{-2} \cdot \mathrm{s}^{-1}$ for a 16 -hour photoperiod at $25 \pm 3{ }^{\circ} \mathrm{C}$. Nodal explants were transferred every 3 weeks for a total culture period of 12 weeks. At each transfer date data were collected on node number, axillary shoot number and length. Initial results indicate that high nutrient salt formulations coupled with low TDZ concentrations performed better at axillary shoot initiation. Poor shoot elongation was observed and further research needs to be performed to address this issue.

\section{(226) Tissue Culture of Vitis sp. for Protoplast Isolation}

Claudine M. Bona*1, Jean H. Gould ${ }^{2}$, J. Creighton Miller, Jr. ${ }^{2}$, David M. Stelly ${ }^{3}$, Eliezer S. Louzada ${ }^{1}$

${ }^{1}$ Texas A\&MUniversity, Horticulture, Weslaco, TX, 78596; ${ }^{2}$ Texas A\&MUniversity, Department of Horticultural Sciences, College Station, TX, 77843-2133; ${ }^{3}$ Texas A\&M University, Soil \& Crop Sciences, Beasley Laboratory, College Station, TX, TX 77843

The highly appreciated Euvitis subgenera species $(2 \mathrm{n}=38)$ are very susceptible to pests and diseases. Tolerance/resistance may be found in the closely related Vitis rotundifolia cultivars $(2 n=40)$, but the poor rooting characteristic of this species is a problem, and conventional crossings between Euvitis and V. rotundifolia are complicated because of different chromosome numbers. Therefore, somatic hybridization may be an alternative for gene transference between these species. The establishment of an efficient in vitro procedure may facilitate future genetic manipulations. Furthermore, in vitro success may be an indicative of protoplast totipotency. The goal of this research was to test 11 cultivars from different species for their in vitro cultivation and protoplast isolation capacity. Different doses of benzyladenine (BA) were tested and explants were cultivated in both Lloyd and McCown's Woody Plant Medium (WPM) and Murashige and Skoog medium (MS). We established an efficient in vitro procedure and plants of C. sauvignon, Syrah, SV 12-375, Scuppernong, Magnolia, Higgens and B. beauty were regenerated. No rooting problem was observed in vitro. Black spanish and Herbemont callus were kept in vitro, but plants were not regenerated. SV-12327 and Jumbo died. WPM was more efficient than MS for most cultivars. The $V$. vinifera cultivars C. sauvignon and Syrah developed well in both media. Protoplast isolation was more efficient using leaves rather than callus or suspension cells. BA at 3 $\mu \mathrm{M} \cdot \mathrm{L}^{-1}$ induced organogenesis while $10 \mu \mathrm{M} \cdot \mathrm{L}^{-1}$ induced callogenesis except for Syrah, where $1 \mu \mathrm{M} \cdot \mathrm{L}^{-1}$ induced organogenesis. Protoplasts were isolated from Herbemont and C. sauvignon and microcallus were obtained.

\section{(227) Guava Callus Production In Vitro}

Guochen Yang*, Zhongge (Cindy) Lu, Carl E. Niedziela, Jr.

North Carolina A\&T State University, Natural Resources \& Environmental Design, Greensboro, NC, 27411

This research was initiated to study different culture media and plant growth regulators for their influences on callus initiation and production, with a research goal of developing an efficient in vitro callus regeneration protocol for guava (Psidium guajava L.). Guava is an important tropical fruit species that is rich in vitamins and vitamin precursors, minerals, organic acids, and pectins. Seventy-nine phytochemicals provide guava with many unique properties and actions, including anti-microbial, astringent, bactericidal, cicatrizant, emmenagogue, hypoglycemic, laxative, nutritive, and spasmolytic. Different concentrations of various plant growth regulators (PGR), such as 6-benzyladenine (BA), kinetin, or 2,4-dichlorophenoxyacetic acid (2,4-D), and naphthaleneacetic acid (NAA) were added to basic Murashige and Skoog (MS) and woody plant medium (WPM) and tested for their influences. Differences in callus initiation and morphology were noticed between MS and WPM, and among PGR concentration treatments. 


\section{(228) In Vitro Rooting of Surinam Cherry}

John L. Griffis, Jr.*

University of Hawaii at Manoa, Tropical Plant \& Soil Sciences, Honolulu, Hawaii, 96822

Surinam cherry (Eugenia uniflora L.) has value as a minor tropical fruit crop and as an ornamental plant in tropical and subtropical regions. In the United States, Surinam cherry is propagated by seed, as stem cuttings do not root. Elite selections are propagated by grafting, but grafts have not had high rates of success. Micropropagation of Surinam cherry has also been mostly unsuccessful. In this trial, 100 seeds from a self-cross of the cultivar Zill Dark were surface-disinfested and placed in vitro in $150 \times 25$-mm tubes on a medium of deionized water solidified with $8 \mathrm{~g} / \mathrm{L}$ of agar. Seed cultures were placed on unlighted shelves. After 3 weeks without lights, seed cultures were transferred to lighted shelves where they readily germinated $(100 \%)$ over the next 7 to 14 days. Seedlings were strongly tap-rooted and the roots quickly reached the bottoms of the tubes. After the 2 weeks under lights, $2 \mathrm{~mL}$ of autoclaved, halfstrength liquid McCown's Woody Plant Medium (WPM) were added to each tube, creating a two-phase culture environment. Every 4 weeks, another $2 \mathrm{~mL}$ of half-strength WPM liquid medium were added to the cultures. Most seedlings elongated and produced three or more stems nodes with leaves after 10 weeks under lights. After this 10 -week growth period, several of the seedlings had also produced adventitious roots at the first, second, and third stem nodes. After an additional 4 weeks in culture, $50 \%$ of the seedlings (50) had produced adventitious roots at one or more nodes. Additionally, tip cuttings taken from some of the seedlings that did not initially produce adventitious roots, produced roots at nodes when the stems were inserted directly in WPM medium supplemented with $20 \mathrm{~g} / \mathrm{L}$ sucrose and various auxins.

\section{(229) Fertility Affects Cutting Production and Quality of Rooted Cuttings of Iva imbricata}

\section{Josiah Raymer ${ }^{1}$, Mack Thetford*1, Debbie Miller ${ }^{2}$}

University of Florida-Milton, Environmental Horticulture, Milton, Florida, 32583; ${ }^{2}$ University of Florida-Milton, Wildlife Ecology and Conservation, Milton, Florida, 32583

Seacost Marshelder (Iva imbricata Walter [Asteraceae]), a dominant Atlantic and Gulf region seashore plant, is a broad-leaved plant with a potential for building and stabilizing foredunes in the South Atlantic coast of the United States, and is recognized as an important food for beach mice. Two experiments were conducted where nursery liners were potted as stock plants and produced at four rates of fertility using

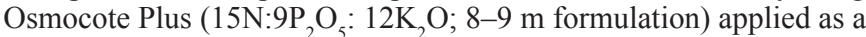
top dress at 5.5, 11.0, 15.0, and $21.0 \mathrm{~g} / 3.7$-L container. The experiment was arranged as a CRD with 12 single-plant replicates of each fertility rate. Stock plant growth, cutting production, and subsequent rooting characteristics (percent rooting, root number, length) were evaluated for cuttings harvested at each of four harvests (30-day interval). Stock plant height increased as fertility rate increased for all harvests. After the first harvest, plant height did not differ among fertility rates above $5.5 \mathrm{~g}$. Growth indices demonstrated that a 21.0-g application of fertilizer was necessary to increase stock plant size. The number of cuttings produced per stock plant increased linearly with increasing rate of fertility for all harvests. Cutting weight of individual cuttings increased linearly with an increase in fertilizer rate for harvests one and two, but cutting weight did not differ thereafter. The rooting response differed depending on the time of harvest. Percent rooting decreased with an increase in fertility rate for harvests two and three. Increased fertility rate did result in a decrease in root number for harvest one, but no further decrease was evident thereafter. Root length did not differ among harvest dates or fertility rates.

\section{(230) Effect of Five Doses of Indole Butyric Acid on the Aerial Layer Induction Root of Litchi}

Juan Manuel Gonzalez-Gonzalez, Salvador Guzman-Gonzalez*, Jorge Medina-Grijalva

Universidad de Colima, Facultad de Ciencias Biologicas y Agropecuarias, Autopista Colima-Manzanillo Km 40, Tecoman, Colima, 28100, Mexico
We evaluated the effect of five doses $(0,500,1000,5000$, and 10,000 $\mathrm{ppm}$ ) of indole butyric acid (IBA) on the aerial layer induction root of Litchi (Litchi chinensis Sonn.). The experiment was conducted in the coastal zone of Tecoman, Colima, Mexico, at the La Perla farm $\left(18^{\circ} 15^{\prime} \mathrm{N}\right.$; $103^{\circ} 52^{\prime} \mathrm{W}$ and $33 \mathrm{~m}$ above sea level). The ambient conditions were dry tropics with an average yearly rainfall of $710 \mathrm{~mm}$ and $26{ }^{\circ} \mathrm{C}$ annual medium temperature (BS1). The evaluated variables were: 1) the number of roots emitted by layer, and 2) percentage of layers taken root by treatment. The experiment was carried out under a randomized block arrangement. We used five treatments with 12 repetitions, considering one tree to be a block, in which five treatments were effected with four repetitions into every one tree utilized. Results of Duncan's test averaged 5\%. The results obtained indicated that dose of $500 \mathrm{ppm}$ was the best IBA level as the percentage of layers taken root by treatment $(96.7 \%)$. They are statistically different.

\section{(231) Habitat-correlated Germination and Growth Characteristics in Intermountain Allium (Liliaceae)}

Nathan C. Phillips ${ }^{* 1}$, Daniel T. Drost ${ }^{1}$, Bill Varga ${ }^{2}$, Leila Shultz ${ }^{3}$, Susan E. Meyer ${ }^{4}$

${ }^{1}$ Utah State University, Plants, Soils, and Biometeorology, Logan, Utah, 84322-4820; ${ }^{2}$ Utah Botanical Center, Director, Kaysville, Utah, 84037; ${ }^{3}$ Utah State University, Forest, Range, and Wildlife Sciences, Logan, Utah, 84322-5230; ${ }^{4}$ USDA Forest Service, RMRS-Shrub Sciences Laboratory, Provo, Utah, 84606

Seed germination timing strategies and seedling growth characteristics in wild populations have evolved in response to their life history, ecology, and habitat. In this study, we examined the ecophysiological aspects of seed germination and growth in three Allium species native to the Intermountain West (A. acuminatum, A. brandegei, and A. passeyi). Three populations of each species were studied along an elevation gradient resulting in low, mid, and high elevation sites for each species. We investigated seed dormancy patterns within and among species and their relation to habitat. Seeds collected at the study sites were subjected to cold $\left(3^{\circ} \mathrm{C}\right)$ moist stratification in low light to simulate the natural winter environment under snow. Stratification periods ranged from 0 to 24 weeks. After stratification, seeds were placed in lighted growth chambers at $8{ }^{\circ} \mathrm{C}$ to simulate the natural spring environment. Germination was observed for 4 weeks. Germinated seeds were then grown at either $12{ }^{\circ} \mathrm{C}$ or $16^{\circ} \mathrm{C}$ until leaf senescence. Destructive sampling occurred at 2, 4 , and 8 weeks. Bulb mass and water content were also assessed after leaf senescence. In the germination experiment, all species responded favorably to cold moist stratification, suggesting physiological seed dormancy. Germination percentages among species varied greatly with $98 \%$ germination in A. acuminatum, but only $33 \%$ in $A$. brandegei. Seedling survival and growth varied among species and in response to growing temperature. Observed patterns in seed germination and growth are typical of survival strategies in other spring ephemerals. Seed dormancy traits and seedling growth characteristics in these species have evolved to allow optimal success for their specific habitat.

\section{Poster Session 9-Nursery Crops 1}

27 July 2006, 1:15-2:00 p.m.

\section{(35) Foliar Mineral Nutrition of Colorado Spruce Trees after Digging Affects Shoot Growth in the Landscape}

Robert R. Tripepi*, Mary W. George, K. Amanda Linskey, Jennifer L. Van Wagoner, John E. Lloyd

University of Idaho, Horticultural Sciences Division, PSES, Moscow, ID, 83844-2339

The goal of this study was to determine if nutrient treatments applied to Colorado spruce (Picea pungens Engelm.) trees while they were held in a mulch bed one season after digging affected subsequent shoot growth of the trees after they were planted in the landscape. Sixty 1.5 - to 1.8 -m-tall trees with $61-\mathrm{cm}$ (24-inch) diameter root balls were heeled 
into a holding bed of fresh pine bark mulch. The nutrient treatments applied to the root balls were a control (pine bark without fertilizer), 114.2 g Osmocote 15-9-12 distributed over the top of the ball (label rate), one Ross Gro-Stake 10-10-10 Evergreen fertilizer spike per ball, one-half cartridge of Ross Root Feeder 10-12-12 evergreen fertilizer injected into the root ball at four points, or a 50:50 mixture (by volume) of Eko Compost mixed with pine bark. After one growing season in the mulch bed, the trees were transplanted to a landscape site. The height increases of the terminal leaders on all trees were determined for the next 2 years. Changes in tree height by the end of the growing season in the mulch bed were unaffected by the nutrient treatments. By fall, needles from trees treated with the mixture of 50:50 compost: bark had the highest levels of foliar $\mathrm{N}, \mathrm{Mg}, \mathrm{Ca}, \mathrm{S}, \mathrm{Mn}$, and $\mathrm{B}$. Trees treated with one fertilizer spike had the second-highest levels of foliar $\mathrm{N}$ and S. Leaders on trees that received the compost:bark or fertilizer spike treatments grew at least $70 \%$ or $36 \%$ taller, respectively, than those receiving the other treatments by the end of the second growing season in the landscape. The compost:bark mixture and to some extent the fertilizer spike improved tree foliar nutrition during the first growing season after digging, which later promoted tree height increases in the landscape.

\section{(36) Evaluating an Agroforestry Approach to Woody Cuts Production in Florida}

\section{Mack Thetford*1, Shibu Jose ${ }^{2}$, Edward H. Fletcher III ${ }^{3}$}

${ }^{1}$ University of Florida-Milton, Environmental Horticulture, Milton, FL, 32583; ${ }^{2}$ University of Florida, School of Forest Resources and Conservation, Gainesville, FL, 32611; ${ }^{3}$ University of Florida, School of Natural Resources and Environment, Gainesville, FL, 32611

The demand for special forest products used in the floral industry has a rapidly expanding market. Woody cuts come from perennial shrubs, trees, or woody vines, and are used as floral design materials for the flowering branches, foliage, fruits, or stems. Evaluation of specialty and woody cut production is needed to determine if these plants may be adapted to sustainable agroforestry production systems. An agroforestry approach to woody cuts production for longleaf pine (Pinus palustris) producers in Florida is a natural approach given the relatively open canopy of this timber species and the occurrence of several native species with ornamental characteristics that are currently utilized on a small scale for woody cuts production. The present approach to evaluating the suitability of these systems utilizes the following objectives: 1) Evaluate the production potential of ornamental species in monoculture and agroforestry silviculture systems and determine the biophysical interactions between system components. This objective will assess system design and its role on system productivity; determine time to ornamental yield. 2) Quantify the cost of establishing ornamentals for woody cuts production in both monoculture and agroforestry systems. This objective will identify and track overhead/fixed costs and variable costs associated with the ornamental cuts and timber crops for monoculture and agroforestry production systems over a 3-year period. 3) Investigate potential markets for the distribution and sale of cut foliage, flowers or stems. This objective will lead to consultations with florists and cut foliage wholesalers about potential market volume, price, and specifications for products produced within the longleaf pine agroforestry production system.

\section{(37) Irrigation and Fertilizer Placement Affects Plant and Weed Growth In Container Tree Production}

Glenn B. Fain*1, Patricia R. Knight ${ }^{2}$

${ }^{1}$ USDA-ARS, Southern Horticultural Laboratory, Poplarville, MS, 39470; ${ }^{2}$ Mississippi State University, Coastal Research and Extension Center, Biloxi, MS, 39532

On 24Apr. 2003,3-gallon(11.4-liter) Quercus shumardii were potted into 13.2-gallon (50-liter) containers using a standard nursery mix. Treatment design was a $3 \times 2 \times 2$ factorial with two fertilizer placements, three irrigation methods, and two herbicide rates. Controlled-release fertilizer $17 \mathrm{~N}-2.9 \mathrm{P}-9.8 \mathrm{~K}$ was dibbled (placed $10.2 \mathrm{~cm}$ below the surface of the container media at potting) or top-dressed at a rate of 280 grams per container. Irrigation was applied using one of three methods: 1) a spray stake attached to a 3-gallon- (11.4-L-) per-hour pressure compensating drip emitter; 2) a surface-applied pressure-compensating drip ring delivering water at a rate of 2.3 gallons (8.9-L) per hour; and 3 ) the same drip ring placed 4 inches $(10.2 \mathrm{~cm})$ below the container substrate surface. A granular preemergent herbicide (oxyfluorfen + oryzalin) was applied at $2.0+1.0 \mathrm{lb} /$ acre $\left(2.24+1.12 \mathrm{~kg} \cdot \mathrm{ha}^{-1}\right)$. At 75 days after treatment (DAT), containers with no herbicide and top-dressed fertilizer had a percent weed coverage of $46 \%$ compared to $18 \%$ for dibbled containers with no herbicide. At 180 DAT weed top dry weight was greater for top-dressed containers compared to dibbled. None of the treatments in the study had any effect on height increase. At 240 DAT, trees irrigated with drip rings at the surface had a $28 \%$ greater caliper increase among the dibbled fertilizer-treated containers. Trees irrigated with the drip ring placed below the surface and fertilizer top-dressed had the smallest caliper increase. Irrigation method had no effect on weed control in this study; however, a repeat fall application showed a significantly greater weed control with the drip ring below surface compared to the spray stake.

\section{(38) Planting Depth and Tree Performance}

Mark W. Jarecki*, David J. Williams, Gary J. Kling

University of Illinois at Urbana-Champaign, Natural Resources and Environmental Sciences, Urbana, IL, 61801

Growers, nurseries, landscape contractors and installers, and those responsible for maintenance have observed a trend that trees are too deep within the root ball. This study addresses the relationship between planting depth and its effect on tree survival, root growth, root architecture, and caliper growth. The experiment was initiated to determine the effect of planting depth on nursery-grown trees. Three-year-old, 2.1-2.7 m, bare-root liners of Acer platanoides 'Emerald Lustre', Fraxinus americana 'Autumn Purple', Fraxinus pennsylvanica 'Patmore', and Gleditsia triacanthos f. inermis 'Shade Master' were planted in April 2004 in a completely randomized design with 20 replications per treatment per species. The trees were selected so that the distance between the graft union and the trunk flare was consistent. Trees were planted with the graft union $15.2 \mathrm{~cm}$ below the soil surface, or with the base of the graft union at the finished grade or with the trunk flare at the finished grade. The trees were grown in a nursery field setting with minimal supplemental watering. There were no differences in stem caliper growth at the end of two seasons in any of the four species. Root dry mass, stem elongation, and rooting structure were determined on a representative sample of trees while others were planted into the landscape for a long-term study of the effects of the original planting depth on landscape performance.

\section{(39) Determination of the Optimum Species for Ohio Tree Liner Production in Retractable Roof Greenhouses}

Luke Case*, Hannah Mathers, Elizabeth Grosskurth

The Ohio State University, Hort. and Crop Science, Columbus, OH, 43210

Many Ohio growers import liners from the West Coast due to the increased growing season on the West Coast. Lengthening the season in Ohio may provide a way for Ohio growers to produce liners of their own. Retractable roof greenhouses (RRG) are one possible way to extend the growing season in Ohio. Research done previously at The Ohio State University suggests that retractable roof greenhouses do in fact lengthen the growing season, and tree liners can be produced using RRG. The objectives of this study were: 1) to determine the optimal growing environment from three different environments; and 2) to determine the optimal species for tree liner production in Ohio. In Oct. 2004, 180 liners each of Cladrastis kentuckea, Quercus rubra, Stewartia pseudocamellia, Syringa reticulata, and Tilia cordata were upshifted to 3-gallon pots. In Mar. 2005, 90 of each species were transferred to either a flat roof retractable house (FRRG), peak roof retractable house (PRRG), or polyhouse. Growth was measured in Mar. (initial), June, Aug., and Oct. 2005 by taking leaf area, shoot and root dry weights, 
height, and caliper. There were no differences across species and dates between the environments for any of the parameters measured. Tilia showed the greatest increase in growth from June to October in all the parameters measured except leaf area. Cladrastis showed the greatest increase in leaf area from June to October. There were species by date interactions. Quercus had the greatest root weight in October. Syringa and Quercus were not significantly different from each other and had the highest shoot weights and leaf areas in October. Tilia, Quercus, and Syringa had the highest calipers in October.

\section{(40) Evaluation of Freshly Chipped Pine Tree Substrate for Container-grown Lantana camera}

Cheryl R. Boyer*1, Glenn B. Fain², Charles H. Gilliam¹, H. Allen Torbert ${ }^{3}$, Thomas V. Gallagher ${ }^{4}$, Jeff L. Sibley ${ }^{1}$

'Auburn University, Horticulture, Auburn, AL, 36849; ${ }^{2}$ USDA, Southern Horticultural Laboratory, Poplarville, MS, 39470; ${ }^{3}$ USDA, National Soil Dynamics Laboratory, Auburn, AL, 36832; ${ }^{4}$ Auburn University, Forestry and Wildlife Sciences, Auburn, AL, 36849

Astudy was conducted at Auburn University to evaluate freshly chipped pine trees as an alternative substrate in container nursery crops. Two substrates were tested alone and in combination with aged pine bark $(\mathrm{PB})$, peat $(\mathrm{P})$, and composted poultry litter (PL). A 6:1 (v:v) PB: sand control treatment was also included. The two substrates were both composed of small caliper (2 to $10 \mathrm{~cm}$ ) Pinus taeda processed in a chipper (including needles) (AUC); however, one substrate was additionally processed through a hammermill with a $0.95-\mathrm{cm}$ screen (AUHM). Treatments included were 100\% AUC, 3:1 (v/v) AUC:PB, 3:1 (v/v) AUC:P, 3:1 (v/v) AUC:PL, 1:1 (v/v) AUC:PB, 1:1 (v/v) AUC: $\mathrm{P}, 1: 1(\mathrm{v} / \mathrm{v}) \mathrm{AUC}: \mathrm{PL}$, and the same treatments for the AUHM substrate. There were a total of 15 treatments with six replications per treatment. Each substrate was amended with $0.45 \mathrm{~kg} \cdot \mathrm{m}^{-3}$ gypsum, $6.35 \mathrm{~kg} \cdot \mathrm{m}^{-3}$ Polyon $17-6-12(17 \mathrm{~N}-2.6 \mathrm{P}-10 \mathrm{~K})$ and $0.68 \mathrm{~kg} \cdot \mathrm{m}^{-3}$ MicroMax. Trade gallon (2.8-L) containers were filled with respective substrates and planted with Lantana camera 'New Gold' on 20 July 2005. AUC and AUHM treatments amended with either PL or P resulted in Lantana with growth indices similar to PB:sand (6:1). In general, plants tended to be larger when amended on a 1:1 basis with either PL or P, but were similar statistically to those amended $3: 1$. For example, plants grown with AUHM:P 1:1 or AUHM:PL 1:1 were $7.3 \%$ and $8.8 \%$ larger, respectively, than plants grown in the same medium at 3:1. The lowest growth indices tended to occur with AUC and AUHM alone or amended with pine bark. Lantana root growth followed a similar trend to growth indices in that greatest coverage of the rootball surface occurred with AUC or AUHM treatments amended with PL or P.

\section{(41) Growth of Japanese Holly in Pine Chips and Pine Bark as Influenced by Fertilizer Rate}

Brian E. Jackson*, Robert D. Wright, Jake F. Browder

Virginia Polytechnic Institute and State University, Horticulture, Blacksburg, VA, 24061

Many industrial and agricultural wastes have been evaluated for use as alternative container substrate components. Recently, a new material produced from ground pine logs (Pinus taeda L.) has been utilized as a substitute for peat moss and pine bark (PB). On 17 Aug. 2005, japanese holly (Ilex crenata 'Compacta' Thunb.) plants were potted in milled PB (Pinus taeda L.) and debarked ground pine chips (PC). Pine chips were ground with a hammermill to pass through a $6.35-\mathrm{mm}$ screen. Osmocote Plus 15-9-12 (15N-4P-10K) was incorporated in both PB and PC substrates at the rates of $3.5,5.9,8.3$, and $10.6 \mathrm{~kg} \cdot \mathrm{m}^{-3}$. Plants were greenhouse grown until 22 Nov. 2005. Substrate solution nutrient content and $\mathrm{pH}$ were determined for all treatments in each substrate. Shoots were dried, weighted, and tissue analyzed for N, P, K, Ca, Mg, $\mathrm{S}, \mathrm{Fe}, \mathrm{Cu}, \mathrm{Mn}$, and $\mathrm{Zn}$. Shoot weights were higher in plants grown in $\mathrm{PB}$ than $\mathrm{PC}$ at the 3.5 and $5.9 \mathrm{~kg} \cdot \mathrm{m}^{-3}$ fertilizer rates. At the $8.3 \mathrm{~kg} \cdot \mathrm{m}^{-3}$ rate, shoot dry weight was about the same for each substrate, but at the $10.6 \mathrm{~kg} \cdot \mathrm{m}^{-3}$ rate, growth was higher for plants grown in $\mathrm{PC}$ than in PB. Substrate EC increased with increasing fertilizer rates and with the exception of $\mathrm{Cu}$, was higher in $\mathrm{PB}$ substrates at all fertilizer rates. Plant tissue levels generally increased as fertilizer rate increased in both substrates but were higher in plants grown in PB than PC with the exception of $\mathrm{Cu}$. Therefore, higher rates of fertilizer are required to produce optimal plant growth in $\mathrm{PC}$ compared to $\mathrm{PB}$.

\section{Poster Session 10-Genetics and Germplasm 1}

27 July 2006, 1:15 -2:00 p.m.

\section{(268) Lutein Content in Sweetpotato Leaves}

Michael Cavalier*1, Armen Kachatryan², Evodokia Menelaou², Jack Losso ${ }^{2}$, Don LaBonte

${ }^{1}$ Louisiana State University, Department of Horticulture, Baton Rouge, LA, 70803; ${ }^{2}$ Louisiana State University, Department of Foood Science, Baton Rouge, LA, 70803

Fresh leaves of six sweetpotato [Ipomoea batatas (L.) Lam.] genotypes, 'Beauregard', 'Bienville', L 99-35, L 00-8, L 01-145, and L 01-29 were characterized for lutein. Lutein is a carotenoid capable of delaying blindness-related macular degeneration. The content of lutein in sweetpotato ranged from 0.38 to $0.58 \mathrm{mg} \cdot \mathrm{g}^{-1}$ fresh weight. Beta-carotene separated from lutein on HPLC chromatograms, and, when spiked in pure lutein extract, did not interfere with lutein separation. Stems were also characterized and found not to contain lutein. Our results showed that sweetpotato leaves are an excellent source of dietary lutein and surpass levels found in leafy crucifers. Leaves of sweetpotato and a related species are used as human food in some countries and could be a source of extracted lutein for commercial purposes.

\section{(269) Black Pigmentation in Capsicum-A Biochemical and Molecular Account}

\section{Gordon J. Lightbourn*1, Robert J. Griesbach², John R. Stommel ${ }^{3}$}

${ }^{1}$ Virginia Polytechnic Institute and State University, Department of Biology, Blacksburg, VA, 24061; ${ }^{2}$ USDA, U.S. National Arboretum, Floral and Nursery Plants Research Unit, BARC-West, Beltsville, MD, 20705; ${ }^{3}$ USDA, Plant Sciences Institute, Vegetable Laboratory, BARC-West, Beltsville, MD, 20705

Color observed in plants is due to several pigments, in particular chlorophylls, carotenoids, flavonoids, and betalains. The many hues can be attributed to a number of biochemical factors, inclusive of pigment concentration, pigment combinations and their ratios, and vacuolar $\mathrm{pH}$. Shades of violet to black pigmentation in pepper (Capsicum annuum L.) are attributed to anthocyanin accumulation. The color of unripe pepper fruit varies from green and yellow to ivory, through varying shades of violet and purple to nearly black. Whereas pepper fruit color is important for culinary product quality, foliar pigmentation is also an important aspect of ornamental variety appeal. Foliage and stem color may vary from green to varying shades of green/purple to nearly black. HPLC analysis of violet and black pepper fruit revealed a single anthocyanidin that was identified as delphinidin. Black fruit contained five-fold higher chlorophyll concentrations in comparison to violet fruit, which contained relatively little chlorophyll. Differences in fruit $\mathrm{pH}$ were not statistically significant. Similar to fruit, black pepper leaf tissue contained delphinidin as the predominant anthocyanidin, but in higher concentration relative to that found in fruit. The results demonstrate that high concentrations of delphinidin in combination with chlorophyll account for black pigmentation. Real-time PCR analysis of tissues that varied in pigmentation intensity due to varying anthocyanin concentration revealed functional, but differentially expressed, structural genes in the anthocyanin biosynthetic pathway. Analysis of regulatory gene expression identified a MYB transcription factor that was differentially expressed in response to varying anthocyanin concentration.

\section{(270) Screeing for Melonworm Resistance in Squash and Pumpkins}

Jorge Pérez-Arocho, Linda Wessel-Beaver*

University of Puerto Rico at Mayagüez, Department of Agronomy and Soils, Mayagüez, PR, 00681-9030

Melonworm (Diaphania hyalinata) is one of the most damaging pests 
of squash and pumpkin (Cucurbita sp.) in tropical/subtropical regions of the Americas. In order to identify sources of resistence to melonworm, we evaluated 345 accessions of C. moschata, including both tropical and temperate types, originating from the Americas, Europe, Asia, and Africa. C. argyrosperma (65 accessions) was also evaluated. Accessions were field tested in five single-plant complete blocks planted over a 9-month period in Isabela, P.R. Each plant was evaluated for foliar damage ( $0-4$ scale) at 3 and 6 weeks. Larval counts were made on a five-leaf sample at 8 weeks. Accessions were classified for degree of leaf mottling and pubescence. Differences among accessions were found for foliar damage and number of larva, but ranking of accessions varied, depending on the criteria used to measure resistance. In order to establish independent culling levels, we considered the lower $30 \%$ of accessions for each trait. The upper limit was $\leq 0.42$ for foliar damage at 3 weeks, $\leq 0.50$ damage at 6 weeks, and $\leq 1.25$ larva/plant. This led to the selection of 34 resistant accessions. We used a similar technique to identify the most susceptible accessions. The susceptible accessions will be used as a control group when the 34 selections are further evaluated. Within C. moschata, accessions with either green leaves or less pubescence had less leaf damage and fewer larva than accessions with mottled leaves or more pubescence. As a group, $C$. argryosperma accessions were more susceptible, and nearly all had mottled leaves and little pubescence. Untested accessions with green leaves and/or little pubescence might yield additional sources of resistance to melonworm.

\section{(271) Ornamental Characteristics of Lesquerella (Lesquerella sp.) Plants}

Maria M. Jenderek*

USDA-ARS, NALPGRU, Parlier, CA, 93648

Lesquerella (Brassicaceae) seeds contain high concentrations of hydroxyl fatty acids with long carbon chains, similar to imported castor oil. Although species within the genus are considered as an alternative oil crop, lesquerella plants have ornamental characteristics that may present a valuable landscape alternative for dry open spaces. Seeds of certain Lesquerella species are already a component of wild flower seed mixtures sold commercially. The purpose of this study was to describe ornamental aspects of selected accessions in the USDA Lesquerella germplasm collection maintained at the National Arid Land Plant Genetic Resources Unit. From 2003 to 2005, more than 140 accessions from 30 species were characterized for selected plant characteristics. The majority of lesquerella flowers were yellow, but some species, such as L. mcvaughiana, L. mexicana, L. ovalifolia, L. pallida, L. perforata, and $L$. stoniensis, had white flowers. Petal length ranged from 4 to 11 $\mathrm{mm}$, and the number of flowers per an unbranched stem was from two to seven. While the duration of full bloom of many lesquerella plants was between 15 to 40 days, the full bloom of plants of 10 accessions lasted from 50 (PARL 166, L. argyrea; W6 20836, L. grandiflora; W6 20841, L. lasiocarpa) to 72 days (PI 596362, L. fendleri). Those traits make the plants suitable for planting in landscape borders, low hedges, or color patches. The main use of the USDA, NPGS Lesquerella germplasm collection (201 accessions) is in cultivar development of a new oil crop. However when considering the duration of bloom and the abundance of flowers, several accessions may be used as ornamental crops, especially in semi-arid and arid landscapes where water supply is limited.

\section{(272) An Alternative Method for Estimating Heritability in Facultative Apomictic Guayule}

Maren E. Veatch-Blohm*, Dennis T. Ray, Valerie H. Teetor University of Arizona, Department of Plant Sciences, Tucson, AZ, 85721

Guayule (Parthenium argentatum Gray) has been difficult to improve through classical plant breeding because of its facultative apomictic reproductive system. Attempts have been made to increase rubber concentration and yield by examining traits correlated with rubber production and their heritabilities. We propose a new way of estimating heritability in guayule that more accurately accounts for the contributions of apomictic and sexual reproduction. At two years of growth, there was a significant relationship between the parents and the progeny for all traits measured, except for rubber and guayulin B concentrations. Due to the facultative apomictic nature of guayule reproduction, heritabilities are more accurately presented as a range of values between the narrow and broad sense heritabilities. Since guayule is more apomictic than sexual, most heritabilities will be closer to the broad sense values. To increase resin and rubber yield in the progeny, selection should focus on height and width in the parents because height and width are highly correlated with rubber yield, with the highest heritabilities ( 0.65 to 1.00 and 0.97 to 1.0 , respectively) of the traits measured.

\section{(273) Orchid Seed Storage for Germplasm Preservation}

Alice Mweetwa*1, David Tay ${ }^{1}$, Gregory Welbaum ${ }^{1}$

${ }^{1}$ Virginia Polytechnic Institute and State University, Horticulture, Blacksburg, VA, 24061; ${ }^{2}$ The Ohio State University, Ornamental Plant Germplasm Center, Columbus, OH, 43210-1086

Orchids are important ornamental, food, and medicinal plants. Orchid germplasm preservation is important because some species are endangered due to loss of habitat and human predation. Very few of the world's genebanks are involved in orchid preservation. Orchid germplasm preservation is a priority for the USDA Ornamental Plant Germplasm Center in Columbus, Ohio. Brassia and Phalaenopsis seeds were harvested at different stages of development and stored at $-196{ }^{\circ} \mathrm{C}$ (liquid nitrogen), $-80,-18,4$, and $25{ }^{\circ} \mathrm{C}$ for $6,12,18$, and 24 months to determine the optimum conditions for long-term seed storage. Phalaenopsis and Brassia seeds adjusted to $45.5 \%$ RH over chromium dichromate were able to survive 10-d storage. Seeds frozen in liquid nitrogen for $30 \mathrm{~min}$ were able to germinate and produce protocorms $19 \mathrm{~d}$ after sowing, just a day longer than control seeds. Liquid nitrogen storage also improved germination of some Phalaenopsis seed lots from 0 (control) to $38 \%$. Storing Phalaenopsis seeds at -80 and $4{ }^{\circ} \mathrm{C}$ also improved germination similarly, suggesting dormancy was broken by low-temperature seed treatments. On the other hand, seeds stored at $25{ }^{\circ} \mathrm{C}$ did not germinate. Preliminary results suggest that orchid seeds tolerate freezing even in liquid nitrogen and that cryopreservation may be a viable long-term strategy for orchid germplasm preservation.

\section{Poster Session 11-Fruit Crops}

\section{July 2006, 1:15-2:00 p.m.}

\section{(92) Preplant Practices to Manage Armillaria Root Rot Disease and Other Soil Pathogens on a Commercial Peach Replant Site}

Desmond R. Layne*1, Guido Schnabel ${ }^{2}$

${ }^{1}$ Clemson University, Horticulture, Clemson, SC, 29634-0319; ${ }^{2}$ Clemson University, Entomology, Soils, and Plant Sciences, Clemson, SC, 29634-0315

In 2003, a replicated long-term research trial was established on a commercial peach replant site with a history of Armillaria root rot and other soilborne diseases. The objectives of the trial were to determine the short- and long-term effects of preplant fumigation, rootstock, and preplant root dipping with mycorrhizal fungi and beneficial bacteria on tree growth, productivity, and survival. Preplant fumigants included none (control), methyl bromide, Telone II, or Enzone. Rootstocks tested included Guardian, Lovell, and Halford. Root dipping (or not) was with MycorTree. The scion cultivar was Big Red. There were a total of 24 experimental treatment combinations and the trial site comprised more than 1500 trees on 11.5 acres. By 2 years after planting, fumigation with Enzone was disadvantageous when compared with no treatment at all. Enzone-treated blocks had higher tree mortality or were significantly reduced in growth compared to other treatments. Preplant fumigation with Telone II or methyl bromide, however, resulted in reduced tree stunting and phytotoxicity and increased tree growth when compared 
to the untreated control. After 2 years, $10 \%$ of the total trees planted were dead. Half of these were from the Enzone treatment. Enzone does not appear to be a viable preplant fumigation product for South Carolina peach growers, based on this preliminary data. Both Guardian and Halford rootstocks had performance superior to Lovell during the first 2 years. Although Guardian trees were smaller than Halford at the time of planting, by the end of the second growing season, their TCA was not significantly different. There was no benefit to preplant root dipping with MycorTree. Experimental results were not influenced by the location of trees on the site.

\section{(93) Vegetative and Flower Bud Development, and Fruit Set of Low-chill Peach Cultivars in North-central, Central, and Southwest Florida}

Todd Wert ${ }^{1}$, Jeffrey G. Williamson*1, Robert E. Rouse ${ }^{2}$

${ }^{1}$ University of Florida, Horticultural Sciences Dept., Gainesville, FL, 32611-0690; ${ }^{2}$ University of Florida, S.W. Florida Research and Education Center, Immokalee, FL

Four low-chill peach cultivars were evaluated at three locations in Florida for vegetative and reproductive bud development and fruit set. Twenty trees (five each of 'Flordaprince', 'Tropicbeauty', 'UFgold', and 'Flordaglo') were planted at each site in Feb. 2002. Prior to budbreak in Spring 2004 and 2005, three shoots per tree of average length and diameter were selected at a height between 1.5-2.0 $\mathrm{m}$ and the numbers of vegetative and flower buds per node were recorded for each shoot No consistent pattern for the number of vegetative buds per node was observed among cultivars and locations, or across years. However, 'Tropicbeauty' tended to have fewer vegetative buds per node than 'Flordaprince' during both seasons, although not at all locations. Overall, the number of flower buds per node was greater for north-central Florida than for central or southwest Florida. There were no consistent tends over years and among locations for the ranked order of flower buds per node by cultivar. The percentage of nodes without flower or vegetative buds (blind nodes) was generally greatest for 'Tropicbeauty' at most locations during both years. During 2005, the percentage of blind nodes was greater in central and southwest Florida than in north-central Florida. Overall, fruit set was similar between the central and northcentral Florida locations. Fruit set tended to be higher for 'UFGold' and 'Flordaglo' than for 'Flordaprince' or 'Tropicbeauty'.

\section{(94) White-fleshed Peaches and Nectarines for the Southeastern United States}

Desmond R. Layne*1, W.R. Okie ${ }^{2}$

${ }^{1}$ Clemson University, Horticulture, Clemson, SC, 29634-0319; ${ }^{2}$ SE Fruit \& Tree Nut Res Lab, USDA-ARS, Byron, GA, 31008

White-fleshed peaches and nectarines are delicacies that have been enjoyed for centuries around the world. They are native to China and were introduced to the United States in the 1800s. Some white-fleshed peaches and nectarines are highly perishable and bruise easily, but are of very high eating quality. These are perhaps best suited for the local roadside market, where they can be sold and consumed more quickly. Others are much firmer at harvest, have a longer shelf life. and are suitable for long-distance transport to wholesale markets. White-fleshed peaches and nectarines may have some acidity or they may be very low acid with high sugar content ( ${ }^{\circ}$ Brix). Some novel flat (peento or donut) types also exist. Proximity to an urban market with a substantial Asian population is advantageous because Asians, in particular, often prefer the low-acid flavor and are willing to pay premium prices for high quality fruits. In our peach and nectarine cultivar evaluation program at Clemson University, we are currently evaluating 70 cultivars and advanced selections at four different locations in South Carolina. Several of these have been evaluated since 2000 and the "top performers" over the last six seasons by ripening date (earliest to latest) include the following: 'Sugar May', 'Scarletpearl', 'Snowbrite', 'Southernpearl', 'White Lady', 'Sugar Lady', 'Summer Sweet', 'Sugar Giant', 'Stark's Summer Pearl', 'Snow King', and 'Snow Giant'. In general, most of the white nectarines and the flat/donut peaches and nectarines have serious problems with insect damage and brown rot. Complete details of our peach and nectarine (yellow- and white-flesh) evaluation work in South Carolina since 2000 will be noted by referring to my peach website (http://www.clemson.edu/hort/Peach/index.php).

\section{(95) Fruit Characteristics, Phenolic Compound, and Antioxidant Activity of Asian Pear Fruit from an Organically Cultivated Orchard}

Wol-Soo Kim*, Jung-An Jo

Chonnam National University, Department of Horticulture, 300 Yongbong-dong, Gwangju, 500-757, Korea

Pear (Pyrus pyrifolia) fruits of 'Whangkeumbae' were produced from the organic orchard at Yongam, southwestern Korea, which was managed by spraying with chitin incubated solution (CIS) 15 times from petal fall stage, mid-April to late August, to control pests and diseases during the growing season. The CIS contained about 50 kinds of chitin digestive and/or effective microorganisms and other organic/inorganic biologically active substances by incubating the mixtures at $30^{\circ} \mathrm{C}$ for 7 days. The soil had standard levels of chemical and physical properties in Korea, as well as $3.0 \%$ to $4.0 \%$ organic matter. The organic fruits showed higher soluble solid contents, and fruit firmness was increased in comparison to conventional fruits. The organic fruit skin changed in color from yellow to brown, and black spot occurred; however, there was no difference in flesh tissues in terms of colors and textures. The phenolic compounds were significantly increased in organic fruits and leaves, with especially higher levels for fruit skin than for flesh tissues. Free radical levels dropped sharply in organic fruit, but slowly in conventional fruits. The results showed that the organic pear fruits have higher levels of antioxidant activity, and also showed the phenomena related to the change in fruit skin color from yellow to brown.

\section{(96) Sensory Evaluation of Alternative Pear Varieties for the U.S. West Coast}

Rachel B. Elkins*1, Janet D. Turner ${ }^{2}$, Steve Castagnoli ${ }^{3}$, Clark F. Seavert $^{4}$, Elizabeth J. Mitcham ${ }^{5}$, William V. Biasi ${ }^{5}$, Ann Colonna ${ }^{6}$

${ }^{1}$ University of California Cooperative Extension, Lakeport, CA, 95453; ${ }^{2}$ Oregon State University Mid-Columbia Agricultural Research and Extension Center, Horticulture, Hood River, OR, $97031 ;{ }^{3}$ Oregon State University Cooperative Extension, Horticulture, Hood River, OR, 97031; ${ }^{4}$ Oregon State University Mid-Columbia Agricultural Research and Extension Center, Agricultural Business Management, Hood River, OR, 97031; ${ }^{5}$ University of California, Plant Sciences, Horticulture Subscetion, Davis, CA, 95616-8780; ${ }^{6}$ Food Innovation Center Experiment Station, Food Science and Technology, Portland, OR, 97209

Assessing consumer acceptance is an important aspect of cultivar evaluation. Since 2002, about 2700 consumers have participated in pear preference surveys. Surveys were conducted on multiple dates and at multiple venues from 2002 to 2005 in Oregon and northern California. Survey participants were asked to indicate their preference for pears based on size, appearance, taste, and overall preference. They were also asked to indicate what attributes they liked or disliked about their favorite and least favorite varieties and to indicate their level of purchase intent. Each survey consisted of four to six cultivars, including at least one standard commercial comparison; i.e., Bartlett, Bosc, or Anjou. Data was analyzed (RCBD; Friedman Analysis of Rank or ANOVA/Tukey's HSD) at the OSU Food Innovation Center Experiment Station using Compusense ${ }^{\circledR}$ five v.4.6 software (Guelph, Ont., Canada). Results indicated several alternative possibilities for both summer and winter sales. Among the most preferred cultivars (variable between states) were Anjou (commercial standard winter pear), Bartlett (commercial standard summer pear and most-consumed cultivar), Blake's Pride, Cinnamon, Concorde, and 71655-014. Other major findings were preference for large pears for adults and small for children, overall liking based on sweetness and flavor rather than skin color, and general lack of knowledge of many commercial pear cultivars. Sensory evaluation surveys will be continued in 2006 in California, with focus on differential harvest times for selected preferred cultivars. Consumer preference data is being combined with production and postharvest quality data in order to provide the pear industry a comprehensive data set on potential alternative cultivars. 


\section{(97) Performance of 'Ginger Gold' and 'Gala' on Malling 9 and Budagovsky 9 over Ten Years}

\section{Robert M. Crassweller*, Donald E. Smith}

The Pennsylvania State University, Horticulture, University Park, PA, 16802

An apple planting was established in 1996 comprised of two cultivars: 'Ginger Gold' (GG) and 'Crimson Gala' (CG) on Malling 9 NAKB T337 and Budagovsky 9 at the Horticulture Research Farm at Rock Springs, Pa. The trees were planted at a spacing of $1.5 \times 3.7 \mathrm{~m}$ in a randomized complete-block design with 10 replications. The trees were trained to a vertical axe system with a single wire set at $2.8 \mathrm{~m}$, to which the conduit was attached. Data collected included trunk cross-sectional area (TCA), tree yield, number of fruit, and number of rootsuckers. Calculated data included annual tree growth, tree efficiency, average fruit weight, and crop load. In most years, there were significant cultivar $\times$ rootstock interactions for some variables. At planting and for the first two growing seasons, GG/B.9 were significantly larger than GG/M.9 as measured by TCA. At planting, there were no differences in TCA for CG, but, by the end of 1996, M.9 trees were significantly larger and stayed this way for the rest of the study. The GG/M.9 trees did not have significantly larger TCA than those on B.9 until 2005. Trees on B. 9 were $23 \%$ and $31 \%$ smaller in 2005 for GG and CG, respectively, for B.9 than on M.9. Flowering occurred first and in greater abundance for GG/B.9. At the end of the 10th growing season, there was no difference in number of fruit or total yield per tree within cultivars by rootstock. However, for both cultivars, efficiency was highest for trees on B.9. Rootsuckers were greatest for trees on B.9. Fruit weight, when adjusted with number of fruit/tree as a covariate, was different for GG in some years.

\section{(98) Molecular Analysis of Abscission Layer Activation in Apple Fruit Pedicels}

Lingxia Sun*, Sunchung Park, Martin Bukovac, Steven van Nocker Michigan State University, Department of Horticulture, East Lansing, MI, 48824

Abscission of leaves, floral organs, and fruit is a developmentally and environmentally regulated process initiated in specialized thin layers of cells within abscission zones (AZs). Very little is known about early molecular events that drive abscission, especially of fruit. Commercial apple production relies on the use of flower and fruit abscission-promoting and -inhibiting compounds to enhance fruit quality, control preharvest fruit drop, and maintain consistent annual bearing. The success of chemical treatments is strongly influenced by numerous factors, including environment, genotype, developmental stage of the fruit, and physiological state of the tree. Toward developing improved strategies for regulating fruit abscission, we carried out transcriptional profiling of competent-quiescent and activated abscission layers. We found that a decisive event in the sequential process of abscission layer development is the transcriptional activation of the MdPEL1 gene, encoding a plant pectate lyase protein and potentially involved in the degradation of the middle lamella of adjacent abscission layer cells. Additionally, regulatory elements of at least 12 homologous pectate lyase genes in Arabidopsis thaliana were found to direct expression in floral AZs and in dehiscence zones along valve margins, suggesting that these genes have evolutionary conserved function. This work identifies a novel role for pectate lyases in plants. Furthermore, many abscission-related genes identified in this study are being used to track biochemical and regulatory pathways that participate in abscission in response to chemical treatments or environmental effects.

\section{(99) Using Naphthalene Acetic Acid, Prohexadione- Ca, Ethephon, and Scoring to Reduce Vegetative Growth in Upper Canopy of Apple Trees}

Wesley R. Autio*, James Krupa, Jon M. Clements, Duane W. Greene University of Massachusetts, Department of Plant, Soil, \& Insect Sciences, Amherst, MA, 01003-9294

In 2004, at full bloom, 3-year-old 'Cameo'/G.16, 'Gala'/M.9 NAKBT337, 'Gala'/G.16, and 'Redmax'/B.9 apple trees were treated with naphthalene acetic acid (NAA, $1.5 \%$ in latex paint) in a $7.5-\mathrm{cm}$ band completely around the central leader at the base of 2-year-old wood. NAA treatment reduced 2004 extension growth of the central leader by $14 \%$ and total shoot growth above the treatment area by $32 \%$. 'Cameo'/G.16 trees also were sprayed with prohexadione-Ca $(250 \mathrm{ppm}$ with surfactant and water conditioner) at full bloom, and additional trees were sprayed with ethephon (500 ppm with surfactant) 1 week after full bloom. These spray treatments were made only to the stems and foliage from the base of the central leader's 2-year-old wood to the top of the canopy. Ethephon reduced total shoot growth in 2004 by $26 \%$, and prohexadione-Ca reduced it by $63 \%$. Prohexadione-Ca also reduced fruit set of 'Cameo' in 2004. Scoring (single knife cut completely around the circumference of the trunk) at the base of the 2 -year-old wood in the 'Cameo' trees resulted in a $23 \%$ reduction in leader growth and a $22 \%$ in totals shoot growth in the upper canopy in 2004. In 2005 at full bloom, 4-year-old 'Golden Delicous'/B.9 trees were treated with NAA similarly to trees in 2004, except treatment at the base of 2-year-old wood was compared to treatment at the base of 1 -year-old wood. Treating the base of 1-year-old wood reduced growth to a greater degree than comparable treatment at the base of 2-yearold wood. For the 1- and 2-year-old-wood treatments, the number of laterals produced from the 1-year-old wood was reduced $42 \%$ and $17 \%$, and total shoot growth from 1 -year-old wood was reduced by $49 \%$ and $31 \%$, respectively.

\section{(100) Effect of Cropload, Irrigation, and Fertilization on Yield and Postharvest Bitter Pit Incidence of 'Honeycrisp' Apple}

\section{Sergio Lopez-Cuevas*, Terence Robinson}

Cornell University, Dept. of Horticultural Sciences, Geneva, NY, 14456

A factorial field experiment was conducted at the New York State Agricultural Experimental Station in Geneva, N.Y., during 2004 and 2005 with 'Honeycrisp' apple trees on M.9 rootstock. The main plot factors were three levels of applied nitrogen $(0 \mathrm{~kg} / \mathrm{ha}, 50 \mathrm{k} / \mathrm{ha}$, and 100 $\mathrm{k} / \mathrm{ha})$; three levels of applied $\mathrm{K}_{2} \mathrm{O}(0 \mathrm{k} / \mathrm{ha}, 100 \mathrm{~kg} / \mathrm{ha}$, and $200 \mathrm{~kg} / \mathrm{ha})$; \pm foliar nutrient sprays containing $\mathrm{N}, \mathrm{B}, \mathrm{Zn}$, and $\mathrm{Mg}, \pm$ foliar sprays of $\mathrm{CaCl}_{2}$ and \pm trickle irrigation. The subplot factor was cropload $(3,6$, 9,12 , and 15 fruits $/ \mathrm{cm}^{2} \mathrm{TCA}$ ). Trees receiving irrigation or potassium had higher yields and the effect was greater as cropload was increased. There was no effect of nitrogen fertilization, foliar $\mathrm{Ca}$, and foliar N, B, $\mathrm{Zn}$, and $\mathrm{Mg}$ on yield. Irrigation and increased potassium fertilization rate reduced fruit soluble solids at harvest. Foliar calcium applications, foliar $\mathrm{N}, \mathrm{B}, \mathrm{Zn}$, and $\mathrm{Mg}$ applications, and nitrogen fertilization rate did not affect fruit soluble solids at harvest. No treatment factor had an effect on fruit firmness at harvest, but, after 4 months on cold storage, fruits from irrigated trees had greater firmness. Bitter pit incidence was lower on apples from trees that did not receive irrigation compared to irrigated trees. The difference was constant under all cropload levels. Foliar calcium applications, foliar N, B, Zn, and $\mathrm{Mg}$ applications, nitrogen fertilization rate and potassium fertilization rate did not affect bitter pit incidence.

\section{(101) Effects of Fall Applications of Urea and Zinc Sulfate to 'Bing' Sweet Cherry Spring Budbreak}

\section{Kitren Glozer*1, Joseph A. Grant ${ }^{2}$}

${ }^{1}$ University of California, Davis, Plant Sciences, Davis, CA, 95616; ${ }^{2}$ University of California, Cooperative Extension, Stockton, CA, 95205

While rest-breaking agents have become commonly used in California cherry production, application timing continues to involve a certain amount of uncertainty from year to year. In order to use any chilling model adequately and thereby schedule rest-breaking treatments, both the beginning point of dormancy and the beginning point of chill accumulation must be understood. One method of testing dormancy onset is tree defoliation, which may be used to alter the pattern of budbreak and regrowth in spring. Defoliation is used in many tropical and subtropical fruit-growing regions to promote budbreak and flowering in species that are not adapted to less than adequate chilling 
conditions. Recent trials in California compared hand defoliation to applications of urea and zinc sulfate to determine effects on budbreak and flowering of sweet cherry, as well as to better identify entry into dormancy. Chemical applications were at concentrations lower than those used to effect complete defoliation. We found that chemical applications tended to advance bloom and that the most effective timings were consistent, based on chill portion accumulation and the Dynamic Model. In one of two years, chemical treatments tended to decrease floral bud death and increase fruit set when compared to hand defoliation and untreated trees.

\section{(102) The Dynamic Model and Rest-breaking Agents in California 'French' Prune Production}

\section{Kitren Glozer*1, Franz J. Niederholzer ${ }^{2}$}

'University of California, Davis, Plant Sciences, Davis, CA, 95616; ${ }^{2}$ University of California, Cooperative Extension, Yuba City, CA, 95991-5593

Use of rest-breaking chemicals may partially substitute for chill requirement in "French' prune. Many California prune growers use oil in the dormant season to tighten and advance bloom, with application timing judged by experience and calendar date. Other rest-breaking agents have become commonly used in California cherry production and their application is generally timed by chill portion accumulation, calculated by the Dynamic Model. We evaluated the effects of treatments of dormant oil or CAN17 (calcium ammonium nitrate) + Entry on budbreak and bloom progression in 'French' prune with applications timed at regular intervals. While most treatments improved fruit set and reduced reproductive bud death, an optimum range for both types of rest-breaking treatments was found for advancement and compression of bloom. All rest-breaking treatments advanced fruit maturity equally, compared to the untreated control, as measured by fruit firmness. Although chill hour (hours $\leq 7^{\circ} \mathrm{C}$ ) calculations might also be used for timing these treatments, when chill portion and chill hour accumulations are compared for the 2004-05 dormant season at several different sites, differences from site-to-site are small for chill portions, and much greater for chill hours. This fact supports experimental evidence from numerous California trials in sweet cherry in which rest-breaking treatment timings based on the Dynamic Model tend to be more consistent than the timings based on the "chill hour" model.

\section{(103) Effects of Dormant Application Timing in 'Bartlett' Pear}

\section{Kitren Glozer*1, Charles Ingels ${ }^{2}$}

${ }^{1}$ University of California, Davis, Plant Sciences, Davis, CA, 95616; ${ }^{2}$ University of California, Cooperative Extension, Sacramento, CA, 95827-3898

Pear growers in California's Sacramento River Delta and, to some extent, other pear-growing areas in California, use dormant oils for pest control and dormant bud growth stimulation. It is generally believed that well-timed applications can advance flowering, improve uniformity of flowering and fruit ripening, and improve vegetative budbreak. Traditionally, dormant oils have been applied in late December to mid-January, based on experience and calendar date. However, bud development and full bloom dates may differ from year to year, with variable weather cycles and chill accumulation experienced by the plant. In the 2004-05 dormant season, some dormant oil applications timed at intervals calculated by chill portions (defined by the Dynamic Model) advanced and compressed the bloom period. Fruit size (diameter and weight) and total estimated yield were improved by dormant oil treatments applied within a certain range of chill portion accumulation without reduction in total number of fruit per tree, while the percentage of undersized fruit was decreased by $65 \%$ to $83 \%$ when compared to the untreated control. The use of chill portions and the Dynamic Model to time applications of dormant oil appears to benefit fruit quality. Although chill was not limiting in the trial dormant season, there may be benefit even in years when chill accumulation is adequate.
(104) Evaluation of Grafting Methods in Starfruit (Averrhoa carambola L.) in the Dry Tropics of Mexico

Juan Manuel González-González, Salvador Guzmán-González*, Sergio Chavez-Luna

Universidad de Colima, Facultad de Ciencias Biológicas y Agropecuarias, Autopista Colima-Manzanillo km 40, Tecomán, 28100, México

Starfruit (Averrhoa carambola L.) is reproduced by seeds from 'Criollo' cultivars. The replication of desirable agronomic traits is difficult when selected plants are from sexual reproduction. The heterogeneity of plants is observed as higher trees, irregular fresh fruit yield, variable fruit quality, differential insect pest and disease susceptibilities, and extended period for recovering the inversion. Vegetative propagation is an alternative for reducing the heterogeneity of starfruit trees. Four grafting methods for propagating starfruit in the coast of Colima, Mexico: splice-side graft, wedge graft, whip graft, and bud graft were evaluated. The experiment was carried out on the Tecoman campus of the Universidad de Colima. The ambient conditions were dry tropic (BS1). Seven-month-old rootstocks were obtained from Criollo seedlings, and the scion was obtained from a healthy 15-year-old 'Miss' donor tree. The experiment was distributed under a completely randomized design. The splice-side graft had $70 \%$ success and was the best, bud graft had $40 \%$ success, wedge graft, had 5\% success and whip graft $0 \%$ success, and was the least successful.

\section{Poster Session 12-Organic/Sustainable Horticulture}

28 July 2006, 12:00-12:45 p.m.

\section{(157) Weed Control in Organic Edamame Soybean Production}

Anthony Silvernail, Michael K. Bomford*

Kentucky State University, Community Research Service, Frankfort, KY, 40601

Weed control is a major challenge confronting growers transitioning to organic vegetable production. Organic standards require that growers manage weeds without synthetic herbicides while maintaining or enhancing soil quality. In 2005, we evaluated the effects of two seedbed preparation methods and six weed management tactics, compatible with organic standards, on soil quality indicators, weed pressure, and yield of edamame soybean [Glycine $\max$ (L.) Merrill]. Seedbed preparation was conducted with either a moldboard plow and roto-tiller or a spading machine. Weeds were managed by a) regular hand weeding, b) pre-emergent flaming, c) post-emergent incorporation of $100 \mathrm{~g}$ of corn gluten meal $/ \mathrm{m}^{2}$, or weekly passes from crop emergence until row closure with d) a spring-tine weeder, e) a rolling cultivator, or f) a between-row flame weeder. Dominant weeds were smooth pigweed [Amaranthus hybridus (L.)], goosegrass [Eleusine indica (L.) Gaertn.], and giant crabgrass [Digitaria sanguinalis (L.) Scop.]. Smooth pigweed dominated in the corn gluten meal and spring-tine weeder treatments; goosegrass and giant crabgrass dominated in the two flamed treatments. Weed pressure was lowest, and crop yield highest, in the hand-weeded control and rolling cultivator treatments. Relative to these, crop yield was severely depressed by weed pressure in other treatments. The labile carbon concentration and enzymatic activity of soils was tested midseason, and at harvest, showed no significant treatment effects. Results suggest that the rolling cultivator offered the best weed control among the tactics tested, without adversely affecting soil quality.

\section{(158) Gardening Made Easy-Teaching Organic Gardening at a Land-grant University}

Carl Motsenbocker*, Sandra Allain

Louisiana State University Agricultural Center, Department of Horticulture, Baton Rouge, LA, 70803

An organic gardening class was developed to provide nonhorticulture 
students an opportunity to become acquainted with horticultural science and the basics of gardening organically. The course was developed as a 3-hour (1 hour lecture, 2 hours lab), two-credit course taught in the fall semester using an organic gardening textbook. A major component of the lab is the development and maintenance of a small individual garden plot during the semester. Students grow their own plant materials, plant, fertilize, and monitor pests, and harvest at the end of the semester. The organic gardening class was taught for 7 years and evolved into having a mandatory service-learning component that supports service projects in the local community. Projects included working with the local farmers' market, supporting school projects such as growing plants, school grounds beautification, gardening, or mulching, and gleaning product from research and garden plots for the local food bank. The poster will provide information on the class syllabus and materials, record of service projects, and reflections of the students during and at the end of the class.

\section{(159) Effects of Sulfur Compounds on $\mathrm{CO}_{2}$ Assimilation, Evapotranspiration, and Stomatal Conductance of Apple}

Jason D. McAfee, Curt R. Rom*

University of Arkansas, Horticulture, Fayetteville, AR, 72701

Pesticides and alternative fruit thinners are needed for certified organic fruit growers. Transient reductions in photosynthesis $(\mathrm{Pn})$ have proven an effective technique for fruit thinning. Pesticides can be detrimental to plant growth by Pn reduction. A two-part study was developed to measure plant response to foliar applications of sulfur compounds. In study $1,2 \%$ concentrations of various sulfur compounds were observed for potential physiological or pesticidal effects. Foliar treatments were applied to vegetative apple trees grown under controlled environment conditions to study photosynthetic effects. No treatments significantly reduced $\mathrm{CO}_{2}$ assimilation (A) and stomatal conductance $\left(\mathrm{g}_{\mathrm{s}}\right)$. Copper sulfate, ammonium sulfate, and potassium sulfate significantly reduced evapotranspiration (Et) 7 days after treatment. No significance was observed for plant growth. In study 2 , a $2 \%$ potassium sulfate concentration significantly reduced A 22 days after treatment; however, no differences were observed for Et and $\mathrm{g}_{\mathrm{s}}$. Differences in plant growth were not significantly different among treatments.

\section{(160) Seasonal Variations of Nutrient Status in Soil and Leaves, Soil Properties, and Tree Growth under Different Organic Apple Groundcover Management Production Systems}

Hyun-Sug Choi*, Curt R. Rom, Mengmeng Gu, Jason McAfee

University of Arkansas, Horticulture, Fayetteville, AR, 72701

Seasonal variations of nutrient concentrations in soil and apple leaves, soil properties, weed density, and tree performance were observed for response to four groundcover managements systems: 1) mowed control; 2) plastic woven landscape fabric; 3) wood chip mulch; and 4) shredded commercial paper mulch. Soil sampled below the wood chip and shredded paper mulch treatments had higher $\mathrm{NO}^{3}-\mathrm{N}$ concentrations during the season. Soil below the shredded paper mulch had greater soil $\mathrm{Ca}, \mathrm{Na}$, and $\mathrm{Zn}$ than other treatments. Soil sampled below wood chip mulch had higher $\mathrm{Mg}$ and $\mathrm{B}$. Leaf $\mathrm{K}$ was greater for trees grown with bark chip mulch than the other treatments. Overall, the seasonal patterns of $\mathrm{N}, \mathrm{P}$, and $\mathrm{K}$ decreased and had similar patterns as previously reported conventionally grown orchards. The leaf $\mathrm{Ca}$ and $\mathrm{Mg}$ increased during the season for all treatments. The concentration of other microelements had patterns similar among all treatments. Seasonal soil $\mathrm{pH}$ decreased during the season and was affected by treatments. During the season, water infiltration was faster into the soil covered with shredded paper mulch. The organic matter was greater in soil under the wood chip mulch at the $15-\mathrm{cm}$ soil depth. Very little weed invasion occurred in the landscape fabric through August. Trees grown with shredded paper and wood chip mulch treatments had greater trunk cross-sectional area compared to trees grown under landscape fabric after 5 years; however, the latter treatment resulted in greater tree height, tree canopy spread, and fruit yield.

\section{(161) Nitrogen and Carbon Cycling and Partitioning in Managed Understories of Organic Apples}

Lori Hoagland*1, Lynne Carpenter-Boggs ${ }^{1}$, David Granatstein ${ }^{2}$, Frank Peryea ${ }^{3}$, Jeff Smith ${ }^{4}$, John Reganold ${ }^{1}$

${ }^{1}$ Washington State University, Crop and Soil Sciences, Pullman, WA, 99164-6420; ${ }^{2}$ Washington State University, Center for Sustaining Agriculture and Natural Resources; ${ }^{3}$ Washington State University, Tree Fruit Research and Extension Center; ${ }^{4}$ Washington State University, USDA-ARS

Organic orchards represent a significant and growing component of Washington state agriculture. Comparison studies have shown that organic apple systems can be equally profitable yet more environmentally sustainable than their conventional counterparts. Despite this success, sustainable methods of weed control, fertility, and soil quality stabilization and improvement have remained a challenge. Intensive cultivation is commonly used to control weeds in organic orchards. This can lead to reduced or degraded soil organic matter, structure, water infiltration, aerated pore space, and other soil productivity parameters. In addition, tillage accelerates nutrient cycling and can result in the loss of valuable nutrients from the system. To address the need for sustainable organic methods of weed management, an integrated study of alternative understory management options was established in a newly planted orchard in 2005. Weed control measures included efficient tillage using a Wonder weeder, organically approved herbicide, wood chip mulch, and living cover mulches. Three rates of nitrogen (low, medium, and high) were applied across the Wonder weeder, wood chip, and living cover mulch plots in order to determine ideal $\mathrm{N}$ fertility rate. Analyses of total $\mathrm{C}$ and $\mathrm{N}$ and $\mathrm{N}^{-15}$ in organic fertilizers, soil pools, living cover biomass, and tree leaves are being used to track $\mathrm{N}$ and $\mathrm{C}$ cycling and partitioning, N-use efficiency, soil quality, and to determine optimal fertility guidelines. Preliminary results indicate intense competition between living mulch understory and orchard trees, and a trade-off may exist between maximizing soil quality and orchard productivity.

\section{(162) Multi-level Comparisons of Organic (OFP) and Integrated Fruit Production (IFP) Systems for 'Liberty' Apple in a New York Orchard}

Gregory Peck*, Ian M. Merwin, Emily Vollmer, Kristine Averill Cornell University, Horticulture, Ithaca, NY, 14853

Apple growers in New York lack the tools to produce high quality fruit for the organic or IFP marketplace. We are systematically evaluating OFP and IFP systems for pest control efficacy, fruit and soil quality, environmental impacts, and economic sustainability, in an orchard of disease-resistant 'Liberty' on M.9 rootstock. The OFP system follows USDA-NOP standards and the IFP system follows newly developed NY IFP standards. In the first year of this study (2004), both systems were equally productive, but variable costs for OFP were twice that of IFP, due to 11 kaolin applications, while returns were comparable. In 2005 , OFP yields were $25 \%$ greater than IFP yields, but $30 \%$ of OFP fruit was unmarketable largely due to insect damage. This loss, plus small fruit size, resulted in OFP returns of $\$ 5432$ per hectare, about half the IFP returns. With only four kaolin applications in 2005, OFP costs were $\$ 2437$ per hectare, marginally greater than the $\$ 2083$ per hectare costs for IFP apples. Harvest maturity indices were similar and peak fruit quality was attained in both systems in early Oct. In 2004, consumer panelists could not detect differences between fruit from the two systems, but in 2005 panelists rated OFP apples as sweeter, more tart, better flavored, and more acceptable overall. Antioxidant activity, total phenolics concentrations, and mineral content of apples were similar between systems in both years. Values for all essential plant nutrients, organic matter content, $\mathrm{pH}$, and $\mathrm{CEC}$ were also equivalent in each system both years. Cultivation was likely responsible for lowering the bulk density, soil strength, and aggregate stability of the OFP top soil in 2005. While OFP remains very challenging, IFP can be implemented successfully in New York orchards. 


\section{(163) Organic and Biorational Fungicides for Managing Gray Mold on Raspberries}

\section{Graham Sanders*, Elsa Sanchez, Kathleen Demchak}

Pennsylvania State University, Horticulture, University Park, PA, 16802

The increased demand for organic and sustainably grown produce has resulted in a demand for information on organic and biorational fungicides. The efficacy of these fungicides is often not established, yet they are aggressively advertised. In 2005 the efficacy of six organic and biorational fungicides and two controls were evaluated on fieldgrown red raspberries (Rubus idaeus 'Prelude' and 'Nova') for gray mold (Botrytis cinerea) management. Phytotoxicity of the fungicide treatments was evaluated on a weekly basis following each fungicide application. Fruit was harvested by hand, sorted into marketable and unmarketable categories and weighed. Subsamples of fruit were evaluated for postharvest disease development. Data analysis showed 'Nova' was more susceptible to phytotoxicity than 'Prelude'. The application of Phostrol resulted in the highest phytotoxicity rating when compared to all other fungicide treatments. The water spray control, standard fungicide (Captan/Elevate rotation) control, Endorse, and Lime Sulfur treatments resulted in negligible phytotoxity ratings. Applying Milstop, Milstop + Oxidate, and Oxidate + Vigor Cal Phos resulted in similar intermediate phytotoxicity ratings. Differences in marketable yield were nonexistent for the two cultivars and eight fungicide treatments. The predominant diseases observed in the postharvest evaluations were gray mold, blue mold (Penicillium sp.), and rhizopus soft rot (Rhizopus sp.) and/or mucor mold (Mucor sp.). This evaluation will be repeated in 2006 .

\section{(164) The Influence of Mulch Applications on Vegetation Dynamics in Organically Managed Highbush Blueberry}

\section{Nicole E. Burkhard*1, Derek H. Lynch ${ }^{1}$, David C. Percival ${ }^{2}$}

Nova Scotia Agricultural College, Plant and Animal Sciences, Truro, Nova Scotia, B2N 5E3, Canada; ${ }^{2}$ Nova Scotia Agricultural College, Environmental Science, Truro, Nova Scotia, B2N 5E3, Canada

Within-row weed management of highbush blueberry (Vaccinium corymbosum L.) is reliant upon herbicide applications. However, in organic production, herbicides are typically not permitted and alternative methods must be used. The impact of thick $(25-\mathrm{cm})$ mulch applications on weed pressure in an organic production system was initiated at a commercial operation in Nova Scotia, Canada, during 2005. A splitplot experimental design was used with five blocks (replications), six treatments, and five plants per split plot (cv. Duke). The whole-plot factor consisted of mulch/fertility treatments and included: i) control (no amendment); ii) ammonium sulphate fertilizer $\left(30 \mathrm{~kg} \cdot \mathrm{ha}^{-1} \mathrm{~N}\right)$; iii) pelletized poultry manure $\left(60 \mathrm{~kg} \cdot \mathrm{ha}^{-1} \mathrm{~N}\right)$; iv) pine needles $\left.\left(80 \mathrm{t} \cdot \mathrm{ha} \mathrm{h}^{-1}\right) ; \mathrm{v}\right)$ horse manure and sawdust compost $\left(550 \mathrm{t} \cdot \mathrm{ha}^{-1}\right)$; and vi) seafood waste compost $\left(360 \mathrm{t} \cdot \mathrm{ha}^{-1}\right)$. The split-plot factor consisted of level of hand weeding $(-/+)$. Weed control was assessed by sampling percent ground cover and weed shoot biomass in three $0.25-\mathrm{m}^{2}$ quadrats in nonweeded subplots. Blueberry leaf $\mathrm{N}$ content, plant canopy volume, and berry yield (fresh weight and number) were recorded. The manure/sawdust compost and pine needle treatments had the lowest weed biomass and percent ground cover values, thereby providing the best weed control. Weed shoot biomass, blueberry leaf N, plant canopy volume, and berry yield were greatest in the seafood waste compost treatment. Results from this preliminary study indicate the potential of using these groundcover treatments to improve organic cultural management practices.

\section{(165) University of Guam Triton Farm}

Mari Marutani, John Brown, Mark Acosta, Joseph Sablan, Sheeka Afaisen, James McConnell*

College of Natural and Applied Sciences, University of Guam, Agricultral Experiment Station, Mangilao, GU, 96923

A grant to construct a "Model Farm" on Guam and the Virgin Islands was approved in 2000 by the USDA/CSREES/Initiative for Future
Agriculture and Food Systems Program. The main goal was to establish an integrated model farm that had potential benefits for small agricultural enterprises operated by Asian-Pacific and Caribbean Islanders. University of Guam Triton Farm was established on 3.75 acres (1.5 ha) of the Agricultural Experiment Station. Initially we conducted a soil survey, and established windbreaks/hedgerows. We also built the foundation for aquaculture/aquaponic system, field irrigation systems, and animal production facilities. Then, we planted long-term fruit and ornamental plants while growing short-term vegetable crops for quick returns. Currently we raise tilapia (Oreochromis niloticus), goats (Capra hercus) and layer-chickens (Gallus gallus). We grow banana (Musa spp.), calamansi (X Citrofortunellomitis, hot peppers (Capsicum spp.), cucumbers (Cucumis sativus), lettuce (Lactuca sativa), eggplants (Solanum melongena), and Ti-leaf (Cordyline terminalis). We also try to develop value-added products using local produce. Occasionally we investigate other potential commodities and operational schemes for the farm. These must be suitable for Guam's agro-climate and social and economic structure. We focus on conservation of natural materials, composting, and sustainable agriculture. Education and outreach activity is also an important component of the farm to disseminate technologies and to educate young children about farming.

\section{(166) Weed Suppression and Nitrogen Management of Organic Broccoli}

Daniel Schellenberg*, Ronald Morse, Gregory Welbaum

Virginia Polytechnic and State University, Department of Horticulture, Blacksburg, VA

Weed suppression and nitrogen $(\mathrm{N})$ management present the greatest challenges to organic growers. Cover crops, the strategic use of tillage, and multiple nitrogen sources are being investigated in order to develop integrated management practices. Combinations of legume and grass cover crops are being utilized as alternative $\mathrm{N}$ sources and as tools for weed suppression. Another objective is to compare conventional and no-till practices to determine when the strategic use of tillage is most beneficial for $\mathrm{N}$ management and weed control. The last objective is to evaluate the fate of applied $\mathrm{N}$ and $\mathrm{N}$ released from cover decomposition on crop development. The best combinations of cover crop species, the frequency and intensity of tillage, and optimum $\mathrm{N}$ rates will be determined for the production of organic broccoli. This project will aid growers interested in transitioning to organic farming. In addition, integrated management practices that balance the short-term needs for crop productivity and the long-term interests of sustainable production will be reported.

\section{Poster Session 13-Pest Management}

28 July 2006, 12:00-12:45 p.m.

\section{(216) Beach Sand Hydrophobicidity Induced as a} Result of the Presence of Beach Vitex

Matthew Cousins*1, Charles A. Gresham², Melissa B. Riley ${ }^{3}$, Ted Whitwell ${ }^{1}$

${ }^{1}$ Clemson University, Dept. of Horticulture, Clemson, SC, 29634-0319; ${ }^{2}$ Clemson University, Dept. of Forestry and Natural Resources, Georegtown, SC, 29442; ${ }^{3}$ Clemson University, Dept. of Entomology, Soils and Plant Sciences, Clemson, SC, 29634-0319

Beach Vitex (Vitex rotundifolia Lf.) was introduced to coastal Carolina areas in the 1980s. Since its introduction, it has become a major invasive plant problem. Beach Vitex rapidly dominates the vegetation and eliminates many native plant species on primary and secondary coastal dunes. It grows rapidly and reproduces vegetatively by rooting at the nodes. Thousands of fruits, containing one to four seeds each, are produced annually and assist in the plant's spread. Beach sand in areas dominated by Beach Vitex was found to possess hydrophobic qualities, while sand collected from areas not populated by Beach Vitex readily allowed water infiltration. GC-MS analysis of hydrophobic sand extracts showed four peaks that were absent from extracts of non-hydrophobic sand. These peaks were also present in chromatograms of water extracts 
of Beach Vitex fruits and leaves. Comparison of GC-MS spectra with compounds previously identified in Beach Vitex indicated that one compound was a diterpene (likely ferruginol or abietatrien-3ß-ol). The second compound is likely a flavonoid (possibly casticin, artemetin, or vitexicarpin). Two additional compounds are present at low levels and are possibly phenylnaphthalene compounds. These four compounds appear to be synthesized and incorporated into surface tissues of Beach Vitex leaves and fruits and are transferred to sand during rain events and decomposition. Further studies of Beach Vitex plant parts and beach sands are being conducted to further elucidate the possibility that these chemicals are involved in the intriguing property of sand hydrophobicity. This property may aide Beach Vitex in its competition with plants possessing less expansive root systems.

\section{(217) Preemergence Weed Control in Container- grown Herbaceous Perennials}

David Staats*1, James Klett ${ }^{1}$, Teri Howlett ${ }^{1}$, Matt Rogoyski ${ }^{2}$

${ }^{1}$ Colorado State University, Department of Horticulture and Landscape Architecture, Fort Collins, CO, 80523; ${ }^{2}$ Colorado State University, Department of Horticulture and Landscape Architecture, Grand Junction, CO, 81503-9621

During the 2005 season, three preemergence herbicides were applied to four container-grown herbaceous perennials and evaluated for weed control, phytotoxicity, and effect on plant growth. The herbicides and application rates were: 1) Pendimethalin (Pendulum 2G) 2.24, 4.48, and $8.96 \mathrm{~kg} / \mathrm{ha} ; 2$ ) Trifluralin and Isoxaben (Snapshot 2.5 TG) 2.8, 5.6, and $11.2 \mathrm{~kg} / \mathrm{ha}$; and 3) S-metolachlor (Pennant Magnum 7.6 EC) 2.8, 5.6 , and $11.2 \mathrm{~kg} / \mathrm{ha}$. Herbicides were applied to Coral Bells (Heuchera sanguinea), Hopflower Oregano (Origanum libanoticum), CORONADO ${ }^{\mathrm{TM}}$ Hyssop (Agastache aurantiaca), and SPANISH PEAKSTM Foxglove (Digitalis thapsi). Treatments were applied twice with 30 days between applications. Plants were evaluated for phytotoxicity after 1 , 2 , and 4 weeks after applying herbicide treatments. No phytotoxicity symptoms were apparent on any of the plants treated with Pendulum, and plant size (dry mass) was not affected. Snapshot resulted in visual phytotoxicity with Digitalis and Heuchera at the higher rates and also resulted in smaller plants. Pennant Magnum caused phytotoxicity at all rates in all plants and resulted in significantly smaller plants than the control. Weed control was very good with all herbicides, but did not control every weed.

\section{(218) Phytotoxicity of Several Herbicides in Pitahaya Grown under Plant Nursery Conditions}

Arnoldo Michel-Rosales*, Javier Farias-Larios, Juan Alberto OsunaCastro, Elpidio Peña-Beltrán, Juan Manuel González-González, Héctor Javier Garibay-Bautista

Universidad de Colima, Facultad de Ciencias Biológicas y Agropecuarias, Km 40 Atopista Colima- Manzanillo, Tecomán, Colima, 28100, México

At present, pitahaya (Hylocereus undatus Britt and Rose), a nonconventional crop and cactus native from Mexico, is considered very promising because of its high adaptability and tolerance to extreme agricultural conditions of tropical regions (poor soils, drought, and elevated temperatures), where they are cultivated. In addition, pitahaya fruit is well-accepted and identified as a nutraceutical food that lowers cholesterol and glucose levels in blood and might prevent stomach and colon cancers. However, little or no scientific information on chemical control alternatives of weeds in pitahaya commercial plantings have been generated. In this work, the phytotoxicity degree of seven commercial herbicides (metribuzin, glyphosate, glyphosate trimesium, paraqut, paraquat+diuron, atrazine, and halosulfuron methyl) in pitahaya plants grown under plant nursery conditions was assessed. A completely randomized design with 12 replications was used. The experimental unit was a flowerpot with a 5-month-old plants. The phytotoxicity degree was evaluated at 3, 7, 14, and 21 days after application using the scale proposed by EWRS. The herbicides that caused injury to the plants were paraqua+diuron (79\%) and paraquat (77\%), respectively. Metribuzin, halosulfuron-methyl, and atrazine did not cause any injury to the plants.

\section{(219) Organic Watermelon Production Systems: Varieties and Weed Control}

Charles L. Webber III ${ }^{1}$, Angela R. Davis*1, James W. Shrefler ${ }^{2}$, Penelope Perkins-Veazie ${ }^{1}$, Vincent M. Russo ${ }^{1}$, Jonathan V. Edelson ${ }^{2}$

${ }^{1}$ USDA-ARS, South Central Agricultural Research Laboratory, Lane, OK, 74555; ${ }^{2}$ Oklahoma State University, Wes Watkins Agricultural Research and Extension Center

The increasing perception by consumers that organic food tastes better and is healthier continues to expand the demand for organically produced crops. The objective of these experiments was to investigate the impact of different weed control systems on yields of watermelon (Citrullus lanatus var. lanatus) varieties grown organically. Six watermelon varieties were transplanted at two locations (Lane and Center Point, Okla.). The six varieties included three seeded varieties ('Early Moonbeam', 'Sugar Baby', and 'Allsweet') and three seedless varieties ('Triple Crown', 'Triple Prize', and 'Triple Star'). The weed control system at Lane utilized black plastic mulch on the crop row, while the area between rows was cultivated to control weeds. The no-till organic system at Center Point used a mowed rye and vetch cover crop, hand weeding, and vinegar ( $5 \%$ acetic acid) for weed control. When averaged across watermelon varieties, Lane produced significantly more fruit per plant (4.2 vs. 2.3 fruit/plant), greater marketable yields (16.0 vs. $8.4 \mathrm{~kg} / \mathrm{plants})$, and higher average marketable weight per fruit (6.1 vs. $4.0 \mathrm{~kg}$ ) than at Center Point. When comparing locations, four of six varieties had significantly greater number of fruit per plant and higher marketable yields at Lane than at Center Point. Except for 'Early Moonbeam', all other varieties produced significantly heavier fruit at Lane than at Center Point. In contrast, the Center Point location produced a greater percentage of marketable fruit for all varieties except 'Allsweet'. Fruit quality (lycopene and ${ }^{\circ}$ Brix) was as good or greater when harvested from the weedier Center Point location.

\section{(220) Pelargonic Acid Weed Control Parameters}

Charles L. Webber ${ }^{1}$, James W. Shrefler*2

${ }^{1}$ USDA-ARS, So. Central Agric. Res. Lab., Lane, OK, 74555; ${ }^{2}$ Oklahoma State University, WWAREC, Lane, Oklahoma, 74555

Producers and researchers are interested in pelargonic acid (nonanoic acid) as a broad-spectrum postemergence or burn-down herbicide. Pelargonic acid is a fatty acid naturally occurring in many plants and animals, and present in many foods we consume. The objective of this research was to determine the effect of pelargonic acid concentration, adjuvants, and application timing on weed control efficacy as a burn-down herbicide. Field research was conducted at Lane, Okla. (southeast Oklahoma), during the 2005 growing season. One month prior to spraying the weed control treatments, the land was cultivated to kill the existing weeds and provide a uniform seed bed for new weed growth. The factorial weed control treatments included three application concentrations of Scythe (57.0\% pelargonic acid) applied at 3\%,6.5\%, and $10 \%$; three adjuvants (none, orange oil, and non-ionic surfactant); and two application dates. All herbicide treatments were applied with an application volume of $935 \mathrm{~L} /$ ha to seedling weeds. The experiment had a high weed density with multiple species of grass and broadleaf weeds. Weed control across species increased as the herbicide concentrations increased from $0 \%$ to $10 \%$. At all concentrations applied, pelargonic acid produced greater weed control for a longer time period for the broadleaf weeds than the grass weeds. Visual damage to the weeds was often apparent within a few hours after application. There was a significant increase in weed control when applied to the younger weeds. In this research, pelargonic acid was effective in controlling both broadleaf and grass weeds as a burn-down herbicide, although crabgrass was tougher to control.

\section{(221) Phenotypic Plasticity as an Indicator for Exotic Noxious Plants}

Jing Luo ${ }^{1}$, David Tay*2, John Cardina ${ }^{3}$

${ }^{1}$ The Ohio State Unive., Dept. of Horticulture and Crop Science, Columbus, OH, 43210; ${ }^{2}$ The Ohio State Univ., Ornamental Plant Germplasm Center,Columbus, OH, 43210; ${ }^{3}$ The Ohio State Univ., Dept. of Horticulture and Crop Science, Wooster, OH, 44691

Exotic noxious plants, including invasive plants and exotic weeds, 
have caused huge economic loss and ecological damage around the world. To prevent further introductions of such species as crops or ornamental plants, biological and ecological traits associated with invasiveness and weediness need to be identified so that prediction can be made on the potential of being noxious for proposed species. It was suggested that weeds were usually generalists that can survive and reproduce in a wide range of environments; i.e., they were quite "plastic" in response to different environments. In accordance to this idea, phenotypic plasticity has been recently proposed as an indicator and predictor for weeds and invasive plants. This hypothesis is tested using two exotic dandelion species: Taraxacum officinale (common dandelion), widespread weed, and T. laevigatum (red-seeded dandelion), which occurs in a much lower frequency in Ohio. A greenhouse experiment was conducted in which the two species were grown in two soil moisture levels (dry vs. wet) combined with two light exposure levels (full sun vs. shade). Various traits were measured to see whether T. officinale is more plastic than T. laevigatum in these four environments. The results show that, when using coefficient of variance $(\mathrm{CV})$ as a measurement of plasticity, T. officinale has significantly larger $\mathrm{CV}$ than T. laevigatum in plant diameter $(P=0.02)$, shoot : root ratio $(P=0.04)$ and soil $\mathrm{pH}(P=0.02)$. This indicates that $T$. officinale is more plastic in some of the resource-capture-related traits such as leaf morphology and biomass allocation, and presumably also in root exudates, which alter the soil $\mathrm{pH}$.

\section{(222) The Effects of Fertilization on Constitutive and Wound-induced Levels of Total Phenolics and Jasmonic Acid in Gerbera jamesonii}

James D. Spiers*1, Fred T. Davies ${ }^{1}$, Scott A. Finlayson ${ }^{2}$, Chuanjiu $\mathrm{He}^{1}$, Kevin M. Heinz ${ }^{3}$, Terri W. Starman ${ }^{1}$

${ }^{1}$ Texas A\&M University, Horticultural Sciences, College Station, TX, 77843-2133; ${ }^{2}$ Texas A\&M University, Soil and Crop Sciences; ${ }^{3}$ Texas A\&M University, Entomology

This research focused on the effects of nitrogen fertilization on jasmonic acid accumulation and total phenolic concentrations in gerbera. The phytohormone jasmonic acid is known to regulate many plant responses, including inducible defenses against insect herbivory. Phenolics are constitutive secondary metabolites that have been shown to negatively affect insect feeding. Gerbera jamesonii 'Festival Salmon Rose' plants were grown in a growth chamber and subjected to either low fertilization (only supplied with initial fertilizer charge present in professional growing media) or high fertilization (recommended rate $=200 \mathrm{mg} \cdot \mathrm{L}^{-1}$ N). Plants were fertilized with $200 \mathrm{~mL}$ of a $15 \mathrm{~N}-7 \mathrm{P}-14 \mathrm{~K}$ fertilizer at 0 or $200 \mathrm{mg} \cdot \mathrm{L}^{-1} \mathrm{~N}$ at each watering (as needed). Treatments consisted of \pm mechanical wounding with a hemostat to one physiologically mature leaf and the subsequent harvest of that leaf at specified time intervals for jasmonic acid quantification. Total phenolics were measured in physiologically mature and young leaves harvested 0 and 10 hours after \pm mechanical wounding. Low-fertility plants had reduced aboveground dry mass, were deficient in nitrogen and phosphorus, and had about a $10 \times$ higher concentration of total phenolics when compared to high fertility plants. In low-fertility plants, young leaves had greater concentrations of phenolics compared to physiologically mature leaves. There were no differences in total phenolics due to wounding. The effect of nitrogen fertilization on jasmonic acid accumulation will also be discussed.

\section{(223) Profiling of Physical and Molecular Characteristics in Neotyphodium Isolates}

Brad Geary*1, Jared Benson ${ }^{1}$, Steven Wood ${ }^{2}$, James Logan ${ }^{1}$, Ben Brulotte $^{1}$, Alan Chambers ${ }^{1}$, Jeff Maughan ${ }^{1}$, Mikel Stevens ${ }^{1}$

${ }^{1}$ Brigham Young Univestiy, Plant and Animal Sciences, Provo, Utah, 84602; ${ }^{2}$ Brigham Young University, Chemistry and Biochemistry, Provo, Utah, 84602;

Endophytic fungi that are classified into the genus Neotyphodium have developed into a very unique niche. Their specific host plants are the fescues and ryegrasses. Through fungal biosynthesis of secondary metabolites, the host plant receives several benefits. These benefits include resistance to insects such as aphids, chinch bug, and argentine stem weevil, increased drought tolerance, and increased competive- ness. These secondary metabolites comprise four groups of alkaloids. The alkaloids are loline, peramine, Lolitrem B, and ergovaline. The quantitative alkaloid profile is unique for each isolate. The characterization of these endophytes is necessary for identification of specific isolates. We report the characterization of ten endophytic strains Lp1, Lp2, Lp3, Lm4, Lm5, Fp6, Fp7 Fp8, Fp9, Fp10. The characterization of each isolate includes: morphology, sporulation, growth rates, microsatellite fingerprint, and alkaloid profile. The isolated colonies bear resemblance to raised brain-like structures and are yellow to tan in color. Growth rates range between 0.1 and $0.25 \mathrm{~mm} /$ day. No colonies produced any form of sporulation. Fp6 was found to have the highest loline concentration of any isolate. AFLP analysis was performed on the isolates to test for relatedness. Distinct clades were formed and grouped by host. The main groups were those isolated from Lolium or Festuca varieties. Isolates $\mathrm{Fp} 8$ and $\mathrm{Fp} 9$ were most related to each other, and have also been found to be doubly infected. The double infection is described to be Phialophora-like, due to the presence of thin highly branched hyphae when observed under light microscopy with aniline blue staining.

\section{(224) Weed Control in Norway Spruce Christmas Trees with Applied Films}

Laura M.R. Rinaldi*1, Orazio la Marca ${ }^{2}$

${ }^{1}$ CNR, IVALSA, Via Madonna del Piano, Sesto Fiorentino, Firenze, 50019, Italy; ${ }^{2}$ Università degli Studi. Firenze, DISTAF, Via S. Bonaventura, 13, Firenze, Italia, 50145

Weed management systems for Norway spruce (Picea abies L.) Christmas trees were investigated under field conditions. Potential alternative methods to replace the use of herbicides included the application of three different soil covers: plastic film ( $100 \%$ recoverable), biodegradable film $40-\mu$ thick, and biodegradable film $70-\mu$ thick. On another group, weed control was carried out mechanically (control plants). Each treatment consisted of 27 plants with three replications. At the time of the first growing season, the percentage of dead and survived plants in treated plants and in the control plants did not differ significantly. Data were recorded on plant height and quality during the second year of growth. Control plants always showed height increases shorter than other plants. Application of these films significantly affected growth and plant quality. In plastic film-treated plants, the average height increases were significantly higher than those observed on control plants mechanically treated (19 vs. $12 \mathrm{~cm}$, respectively), and did not differ from biodegradable film-treated plants $(17 \mathrm{~cm})$. Plants responded similarly to the biodegradable films of varying thickness. The results indicate that all three films have potential for use in Christmas tree production. However, the use of biodegradable films would be preferable because they do not need to be removed at the end of the rotation (about 6-7 years). Furthermore, this culture system would be an efficient way to achieve three objectives: 1) to enhance weed control, avoiding the application of herbicides by many Christmas tree producers; 2) to improve quality and plant commercial value; and 3) to obtain a shorter rotation.

\section{Poster Session 14-Genetics and Germplasm 2}

\section{July 2006, 12:00-12:45 p.m.}

\section{(274) Genetic Diversity of Wild Pyrus communis L.}

Gayle Volk ${ }^{1}$, Christopher Richards ${ }^{1}$, Adam Henk ${ }^{1}$, Ann Reilley ${ }^{1}$, Nahla Bassil*2, Joseph Postman ${ }^{2}$

${ }^{1}$ National Center for Genetic Resources Preservation, USDA-ARS, Fort Collins, CO, 80521; ${ }^{2}$ National Clonal Germplasm Repository, USDA-ARS, Corvallis, Ore.

Edible European pears (Pyrus communis sp. communis L.) are thought to be derived from wild relatives native to the Caucasus Mountain region and eastern Europe. We collected genotype, phenotype, and geographic origin data for 145 P. communis individuals derived from seeds collected from wild relatives. These individuals are currently maintained in the USDA-ARS National Plant Germplasm System (NPGS) in Corvallis, 
Ore. Pear genotypes were obtained using 13 microsatellite markers. A Bayesian clustering method grouped the individual pear genotypes into 12 clusters. The subspecies of pears native to the Caucasus Mountains of Russia, Crimea, and Armenia could be genetically differentiated from the subspecies native to eastern European countries. Pears with large fruit clustered closely together and are most closely related to a group of genotypes that are intermediate to the other groups. Based on the high number of unique alleles and heterozygosity in each of the 12 clusters, we conclude that the genetic diversity of wild P. communis is not fully represented in the NPGS

\section{(275) Genetic Relationship of Fruiting-mei (Prunus mume Sieb. et Zucc.) Cultivars Evaluated by AFLP and SNP Markers}

Jinggui Fang ${ }^{1}$, Tal Twito ${ }^{2}$, Zhen Zhang ${ }^{3}$, ChihCheng T. Chao*1

${ }^{1}$ University of California-Riverside, Department of Botany and Plant Sciences, Riverside, CA, 92521-0124; ${ }^{2}$ The Volcani Center, Agricultural Research Organization, Bet-Dagan, 50250 , Israel; ${ }^{3}$ Nanjing Agricultural University, Horticultural College, Nanjing, 210095, China

The genetic relationship among 50 fruiting-mei (Prunus mume Sieb. et Zucc.) cultivars from China and Japan was investigated using 767 amplified fragment length polymorphism (AFLP) and 103 single nucleotide polymorphism (SNP) markers. The polymorphism among the cultivars was $69.77 \%$ based on EcoR I + Mse I AFLP primer pairs. The sequence alignment of 11 group sequences derived from 50 samples yielded 103 SNPs with a total length of 3683-bp genomic sequences. Among these SNPs, 73 were heterozygous in the loci of different cultivars. The SNP distribution were: $58 \%$ transition, $40 \%$ transversion, and $2 \%$ InDels. There was also one tri-nucleotide deletion. Both AFLP and SNP allowed the evaluation of genetic diversity of these 50 fruiting-mei cultivars; however, the two derived cladograms have some differences: 1) all the cultivars formed two sub-clusters (1A and $1 \mathrm{~B})$ within cladogram based on AFLP polymorphisms, and there were three sub-clusters (2A, $2 \mathrm{~B}$ and $2 \mathrm{C}$ ) formed in the cladogram based on SNP polymorphisms; and 2) most cultivars from G-F, Y-H-S regions and Japan are grouped in cluster $1 \mathrm{~A}$ and $18(78.26 \%)$ out of 23 cultivars from $\mathrm{J}-\mathrm{Z}$ origin are grouped in cluster 1B in the cladogram generated based on AFLP polymorphisms. The results show cultivars from Japan are clustered within cultivars from China and supports the hypothesis that fruitingmei in Japan was introduced from China in the past. Cultivars from J-Z region of China have higher genetic similarities. Cultivars from G-F and Y-S-H regions have lower genetic similarities and suggest more germplasm exchanges in the past.

\section{(276) Assessing Genetic Diversity of Spinach Germplasm using TRAP Markers}

\section{Jinguo $\mathrm{Hu}^{1}$, Beiquan Mou*2, Brady A. Vick ${ }^{1}$}

${ }^{1}$ USDA-ARS, Red River Valley Agricultural Research Center, Fargo, ND, 58105; ${ }^{2}$ USDA-ARS, Salinas, CA, 93905

Target region amplified polymorphism (TRAP) markers were used to evaluate genetic variability among 48 accessions of spinach (Spinacia oleracea L.), an economically important leafy vegetable crop in many countries. Thirty-eight accessions collected and preserved by the USDA National Plant Germplasm System (NPGS) and 10 commercial hybrids were used in the current study. For assessing genetic diversity within accessions, DNA samples were prepared from nine to 12 individual seedlings from six germplasm accessions and two hybrids. Relatively high levels of polymorphism was found within accessions based on 61 polymorphic TRAP markers generated with two fixed primers derived from the Arabidopsis-type telomere repeat sequence and two arbitrary primers. For evaluating inter-accession variability, DNA was extracted from a bulk of six to 10 seedlings of each accession. Of the 1092 fragments amplified by 14 primer combinations, $96(8.8 \%)$ were polymorphic and discriminated the 48 accessions from each other. The average pair-wise genetic similarity coefficient (Dice, Nei) was $57.5 \%$ with a range from 23.2 to $85.3 \%$. A dendrogram was constructed based on the similarity matrix. It was found that the genetic relationships were not highly correlated with the geographic locations in which the accessions were collected. However, seven commercial hybrids were grouped in three separate clusters, suggesting that the phenotype-based breeding activities have effect on the genetic variability. This study demonstrated that TRAP markers are effective for fingerprinting and evaluating genetic variability of spinach germplasm.

\section{(277) Morphological and Molecular Diversity in Coreopsis leavenworthii Populations}

David M. Czarnecki II*1, Zhanao Deng ${ }^{1}$, Madguhuri N. Rao², Frederick G. Gmitter, Jr. ${ }^{2}$, Young A. Choi ${ }^{2}$, Jeffrey G. Norcini ${ }^{3}$, David G. Clark ${ }^{4}$

${ }^{1}$ University of Florida, Environmental Horticulture, Wimauma, FL, 33598; ${ }^{2}$ University of Florida, Ornamental Horticulture, Lake Alfred, FL, 33850; ${ }^{3}$ University of Florida, Environmental Horticulture, Quincy, FL, 32351; ${ }^{4}$ University of Florida, Environmental Horticulture, Gainesville, FL, 32611

As one of the Florida's state wildflowers, Coreopsis leavenworthii is highly desirable for roadside plantings in all parts of the state. Seeds of this species are being produced by growers. Where should seed be produced for different ecotypes? Where can the seed be used? These are among questions that have arisen in commercial seed production and distribution. To address these questions, it was necessary to assess the levels of genetic diversity. Eleven populations (242 total individuals) were collected from different parts of Florida, grown at one location in central Florida, and observed for morphological variations. North Florida natural populations had more complex leaves, while south Florida natural populations had smaller flowers. Principal component analyses revealed that two of the seven characteristics studied accounted for as much as $88 \%$ of the morphological variations observed. Molecular diversity was analyzed by using the fluorescent amplified fragment length polymorphism (AFLP) technique and the capillary sequencing system. Four primer combinations detected 320 AFLP fragments, of which $90.6 \%$ were polymorphic. The overall genetic diversity in the species was 0.2206 (estimated using AMOVA), of which $77.9 \%$ was within populations and $22.1 \%$ was among populations. The genetic distance among populations seemed to be loosely correlated with geographical distances. A high level of gene flow was found in several populations. Based on the results, a model has been developed to describe the genetic relationship of Coreopsis leavenworthii populations.

\section{(278) Genetic Variability and Relationship of Caladium Cultivars As Revealed with Molecular Markers}

Zhanao Deng ${ }^{1}$, Jinguo $\mathrm{Hu}^{2}$, Fahrettin Goktepe*1, Brady A. Vick ${ }^{2}$, Brent K. Harbaugh ${ }^{1}$

${ }^{1}$ University of Florida, Gulf Coast Research and Education Center, Wimauma, FL, 33598; ${ }^{2}$ USDA-ARS, Northern Crop Science Laboratory, Fargo, ND, 58105

Cultivated caladiums are valued for their bright colorful leaves and are widely used in containers and landscapes. More than 1500 named cultivars have been introduced during the past 150 years, yet currently only about 100 cultivars are in commercial propagation in Florida. Caladium tubers produced in Florida account for $95 \%$ of the world supplies. Loss of caladium germplasm or genetic diversity has been a concern to future improvement of this plant. In addition, the relationship among the available cultivars, particularly those of close resemblance, has been lacking. This study was conducted to assess the genetic variability and relationship in commercial cultivars and species accessions. Fifty-seven major cultivars and 15 caladium species accessions were analyzed using the target region amplification polymorphism marker technique. This marker system does not involve DNA restriction or adaptor linking, but shares the same high throughput and reliability with the amplified fragment length polymorphism system (AFLP). Eight primer combinations amplified 379 scorable DNA fragments among the caladium samples. A high level of polymorphism was detected among the species accessions as well as among cultivars. These markers allowed differentiation of all the cultivars tested, including those hardly distinguishable morphologically. Clustering analysis based on these DNA fingerprints separated the cultivars into five clusters and 
Caladium lindenii far from other caladium species. The availability of this information will be very valuable for identifying and maintaining the core germplasm resources and will aid in selecting breeding parents for further improvement.

\section{(279) Morphological Investigation of Astilbe}

Brian W. Trader, Holly L. Scoggins*, Richard E. Veilleux

Virginia Polytechnic Institute and State University, Horticulture, Blacksburg, VA, 24060

The genus Astilbe (Saxifragaceae) is comprised of approximately 20 species and is ranked consistently among the top ten landscape perennials. Through extensive hybridization, selection, and marketing, the lineage of many Astilbe has been lost. Subdioecious Astilbe biternata is the only species in the genus native to North America, while other members of the genus are endemic to Asia and monoecious. Due to the unusual geographic distribution of the species and the variation in floral development among them, investigation of morphological characters may help establish lineage within the genus. Herbarium material representing described species and varieties of Astilbe was acquired from several herbaria nationwide. Twenty-seven character states were selected to help distinguish members among the genus. Morphological character states chosen for inferring differences among species in Astilbe varied from degree of pubescence to leaf branching with an emphasis on floral characteristics such as sepal and petal variation. Character state matrix was assimilated for 20 taxa of Astilbe and analyzed using maximum parsimony. The monotypic genus Saxifragopsis was utilized as the outgroup taxa. Resulting phylogenetic trees show Astilbe simplicifolia as the species from which all members of the genus were derived. The American species, Astilbe biternata, separated away from other members within the genus. There is evidence from the phylogeny based on the morphological character states that some described species may actually represent variation within populations of species. Combination of this morphological data with molecular sequence information may be informative for further description of the Astilbe genus.

\section{Poster Session 15-Ornamental/Landscape and Turf 1}

\section{July 2006, 12:00-12:45 p.m.}

\section{(50) Evaluating Low Light Level Effects on Chlorophyll Content and Commercial Quality in Several Species of Bambuseae}

Harry G. Simmons*, Alisara Menakanit, Surawit Wannakrairoj, Poonpipope Kasemsap

Kasetsart University, Horticulture, Chathuchak, Bangkok, 10900, Thailand

Bamboo has increasingly become a popular exterior ornamental plant because of its durability, versatility, and evergreen qualities in conditions of extreme temperature and moisture variations. Use as an interior foliage plant has been limited due to the difficulty of finding species adaptable to lower light levels. Nineteen species from seven genera (Bambusa, Cephalostachyum, Dendrocalamus, Gigantochloa, Schizostachyum, Thyrsostachys, and Vietnamosasa) were evaluated. Fifteen plants from each species were potted in like conditions $(50 \%$ leaf mold; 50\% topsoil; $5 \mathrm{~g}$ of 14-14-14 controlled-release fertilizer) and grown under a maximum daily photosynthetic photon flux density $(P P F D)$ range between 1200 to $2000 \mu \mathrm{mol} \cdot \mathrm{m}^{-2} \cdot \mathrm{s}^{-1}$ for 6 weeks. Chlorophyll content of leaves was measured. The commercial quality of leaves, culms, and general appearance was also recorded. Light was then limited to a maximum PPFD of 150 to $300 \mu \mathrm{mol} \mathrm{m} \mathrm{m}^{-2} \mathrm{~s}^{-1}$ for 6 weeks and all measurements were again recorded. Five species had significant increases in chlorophyll content after the 6-week period of reduced light levels. Species with a larger maturity size had a greater mortality percentage as well as lower quality leaf and overall appearance when grown under reduced light levels. Culm quality remained constant in 18 of the 19 species after the 6-week period. Vietnamosasa ciliata showed the greatest increase in chlorophyll levels as well as highest commercial quality of leaf and overall appearance.

\section{(51) Intermountain West Native and Adapted Grass Species and Their Management for Turfgrass Applications}

Tracy Dougher*1, Toby Day ${ }^{1}$, Paul Johnson², Kelly Kopp², Mark Majerus $^{3}$

${ }^{1}$ Montana State University, Plant Sciences and Plant Pathology, Bozeman, MT, 597173140; ${ }^{2}$ Utah State University, Plants, Soils, and Biometeorology, Logan, UT, 84322-4820; ${ }^{3}$ USDANRCS, Plant Materials Center, Bridger, MT, 59014-9718

The ongoing drought in the Intermountain West has brought a great deal of attention to water conservation over the past several years. During that time, turfgrass irrigation has been targeted as a source for large potential water savings. Some communities promote downsizing turfgrass areas as the best water conservation measure. In reality, turfgrass controls erosion, reduces evaporation from a site, and provides a safe surface for human activities. One alternative to elimination would be wider use of low water-use-grasses appropriate to the area. However, many questions arise regarding the choice of such grasses and their management. Our research addresses these questions. Plots have been established at Montana State University, Bozeman; Utah State University, Logan; and USDA-NRCS Plant Materials Center, Bridger, Mo. The grasses considered include 12 single species and 12 mixed species stands of 'Cody' buffalograss, 'Foothills' Canada bluegrass, 'Bad River' blue grama, sheep fescue, sandberg bluegrass, muttongrass, and wheatgrasses 'Sodar'streambank, 'Road Crest' crested, 'Rosana' western, and 'Critana' thickspike with Kentucky bluegrass and tall fescue as controls. Line source irrigation allowed the plots to be evaluated at a number of levels of irrigation. Experimental measurements on the plots included growth response as determined by clipping yield and quality ratings, and species composition. Fescues and wheatgrasses retained their color, texture, and density throughout the growing season, regardless of moisture level. Warm-season grasses performed well in June, July, and August only, and worked poorly in mixtures as the green cool-season grasses could not mask the brown dormant leaves in cooler weather.

\section{(52) Evaluation of California Native Grasses for Revegetation Sod}

\section{Lance Stott*1, Lisa Rew ${ }^{2}$, Tracy Dougher ${ }^{1}$}

${ }^{1}$ Montana State University, Plant Sciences and Plant Pathology, Bozeman, MT, 59717; ${ }^{2}$ Montana State University, Land Resources and Envrionemental Sciences, Bozeman, MT, 59717

The California Department of Transportation (Caltrans) has used hydroseeding, imprinting, and drill seeding methods to revegetate highway construction sites, with varying degrees of success. Ecological concerns, particularly in areas with high erosion potential, have led Caltrans to search for more-reliable plant establishment methods. One possibility is native sod, which should reduce erosion potential, and, the species would also be better suited to local environments, require less maintenance, and pose no invasive threat to adjacent ecosystems. In addition, the use of native sod may also reduce or prevent weed establishment. Our project aims to evaluate different native grass species mixes to determine the best species combinations for sod. We selected 21 species of native grasses in order to determine their suitability for sod production in six Californian ecoregions. Grasses were grown in six growth chambers that mimic the climate of the six ecoregions. Mixtures of varying species included either one rhizomatous species with three bunch grasses, one rhizomatous species and five bunch grasses, two rhizomatous species with three bunch grasses, or two rhizomatous species with five bunch grasses for each ecoregion. The mixtures were grown and tested for yield, species composition, and percentage of cover over time. At the end of the 6-month production time, a final harvest evaluated root depth and biomass as well as sod strength. Rhizomatous grasses, if planted with Bromus sp., were quickly overwhelmed. At the first harvest ground coverage was between $10 \%$ and $15 \%$ for all species mixes. Ground coverage increased over the 
production cycle, but maximum ground coverage remained less than $80 \%$ overall.

\section{(53) Freezing Tolerance of Twenty-Seven Saltgrass Ecotypes Was Similar in 2004 and 2005}

\section{Hrvoje Rukavina*, Harrison Hughes, Yaling Qian}

Colorado State University, Horticulture and Landscape Architecture, Fort Collins, CO, 80523-1173

Freezing is the major abiotic stress that limits geographical distribution of warm-season turfgrasses. Prior studies have indicated variation in freezing tolerance in saltgrass clones. Therefore, this 2-year study examined the freezing tolerance of 27 saltgrass clones as related to collection sites in three zones of cold hardiness. Furthermore, these clones were evaluated for time of leaf browning in the fall with the intent to determine if there was a correlation between this trait and freezing tolerance. Rhizomes were sampled during 2004 and 2005 midwinters from clones established in Fort Collins, Colo., and then subjected to a freezing test. Saltgrass freezing tolerance was highly influenced by the climatic zone of clone origin in both years of the experiment. Clones with greater freezing tolerance turned brown earlier in fall in both seasons. Ranking of zones for the average $\mathrm{LT}_{50}$ was: zone $4\left(-17.2^{\circ} \mathrm{C}\right)<$ zone $5\left(-14.4^{\circ} \mathrm{C}\right)<$ zone $6\left(-11.1^{\circ} \mathrm{C}\right)$ in 2004 and zone $4\left(-18.3^{\circ} \mathrm{C}\right)<$ zone $5\left(-15.7^{\circ} \mathrm{C}\right)<$ zone $6\left(-13.1^{\circ} \mathrm{C}\right)$ in 2005 . Clones from northern areas tolerated lower freezing temperatures better overall. This confirmed that freezing tolerance is inherited. Large intraspecific variation in freezing tolerance may be effectively used in developing cold-hardy cultivars.

\section{(54) Utilization of Herbaceous Groundcovers for Weed Suppression and Aesthetic Appeal in Landscapes and Roadsides}

\section{Leslie A. Weston*1, Andrew F. Senesac ${ }^{2}$}

${ }^{1}$ Cornell University, Horticulture, Ithaca, NY, $14853 ;{ }^{2}$ Cornell University-LIHREC, Suffolk County Cooperative Extension, Riverhead, NY, 11901

For the past 5 years, we have evaluated more than 100 herbaceous perennial groundcovers, including both grasses and grass mixtures, as well as ornamental broadleaf materials, for their ability to establish, suppress weeds, provide aesthetic appeal, and resist pests in various landscape and roadside settings across New York State. By working in cooperation with the NYSDOT, we have developed recommendations for materials that have performed well in difficult, potentially stressful, roadside and landscape settings. We have performed replicated research and demonstration trials that have clearly shown that certain species and cultivars provide effective weed suppression; great aesthetic appeal due to foliar texture, color, or flowering, resist pests and diseases; and require low maintenance over time. In addition, certain materials tolerate high levels of salt $(\mathrm{NaCl})$, simulating roadside salt application exposure, in supplemental greenhouse studies. Materials generally suppressed weeds effectively by forming a dense canopy in a short period of time, and reducing light interception at the soil surface under this dense canopy. Certain groundcovers also appeared to exhibit strong potential allelopathic properties when grown either in field or laboratory settings. The selection of new plant materials for use in low-maintenance landscape settings offers potential to reduce time and maintenance inputs in difficult landscape or roadside settings, with the added benefit of reducing pesticide application in these settings for weed management. Additional studies are currently underway to develop further recommendations for use of warm- and cool-season turfgrasses in these settings.

\section{(55) Leaf Abnormality on White and Red Oak Linked to Drift of Chloroacetanilide Herbicides}

Jayesh B. Samtani*, John B. Masiunas, James E. Appleby

University of Illinois at Urbana-Champaign, Natural Resources and Environmental Sciences, Urbana, IL, 61801

In some years, the emerging leaves of white oak and, to a lesser extent, of red oak in the Midwest have developed abnormally. This abnormality is referred to as leaf tatters. Reports to state foresters and Extension specialists associated tatters with herbicide applications. In 2005, white and red oak seedlings were treated in a spray chamber delivering 187 $\mathrm{L} / \mathrm{ha}$, with seven herbicides at three concentrations, $1 / 4 \times, 1 / 10 \times$, and $1 / 100 \times$ of the standard field use rate. These herbicides and their standard field use rate of the active ingredients included atrazine at $2.3 \mathrm{~kg} / \mathrm{ha}$ and chloroacetanilide herbicides: acetochlor at $2.0 \mathrm{~kg} / \mathrm{ha}$, metolachlor at $2.1 \mathrm{~kg} / \mathrm{ha}$, and dimethenamid at $0.8 \mathrm{~kg} / \mathrm{ha}$ alone or mixed with atrazine at $2.3 \mathrm{~kg} / \mathrm{ha}$, at the leaves unfolding stage. After treatment, oaks were placed outdoors in a randomized complete-block design. Leaf symptoms in our study were similar to those seen in the landscape. In chloroacetanilide-treated white and red oak seedlings, browning of interveinal leaf tissues was noticed 5-6 days after treatment. The dried leaf tissues then dropped off, leaving only the main vein with little interveinal leaf area. In few seedlings treated with atrazine, the leaf tissues turned yellow to brown, while in few others, interveinal tissue damage was restricted, leaving small holes in the leaf. When chloroacetanilide herbicides were applied with atrazine, the dominant symptoms were those of leaf tatters. A few seedlings treated with dimethenamid and atrazine had predominately atrazine symptoms. Although new growth later in the season was not injured, the leaves with tatters remained on the plant until the end of the growing season. The study will be repeated in 2006 .

\section{(56) Salt Spray Tolerance of Miscanthus sinensis 'Gracillimus' and Pennisetum setaceum 'Hamelin'}

Erin E. Alvarez*1, David R. Sandrock ${ }^{1}$

${ }^{1}$ University of Florida, Environmental Horticulture, Gainesville, FL, 32611; ${ }^{2}$ Oregon State University, Department of Horticulture, Corvallis, OR, 97331

Salt tolerance of landscape plants is important to ornamental growers as well as residents and landscapers in coastal communities. Damage to ornamental plants from salt spray can be prevented by evaluating and selecting plants that exhibit tolerance to aerosol salts. Ornamental grasses are frequently recommended for low-maintenance landscape situations and may be candidates for coastal plantings once they are evaluated for their salt spray tolerance. The objective of this study was to determine the salt spray tolerance of Miscanthus sinensis 'Gracillimus' and Pennisetum setaceum 'Hamelin'. The experiment was conducted for 90 days from 7 July to 5 Oct. 2005 in a polyethylene greenhouse in Gainesville, Fla. Plants were subjected to four treatments $(100 \%$ seawater, $50 \%$ seawater, $25 \%$ seawater, or $100 \%$ deionized water) applied by spraying each plant to runoff three times per week. Plant heights, flower number, and aesthetic ratings were recorded biweekly for the duration of the experiment. Root and shoot dry weights were determined at the initiation and completion of the study. Significant growth rate differences were found between treatments. Growth rates of plants treated with $100 \%$ seawater were significantly lower than the control and other seawater concentrations. Root and shoot dry weights of the plants treated with $100 \%$ seawater were significantly lower than the other treatments. In addition, significant differences were found between the $100 \%$ seawater treatment, the $25 \%$ seawater treatment, and the control in the aesthetic ratings of plants at the end of the study.

\section{Poster Session 16-Pomology 1}

28 July 2006, 12:00-12:45 p.m.

\section{(105) Variation in Cornelian Cherry Phytonutrient Capacity}

Mustafa Ozgen ${ }^{1}$, Artemio Z. Tulio, Jr. ${ }^{2}$, Ann M. Chanon ${ }^{2}$, Nithya Janakiraman ${ }^{2}$, R. Neil Reese ${ }^{3}$, A. Raymond Miller ${ }^{2}$, Joseph C. Scheerens*2

${ }^{1}$ Gaziosmanpasa Univ., Horticulture, Tasliciftlik, Tokat, 60240, Turkey; ${ }^{2}$ The Ohio State Univ., Horticulture \& Crop Science, Ohio Agricultural Res. \& Development Center, Wooster, OH, 44691; ${ }^{3}$ South Dakota State Univ., Biology \& Microbiology, Brookings, SD, 57007

To investigate the variation in the phytonutrients of Cornelian cherry (Cornus mas L.), fruit was harvested at the blush (S1), red (S2), and ripe 
(S3) stages from five genotypes maintained at the Secrest Arboretum, Wooster, Ohio. The S1-S3 samples were characterized for color reflectance and then frozen at $-28^{\circ} \mathrm{C}$. After storage, samples were analyzed for dry weight (DW), total soluble solids (TSS), sugars (FRU + GLU), organic acids (ORG), total phenols (PHE), total anthocyanins (ACY), individual anthocyanins (IA), hydroyzable tannins (HT), and antioxidant capacity (FRAP and ABTS). From S1 to S3, DW and TSS increased by $24 \%$ and $21 \%$, respectively, and $\mathrm{L}$, hue angle, and chroma values decreased. On a DW basis, all analytical parameters were significantly influenced by genotype and stage. The ACY levels rose 7-fold during ripening, but PHE contents declined by $10 \%$. In ripe fruit, HT comprised the bulk of the PHE constituents, whereas ACY accounted for only $7.6 \%$ of PHE levels. Variability among genotypes was moderate for all ripe fruit parameters but ACY. Ripe fruit varied little in color parameters and ACY (fwb) and IA (fwb) were not significantly different among cultivars. The Cy 3-gal and pel 3-gal levels were negatively correlated. Antioxidant capacity declined $16 \%$ to $18 \%$ during ripening. Ripe fruit FRAP and ABTS values were higher than those reported for most fruits, averaging $596 \pm 85$ and $629 \pm 85 \mu \mathrm{mol}$ TE eq./gDW, respectively. ABTS and FRAP values were highly correlated with each other and with PHE and HT contents, but were loosely and negatively related to ACY levels. Considering our limited sample size, we concluded that the phytonutrient capacity of cornelian cherry is substantial, predominantly associated with tannins and moderately variable among genotypes.

\section{(106) Delay of Flower Bud Phenology of Rabbiteye and Southern Highbush Blueberries With Soybean Oil and Abscisic Acid}

\author{
Dennis E. Deyton ${ }^{1}$, Carl E. Sams*1, Jim R. Ballington², \\ John C. Cummins ${ }^{1}$ \\ ${ }^{1}$ University of Tennessee, Department of Plant Sciences, Knoxville, TN, 37996-4561; ${ }^{2}$ North \\ Carolina State University, Department of Horticulture Science
}

'Legacy' southern highbush blueberry plants at the Middle Tennessee Research and Education Center were sprayed on 22 Feb. 2005 with $0 \%, 6 \%, 9 \%$, or $12 \%$ soybean oil. The treatments were arranged in a randomized complete-block design with five replications. Flower bud abortion was evaluated by sampling 25 flower buds/plant on 21 Mar., dissecting, and visually examining buds for browning of ovaries. Flower bud phonology was rated periodically until first bloom and then percentage of open bloom was rated every 2 to 3 days. Fruit were harvested for yield and 50-berry samples taken weekly for the first 4 weeks to determine berry size. Sprays of $6 \%, 9 \%$, and $12 \%$ soybean oil delayed the $50 \%$ open bloom date of 'Legacy' by 2, 4, and 9 days, respectively, but also caused $9 \%, 35 \%$ and $87 \%$ mortality of flower buds. 'Legacy' bushes sprayed with $0 \%, 6 \%, 9 \%$ and $12 \%$ soybean yielded 11.6, 13.7, and 10.3, and $4.5 \mathrm{lb} /$ bush, respectively. Berry size was increased by $14 \%$ to $23 \%$ by oil sprays. In a second experiment, 'Climax' blueberries in a commercial planting in Spring City, Tenn., were sprayed on 4 Mar. with water, $5 \%$ TNsoy 14 (96\% soybean oil, a.i.), 500 ppm abscisic acid (ABA) (Valent BioSciences Corp., Long Grove, Ill.), or the combination of oil and ABA (seven replications). Flower bud development and bloom were rated as previously described. Spraying $5 \%$ TNsoy 14 or 500 ppm ABA delayed the $50 \%$ open bloom date by 1 day and the combination of the two delayed bloom by an additional day. On 5 Apr., 'Climax' bushes sprayed with 5\% TNsoy14, 500 ppm ABA, and $5 \%$ TNsoy 14 plus 500 ppm ABA had $49 \%$, $41 \%$, and $20 \%$ open bloom compared to $70 \%$ open bloom on control plants. The $5 \%$ oil, 500 ppm ABA, and the oil plus ABA treatments did not significantly affect crop load or berry size.

\section{(107) Ripening of Pawpaw (Asimina triloba L.) Fruit Affects Pulp Phenolic Content and Antioxidant Capacity}

Hideka Kobayashi*1, Changzheng Wang ${ }^{1}$, Kirk W. Pomper ${ }^{2}$

${ }^{1}$ Kentucky State University, Human Nutrition, Frankfort, KY, 40601; ${ }^{2}$ Kentucky State University, Plant and Soil Science, Frankfort, KY, 40601

Pawpaw (Asimina triloba L.), a species of the eastern United States, bears the largest edible fruit of all native trees. Relatively little is known about ripening of pawpaw, and several problems, such as short shelf life and duration of harvesting, hamper pawpaw production. While previous investigations have resulted in identifying physical properties associated with ripening, the effects on phenolic content and antioxidant capacity have not been investigated. The objectives of the study were to investigate changes in phenolic content and antioxidant capacity and to identify physical parameters of pawpaw pulp during ripening. Sample extraction of pawpaw was achieved by adding acetone ( $2 \mathrm{~mL} / 1 \mathrm{~g}$ of sample) to pulp of a pawpaw cultivar, PA Golden, and then vortexing ( $30 \mathrm{~s})$ and sonicating (15 min) the sample and solvent, prior to centrifugation $(15 \mathrm{~min})$ twice at $2987 \times g$. Folin-Ciocalteu assay and ferric reducing antioxidant power (FRAP) assay were used for the estimation of phenolic content and the antioxidant capacity, respectively. While soluble solid content increased during ripening, the hardness of the fruit decreased, confirming previous reports. The pulp of unripe fruits had the greatest phenolic content (gallic acid eq. $131.2 \mathrm{mg} / 100 \mathrm{~g} \mathrm{FW}$ ) and antioxidant capacity (Trolox eq. $22.7 \mu \mathrm{M} / \mathrm{g}$ FW), which decreased by about $20 \%$ as the fruit ripened. Of three color properties measured, chroma, an estimate of color saturation, increased with ripening, while lightness of pawpaw pulp remained the same. A high correlation was found between chroma and hardness of fruits $(r=$ 0.62 ), and between phenolic content and antioxidant capacity of pawpaw pulp $(r=0.80)$, suggesting these parameters can be incorporated into methods to estimate the ripeness of pawpaw fruit.

\section{(108) Early Flower Bud Production and Field Establishment of Two Pawpaw Cultivars on Five Seedling Rootstocks}

Kirk Pomper*1, Sheri Crabtree ${ }^{1}$, Desmond R. Layne ${ }^{2}$

${ }^{1}$ Kentucky State University, Land Grant Program, Frankfort, KY, 40601; ${ }^{2}$ Clemson University, Department of Horticulture, Clemson, SC, 29634

The pawpaw [Asimina triloba (L.) Dunal] is native to the southeastern United States and has potential as a new tree fruit crop. Clonal rootstocks are not currently available for pawpaw cultivars; therefore, nurseries graft cultivars onto rootstock derived from locally available seed. Great variation in rootstock vigor with this seedstock can result in grafted trees that lack vigor and have delayed fruit production. Pawpaw rootstocks that promote precocity would be desirable to growers. The objectives of this study were to determine if rootstock source and pruning system influenced precocity and field establishment of two pawpaw cultivars. In May 2004, a rootstock trial was planted at the Kentucky State University Research Farm that consisted of 'Sunflower' and 'Susquehanna' budded onto five seedling rootstocks (PA-Golden, Sunflower, Susquehanna, K8-2, and commercially available seed) with either a minimal or central leader pruning system. There were eight replicate blocks with each treatment combination, for a total of 160 trees. In Fall 2005, field mortality was greatest (58\%) for 'Susquehanna' budded onto Susquehanna seedling rootstock, whereas mortality was about $25 \%$ with other scion/rootstock combinations. The number of flower buds present on each tree was evaluated in Feb. 2006. Rootstock and pruning method did not influence the number of trees exhibiting flower buds. However, cultivar did influence the number of trees with flower buds; more trees of 'Sunflower' (48\%) had flower buds than 'Susquehanna' ( $8 \%$ ), and 'Sunflower' (3.46) had more flower buds per tree than Susquehanna (0.43). Pruning system did influence the number of flower buds per tree; minimal pruned trees (2.65) had more flower buds per tree than central leader (1.21) trained trees.

\section{(109) The Kentucky State University Pawpaw Regional Variety Trial: 1998-2005 Overview}

Sheri B. Crabtree*1, Kirk W. Pomper ${ }^{1}$, Desmond R. Layne ${ }^{2}$, R. Neal Peterson ${ }^{3}$

${ }^{1}$ Kentucky State University, Land Grant Program, Frankfort, KY, 40601; ${ }^{2}$ Clemson University, Department of Horticulture, Clemson, SC, 29634; ${ }^{3}$ Peterson Pawpaws, Nursery Production and Sales, Harpers Ferry, WV, 25425

The pawpaw [Asimina triloba (L.) Dunal] is a tree fruit native to the 
eastern United States with potential as an alternative crop for small farmers. The Pawpaw Regional Variety Trial (PRVT) was established in 1993 by Kentucky State University (KSU) and the PawPaw Foundation (PPF) and includes 28 cultivars and advanced selections planted at 12 sites. The PRVT was established at the KSU Research Farm in Frankfort, Ky., in 1998. Data has been collected on the KSU-PRVT annually since its inception. The first fruit were produced in 1999, with Middletown, Mitchell, Overleese, and Sunflower being the most precocious varieties. A frost occurred in early April 2000, decimating the crop, with only eight fruit being produced across the orchard. In $2001,12 \%$ of the trees produced fruit, with PA-Golden having the best early production. In 2002, 68\% of trees in the PRVT fruited, producing a total of 3,500 fruit. Selections with the largest fruit (over $200 \mathrm{~g}$ ) were Susquehanna, 5-5, 4-2, and 1-7-2. In 2003, a spring frost destroyed most of the flowers and developing fruit. Only 32 out of the 224 trees in the PRVT retained fruit, a total of only 131 fruit in the entire orchard. In 2004, the PRVT produced about 25,000 fruit across the entire orchard. Selections 4-2 and 7-90 produced the largest fruit, over 200 g. Shenandoah, 10-35, and 8-20 were the highest-yielding clones, all producing over $15 \mathrm{~kg}$ of fruit per tree. In 2005, spring frosts and a severe summer drought diminished fruit set and retention in the PRVT, with the orchard producing 8,900 fruit. Selections 4-2, 5-5, and Susquehanna produced the largest fruit, all weighing over $200 \mathrm{~g}$. The highest yielding selections were 10-35, PA-Golden, and 1-7-2, all producing over $8 \mathrm{~kg}$ of fruit per tree.

\section{(111) Evaluation of the Salt Tolerance of Walnut Rootstocks}

Janet Caprile*1, Steve Grattan ${ }^{2}$

${ }^{1}$ University of California, Cooperative Extension, Pleasant Hill, CA, 94523; ${ }^{2}$ University of California, Land, Air, Water Resources, Davis, CA, 95616

In areas of California with a high incidence of walnut blackline disease, walnut orchards are increasingly being planted on English walnut (Juglans regia) rootstocks that are tolerant to the virus. There is limited documentation on the salt tolerance of this rootstock. This work was done to quantify the response of English walnut rootstocks to high boron $(\mathrm{B})$, chloride $(\mathrm{Cl})$, and sodium $(\mathrm{Na})$ and to compare this to the more common rootstocks, Northern California Black (J.hindsii) and Paradox $(J$. hindsii $\times J$. regia). The trial was configured as a randomized complete-block design with 20 plots. Plots consisted of three proximate, matched 'Chandler' trees, each on a different rootstock. Leaf samples over a 2-year period showed that trees on the English rootstock had a significantly higher salt uptake than trees on Paradox, which had a significantly higher uptake than trees on Black. Bark cores showed little difference in B uptake between any of the rootstocks. Bark cores also showed that all rootstocks accumulated significantly more $B$ than the scion portion of the tree, indicating that $\mathrm{B}$ transport may be limited by the graft union. Trees on English rootstock had significantly more B in the scion bark cores than trees on either Black or Paradox, indicating that rootstocks with a $J$. hindsii parent may be better at reducing salt transport across the graft union.

\section{(110) Suppression Subtractive Hybridization (SSH) Analysis for Detecting Genes Involved in Condensed Tannin Accumulation in Persimmon Fruit}

Keizo Yonemori*1, Junya Yoshida ${ }^{1}$, Ayako Ikegami ${ }^{1}$, Akihiko Sato ${ }^{2}$, Masahiko Yamada ${ }^{3}$, Akira Kitajima ${ }^{1}$

${ }^{1}$ Kyoto University, Graduate School of Agriculture, Kitashirakawa, Sakyo-ku, Kyoto, 6068502 , Japan; ${ }^{2}$ National Institute of Fruit Tree Science, Department of Breeding and Genetics; ${ }^{3}$ National Institute of Fruit Tree Science, Department of Grape and Persimmon Research

Pollination-constant and non-astringent (PCNA)-type persimmon has probably originated from astringent (non-PCNA)-type as a mutant that terminates condensed tannin accumulation at an early stage of fruit development. This trait is confirmed to be recessive and is controlled by a single locus. Since PCNA-type fruit stops tannin accumulation at an early stage, comparison of the gene expressions between PCNAand non-PCNA-type will reveal the genes conferring condensed tannin accumulation in persimmon fruit. We performed suppression subtractive hybridization ( $\mathrm{SSH}$ ) analysis for detecting differentially expressed genes in non-PCNA-type fruit using $\mathrm{BC}_{1}$ offspring from a cross between PCNA 'Fuyu' and non-PCNA " $275-13$ " ( $\mathrm{F}_{1}$ progeny derived from non-PCNA 'Aizumishirazu' $\times$ PCNA 'Taishu'). Fruits from seven individuals of PCNA or non-PCNA offspring in $\mathrm{BC}_{1}$ were sampled at early two stages of fruit development and total RNA was extracted by hot borate method from each fruit of different stage. Then, RNA was pooled as PCNA or non-PCNA bulk at two stages and cDNA was synthesized from each bulk for SSH analysis. A total of 5000 clones expressed differentially in non-PCNA-type fruit were picked from SSH library of two stages and 198 positive clones confirmed by differential screening were sequenced. The homologous sequences for the genes involved in flavonoid biosynthesis (CHS, CHI, F3H, F3' 5'H, DFR, UFGT, and ANS) were obtained from the clones. The genes that are not considered to be involved in flavonoid biosynthesis so far (SCPL and DHQ) were also detected with high frequencies. We will discuss the role of these genes for condensed tannin accumulation in persimmon fruit.

\section{Poster Session 17-Ornamental Plant Breeding 2}

28 July 2006, 1:15-2:00 p.m.

\section{(239) Evaluation of Self-compatibility in Clethra alnifolia}

Sandra M. Reed*

USDA-ARS, Floral and Nursery Plants Research Unit, McMinnville, TN, 37110

Clethra alnifolia, which is commonly known as summersweet, is an attractive deciduous shrub that produces fragrant flower in mid-summer. Breeding efforts are hampered by a lack of information on the reproductive behavior of this native species. The objective of this study was to evaluate self-compatibility in $C$. alnifolia. Pollen germination and pollen tube growth in styles were examined following self- and cross-pollinations using fluorescence microscopy. Seed set and germination were compared following self- and cross-pollinations. While self-pollen tubes appeared to grow slightly slower than cross-pollen tubes, there was no indication of a self-incompatibility system acting at the stigmatic or stylar level in C. alnifolia. Self-pollinations of 'Hummingbird' and 'Ruby Spice' produced fewer seeds than did cross-pollinations of these cultivars. Germination of all seed obtained from this study was too poor to allow a comparison of germination rates of the self- and cross-pollinated seed. However, because a few self-progeny were obtained, emasculation is recommended when making controlled pollinations. The presence of a late-acting self-incompatibility system or early acting inbreeding depression was proposed as being responsible for the lower seed set following self-pollination.

\section{(240) Cytological Analyses of $\mathrm{BC}_{1}$ Hybrids Derived from IMR 2n Gamete of Interspecific Hybrid Between $L$. auratum and L. henryi}

Mi-Young Chung ${ }^{1}$, Jae-Dong Chung ${ }^{1}$, Jaap Van Tuyl ${ }^{2}$,

Ki-Byung Lim*1

${ }^{1}$ Kyungpook National University, Department of Horticulture, Daegu, 702-701, Republic of Korea; ${ }^{2}$ Plant Research International, Biodiversity \& Breeding, Wageningen, The Netherlands

Intergenomic $\mathrm{F}_{1}$ hybrids between L. auratum and L. henryi were made and backcrossed to Oriental hybrids to produce $\mathrm{BC}_{1}$ progenies. The $\mathrm{F}_{1}$ intergenomic hybrids produced a relevant frequency of 2 -gamete and fertile pollen. Analyses of pollen size, viability, and germination ability were checked under microscopic observation. GISH analysis confirmed that $F_{1}$ intergenomic hybrids possess a set of chromosomes from both parents and showed an intermediate morphological phenotype. Twenty $\mathrm{BC}_{1}$ plants were generated by in vitro embryo rescue technique, and analyzed for genome composition by GISH. All plants were triploid, 
showing 12 from female parent $(2 \times$ Oriental) and 24 from male $(2 \times$ $\mathrm{F}_{1}$ hybrid). Based on the GISH analyses, $19 \mathrm{BC}_{1}$ plants were derived from FDR 2n-gamete and only one plant was derived from IMR 2ngamete of $\mathrm{F}_{1}$ hybrid. The genome composition of $19 \mathrm{BC}_{1}$ plants from FDR 2n-gamete possess 12 Orientals +12 L. auratum +12 L. henryi chromosomes with some extent of homoeologous recombination between $L$. auratum and $L$. henryi. However, one plant from IMR $2 n$-gamete origin contains an odd number of parental chromosomes from $\mathrm{F}_{1}$ hybrid, showing 12 Oriental +14 L. auratum +10 L. henryi chromosomes. In this case, two $L$. auratum chromosomes recombinant with $L$. henryi chromosome segments were added and $L$. henryi counterpart chromosomes were deleted, respectively.

\section{(241) Susceptibility of Catalpa, Chilopsis, and Hybrids to Powdery Mildew and Catalpa Sphinx Larvae}

Richard T. Olsen*, Thomas G. Ranney

North Carolina State University, Horticultural Science, Mount. Hort. Crops Res. and Ext. Center, Fletcher, NC, 28732-9244;

A diverse collection of germplasm representing 24 taxa from Catalpa sect. Catalpa Paclt and sect. Macrocatalpa Grisebach, Chilopsis D.Don, and $\times$ Chitalpa Elias \& Wisura were screened for susceptibility to powdery mildew (PM), Erysiphe elevata (Burr.) U. Braun \& S. Takam, and Catalpa sphinx larvae(CSL), Ceratomia catalpae (Boisduval), feeding. The PM screening was conducted in 2004-05, with plants grown in a lathhouse ( $50 \%$ shade) in 2004 , and a gravel pad (100\% full sun) in 2005. The PM causal organism was identified as Erysiphe elevata both years. Disease incidence and severity were recorded at 2 -week intervals for 6 weeks and used to calculate area under the disease progress curves (AUDPC) for each taxon for each year. North American Catalpa in sect. Catalpa, Chilopsis, and $\times$ Chitalpa taxa were all moderate to highly susceptible to PM. Chinese Catalpa in sect. Catalpa and West Indian species in sect. Macrocatalpa were resistant to PM. Hybrids between North American and Chinese Catalpa in sect. Catalpa varied in susceptibility, indicating inheritance of partial resistance to PM. A no-choice feeding study conducted with CSL in 2005 found no differences in survival or growth of larvae reared on taxa from Chilopsis, $\times$ Chitalpa, or either section of Catalpa. Future breeding of $\times$ Chitalpa can utilize two different sources of PM resistance, but a source for resistance to CSL was not identified.

\section{(242) Callus Induction and Regeneration in Hydrangea macrophylla (Thunb.) Ser.}

Erik C. Fargo*, Jeffrey A. Adkins

University of Rhode Island, Plant Sciences, Kingston, RI, 02881

Development of a reliable method for Hydrangea macrophylla (Thunb.) Ser. organogenesis is critical for developing an in-vitro mutagenesis protocol. Container-grown (11.8 L) H. macrophylla 'Nikko Blue' plants were maintained in a controlled environment greenhouse, with supplemental lighting (1600 HR to $2400 \mathrm{HR}$ mercury vapor lamp), fertilized with $65 \mathrm{~g}$ Nutricote total (18N-2.6P-6.6K, Agrivert, Inc., New York, N.Y.) and hand-watered. To reduce fungal contamination, stock plants were sprayed to run-off biweekly with Alliette WDG (375 $\mathrm{mg} \cdot \mathrm{L}^{-1}$, aluminum tris), Bayleton $\left(250 \mathrm{mg} \cdot \mathrm{L}^{-1}\right.$, triadimefon), and Heritage (25 $\mathrm{mg} \cdot \mathrm{L}^{-1}$, azoxystrobin). Leaf explants were sterilized with $0 \%, 10 \%, 15 \%$, or $20 \%$ bleach $(5.25 \%$ sodium hypochlorite) (by volume) for 10 or $15 \mathrm{~min}$, and stem explants were sterilized with $0 \%$, $10 \%, 25 \%$, or $50 \%$ bleach $(5.25 \%$ sodium hypochlorite) for 10 or 15 min. About $97 \%$ of fungal contaminates were eliminated from leaf and stem explants when treated with $10 \%$ bleach for either 10 or $15 \mathrm{~min}$. Leaves were plated on Gamborg B5 media at pH 5.7 containing $0,2.5$, 5 , or $10 \mu \mathrm{M} 2,4-\mathrm{D}$ and $0,0.25,0.5$, or $1.0 \mu \mathrm{M}$ BAP and placed in a controlled environment growth room under a 14-h photoperiod or in a dark growth chamber. Callogenesis followed by root organogenesis was observed on explants treated with a variety of concentrations and combinations of 2,4-D and BAP. Strongest callogenesis was observed on media supplemented with $10 \mu \mathrm{M} 2,4-\mathrm{D}$. A greater callus concentration was observed along the edges of dark cultured leaf discs. Indirect root induction was greatest on $10 \mu \mathrm{M} 2,4-\mathrm{D}$.

\section{(243) Release of New Scaevola sericea Cultivars}

\section{James McConnell*}

University of Guam, College of Agriculture and Life Sciences/Agricultural Experiment Station, Mangilao, GU, 96923

Scaevola sericea is a plant native to Guam. The normal flower has petals that are usually white with slight, thin, magenta bands. The seeds for these plants were collected from a parent plant with dark magenta flowers growing in the wild. Plans are to self the parent plant to observe the variation in the seedling population. Four selections of $S$. serica were made and are being propagated for public release. Three of these selections have white petals with broad magenta bands or spots on the flower petals, in contrast to the usual white flower. One selection has a floral fragrance.

\section{(244) Genetic Breeding of Gladiolus hybridus in Romania}

\section{Maria Cantor*}

University of Agricultural Sciences and Medicine Veterinary Cluj-Napoca, Floriculture, Manastur, No. 3-5, Cluj-Napoca, Cluj, 400372, Romania

Gladiolus is one of the most popular flower crops grown in Romania. The breeding program at the University of Agricultural Sciences and Veterinary Medicine Cluj-Napoca of this species has been especially focused on the improvement of main characteristics, such as color, number and form of florets, plant height, multiplication capacity, diseases resistance, etc. A program for genetic breeding of gladiolus varieties using different genitors (Romanian and foreign cultivars) was initiated. An intraspecific crossing between cultivars has been made followed by clonal selection and vegetative multiplication of the selections. In this paper, we show 15 new gladiolus selections, which were observed and analyzed in 2004-05. The selections obtained have a great uniformity of their morphological characteristics. These selections are more vigorous, producing greater number of florets with superior quality, have new colors of flower, and are distinguished by a long blooming time. The intraspecific variability of the above-mentioned characteristics was more than low, and rarely medium, high, or very high. These data suggest fair possibilities to choose the best selections that will be proposed for testing and homologation as new cultivars. The hybrids represent a step forward in combining high qualities in gladiolus. They will contribute to improving the assortment of gladiolus for cut flowers, landscape, or as genetic material, which can be used for new crossing in order to obtain new cultivars. Scientifically, a series of findings appeared considering the combining capacity of genitors, transmission of some useful qualities, and other aspects that contribute to improve of the new varieties.

\section{(245) Oryzalin Use on Buddleja to Facilitate Interspecific Hybridization}

Bruce L. Dunn*, Jon T. Lindstrom

University of Arkansas, Horticulture, Fayetteville, AR, 72701

Ploidy level and fertility status are often the two biggest barriers a breeder must overcome when trying to incorporate novel characteristics among related taxa. This study was aimed at developing an efficient chromosome doubling method for Buddleja L., commonly known as butterfly bush, with the goal of equalizing the ploidy level and restoring the fertility of a diploid $(2 n=38) F_{1}$ interspecific hybrid that has a unique orange color but happens to be sterile. This method would ease the crossing of the hybrid to the tetraploid $(2 n=76)$ B. davidii Franch. cultivars commonly found in the industry. An antimitotic treatment of oryzalin was tested on 02-25-142 (B. madagascarensis Lam. $\times$ B. crispa Benth.) in vitro using nodal sections. A factorial of varying concentrations $[3,5$, and $7 \mu \mathrm{M}$ (micromolar)] by different exposure times $(1,2$, 
and 3 day) plus controls was set up. Oryzalin appeared to be an efficient agent for chromosome doubling in Buddleja. Significant differences in the number of polyploids were not seen between chemical concentrations and exposure times. However, higher chemical concentrations and exposure times did have a significant effect on the number of nodes that survived tissue culture. Increased leaf size and color, stem thickness, shortened internode length, and upright growth habit were all good early phenotypic indicators of polyploidy induction as later confirmed by flow cytometry. Significant increases in pollen viability accompanied chromosome doubling as crosses between 02-25-142 $\times$ B. davidii cultivars produced viable seedlings.

\section{Poster Session 18-Ornamental/Landscape andTurf 2}

28 July 2006, 1:15-2:00 p.m.

\section{(57) Growth and Phenology of Lagerstroemia Hybrids in South Mississippi}

Patricia R. Knight*, John M. Anderson, Wayne McLaurin, Christine Coker

Mississippi State University, Coastal Research and Extension Center, Biloxi, MS, 39532 Lagerstroemia indica $\times$ fauriei 'Tonto' and 'Sioux' were planted in Mar. 1995. All other cultivars were planted in Oct. 1985. Plants were planted into a Ruston sandy loam on a $12 \times 12 \mathrm{ft}(3.7 \times 3.7 \mathrm{~m})$ spacing. Trees were pruned to develop multiple trunks. Trees are pruned annually in winter to remove any limbs smaller than $0.6 \mathrm{~cm}$ in diameter. Pruning cuts are made $6-8$ in $(15.2-20.3 \mathrm{~cm})$ above prior cuts. Severe pruning is performed every 5 years. Trees were evaluated at 2 -week intervals during the flowering season to determine total length of flowering and duration of good to superior flowering. Growth indices (height + width + perpendicular width) $/ 3$ were recorded after plants were dormant. Total days of flowering and floral display $(0-5$ with 0 representing no flowers and 5 representing superior flowering) were rated. 'Muskogee' had the greatest growth index after the 2004 growing season. 'Seminole' had the least. However, 'Seminole' had the greatest number of flowering days. 'Biloxi' had the fewest flowering days. 'Tonto' had the most good to superior flowering days, while 'Tuskegee' and 'Muskogee' had the fewest. In 2005, 'Muskogee' again had the greatest growth index, while 'Sioux' had the least. 'Yuma' and 'Seminole' had the greatest number of flowering days, and 'Biloxi' again had the fewest. 'Tonto' again had the most good to superior flowering days, while 'Biloxi' and 'Acoma' had the fewest.

\section{(58) Evaluation of Select Perennial Ornamental Cultivars for Potential Roadside Beautification Application}

Rodulfo O. Pacumbaba, Jr.*, Catherine Sabota, Rhonda Britton

Alabama A\&M University, Plant and Soil Science, Normal, AL, 35762

Sixty-six perennial ornamental cultivars were established and then grown under low maintenance, intensive weed competition, and severe mowing conditions. These cultivars were evaluated for their potential application for roadside/median beautification. Experimental plots were cleared with Roundup ${ }^{\circledR}$ prior to planting. During the first 3 weeks of establishment, plants were irrigated as needed. Plants were grown for one season, then pruned back to simulate bush-hog mowing. Plants were grown under low maintenance and no weed control conditions for two growing seasons. Plants were evaluated each season for simulated bush-hog damage recovery potential, survivability under severe weed competition, height, and spread. Two-way analysis of variance with repeated measurements showed that height and spread variation had a significant interaction between plant cultivar and time of evaluation. Several Zephyranthes sp. cultivars performed poorly under severe weed competition and mowing damage resulting in a high mortality rate. Cultivars that did perform well for the 2-year evaluation period include Lagerstroemia indica $\times$ fauriei 'Natchez,' Lagerstroemia indica $\times$ fauriei 'Muskogee,' Vitex agnus-castus 'Shoal Creek,' and Myrica cerifera. Rosa $\times$ 'Chuckles' and Rosa $\times$ 'Knock Out' cultivars, with their popular showy appearance, performed moderately well and showed high potential for roadside/median beautification applications.

\section{(59) Encore Azalea Selections for the Mid South}

Mark Windham*1, Robert Trigiano ${ }^{1}$, Donna Fare ${ }^{2}$, Cecil Pounders 3 , Lisa Vito ${ }^{1}$, James Mynes ${ }^{1}$

${ }^{1}$ University of Tennessee, Entomology and Plant Pathology, Knoxville, TN, 37996-4560; ${ }^{2}$ U.S. National Arboretum, USDA ARS,McMinnville, TN, 37110; ${ }^{3}$ Southern Horticultural Laboratory, USDA ARS, Poplarville, MS, 39470

Encore Azaleas ${ }^{\circledR}$ have become very popular in the Deep South due to multiple bloom cycles. All cultivars are rated for plant hardiness zone 7 and have also performed well in zone 8 . The ability of Encore Azalea ${ }^{\circledR}$ cultivars to perform well in the Mid South (zones 6a and 6b) is unknown. A 3-year study was undertaken to determine the performance of 21 cultivars of Encore Azaleas ${ }^{\circledR}$ in multiple locations in zones $6 \mathrm{a}$ and $6 \mathrm{~b}$. After one winter, several cultivars have had multiple bloom cycles in zone $6 \mathrm{a}$ and $6 \mathrm{~b}$ and suffered little or no freeze damage. These cultivars were Autumn Amethyst ${ }^{\mathrm{TM}}$, Autumn Bravo ${ }^{\mathrm{TM}}$, Autumn Carnival ${ }^{\mathrm{TM}}$, Autumn Chiffon ${ }^{\mathrm{TM}}$, Autumn Coral ${ }^{\mathrm{TM}}$, Autumn Monarch ${ }^{\mathrm{TM}}$, Autumn Rouge $^{\mathrm{TM}}$, and Autumn Ruby ${ }^{\mathrm{TM}}$. Autumn Amethyst ${ }^{\mathrm{TM}}$ had the most consistent bloom cycles in both spring and fall cycles of all cultivars tested. Superior winter hardiness of Autumn Amethyst $\mathrm{t}^{\mathrm{TM}}$ may be due to known winter hardiness of its female parent - 'Karen's' (Hindodegiri $\times$ Rhododendron yeodensis var. poukhanese).

\section{(60) Establishment and Growth of Ginger Lilies Under a Sustainable Agroforestry Production System with Moringa in the U.S. Virgin Islands}

Ramon Arancibia*1, Manuel Palada ${ }^{1}$, Mack Thetford ${ }^{2}$, Shibu Jose ${ }^{2}$ ${ }^{1}$ University of the Virgin Islands, Agricultural Experiment Station, Kingshill, VI, 00850; ${ }^{2}$ University of Florida, West Florida Research and Education Center, Milton, FL, 32583

Specialty cut flowers may be suited to sustainable production system in the tropics and an agroforestry approach was developed to add a commercial value to unused forest areas. Ginger lily (Alpinia purpurata), a specialty tropical cut flower, was planted under a sustainable alley cropping system with moringa (Moringa oleifera), to evaluate the biophysical interactions between system components. Moringa trees were planted in rows $5 \mathrm{~m}$ apart and were 5 years old at the time ginger lilies were planted on 1 June 2005. Two rows of ginger lilies spaced $0.6 \mathrm{~m}$ in row and $1.7 \mathrm{~m}$ between rows were planted on a 1 foot-high bed between moringa rows when trees were about $6 \mathrm{~m}$ tall. Alley plot length was $10 \mathrm{~m}$. After a month, plant establishment was $96 \%$. In July, the moringa trees were pruned down to $1.5 \mathrm{~m}$ and the biomass (foliage) was used as green manure. Ginger lilies were also mulched with straw. Plots were gradually shaded as moringa shoots developed reducing the photosynthetic photon flux to $40 \%$ of direct sun light in September and to 15\% four months later. Six months after planting, height and number of shoots in shaded ginger lilies were $58 \%$ and $30 \%$ of plants in full sun, respectively. Ginger lilies began to flower 5 months after planting in the sunny plots, but no flowers were produced after 7 months in the shady plots. Since soil and tissue nitrate- $\mathrm{N}$ was the same between treatments, moringa biomass appears to be insufficient to increase the nutrient status of the crop. In addition, the low light intensity in the alley appears to be suboptimal for growth and production of ginger lilies.

\section{Poster Session 19-Postharvest 2}

\section{July 2006, 1:15-2:00 p.m.}

\section{(187) The Use of Essential Oils as Natural Preservatives for Berry Fruits}

Chien Wang*

U.S. Department of Agriculture, Produce Quality and Safety Laboratory, Beltsville, MD, 20705-2350

Berry fruits such as blackberries (Rubus sp.) and blueberries (Vaccinium 
corymbosum L.) are highly perishable after harvest. In addition to rapid deterioration in quality, they are also very susceptible to microbial invasion. The shelf life of these berries is usually terminated by decay. Several natural antimicrobial compounds derived from essential oils of plants were studied for their efficacies in inhibiting decay and extending shelf life of berry fruits. The severity of decay in blackberries and blueberries stored at $10{ }^{\circ} \mathrm{C}$ was significantly reduced by treatment with thymol. Treatments with menthol or eugenol also suppressed the fungal growth, but to a lesser extent. All of these three natural antimicrobial compounds extended shelf life of blackberries and blueberries as compared to the control. Berries treated with thymol, menthol, or eugenol also maintained better fruit quality with higher levels of sugars, organic acids, and oxygen radical absorbance capacity than the untreated fruits. The effects of these natural antimicrobial agents on the quality and shelf life of other fruits will be investigated.

\section{(188) Effects of Storage Temperatures on the Antioxidant Capacity and Anthocyanin Contents of Black Raspberries}

Artemio Z. Tulio, Jr. ${ }^{1}$, Ann M. Chanon ${ }^{1}$, Nithya Janakiraman ${ }^{2}$, Mustafa Ozgen ${ }^{3}$, Gary D. Stoner ${ }^{4}$, R. Neil Reese ${ }^{5}$,

A. Raymond Miller ${ }^{1}$, Joseph C. Scheerens*1

${ }^{1}$ The Ohio State University, Horticulture and Crop Science, Wooster, OH, 44691; ${ }^{2}$ The Ohio State University, School of Environment and Natural Resources, Wooster, OH, 44691; ${ }^{3}$ Gaziosmanpasa University, Horticulture, Tasliciftlik, Tokat, 60240, Turkey; ${ }^{4}$ The Ohio State University, James Cancer Hospital and Solove Research Institute, Columbus, OH, 44691; ${ }^{5}$ South Dakota State University, Biology and Microbiology, Brookings, SD, 57007

This study was conducted to determine the effects of postharvest storage temperatures on the antioxidant capacity, anthocyanin compounds, phenolic constituents, and physico-chemical properties of black raspberries. Fresh 'MacBlack' berries were stored at $4,12,20$, and $28^{\circ} \mathrm{C}$ for up to $11,6,4$, and 3 days, respectively. Results showed that higher storage temperatures promoted tissue deterioration (cellular leakage), fungal growth, and moisture loss. The levels of the two major anthocyanins, cyanidin 3-rutinoside and cyanidin 3-xylosylrutinoside, increased by up to 2.7- and 1.9-fold, respectively, with increasing storage temperatures. The antioxidant capacity of berries, as measured by FRAP and ABTS assays, increased by up to 1.5- and 1.4-fold, respectively, which was accompanied by increases in soluble solids, total sugars, total phenolics, and total anthocyanin contents. Our findings indicate that postharvest storage at higher temperatures increases the level of bioactive compounds and antioxidant capacity in black raspberries, but this increase may be due in part to moisture loss and sugar metabolism. Storage at $4{ }^{\circ} \mathrm{C}$ maintained the level of bioactive compounds and antioxidant capacity present at harvest and prolonged the effective shelf life of the product. Further studies of black raspberry bioactive components as influenced by postharvest conditions and processing procedures (e.g., IQF, freeze-drying, air-drying) are warranted.

\section{(189) Cultivar and Maturity Effects on Fruit Quality and Antioxidant Properties in Blackberry}

Floyd M. Woods*1, William A. Dozier ${ }^{1}$, Robert C. Ebel ${ }^{1}$, Raymond Thomas $^{1}$, Monte Nesbitt ${ }^{1}$, Bryan S. Wilkins ${ }^{1}$, David G. Himelrick ${ }^{2}$

${ }^{1}$ Auburn University, Horticulture, Auburn, AL, 36849-5408; ${ }^{2}$ Louisiana State University, Horticulture, Baton Rouge, LA, 70803-2120

Changes in fruit quality attributes and antioxidative properties from six cultivars of thornless blackberries (Rubus sp.) ('Apache', 'Arapaho', 'Chester', 'Loch Ness', 'Navaho', and 'Triple Crown') during four different ripening stages (red, mottled, shiny-black, and dull-black) were determined under Alabama growing conditions. Berry fruit samples were evaluated for $\mathrm{pH}$, titratable acidity, total soluble solids, TSS/TA ratio, soluble sugars, vitamin C (reduced, oxidized and total), and antioxidant capacity (measured as trolox equivalent antioxidant capacity, TEAC). Significant variation among cultivars were noted in fruit quality attributes and antioxidative properties, which were influenced by maturity at harvest. An increase in fruit $\mathrm{pH}$ concomitant with a decline in titratable acidity (TA) was observed during ripening for all cultivars. Total soluble solids (TSS) values increased from $5.7 \%$ to $11.6 \%$, with associated TSS/TA ratio values ranging from 11.92 to 63.56 in ripening fruit. Highest reducing and total sugar content were contained in dull-black fruit. Vitamin C content either declined or remained unchanged with ripening, and the pattern was dependent on cultivar, maturity at harvest and form determined. In general, antioxidant activity declined between red and dull-black ripening stages. The results suggest that the TSS/TA ratio may provide the best maturity index in determining optimal eating quality and antioxidant capacity in terms of TEAC value the best indicator of optimal nutritional quality as influenced by maturity at harvest.

\section{(190) Sensory Quality and Postharvest Performance of Southern Highbush Blueberry Cultivars Grown in Southern California}

Elizabeth Mitcham*1, William Biasi ${ }^{1}$, Mark Gaskell², Ben Faber ${ }^{3}$, Ramiro Lobo ${ }^{4}$

${ }^{1}$ University of California, Plant Sciences, Davis, CA, 95616; ${ }^{2}$ University of California, UCCE Santa Maria, Santa Maria, CA, 93455; ${ }^{3}$ University of California, UCCE Ventura County, Ventura, CA, 93003-5401; ${ }^{4}$ University of California, UCCE San Diego County, San Diego, CA, 92123-1219

Blueberry fruit were harvested at commercial maturity from variety trials and shipped overnight to UC Davis. Fruit quality was evaluated upon receipt and after 6 and 20 days of cold storage at $0.5{ }^{\circ} \mathrm{C}$ in air shelf life. Firmness, external color, soluble solids, and titratable acidity were measured. Sensory evaluations were conducted by trained tasters to rate the blueberries for crispness, mealiness, sweetness, tartness, blueberry flavor, and off-flavors at harvest and again after 21 days of storage. Many of the blueberries increased in firmness during cold storage. Firmness at harvest tended to be softer in 'Santa Fe' and 'Jewel' and firmer in 'Star'. Sensory data also found 'Sharpblue' and 'Southmoon' to be more firm; however the objective measurements did not agree. Overall, 'Saphire' was low in sugars and acids, and 'Jewell' and 'Star' were high in acids. 'Misty' and 'Sharpblue' were consistently high in sugars and acids. Overall objective fruit quality ratings were highest for 'Misty', 'Sharpblue', and 'Southmoon', and lowest for 'Santa Fe'. Blueberry flavor was rated highest in 'Jewell', 'Star', and 'Sharpblue', and lowest in 'Santa Fe', 'Saphire', 'Misty', and 'Emerald'. These data indicate that blueberry flavor may be closely tied to acid content, as most of the high-flavor varieties had high acid and many of the low-flavor varieties had low acid. Over 3 years, the varieties consistently rated highest for overall objective quality were 'Misty' and 'Southmoon'. 'Star' was rated high for overall quality in 2 years and moderate in 1. 'Jewell', 'Star', and 'Sharpblue' were rated highest in flavor. 'Santa Fe' was ranked low in flavor quality in 2 out of 3 years. Selection of variety appears to have a strong influence on the sensory quality of the blueberries marketed.

\section{(191) UVC Light Treatment Reduces Decay of Blueberries}

Penelope Perkins-Veazie*, Julie Collins USDA-ARS, Lane, OK, 74555

Ultraviolet light treatment has been used successfully to reduce postharvest fungal decay in tomatoes, strawberries, peaches, and citrus, presumably through elevated spore death and/or increased phytoalexins. The purpose of this experiment was to determine the effectiveness of UVC light as a postharvest treatment for blueberries. 'Blue Crop' and 'Collins' fruit were harvested from a local grower in 2003 and 2004 and exposed to $0,1000,2000$, and 4000 Joules of light (354 nm) supplied from $30-\mathrm{W}$ germicidal bulbs. Fruit were held at $5{ }^{\circ} \mathrm{C}$ for 14 days. Application of 1000 to $2000 \mathrm{~J}$ UVC light reduced decay incidence by $10 \%$ compared to controls. The major decay organism was ripe rot (Collectotrichum gloeosporioides). Total phenolics, total anthocyanin, and ferric reducing absorbance power differed with variety, increased with storage, and were similar among light treatments. Firmness of non-decayed fruit was not affected by storage or treatment. Application of UVC light offers a means for reducing fungal decay in blueberries if applied at rates between 1000 and $4000 \mathrm{~J}$. 
(192) Effect of Controlled Atmosphere in Postharvest Life of 'Elliot' Blueberry

Luis Luchsinger, Alvaro Villalobos, Antonio Lizana*

Fac. Cien. Agr. University of Chile, CEPOC Postharvest Study Center, Santa Rosa 11.315 (La Pintana), Santiago, Chile

Postharvest response to high $\mathrm{CO}_{2}$ controlled atmosphere (CA) was studied in the blueberry (Vaccinium corymbosum L.) cultivar Elliot. Fruit was stored at $0{ }^{\circ} \mathrm{C}, 90 \%$ relative humidity and $15 \%, 18 \%$, and $21 \%$ of $\mathrm{CO}_{2}$ and $5 \%$ of $\mathrm{O}_{2}$ and in air $\left(0.03 \% \mathrm{CO}_{2}\right.$ and $\left.21 \% \mathrm{O}_{2}\right)$. Evaluations were performed after 30 and 60 days of storage and an aditional period of 3 and 6 days at $10^{\circ} \mathrm{C}$ (ripening period). Parameters meassured were: color (lightness, hue, and chroma), firmness, soluble solids (SS), titrable acidity (TA), SS/TA ratio, $\mathrm{pH}$, weight loss, decay, physiological disorders, and appearance. The CA caused a positive effect, preserving the quality of the fruit in storage, by decreasing the respiratory rate and decay incidence. The $15 \% \mathrm{CO}_{2}$ controlled atmosphere presented the best firmness and lowest decay. Acceptable conditions of quality were kept for 60 days of storage.

\section{(193) Effect of Pectin Oligomers on Strawberry Fruit Decay and Ethylene Production}

Elizabeth Baldwin*, Jan Narciso, Randy Cameron, Anne Plotto USDA/ARS, Citrus \& Subtropical Products Laboratory, Winter Haven, FL, 33881

Strawberry fruit were harvested on three different dates from the Strawberry Association plot (cv. Festival), a commercial farm (cv. Camino Real), and at the University of Florida Gulf Coast Research and Education Center (cv. Sweet Charlie), in central Florida in 2005 and 2006. Fruit were transported to the USCSPL in Winter Haven, Fla., sorted, dipped for $10 \mathrm{~s}$ in treatment solutions, drained and stored in commercial clam-shells at 15 to $19^{\circ} \mathrm{C}$. Percentage of decay (number of fruit with lesions) was monitored during storage. There were 10 fruit per replicate clamshell, and three to four replicates per treatment for each harvest. Treatments included three size classes of galacturonic acid (GA) oligomers with a degree of polymerization (DP) ranging from $1-13,8-24$, and $22-46$ and undigested polygalacturonic acid at $0.2 \%$ in $50 \mathrm{mmol} \mathrm{LiOAC}, \mathrm{LiOAC} / \mathrm{NaOAC}$, with $22 \% \mathrm{ETOH}$, or KOAC buffer (all buffers at $\mathrm{pH} \approx 4.4$ ), prepared by enzymatic digestion followed by differential $\mathrm{pH}$ and alcohol precipitation. The main pathogens found on these fruit were Rhizopus stolonifer and Botrytis cinera at $1 \times 10^{5}$ $\mathrm{cfu} / \mathrm{g}$ fruit in 2005 and $5 \times 10^{7}$ in 2006 . The medium range oligomers (DP 8-24) reduced decay significantly compared to buffer alone or to the lower or higher DP GA oligomers, and elicited ethylene production. Oligomers in this pectin size class have previously been reported to elicit ethylene and plant defense responses in plant tissues.

\section{Poster Session 20-}

Computer Applications in Horticultural Science

28 July 2006, 1:15-2:00 p.m.

\section{(316) Simulation Study of the Competitive Ability of} Erect, Semi-erect, and Prostrate Cowpea Genotypes

Guangyao Wang ${ }^{1}$, Milton E. McGiffen, Jr.*1, John L. Lindquist ${ }^{2}$, Jeff D. Ehlers ${ }^{1}$, Ivan Sartorato ${ }^{3}$

${ }^{1}$ University of California, Botany and Plant Sciences, Riverside, CA, 92521-0124; ${ }^{2}$ University of Nebraska, Department of Agronomy and Horticulture, Lincoln, Nebraska, 68583-0817; ${ }^{3}$ (IBAF)-CNR, Istituto di Biologia, Agroambientale e Forestale, Sezione di LegnaroAgripolis, via Romea 16, (Legnaro) Padova, Venetto, 35020, Italia

Ecophysiological simulation models provide a quantitative method to predict the effects of management practices, plant characteristics, and environmental factors on crop and weed growth and competition. The INTERCOM interplant competition model was parameterized, calibrated by monoculture data for three cowpea (Vigna unguiculata) genotypes that differed in growth habit, common sunflower (Helianthus annuus), and common purslane (Portulaca oleracea), and used to simulate competition of cowpea cover crops with sunflower or purslane. The simulation results were compared with observations from field competition experiments in 2003 and 2004. INTERCOM did not simulate biomass production and leaf area index (LAI) of cowpea and purslane well, probably due to a lack of published data on purslane physiology. INTERCOM simulated the competition of cowpea genotypes and sunflower accurately. The simulation model of cowpea and sunflower at two densities was used to study the effects of cowpea growth habits on final biomass production of cowpea and sunflower. The model suggested that the erect growth habit was more competitive than the semi-erect and prostrate growth habits when cowpea genotypes were grown with sunflower. Cowpea leaf area distribution was important to higher cowpea biomass production, while cowpea height growth was important to reduce sunflower biomass.

\section{(317) A New Seed Vigor Testing System for Ornamental Species using Computerized Imaging Technology}

Xiaolei Hu*, Miller McDonald, David Tay

The Ohio State University, Department of Horticulture and Crop Science, Columbus, $\mathrm{OH}, 43210$

During the past 2 decades, automated plug production in the flower seed industry has created important requirements by growers for highquality flower seeds. Using computerized imaging technology, a new seed vigor testing system, Seed Vigor Imaging System (SVIS), was developed at The Ohio State University. By analyzing the digital images of seedlings, it can detect and measure the length of hypocotyls and radicles separately, and then generate a value for the growth and uniformity each. This system provides a fast, labor-saving and objective approach to measuring seed quality. In this study, its capacity and correlation with field performance was studied and compared with other traditional tests, i.e. standard germination test, germinate rate, and accelerated aging test. Five species (dianthus, cleome, rudbeckia, salvia, and lettuce) were selected and their quality was tracked continuously by SVIS and other mentioned tests. It was found that stressed test (ageing test) was able to detect the quality deterioration earlier than others under ideal conditions, but SVIS could generate much more information, such as the growth, uniformity, and vigor level of the seed lot. Therefore, SVIS following 3-day ageing was developed and shown to be the most sensitive and comprehensive vigor test for those ornamental species mentioned above. Being fast and objective, this system will also benefit the global seed trade by providing a unique quality standard. In addition, it can also be of great usage to seed companies and germplasm centers worldwide for the routine quality track during shipment/storage and inventory management.

\section{(318) The Flat Bed Scanner as a Close-up Digital Camera}

James McConnell*

University of Guam, College of Agriculture and Life Sciences/Agricultural Experiment Station, Mangilao, 96923, Guam

A flat bed scanner can be used as a high-resolution digital camera with close-up capabitlities for photographing plant material such as leaves, flowers, and plant pests. The scanner is very useful as a diagnostic and instructional tool that is more portable and less expensive than a camera and dissecting microscope. The quality of the images can be very good and can be enhanced in post-production using image editing software. The main disadvantage is the shallow depth of field, which requires the object be on a single plane.

\section{(319) Addtional Features Possible with Electronic Publications}

James McConnell*

University of Guam, College of Agriculture and Life Sciences/Agricultural Experiment Station, Mangilao, 96923, Guam

An electronic document does not have to be limited to text and static 
images. Electronic publications greatly expand the potential of types of images that can be included compared to print media. With increased ease of accessing the internet and increased bandwidth availability, individuals have less limitations for downloading the enhanced documents. These documents include much more than color images. Options such as hypertext links, interactive graphics, movies, presentations, and audio are discussed.

\section{(320) Photographic and Post-processing Techniques for Horticultural Images}

James McConnell*

University of Guam, College of Agriculture and Life Sciences/Agricultural Experiment Station, Mangilao, GU, 96923

Numerous shooting and post-production techniques can be used to improve the quality of images used in horticultural publications. Certain lenses, lens attachments, and camera accessories are useful for enabling greater success in photographing plants. Small diffusers and reflectors allow the shooting of close-ups in the field, even when the sun is directly overhead. Shift lenses can be used to photograph trees at a closer distance without the extreme distortion of wide focal length lenses. Stitching of multiple images to produce panoramic shots can produce images with increased resolution, less distortion, and without the need for a wide-angle lens. Experiences with digital asset management management and post-production workflows are also presented.

\section{(321) Development of a GIS-based Model for Predicting Sweetpotato Weevil Infestation Risk in Louisiana: Progress, Problems, and Prospects}

Arthur Villordon*1, Craig Roussel ${ }^{2}$, Tad Hardy ${ }^{2}$

${ }^{1}$ LSU AgCenter, Sweet Potato Research Station, Chase, LA, 71203; ${ }^{2}$ Louisiana Department of Agriculture and Forestry, Horticulture and Quarantine Programs

The sweetpotato weevil [SPW, Cylas formicarius (Fabricius)] is an important economic pest in "pink-tagged" or SPW-infested areas of Louisiana. From time to time, sweetpotato weevils are detected in "green-tagged" or SPW-free locations. When sweetpotato weevils are detected in "green'tagged" areas, the produce is quarantined and may not be shipped to locations that do not allow "pink-tagged" sweetpotatoes. As part of the statewide SPW monitoring program, the Louisiana Department of Agriculture and Forestry (LDAF) conducts a statewide pheromone-based trapping program to monitor SPW presence in beds and fields. We used SPW presence-absence data with a GIS-based logistic regression modeling tool to assess the feasibility of developing a model for predicting SPW risk in sweetpotato beds. Using pheromone trap data from 2001-03, we performed stepwise logistic regression experiments to assess the role of various weather variables (daily mean maximum and minimum temperature, rainfall) in the occurrence of SPW in beds. Our modeling experiments showed a strong relationship of mean daily minimum temperature during the winter months with SPW occurrence in beds. In particular, a logistic regression equation developed from 2003 trap data and mean April daily minimum temperature created a spatially accurate map of SPW risk for 2002. However, the same model did not accurately predict the 2001 SPW risk. These results indicate that additional variables are needed to improve the predictive ability of the model. Spatial risk mapping can be a potentially useful tool for decision makers in choosing between risk-averse and -prone decisions.

\section{(322) Development of a Web-accessible Germplasm Collection Database Using Public Domain Software Tools}

Arthur Villordon*1, Wambui Njuguna ${ }^{2}$, Simon Gichuki ${ }^{3}$, Philip Ndolo $^{4}$, Heneriko Kulembeka ${ }^{5}$, Simon Jeremiah ${ }^{5}$, Don LaBonte ${ }^{6}$, Bernard Yada ${ }^{7}$, Phinehas Tukamuhabwa ${ }^{7}$, Robert Mwanga $^{8}$

${ }^{1}$ LSUAgCenter, Sweet Potato Research Station, Chase, LA, 71324; ${ }^{2}$ Oregon State University, Department of Horticulture; ${ }^{3}$ Kenya Agricultural Research Institute, Biotechnology Centre,
Kenya; ${ }^{4} \mathrm{MAF}$ Department of Research and Development, ARI-Ukiriguru, Kenya; ${ }^{5} \mathrm{MAF}$ Department of Research and Development, ARI-Ukiriguru, Tanzania; ${ }^{6}$ Louisiana State University, Department of Horticulture; ${ }^{7}$ Makerere University, Department of Crop Science, Uganda; ${ }^{8}$ Namulonge Aric. \& Animal Production Res. Institute, NARO, Uganda

Web-based information delivers real-time or near-real-time data to clientele and other stakeholders. Although proprietary methods are available for interactively searching and updating databases through web interfaces, these methods generally require varying costs to maintain licensing agreements. The availability of publicly available software that require minimal or flexible licensing costs provide a cost-effective alternative to institutions that are considering access to databases via a web-accessible interface. For example, if a current web server is already configured to support hypertext preprocessor (PHP) scripts and MySQL databases, all that needs to be installed is a form script to allow the searching, inserting, and deleting of records. We describe procedures, software, and other applications that we used to develop a publicly accessible web interface to an experimental database of representative sweetpotato accessions in Kenya. The web address of this database is http://www.viazivitamu.org. This site also contains links to sweetpotato collection sites in Kenya, Tanzania, and Uganda graphically shown using a public domain GIS viewer. This demonstrates that public domain web-based tools can be configured not only to support collaborative activities among researchers in various locations, but also to provide relevant data to clients and other stakeholders.

\section{(0) A Website of Horticulturally Important Plants on the University of Hawaii Campus}

Kent D. Kobayashi*, Andrew J. Kaufman, Allison A. Ohama

University of Hawaii at Manoa, Tropical Plant \& Soil Sciences, Honolulu, HI, 96822-2279

The University of Hawaii at Manoa campus offers a rich diversity of plants for students, university personnel, and the public. Although providing botanical facts, a current university web site and an arboretum brochure about campus plants lack horticulturally related information. By highlighting the unique horticultural plants on campus, a web site would provide valuable information on the uses, care, and propagation of these plants. The purpose of this project was to develop a web site featuring horticulturally important plants on campus. The home page explains why plants are beneficial in interior spaces. Other sections of the web site include basic plant care, plant selection, plant names, and plant pictures. Basic plant care covers planting media, containers, watering, lighting, fertilizing, pruning, propagation, and pest control. Users can select plants using two criteria-lighting in the plant's desired location (low, medium, and high) and low plant maintenance. Information on a specific plant is accessed by common name, scientific name, or a plant's picture. Each plant's web page provides details on its background, care, and propagation. By emphasizing the important horticultural plants on campus, this web site helps students, university personnel, and the public select and grow plants for their dormitories, apartments, offices, and homes. In addition, users gain knowledge about the lush landscape environment on campus. Lastly, the web site enhances the learning experience of students in horticulture and botany courses, serves as a resource for $\mathrm{K}-12$ students for their visits to the campus to learn about tropical plants, and aids tourists in planning a more informative visit to campus to see the plants they learned about on the web site.

\section{Poster Session 21 -Vegetable Breeding 1}

28 July 2006, 1:15-2:00 p.m.

(246) Is High Carotenoid Content Enough? Oxygen Radical Absorbance Capacity (ORAC) As a Breeding Tool: A High Throughput Strategy and Methodology Validation

Jennifer L. Waters*, Stephen R. King

Texas A\&M University, Horticulture Sciences, College Station, TX, 77843

Carotenoids are important phytochemical components of our diet and 
have gained recent attention as important nutritive compounds found mainly in fruits and vegetables with red, orange, and yellow hues. Lycopene is often cited as being inversely correlated with the occurrence of various cancers, in lowering rates of cardiovascular disease, and improving other various other immune responses. Antioxidant activity, specifically oxidative radical quenching power, is the putative rationale for carotenoids' involvement in disease risk reduction. It is unlikely, however, that carotenoid content and antioxidant capacity are directly correlated in the whole food since there are other antioxidants present in watermelon, such as various free amino acids. A total measure of antioxidant potential may prove to be a useful tool for measuring watermelon nutritional value and implementing pursuant breeding goals. One assay that has gained recent popularity is the oxygen radical absorbance capacity (ORAC) assay. ORAC includes two assays that separate lipophylic and hydrophilic antioxidants. Currently, most ORAC protocols use isolated compounds or freeze-dried fruit or vegetable samples. Here, the application of a standard hexanetype extraction method, which is more amenable to whole food carotenoid-containing samples, was investigated as a candidate extraction method for the ORAC assay. Variants of this method as well as of the standard ORAC extraction were compared for extraction efficiency. Finally, ORAC values were correlated with carotenoid content and shown to hold a loose negative correlation. Possible reasons for this are considered and discussed.

\section{(247) Identification of Molecular Markers Associated with Carotenoid and Tocopherol Variability in Broccoli}

Kanta Kobira, Khalid Ibrahim*, Elizabeth Jefferey, John Juvik

University of Illinois, Department of Natural Resources and Environmental Sciences, Urbana, IL, 61801

Considerable epidemiological evidence exists on the association between consumption of antioxidant-rich vegetables and incidence of chronic diseases, including cancer and cardiovascular disease. Broccoli (Brassica oleracea L. sp. italica) florets are relatively abundant sources of antioxidants, and potentially amenable to genetic manipulation to enhance this vegetable's health-promoting properties. This investigation focuses on the identification of chromosomal segments in the nuclear genome of broccoli associated with antioxidant carotenoid and tocopherol variability. A broccoli $\mathrm{F}_{2: 3}$ population consisting of 163 families derived from a cross between two parents (VI-158 and BNC) and previously mapped with 62 polymorphic SSR and SRAP marker loci was evaluated for carotenoid and tocopherol concentration in floret tissue over two growing seasons. Significant differences were observed among $\mathrm{F}_{2: 3}$ family means for concentrations of lutein (10fold difference between the lowest and highest family), beta-carotene 17-fold), alpha-tocopherol (8-fold) and gamma-tocopherol (6-fold). On a concentration basis, beta-carotene, lutein, alpha-tocopherol, and gamma-tocopherol were the most abundant antioxidant forms in broccoli. Heritability estimates of primary phytochemicals ranged from 0.35 to $0.38,0.40$, and 0.44 for beta-carotene, alpha-tocopherol, gamma-tocopherol, and lutein, respectively. Composite interval mapping (CIM) identified two quantitative trait loci (QTL) associated with carotenoid variability on two linkage groups and five QTL associated with tocopherol variability on four linkage groups. The QTL identified in this study have potential for use in marker-assisted crop improvement programs to develop elite germplasm designed to promote health among the consuming public.

\section{(248) Does Harvesting Stage Affect Bulb Quality in Spring-sown Onions?}

Neel Kamal*, Christopher S. Cramer

New Mexico State University, Plant and Environmental Sciences, Las Cruces, New Mexico, 88003

Onions grown in New Mexico are currently harvested manually at $80 \%$ tops down (TD). Mechanical harvesting is a matter of urgency for growers in order to remain competitive and to reduce their cost and time. The objective of this study was to find the effect of different harvest stages on bulb quality. Twelve different onion cultivars were sown in Feb. 2004 in Las Cruces, N.M. The experiment was laid out in split-plot design with four harvest treatments based on physiological maturity-20\% TD, $80 \%$ TD, 1 week after $80 \%$ TD, and 2 weeks after $80 \%$ TD as whole plots, with cultivars as sub-plots. After curing, data on harvest date, bulb diameter, height, firmness, number of growing points, average center diameter, fleshy scale number, and scale thickness were collected. Maximum number of scales was observed when bulbs were harvested 2 weeks after $80 \%$ TD, while average scale thickness was greatest when bulbs were harvested 1 week after $80 \%$ TD. Significant treatment by cultivar interaction was observed for bulb firmness. Cultivars Cimarron, Sierra Blanca and NMSU 0452-2 produced firmer bulbs in all treatments, while NuMex Casper, NuMex Jose Fernandez and NuMex Centric produced firmer bulbs than others, only at $20 \%$ TD. Maximum bulb firmness was observed in NMSU 04-28 and NMSU 03-52-1 than others, when harvested 1 or 2 weeks after $80 \%$ TD. Overall, bulbs harvested 1 to 2 weeks after $80 \%$ TD exhibited firmer bulbs with more scales and greater scale thickness.

\section{(249) Partition Variability in Sweet Corn and Broccoli Carotenoid and Tocopherol Content}

Khalid Ibrahim*, John Juvik

University of Illinois, Natural Resources and Environmental Sciences, Urbana, IL, 61801

Vegetables are a rich source of dietary carotenoids and tocopherols, powerful antioxidants that have the capacity to protect cells against oxidative damage caused by free radical reactions. There is evidence for a negative correlation between the incidence of certain types of cancer, age-related macular degeneration, cataract development, and cardiovascular disease with increased carotenoid and tocopherol intake. Development of elite vegetable germplasm with enhanced levels of these phytochemicals will potentially promote health among the consuming public. To assess the feasibility for genetic improvement in phytochemical content, it is necessary to partition the phenotypic variability into its component sources (genotype, environment, and genotype by environment interaction). To provide data for comparison and partition of phenotypic variation, 41 sweet corn and 13 broccoli genotypes were grown and harvested in one location for 3 years and analyzed for phytochemical content by HPLC. The most abundant form of carotenoids and tocopherols were lutein and gamma-tocopherol in sweet corn and beta-carotene and alpha-tocopherol in broccoli. Analysis of variance showed that, in sweet corn, the differences among genotypes described most of the phenotypic variation $(76 \%$ for lutein, and $78 \%$ for gamma-tocopherol). Genotype by year interaction was a second significant factor, while variation affiliated with the year was found to be a minor component. In contrast, in broccoli, the three sources of variability contributed equally to describe the total phenotypic variation for beta-carotene and alpha-tocopherol. These results suggest that elite sweet corn and broccoli germplasm with improved carotenoid and tocopherol levels can be developed using conventional breeding protocols.

\section{(250) Monogalactosyl-diglyceride Contents in Sweetpotato Clones}

Howard F. Harrison*1, Joseph K. Peterson ${ }^{1}$, Maurice E. Snook ${ }^{2}$

${ }^{1}$ U.S. Vegetable Laboratory, UDSA/ARS, Charleston, SC, $29414 ;{ }^{2}$ Richard Russell Research Center, USDA/ARS, Athens, GA, 30601

Bioasssay-guided investigation of constituents possibly contributing to the allelopathic potential of sweetpotato led to the isolation of a nonpolar seed germination inhibitor in sweetpotato (Ipomoea batatas L.) roots. Mass spectral data supported by HPLC s pectroscopic analyses and data obtained from hydrolysis products revealed the presence of three monogalactosyl-diglycerides (MGDGs) (galactosyl-di-linoleneoyl glyceride, galactosyl-linoleneoyl-linoleoyl glyceride, and galactosyl-di-linoleoyl glyceride) in storage roots. The compounds inhibited proso millet germination, and at $100 \mathrm{ppm}$ 
inhibition was about $90 \%$. MGDG with fully saturated fatty acids (galactosyl-distearoyl glyceride) was not inhibitory in the bioassay. An efficient method for quantitation of individual MGDGs was developed, and the contents of each compound in the storage root tissues of 12 genetically diverse cultivars and breeding lines were determined. On a dry weight basis, total MGDG contents ranged between 107 and $452 \mu \mathrm{g} / \mathrm{g}$ in the periderm, 298 and $807 \mu \mathrm{g} / \mathrm{g}$ in the cortex, and 296 and $755 \mu \mathrm{g} / \mathrm{g}$ in the stele. Also, large differences in the ratios of the three compounds between clones and between tissues within a clone were noted. The differences between clones indicate that manipulating total content and ratios of MGDGs through plant breeding is feasible.

\section{(251) Screening Spring-seeded Onion Cultivars for Iris Yellow Spot Virus}

Parminder Singh Multani*, Christopher S. Cramer

New Mexico State University, Plant \& Environmental Sciences, Las Cruces, NM, 88003

Identification of resistant cultivars offers the best control for Iris yellow spot virus (IYSV), a new onion disease vectored by Thrips tabaci. In this study, 18 spring-seeded onion cultivars were screened for IYSV. Each alternate plot in the field was planted with infected bulbs from the previous year to serve as a source of virus inoculum and thrips. With increased thrips population and temperature over time, straw-colored, necrotic lesions typical to IYSV infection were observed on plant leaves. Plants were analyzed by enzyme linked immunosorbant assay to confirm the IYSV infection and determine the virus titer. Ten randomly selected plants from each plot were rated for IYSV symptoms on a scale of 1 to 9 , with 1 representing no symptomatic tissue and 9 representing more than $50 \%$ tissue damage. Starting 1 June, disease ratings were collected each week until 13 July. Nearly all cultivars showed similar disease symptoms when rated on 1 June. By 29 June, NMSU 03-52-1 exhibited some tolerance to IYSV as fewer symptoms were observed. By 13 July, NMSU 03-52-1 exhibited fewer disease symptoms than most of the other cultivars tested, while 'Caballero' showed the highest IYSV symptoms. All other cultivars showed low to high susceptibility for IYSV. The increase in disease severity was accompanied by a relative increase in the virus titer of plants over time. However, virus titer poorly correlated with the amount of disease symptoms in different cultivars. The most tolerant cultivar, NMSU 03-52-1, had higher virus titer than many susceptible cultivars but still performed well. Conversely, some cultivars with low virus titer were susceptible and developed more symptoms. This indicates a difference in the capabilities of different cultivars to resist IYSV.

\section{(252) Inheritance of Phytophthora Stem Blight, Root Rot, and Foliar Blight Resistance in Capsicum}

Ousmane Sy*, Paul W. Bosland

New Mexico State University, Plant \& Environment Science, Las Cruces, NM, 88003

The oomycete fungus Phytophthora capsici Leon. is known to be a limiting factor of chile pepper (Capsicum spp.) production around the world. The genetics of the resistance is becoming better understood due to the specific nature of the host-pathogen interaction; i.e., all plant organs are subject to infection. This study determined whether stem blight was the same disease syndrome as root rot or foliar blight. Stem cuttings of a segregating $F_{2}$ population and testcross progeny facilitated the ability to screen for two disease syndromes concurrently. When the three disease syndromes were compared separately, the $\mathrm{F}_{2}$ populations fit a $3 \mathrm{R}: 1 \mathrm{~S}$ ratio and the testcross progeny fit a $1 \mathrm{R}: 1 \mathrm{~S}$ ratio. When comparative studies were performed (stem vs. foliar and stem vs. root), the $\mathrm{F}_{2}$ populations fit a $9 \mathrm{R} / \mathrm{R}: 3 \mathrm{R} / \mathrm{S}: 3 \mathrm{~S} / \mathrm{R}: 1 \mathrm{~S} / \mathrm{S}$ ratio and the testcross fit a $1 \mathrm{R} / \mathrm{R}: 1 \mathrm{R} / \mathrm{S}: 1 \mathrm{~S} / \mathrm{R}: 1 \mathrm{~S} / \mathrm{S}$ ratio. These ratios are consistent of a single gene controlling the resistance of each system. Therefore, Phytophthora stem blight, root rot, and foliar blight are three separate disease syndromes.
Poster Session 22-Small Fruit

28 July 2006, 1:15-2:00 p.m.

\section{(112) Bird Control in Production Strawberries with}

\section{Falconry}

Oleg Daugovish*, Michi Yamomoto

University of California, UCCE, Ventura, CA, 93003

California leads national strawberry fruit production with annual value in Ventura County alone near $\$ 300$ million. Bird damage to fruit routinely accounts for 3-5\% losses and may exceed 50\% in some fields. Conventional bird control tools have limited or no effect on fruit damage and may contribute to noise pollution. A four-site study at Oxnard, Calif., from Jan. to Apr. 2005 (highest value fresh market season) showed that release of Peregrine, Saker, or Barbary falcons in combination with helium balloon launching (site 4) in response to fruit damage reduced fruit damage from $80-90 \%$ to $15-20 \%$ after 1 week. When fruit damage increased again $(>20 \%)$ a repeated 1-week daily program completely reduced fruit damage during the rest of the season. Falconry alone at site 2 (near man-made structures) for two consecutive days reduced fruit damage from $70-80 \%$ to $10-20 \%$, however, at site 3 , near giant reed, three weeks of daily releases did not eliminate the damage, but confined it to the strawberry beds adjacent to reed shelter (reducing overall damage from $100 \%$ to $25-50 \%$ ). High frequency of release is likely unfeasible and destruction of shelter habitat may be justified. Falconry alone before damage occurrence (site 1) seemed to prevent fruit damage; however, lack of birds and fruit damage before, during, and after releases made it difficult to draw conclusions about the success of the preventive program. In April, no fruit damage occurred even during bird presence suggesting the change in their diet. The study showed that seed-eating birds were the main pests at Oxnard, Calif., and that trained falcons can disperse them, thus, reducing fruit damage. The success of falconry was site-specific and depended on proximity of suitable habitat and availability of food sources for pest birds.

\section{(113) Winter-hardy Strawberries Produce without a Straw Mulch in a Severe Winter Environment}

Becky R. Hughes*1, Adam Dale ${ }^{2}$

${ }^{1}$ University of Guelph, New Liskeard Agricultural Research Station, New Liskeard, ON, P0J 1P0, Canada; ${ }^{2}$ University of Guelph, Department of Plant Agriculture, Simcoe, ON, N3Y 4N5, Canada

Four winter-hardy strawberry selections and three cultivars where planted in northern Ontario in 2003 in a split-split plot trial where half the rows were mulched and half were left uncovered for the winter. Within each split plot, half the rows were sprayed for tarnished plant bugs and half were not. Yield and tarnish plant bug damage data was collected for two picking years. Two selections maintained their yields in the unmulched plots compared to the mulched plots. Yield for one of these selections was higher in the unmulched plots the first picking year and equal to the mulched plots in the second year. The remaining cultivars and selections produced less when not mulched for the winter. Except for the two selections that maintained their yields in the unmulched plots, plots where straw was applied for the winter had less tarnish plant bug damage. When the plots were sprayed for tarnish plant bugs, damage was reduced for most but not all selections and cultivars.

\section{(114) Performance of Cranberry Varieties on an Upland Site in Michigan}

\section{Eric Hanson*1, Annemiek Schilder ${ }^{2}$}

${ }^{1}$ Michigan State University, Department of Horticulture, East Lansing, MI, 48824; ${ }^{2}$ Michigan State University, Department of Plant Pathology, East Lansing, MI, 48824

Twenty cranberry (Vaccinium macrocarpon) genotypes were evaluated for five seasons in an experimental upland planting in southwest 
Michigan. Beds were constructed on a silty clay loam soil by excavating to grade, and filled with 30 to $45 \mathrm{~cm}$ of sand. Four $2 \times 2-\mathrm{m}$ plots of each genotype were planted in 1996. Fruit were harvested with hand scoops from 2000 to 2005 . Yield per plot, average berry weight, and percent berries exhibiting decay were determined. Sound fruit were also stored at $2{ }^{\circ} \mathrm{C}$ for 4 to 8 weeks and sorted to determine the percentage of fruit developing decay in storage. Fungi were isolated and identified by morphological characteristics. Genotypes producing the highest average yields were 'Stevens', 'Ben Lear', \#35, 'LeMunyon', and 'Franklin'. Varieties with the highest average berry weight were 'Pilgrim', 'Stevens', 'Baines', 'Beckwith', 'Searles', and \#35. Genotypes with lower rot incidence at harvest were \#35, 'Early Black', and 'Foxboro Howes', whereas 'Howes' and \#35 developed the least rot during storage. Fungi commonly isolated from decaying fruit were Colletotrichum sp., Coleophoma empetri, Phomopsis vaccinii, Phyllosticta vaccinii, Fusicoccum putrefaciens, Botrytis cinerea, Pestalotia sp., and Allantophomopsis sp. Prevalence of specific fungi differed among cranberry genotypes.

\section{(115) Competition Between Vegetative and Reproductive Growth in Cranberry}

Justine E. Vanden Heuvel*, Carolyn J. DeMoranville

University of Massachusetts Amherst, Cranberry Station, E. Wareham, MA, 02538

Competition between fruit and upright growth in cranberry has not been previously studied, but negative correlations reported between upright length/dry weight and yield indicate that sink demand from vegetative tissues may reduce fruit production. 'Stevens', 'Howes', and 'Early Black' uprights and fruit were collected on either a weekly or bi-weekly basis through the growing seasons of 2002-04. The data indicated a shifting of resource allocation from leaf area and dry weight accumulation to fruit growth when about 1500 growing degree days (GDD, base $4.5^{\circ} \mathrm{C}$ ) had accumulated. Following the initial surge in fruit growth, leaf area and dry weight accumulation resumed at roughly 2300 GDD, resulting in a competition for resources with the developing fruit until after 3000 GDD. A lag phase in fruit diameter and dry weight accumulation was noted in some cultivars in some years, and may be partially due to the resumption of leaf growth. Roots, uprights, and fruit may all compete for resources during the hottest portion of the growing season.

\section{(116) Floral Competence of Primocane-fruiting Blackberries Prime-Jan ${ }^{\mathrm{TM}}$ and Prime-Jim ${ }^{\mathrm{TM}}$ Grown at Three Temperature Regimes}

Michele A. Stanton ${ }^{1}$, Joseph C. Scheerens*1, Richard C. Funt ${ }^{2}$, John R. Clark ${ }^{3}$

${ }^{1}$ The Ohio State University, Horticulture and Crop Science, Ohio Agricultural Research and Development Center Wooster, OH, 44691; ${ }^{2}$ The Ohio State University, Horticulture and Crop Science, Columbus, OH, 43210; ${ }^{3}$ University of Arkansas, Horticulture, Fayetteville, AR, 72701

We investigated the response of staminate and pistillate floral components of Prime-Jan ${ }^{\mathrm{TM}}$ and Prime-Jim ${ }^{\mathrm{TM}}$ primocane-fruiting blackberry (Rubus L. subgenus Rubus Watson) to three different growth chamber temperature regimes, $35.0 / 23.9{ }^{\circ} \mathrm{C}(\mathrm{HT}), 29.4 / 18.3{ }^{\circ} \mathrm{C}(\mathrm{MT})$, and $23.9 / 12.8^{\circ} \mathrm{C}(\mathrm{LT})$. Temperature was negatively related to flower size and morphological abnormalities in floral structures were evident in $41 \%$ and $98 \%$ of the MT- and HT-grown plants, respectively. The viability (stainability) of pollen from LT- and MT-grown Prime-Jan ${ }^{\mathrm{TM}}$ flowers exceeded $70 \%$; that of Prime-Jim ${ }^{\mathrm{TM}}$ pollen was significantly reduced $(<40 \%)$ by the MT regime. Pollen in-vitro germinability was negatively influenced by temperature but was unaffected by cultivar. LT-grown pollen held at $23.9^{\circ} \mathrm{C}$ retained $63 \%$ of its original germinability over a 32-hour period; the germinability of LT-grown pollen held at $35.0{ }^{\circ} \mathrm{C}$ was decreased by $97 \%$ from its original level after 16 hours. Virtually all flowers cultured under HT conditions were male-sterile, exhibiting structural and/or sporogenous class abnormalities including petaloidy, malformation of tapetal cells, and microspores or failure of dehiscence. The duration of stigma receptivity, pistil density, and drupelet set were also negatively influenced by increasing temperature; values for these parameters of floral competency among control plants were reduced by $51 \%, 39 \%$, and $76 \%$, respectively, in flowers cultured under HT conditions. Herein, flowering and fruiting parameters and presumably the yield potential of Prime-Jan ${ }^{\mathrm{TM}}$ and Prime-Jim ${ }^{\mathrm{TM}}$ were adversely affected by increased temperature. However, assessment of their adaptative response to heat stress under field conditions awaits experimentation.

\section{Poster Session 23-Fruit and Nut Breeding}

\section{July 2006, 12:00-12:45 p.m.}

\section{(260) Analysis of Fruit Shape Using Digital Photography}

Andrew P. Wycislo*, Douglas E. Karcher, John R. Clark

University of Arkansas, Horticulture, Fayetteville, AR, 72701

Quantifying fruit shape is challenging, particularly when measurements are made on segregating populations of plants that vary greatly in shape. Objective manual measurements can be performed on small samples of fruit, but this method is not feasible when dealing with larger samples or when shape variations are slight and continuous. Also, subjective rating scales can be utilized, but they are less effective when done by multiple raters due to varying descriptive standards among individuals. Therefore, we have developed a method to analyze digital images containing multiple fruits to characterize fruit shapes. Each segregant of a population of table grapes with parents of significant varying shapes was photographed and analyzed. Image pixels representing fruit were selected and evaluated for area and perimeter, which were subsequently used to calculate a shape factor and compactness value. This was a reasonably simple and quick method for quantifying grape berry shape, giving the researcher valuable phenotypic data in numerical form. This technology should be useful for shape characterizations of other fruits as well.

\section{(261) The Use of Stem Cuttings to Determine Chilling Requirement in Blackberries}

\author{
P. Manjula Carter*1, John R. Clark ${ }^{2}$ \\ ${ }^{1}$ University of Arkansas, Horticulture, SWREC, Hope, AR, 71801; ${ }^{2}$ University of Arkansas,
} Horticulture, Fayetteville, AR, 72701

Chilling requirement, (the number of hours below $7{ }^{\circ} \mathrm{C}$ necessary to break dormancy) has been shown to vary with genotype in blackberry (Rubus subgenus Rubus). Previous work has demonstrated that the chilling requirement of field-grown plants could be accurately determined from stem cuttings of lateral shoots taken at 100-hour intervals of chilling up to 1000 hours, by placing them in a mist chamber maintained at $26^{\circ} \mathrm{C}$ with a daylength of 16 hours, and observing budbreak over a period of 5 weeks. This technique has previously demonstrated clear differences in the chilling requirements of thorny and thornless floricane-fruiting cultivars. In the current study, a comparison of floricane-fruiting and primocane-fruiting blackberries using the stem-cutting technique illustrated a lower chilling requirement associated with the primocane-fruiting trait. The use of the stem-cutting technique can be a simple and effective tool for assessing blackberry adaptation to different hardiness zones.

\section{(262) Screening Citrus Germplasm for Resistance to Xanthomonas axonopodis pv. Citri}

Greg McCollum*1, Kim Bowman ${ }^{1}$, Tim Gottwald ${ }^{2}$

'USDA-ARS, Horticulture and Breeding, Ft. Pierce, FL, 34945; ${ }^{2}$ USDA-ARS, Subtropical Plant Pathology, Ft. Pierce, FL, 34945

Citrus bacterial canker [causal agent Xanthomonas axonopodis pv. citri $(X a c)]$ is a serious threat to the citrus industry. Currently, there are no effective means to control citrus canker. Our objective was to 
determine the resistance of selected citrus species, citrus hybrids, and citrus relatives to $\mathrm{Xac}$. Our first experiment focused on determining if differences in resistance exist among $20 C$. reticulata genotypes and included three other citrus species and citrus relatives (Glycosmis pentaphylla and Clausena hardimandiana). Plants were inoculated with $X a c$ strain A either by injection infiltration or needle-prick. Our second experiment included 10 members of the genus Citrus and Poncirus trifoliata, representing a total of 31 different selections. Plants were needle-prick inoculated with both Xac strain A and Xac strain A Wellington $\left(\mathrm{A}^{\mathrm{W}}\right)$. All inoculations were done using suspensions of $\mathrm{Xac}$ at a concentration of $10^{4} \mathrm{cfu} / \mathrm{mL}$. In both experiments, there were highly significant differences among genotypes in response to inoculation with $X a c$. In the first experiment, regardless of inoculation method, $G$. pentaphylla and $C$. hardimandiana were found to be highly resistant to $X a c$, whereas C. paradisi was least resistant. In the second experiment for both Xac strain A and $\mathrm{A}^{\mathrm{w}}$, Chinotto sour orange, Carrizo citrange, Eustis limequat, and $P$. trifoliata were the most resistant. Thornless key lime $\times$ Meiwa kumquat hybrids showed a range of resistance from among the most susceptible to among the most resistant. Our results expand on previous studies on resistance of citrus and citrus relatives to $X a c$ and indicate that there may be potential for increasing resistance by breeding using selected parents.

\section{(263) Rodent Preference for Pear Germplasm}

David M. Hunter*, Cheryl A. Collucci

Agriculture and Agri-Food Canada, SCPFRC, Vineland Station, Ontario, L0R 2E0, Canada

Fall-dug nursery trees stored in a jacketed cold storage were damaged by rodent feeding over Winter 2004-05. Damage was primarily confined to the lower trunk region of the scion cultivar, with very little feeding damage to the Bartlett seedling rootstocks. Damage ranged from slight nibbling of some buds to complete girdling and bark removal of considerable length of the trunk. Position of the tree bundle in the storage appeared to have no effect on severity of damage. An arbitrary 7 -point scale was used to rate the incidence and severity of damage on 22 cultivars. The least damaged cultivars were Moonglow, Giffard, and Butirra Precoce Morettini, while Thornless Seckel, Conference, and AC Harrow Gold showed the most severe damage. In late Spring 2005 , all trees were replanted back into a nursery row to allow trees to recovery rates. However, only trees with damage ratings in the slight to moderate range showed signs of recovery during the 2005 growing season.

\section{(264) Progress in Developing Non-melting-flesh Peaches for Fresh-market Use}

Thomas Beckman*1, Gerard Krewer ${ }^{2}$, Jose Chaparro ${ }^{3}$, Wayne Sherman ${ }^{3}$

${ }^{1}$ USDA-ARS, Southeastern Fruit and Tree Nut Lab, Byron, GA, 31008; ${ }^{2}$ University of Georgia, Horticultural Dept., Tifton, GA, 31793; ${ }^{3}$ University of Florida, Horticultura Sciences Dept., Gainesville, FL, 32611;

The primary purpose of the three-way cooperative regional project involving the USDA, University of Georgia, and University of Florida, is to develop improved fresh-market peach cultivars for use in the moderate-chill areas of the southeastern United States. Since 1995, this project has concentrated on the development of non-melting flesh materials as an alternative to conventional melting-type cultivars. It is our belief that the slower softening, non-melting characteristic will allow growers to pick fruit several days later at a more mature stage, thus improving eating quality without sacrificing shipping ability. To date, this program has released three non-melting peach cultivars and is poised to release several more. Through our postharvest evaluations we have been able to demonstrate that these new releases and selections have equal, if not superior, firmness compared to current commercial melting-type cultivars, in combination with higher soluble solids and soluble solids/titratable acidity ratios. Compared to current commercial melting-type cultivars, the new non-melting releases and selections display superior red skin blush, fruit shape, and cropping ability. Moreover, they are of comparable size and have a significantly reduced incidence of split and shattered pits.

\section{(265) DNA Sequence Variation within the Promoter of VvmybA1 Associates with Flesh Pigmentation of Intensely Colored Grape Varieties}

Naomi Porret ${ }^{1}$, Peter Cousins ${ }^{2}$, Christopher Owens*2

${ }^{1}$ Cornell University, Food Science; ${ }^{2}$ USDA-ARS, Grape Genetics Research Unit, Geneva, NY

Grapevine (Vitis vinifera L.) is one of our oldest domesticated crops and economically the most important cultivated fruit crop in the world. Cultivated grapes show substantial diversity in fruit color, including: varying shades of black, red, pink, grey, white, and types with pigmented berry flesh. The majority of $V$. vinifera cultivars only possess anthocyanin pigmentation in the skin of the berry (also known as teinturiers). However, some cultivars possess berries with intensely pigmented flesh as well as skin, which is often also associated with greater pigmentation of vegetative tissues. The genetic control and inheritance of fruit color in grapevine is poorly understood, despite evidence that the primary determination of anthocyanin production appears to be controlled by a single dominant locus in $V$. vinifer $a$ with white fruit being a recessive character. Recently, it has been shown that the presence of Gret 1, a Ty3-gypsy-type retro-transposon in the promoter region of a myb-like regulatory gene is present in white-fruited cultivars of $V$. vinifera and that allelic variation in this gene associates with several qualitative classes of grape fruit color. It has been observed that the red-flesh berry phenotype is similarly controlled by a single dominant locus. Considering the association of variation in $V v m y b A l$ with grape berry skin color, it was hypothesized that DNA sequence variation in $V v m y b A 1$ would also be associated with genotypes showing intensely pigmented berry flesh. In this study, we show that allelic variation in VvmybAl associates with the teinturier phenotype both in a panel of accessions possessing red-flesh as well as in a population of full-sibs segregating for the red-flesh phenotype.

\section{(266) Identifying Molecular Markers Correlating with High Beta-carotene Content in Muskmelon}

Alexandra B. Napier*1, Kevin M. Crosby², Soon O. Park ${ }^{2}$

${ }^{1}$ Texas A\&M University, Horticulture, College Station, TX, 77840; ${ }^{2}$ Texas A\&M University, Horticulture, Weslaco, TX, 78596

Muskmelons (Cucumis melo L.) play an important role in the American diet. Ranked as one of the top 10 most-consumed fruits by the USDA, cantaloupe melons have the highest amount of beta-carotene of all the ranked fruits. Beta-carotene, also called pro-Vitamin A, is an essential nutrient required for eye health, and may have the potential, as an antioxidant to reduce the risks associated with cancer, heart disease, and other illnesses. Breeding melons with increased levels of beta-carotene will benefit consumer health. Research has found phytonutrients are most bioavailable when consumed in their fresh form, rather than as vitamin supplements. The high level of beta-carotene found in some melons has a genotypic component, which may be exploited to breed melons high in beta-carotene. Molecular markers and marker-assisted selection (MAS) can be used to increase the efficacy of the breeding process, while lowering breeding costs. An $\mathrm{F}_{2}$ population was created using 'Sunrise', the female parent, containing no beta-carotene crossed with 'TAM Uvalde', a high beta-carotene variety. A field population consisting of $115 \mathrm{~F}_{2}$ individuals and a greenhouse population containing $90 \mathrm{~F}_{2}$ individuals were grown. The resulting fruit were screened phenotypically and ranked according to beta-carotene content. Chisquare values fit the previously reported model of a single dominant gene for presence of beta-carotene (orange-flesh) vs. absence (green or white flesh). A continuous distribution of beta-carotene concentrations from high to low suggested quantitative inheritance for this trait. Two eight-plant DNA bulks composed of either high or low beta-carotene $\mathrm{F}_{2}$ individuals were screened for polymorphic molecular markers using the amplified fragment-length polymorphism technique. 
(267) The Effects of Media Types on Rescued Peach Embryos

Natalie Anderson*1, David H. Byrne ${ }^{1}$, Maria B. Raseira ${ }^{2}$

${ }^{1}$ Texas A\&M University, Horticulture, College Station, TX, 77843-2133; ${ }^{2}$ EMBRAPA, Fruit Breeding, BR 392 km 78, Pelotas, RS, 96001-970, Brazil

A major obstacle faced by programs that breed early-ripening peach cultivars [Prunus persica (L.) Batsch] is the low viability of the embryos from the early-ripening parents that are used as females. Embryo culture techniques have been developed to allow embryos to mature in vitro, thus increasing the chances of germination and survivability. Several media types exist for Prunus embryo culture. Two types, Woody Plant Medium (WPM) and Smith, Bailey, and Hough (SBH) were investigated for this report. The WPM type was studied in two forms, one made from scratch and the other in a prepackaged form. The SBH type was studied with the addition of vitamins and without vitamins. Eight peach genotypes with embryo lengths ranging from 9.6 to $12.7 \mathrm{~mm}$ were used. Surprisingly enough, it was found that WPM from scratch performed better than WPM from a prepackaged mix. For all eight genotypes studied, WPM from scratch resulted in as good as or better germination than SBH with or without vitamins. A large media by genotype effect was found, which is partially attributed to the embryo size. The genotypes with larger embryos $(>11 \mathrm{~mm})$ tended to perform equally on all media tested whereas the embryos $<10.5 \mathrm{~mm}$ germinated better on WPM as compared to SBH.

Poster Session 24-Postharvest 3

29 July 2006, 12:00-12:45 p.m.

\section{(194) Quality Parameters in 'Flame Seedless' Table Grapes Growing in Two Different Microclimatic Areas in Chile}

L. Antonio Lizana*1, Jorge M. Sandoval ${ }^{1}$, Manuel Pinto ${ }^{2}$, Luis Luchsinger ${ }^{1}$

${ }^{1}$ Fac. Agr. Sc., University of Chile, CEPOC (Postharvest Study Center), Santa Rosa 11.315 (La Pintana), Santiago, 00, Chile; ${ }^{2} \mathrm{Fac}$. Agr. Sc. University of Chile, Produccion Agricola, Santa Rosa 11.315 (La Pintana), Santiago, Chile;

An experiment was set up to elucidate the causes of differences in harvest time in the adjacent grape-growing areas of Rapel and Sotaqui in the Limari Valley, Chile. Berry samples of 'Flame Seedless' were collected from each area, from 10 days after last GA spray until harvest (December to February). Soluble solids (SS), titrable acidity (TA), and SS/TA ratios were analyzed and days from full bloom to harvest, growing degree days, and ambient temperatures were recorded. In Rapel, full bloom was 25 Sept.; the harvest by $16^{\circ}$ Brix, started on 3 Jan., and the harvest by $20: 1 \mathrm{SS} / \mathrm{TA}$ ratio (min. $15.5^{\circ} \mathrm{Brix}$ ) on $28 \mathrm{Dec}$. (11, 16, and 24 days earlier, respectively, than Sotaqui). Degree-days (DD) at harvest (16 ${ }^{\circ}$ Brix) were 1058 in Rapel and 837 DD in Sotaqui. In the last 50 days prior to harvest, berry acidity was always lower in Rapel, decreasing from $0.87 \%$ to $0.47 \%$, while in Sotaqui berry acidity decreased from $1.96 \%$ to $0.86 \%$. From 20 Dec. to 2 Jan., the acidity did not decrease significantly (1.96\% to $1.84 \%$ ), but in the next 3 weeks decreased to $0.68 \%$. This difference in the rate of acid degradation is related to the increase in minimum night temperatures in this same period of berry growth. It is concluded that the minimum temperature-dependent rate of organic acid degradation is the main factor influencing the SS/TA harvest index parameter.

\section{(195) Optimizing Storage Conditions for Fresh Cranberries}

Charles F. Forney*, Stephanie Bishop, Michele Elliot, Vivian Agar Agriculture and Agri-Food Canada, Atlantic Food and Horticulture Research Centre, Kentville, Nova Scotia, B4N 1J5, Canada

Extending the storage life of fresh cranberries (Vaccinium macrocarpon Ait.) requires an optimum storage environment to minimize decay and physiological breakdown (PB). To assess the effects of relative humid- ity $(\mathrm{RH})$ and temperature on storage life, cranberry fruit from four bogs were stored over calcium nitrate, sodium chloride, or potassium nitrate salts, which maintained RH at $75 \%, 88 \%$, and $98 \%$, respectively. Containers at each $\mathrm{RH}$ were held at $0,3,5,7$, or $10^{\circ} \mathrm{C}$ and fruit quality was evaluated monthly for 6 months. Both decay and PB increased with increasing RH in storage. After 6 months, 32\%, 38\%, and 54\% of fruit were decayed and $28 \%, 31 \%$, and $36 \%$ developed $\mathrm{PB}$ when stored in $75 \%, 88 \%$, and $98 \% \mathrm{RH}$, respectively. The effects of $\mathrm{RH}$ continued to be apparent after fruit were removed from storage, graded, and held for 7 days at $20{ }^{\circ} \mathrm{C}$. The decay of graded fruit after 4 months of storage in $75 \%, 88 \%$, or $98 \% \mathrm{RH}$ was $10 \%, 13 \%$, and $31 \%$, respectively, while PB was $12 \%, 12 \%$, and $17 \%$, respectively. Fresh weight loss decreased as RH increased averaging $1.9 \%, 1.4 \%$, and $0.7 \%$ per month for storage in $75 \%, 88 \%$, and $98 \% \mathrm{RH}$, respectively. Fruit firmness was not affected by RH. Storage temperature had little effect on decay. However, $\mathrm{PB}$ was greatest in fruit stored at $10{ }^{\circ} \mathrm{C}$, encompassing $55 \%$ of fruit after 5 months of storage. When graded fruit were held an additional 7 days at $20^{\circ} \mathrm{C}$, decay and $\mathrm{PB}$ were greater in fruit previously stored at 0 or $3{ }^{\circ} \mathrm{C}$ than at 5,7 , or $10{ }^{\circ} \mathrm{C}$. Fresh weight loss increased as storage temperature increased, averaging $0.8 \%, 1.0 \%, 1.3 \%, 1.7 \%$, and $1.9 \%$ per month at $0,3,5,7$, and $10{ }^{\circ} \mathrm{C}$, respectively. Fruit firmness decreased during storage, but was not affected by storage temperature. To maximize storage and shelf life, cranberry fruit should be stored in a $\mathrm{RH}$ of about $75 \%$ at $5{ }^{\circ} \mathrm{C}$.

\section{(196) A Comparison of Fruit Quality and Antioxidant Properties of Alabama-grown Kiwi}

Ming-Wei S. Kao*1, Floyd Woods ${ }^{1}$, William A. Dozier ${ }^{1}$,

Robert C. Ebel ${ }^{1}$, Chang Y. Lee ${ }^{2}$, Jun Bae Jee ${ }^{1}$

${ }^{1}$ Auburn University, Horticulture, Auburn, AL, 36849-5408; ${ }^{2}$ Cornell University, Food Science and Technology, Geneva, NY, 14456

The health status of Alabama's population ranks above the national average with respect to the prevalence of poor overall health indicators. Consumer knowledge of the health benefits of consumption of fresh fruit is lacking. The compositional and nutritional qualities of fruit are highly variable among states with different climate, soil, and other environmental conditions. Compositional and nutritional data of fresh fruit that reflect Alabama growing conditions is limited. Commercially fully ripened kiwi fruit (Actinidia deliciosa cvs. Fitzgerald and Hayward) were compared for fruit quality $\left(\mathrm{pH}, \mathrm{TA},{ }^{\circ} \mathrm{Brix},{ }^{\circ} \mathrm{Brix} / \mathrm{TA}\right.$, and soluble sugars), and antioxidant properties; Vitamin $\mathrm{C}$ (reduced, oxidized, and total), Vitamin C Equivalent Antioxidant Capacity (VCEAC), ferric reducing antioxidant power (FRAP), DPPH radical scavenging activity, total phenolics, and flavonoids. In general, 'Fitzgerald' ranked higher in overall fruit quality and antioxidant properties when compared to 'Hayward'.

\section{(197) E-beam Irradiation Influences Grapefruit- Drug Interaction-related Furocoumarins}

Basavaraj Girennavar*, Sara Simpkins, G.K. Jayaprakasha, Bhimanagouda Patil

Texas A\&M University-Kingsville, Dept. of Horticultural Sciences, College Station, TX, 77843

Food and drug interaction has been under discussionm and specifically grapefruit and drug interaction has been under investigation, in recent years. Irradiation of food has multiple benefits in food preservation through several processes, such as sprout inhibition, disinfection, decontamination, delayed maturation, and sterilization. When ionizing radiation is passed through food, it may affect the functional components, including organoleptic characteristics. In addition to naringin, dihydroxybergamottin, paradisin A, and bergamottin, as well as their isomers, are considered putative bioactive furocoumarins present in the grapefruit juice, which interfere with the first pass metabolism of the drugs. These compounds inhibit the activity of CYP P450 3A4 and P-glycoprotein, which, in turn, will increase bioavailability of certain medications. In order to investigate the effect of pre-and postharvest practices on furocoumarins, 'Rio Red' and 'Marsh White' grapefruits were irradiated with 1,5 , and $10 \mathrm{kGys}$ ofe-beam. The irradiated fruit juice 
was analyzed for qualitative and quantitative changes in furocoumarins. Fifty milliliters of grapefruit juice was extracted with ethyl acetate three times and ethyl acetate extract was dried under vacuum and analyzed by HPLC. Irradiation at $1 \mathrm{kGys}$ showed a decrease in the total content of dihydroxybergamottin, paradisin A, and bergamottin compared to 5 $\mathrm{kGys}, 10 \mathrm{kGys}$, and control. This project is based upon work supported by the USDA-CSREES under Agreement USDA IFAFS \# 200152102 02294 and USDA \# 2005-34402-14401 "Designing Foods for Health" through the Vegetable \& Fruit Improvement Center.

\section{(198) Common Strategies to Manipulate Pre- and Postharvest Ripening of Fruit Fail with Pawpaw}

Federica Galli ${ }^{1}$, Rumphan Koslanund ${ }^{1}$, Douglas D. Archbold*1, Kirk W. Pomper ${ }^{2}$

${ }^{1}$ University of Kentucky, Horticulture, Lexington, KY, 40546; ${ }^{2}$ Kentucky State University, USDA Clonal Germplasm Repository for Asimina Species, Frankfort, KY, 40601

Ripening pawpaw [Asimina triloba (L.) Dunal] fruit exhibit climacteric peaks of ethylene and $\mathrm{CO}_{2}$ production 48 to 72 hours after harvest, and thus may be considered climacteric. The development of desirable quality traits and the loss of fruit firmness during ripening is extremely rapid, and a variety of strategies to slow these processes via manipulation of ethylene production and/or response and by more direct techniques like postharvest heat treatment have been attempted. Fruit, branches with fruit, and/or whole trees have been sprayed with ethephon or aminoethoxyvinylglycine to hasten or delay ripening, respectively. After harvest, fruit have been treated with commercial and higher rates of 1-methylcyclopropene for various durations at ambient and cold storage temperatures. Fruit have also been heat-treated at various temperatures, using both brief "shock" treatments above $40{ }^{\circ} \mathrm{C}$ and longer periods at $35^{\circ} \mathrm{C}$ to $40{ }^{\circ} \mathrm{C}$. In addition, in an attempt to alleviate the loss of ripening capacity as well as the development of injury symptoms from cold storage for longer than 4 weeks, cold-stored fruit were warmed to ambient temperature intermittently and then returned to cold storage. While some effects of the treatments were noted, the responses to all of these treatment strategies have failed to appreciably alter fruit ripening, the rapid loss of firmness, or otherwise maintain fruit quality beyond that without treatment.

\section{(199) Effect of Harvest Maturity on Quality of Pear} Salad

Jinhe Bai*1, Kristi Barckley ${ }^{1}$, John Manthey ${ }^{2}$

${ }^{1}$ Oregon State University, Mid-Columbia Agricultural Research and Extension Center, Hood River, OR, 97031; ${ }^{2}$ USDA-ARS, Citrus and Subtropical Products Lab

Pear texture is similar to that of apple-firm and crispy-and is one of the potential alternatives to apple. However, at a crispy stage the taste is flat. Improving the taste of pears is considered the key to the success of pear salad. This study evaluated the effect of harvest maturity on the quality of pear salad. Fruit were harvested at commercial maturity or 1 month delayed. After 2 and 5 months (1 and 4 months for delayed harvested fruit) of storage at $-1{ }^{\circ} \mathrm{C}$, fruit were sliced (eight to 10 wedges per fruit), treated with an anti-browning dip, packaged in zip-lock bags (10 pieces per bag), and stored at $1{ }^{\circ} \mathrm{C}$ for up to 21 days. Delayed harvested fruit were larger in size $(\approx 12.5 \%$ increase in weight), had lower flesh firmness $(\approx 5 \mathrm{~N}$ decrease), lower titratable acidity content $(\approx 20 \%$ decrease), and a lower phenolic content $(\approx 45 \%$ decrease in pulp). There was no significant difference in soluble solids content. After 2 months of storage, ethylene production and respiration rate were initially lower in delayed harvested fruit in either the intact fruit or cut slices, but tended to similar after 7 days in storage. Sensory evaluation results show that about $80 \%$ of the panel preferred delayed-harvested fruit over commercial harvest, especially in terms of visual quality (71\% to $92 \%$ ), sweetness ( $75 \%$ to $93 \%)$, taste $(69 \%$ to $92 \%)$, texture of skin $(61 \%$ to $92 \%)$, texture of flesh (53\% to $92 \%)$, and overall quality $\left(73 \%\right.$ to $92 \%$ ) during 21 days of storage at $1{ }^{\circ} \mathrm{C}$. After 5 months of storage, cutting surface was dry-looking in delayed harvested fruit. However, sensory evaluation showed panels still preferred the delayed-harvested fruit. The results indicate that salad quality of pears can be improved by delaying harvest.

\section{(200) Inhibition of PAL, CHS, and ERS1 Transcription by 1-MCP}

Dan D. MacLean*1, Dennis P. Murr ${ }^{1}$, Jennifer R. DeEl1², Eugene Kupferman

${ }^{1}$ University of Guelph, Plant Agriculture, Guelph, Ontario, N1G 2W1, Canada ${ }^{2}$ Ontario Ministry of Agriculture, Food and Rural Affairs, Fresh Market Quality Program Lead, Simcoe, Ontario, N3Y 4N5, Canada; ${ }^{3}$ WSU, TFREC, Wenatchee, WA, 98801

The ethylene antagonist 1-methylcyclopropene (1-MCP) was investigated for its potential impact on the transcription of key flavonoid biosynthetic (PAL and CHS) and ethylene perception (ERS1) genes during the postharvest storage of pear (Pyrus $\times$ communis L.). Optimally harvested red and green 'd'Anjou' fruit were treated with $1 \mu \mathrm{L} \cdot \mathrm{L}^{-1}$ 1 -MCP for $24 \mathrm{~h}$ at $0{ }^{\circ} \mathrm{C}$ to $1{ }^{\circ} \mathrm{C}$, and subsequently placed in cold storage $\left(0-1{ }^{\circ} \mathrm{C}, 90-95 \% \mathrm{RH}\right)$. Fruit were removed every 21 days for 126 days, and evaluated for firmness, TSS, and ethylene and volatile production for up to 10 days $\left(\approx 21^{\circ} \mathrm{C}\right)$. Tissue samples were collected for Northern blot analysis and determination of flavonoid and chlorogenic acid content. PAL content increased during the 1 -week simulated marketing period irrespective of storage duration, which coincided with an increase in respiration and ethylene content. Although it was still detectable, total PAL content was dramatically reduced by the 1-MCP treatment. CHS was abundant immediately after harvest and after removal from storage, but declined rapidly thereafter, and was not detectable after 1 week at room temperature. The 1-MCP treatment further exacerbated this decreasing trend in CHS content. ERS1 content appears to be stable throughout storage and the simulated marketing period, with levels lower in 1-MCP-treated fruit. These results suggest that 1-MCP significantly inhibits the transcription of key flavonoid and ethylene regulatory enzymes, possibly compromising the nutraceutical content of pear fruit. The increase in PAL with the concomitant decrease of CHS after removal from storage suggests a diversion of carbon from flavonoid compounds into simple phenols, such as chlorogenic acid.

\section{(201) Internal Ethylene Concentration and Harvest Date Effects on Responses of Apple Fruit to 1-MCP}

Seok-Kyu Jung*, Jacqueline F. Nock, Chris B. Watkins Cornell University, Horticulture, Ithaca, NY

Late-harvested apple fruit generally are less responsive to 1-MCP than early harvested fruit, but the effect of harvest date on these responses can vary greatly by cultivar. Little is known about the relationships between internal ethylene concentration (IEC) and responses of fruit to 1-MCP. We have investigated the effects of 1-MCP on 'McIntosh', 'Cortland', and 'Empire' apples in two experiments. In the first, fruit of each cultivar were picked three to five times during the normal harvest season, untreated or treated with $1 \mu \mathrm{L} \cdot \mathrm{L}^{-1} 1-\mathrm{MCP}$, and stored in air. Fruit IEC and firmness were then measured at monthly intervals for 4 months. In the second experiment, fruit were harvested several times during maturation, and, at each harvest, fruit were categorized into groups based on their IEC $(<0.5,0.5-1.0,1-10$, 10-50, 50-100; and $\left.>100 \mu \mathrm{L} \cdot \mathrm{L}^{-1}\right)$, treated with $1 \mu \mathrm{L} \cdot \mathrm{L}^{-1} 1-\mathrm{MCP}$ for 24 hours at room temperature, and stored in air. The IEC and firmness of each fruit was then measured at set intervals during storage. Increasing IECs were associated with declining effectiveness of 1-MCP, but the individual fruit study showed that, even in high-IEC fruit, there was an initial inhibition of IEC values during storage before the IECs increased. A Lower IEC at harvest indicated a longer delay before the IEC ultimately increased. Collectively, the data show that it should be possible to determine the response of fruit to $1-\mathrm{MCP}$ based on their IEC.

\section{(202) Quality of Sapote Mamey Fruits Treated with Hot Water and Stored at $12{ }^{\circ} \mathrm{C}$}

Arturo Martinez-Morales ${ }^{1}$, Iran Alia-Tejacal ${ }^{2}$, Maria-Teresa Colinas-Leon*3 $^{* 3}$, Victor Lopez-Martinez ${ }^{4}$, Cecilio Bautista ${ }^{3}$

${ }^{1}$ Universidad Juarez Autonoma de Tabasco, Universidad s/n Zona de la Cultura, Tabasco, 86040, Mexico; ${ }^{2}$ Universidad Autonoma del Edo. de Morelos, Universidad 1001, Col. 
Chamilpa, Cuernavaca, Morelos, 62210, Mexico; ${ }^{3}$ Universidad Autonoma Chapingo, Fitotecnia, Carretera Mexico-Texcoco Km. 38.5, Chapingo., Texcoco, 56230, Mexico; ${ }^{4}$ Universidad Autonoma del Estado de Puebla, Universidad 1001. Col. Chamilpa., Cuernavaca, Morelos, 62210, Mexico;

Sapote mamey (Pouteria sapota) fruit commercialization to different markets is limited due to the fact that it is a host of the fruit fly $(A$. serpentina), so there is a special interest in generating a quarantine treatment protocol. In the present study, fruits from Jalpa de Mendez, Tabasco, Mexico, were harvested at physiological maturity and divided in two groups: a) fruits treated with hot water $\left(46.1{ }^{\circ} \mathrm{C}\right)$ for $1 \mathrm{~h}$, and b) control fruits, with no hot water treatment. Fruits were then stored at $12{ }^{\circ} \mathrm{C}$ for $7,14,21$, and 28 days. After storage, days to ripening as well as respiration rate, ethylene production, and weight loss were evaluated for 6 days. Pulp color (ligthness, hue angle, and chroma), fruit firmness, total soluble solids and sugars, and total phenols (at the end of storage and 6 days after) were also evaluated. Results show that fruits stored for 0 days ripened in 5.8 days, while fruits stored between 7 and 28 days took between 3.2 and 5.6 days to reach the ripe stage. Considering the storage periods, effective postharvest life was increased between 11 and 32 days. Respiration rate markedly increased in control fruits after 21 days of storage, but no chilling injury symptoms were observed. Hot water treatment did not affect ethylene production, sugar or phenol content, color, and fruit firmness. Total soluble solids and sugars increased as storage period increased and even more after storage, thus suggesting that storage temperature does not stop the ripening process. No significant changes were observed in the color components. Results suggest that the hot water inmersion treatment is an alternative to reach the quarantine protocol (not affecting quality) and when combined with refrigeration could be used to sent fruit to distant places.

\section{(203) Responses of 'Golden Delicious' Apples to 1-MCP Applied in Air and Water}

Luiz Argenta*1, Xuetong Fan², James Mattheis ${ }^{3}$

${ }^{1}$ EPAGRI, Experimental Extension of Cacador, 1500, Abilio Franco, Cacador, SC, 89.500-000, Brazil; ${ }^{2}$ USDA-ARS, ERRC, Wyndmoor, PA, 19038; ${ }^{3}$ USDA-ARS, TFRL, Wenatchee, WA, 98801

The efficacy of the ethylene action inhibitor 1-methylcyclopropene (1$\mathrm{MCP}$ ) applied in water to slow ripening of 'Golden Delicious' [Malus sylvestris var. domestica (Borkh.) Mansf.] apples was evaluated in comparison with 1-MCP applied as a gas in air. The material was applied by dipping fruit in 1-MCP water solutions $(0,0.03,0.3$ or $3 \mu \mathrm{M})$ for $4 \mathrm{~min}$, or by exposing fruit to 1 -MCP gas $\left(0,0.01,0.1\right.$ or $\left.1 \mu \mathrm{L} \cdot \mathrm{L}^{-1}\right)$ in air for $12 \mathrm{~h}$. Fruit were held in air at $20^{\circ} \mathrm{C}$ for 25 days after treatment or stored at $0.5^{\circ} \mathrm{C}$ in air for up to 6 months followed by 7 days in air at $20^{\circ} \mathrm{C}$. Application of 1-MCP in water or air delayed the increase in respiration and ethylene production associated with fruit ripening, and reduced the amount of fruit softening, loss of acidity and change in peel color. Treatments applied in water required a concentration 700 -fold higher compared to those applied in air to induce similar physiological responses. Fruit responses to $1-\mathrm{MCP}$ varied with treatment concentration, and the maximum effects were obtained at concentrations of 0.1 or 1 $\mu \mathrm{L} \cdot \mathrm{L}^{-1}$ in air and $3 \mu \mathrm{M}$ in water. Peel color change was impacted less than retention of firmness and titratable acidity for some 1-MCP treatments. Treatment with 1-MCP was less effective for slowing peel degreening when treated fruit were stored at $0.5^{\circ} \mathrm{C}$ compared to storage at $20^{\circ} \mathrm{C}$. In 1 of the 3 years of this study, fruit treated with $1-\mathrm{MCP}$ and stored in air at $0.5{ }^{\circ} \mathrm{C}$ developed a peel disorder typified by a gray-brown discoloration that is unlike other disorders previously reported for this cultivar.

\section{Poster Session 25-Plant Biotechnolgy 1}

29 July 2006, 12:00-12:45 p.m.

\section{(280) Temporal and Spatial Expression of $L E A F Y$} and TERMINAL FLOWER 1 Homologues in Floral Bud of Japanese Pear and Quince

Tomoya Esumi*, Ryutaro Tao, Keizo Yonemori

Kyoto University, Graduate School of Agriculture, Kitasirakawa-Oiwake-cho Sakyo-ku,
Kyoto, Kyoto, 6068502, Japan

Japanese pear (Pyrus pyrifolia) and quince (Cydonia oblonga), both classified in the subfamily Maloideae, show differences in inflorescence architectures despite of the fact that they are genetically closely related. We previously isolated flowering related genes, $L E A F Y(L F Y)$ and TERMINAL FLOWER 1 (TFL1) homologues, from these species and showed that they had two types of homologues for each gene. In this study, we examined the expression pattern of $L F Y$ and TFL1 homologues in these species by in situ hybridization and RT-PCR. The floral bud was dissected to small pieces under stereomicroscope; apical meristem, scales/bracts, pith, floral meristem, and inflorescence; and then used for RT-PCR. The LFY homologues were expressed in apical meristem and scales/bracts before the floral differentiation in both Japanese pear and quince. After floral differentiation, the expression was observed in floral meristem, scales/bracts and pith in both the species. The TFL1 homologues were strongly expressed in the apical meristem, but their expression was drastically decreased just before floral differentiation. It is considered that the decrease of expression of TFL1 homologues is a sign of floral initiation. The expression of TFL 1 homologues was transiently increased at the beginning of floral differentiation in both species. Moreover, one of TFL1 homologues in Japanese pear was continuously expressed in the inflorescence part in the floral primordia, whereas expression of TFL1 homologues in quince almost completely disappeared after a solitary floral meristem was initiated. It was suggested that TFL1 homologues may also be involved in the inflorescence development of Japanese pear.

\section{(281) Micropropagation of Trifoliate Orange Root- stock (Poncirus trifoliate Raf.)}

Abdelrahman Al-Wasel*

Qassim University, Plant Production and Protection, College of Agriculture and Vet. Med., Buriedah, Qassim, 81888, Saudia Arabia

In vitro propagation of trifoliate orange rootstock (Poncirus trifoliate Raf.) was achieved using axillary buds taken from new flushes of mature trees and then cultured on Murashige and Skoog medium (MS). The addition of growth regulators $\left[0.5 \mathrm{mg} \cdot \mathrm{L}^{-1}\right.$ gibberellic acid $\left(\mathrm{GA}_{3}\right)$ or 0.1 $\mathrm{mg} \cdot \mathrm{L}^{-1}$ 6-benzyladenine (BA) and $0.1 \mathrm{mg} \cdot \mathrm{L}^{-1}$ indol-3-butyric acid (IBA) were necessary to promote bud breakage and shoot elongation. Shoot proliferation was induced on MS medium supplemented with various levels of BA $\left(0.0,0.5,1.0,1.5\right.$, and $\left.2.0 \mathrm{mg} \cdot \mathrm{L}^{-1}\right)$ and $\alpha$-naphthalene acetic acid (NAA) $\left(0.0,0.1\right.$, and $\left.0.5 \mathrm{mg} \cdot \mathrm{L}^{-1}\right)$. Maximal shoot multiplication $(9.3$ shoots/explant) and elongation $(2.3 \mathrm{~cm})$ occurred on media containing either $1.0 \mathrm{mg} \cdot \mathrm{L}^{-1} \mathrm{BA}$ alone or with $0.1 \mathrm{mg} \cdot \mathrm{L}^{-1} \mathrm{NAA}$. Shoots rooted better and gave high root number $(7.6$ roots/shoot) and long roots $(5.4 \mathrm{~cm})$ when cultured on a liquid MS medium provided by $0.1 \mathrm{mg} \cdot \mathrm{L}^{-1} \mathrm{NAA}$. Rooted shoots were successfully established in soil ( $\geq 90 \%)$.

\section{(282) Identification of MicroRNAs in Citrus}

\section{Jinggui Fang, ChihCheng T. Chao*}

University of California-Riverside, Department of Botany and Plant Sciences, Riverside, CA, 92521-0124

MicroRNAs (miRNA) are endogenous tiny RNAs (about 22 nucleotides in length) that can play important regulatory roles in plants and animals by targeting mRNAs for cleavage or involved in translational suppression. Based on the sequence conservation of many miRNA genes in different plant genomes, it is possible to identify miRNAs in citrus. Identification of miRNA is the prerequisite for understanding the miRNA function in citrus. Citrus is an important fruit crop in the world and the publicly available citrus EST databases are increasing. Thirty known miRNAs from Arabidopsis were used to search the citrus EST databases for miRNA precursors. Nine possible citrus miRNA sequences were predicted to have fold-back structures. The Northern results indicated most of the 26 Arabidopsis miRNAs are expressed ubiquitously in the leaf, young shoot, flower, and root tissues of Nules Clementine mandarin (Citrus clementina Hort. Ex Tan.) and Trifoliate orange (Poncirus trifoliata [L.] Raf.). Some miRNAs accumulated preferentially in different tissues. 
(283) Biolistic Genetic Transformation of Carica papaya $\mathrm{L}$. using the Helios ${ }^{\mathrm{TM}}$ Gene Gun

Salvador Guzmán-González*1, Pedro Valadez-Ramírez', Rosa-Edith Robles-Berber ${ }^{1}$, Laura Silva-Rosales ${ }^{2}$,

José-Luis Cabrera-Ponce ${ }^{2}$

${ }^{1}$ Universidad de Colima, Facultad de Ciencias Biológicas y Agropecuarias, Autopista Colima-Manzanillo km 40, Tecomán, Colima, 28100, México $;{ }^{2}$ Instituto Politécnico Nacional, CINVESTAV-Irapuato, Irapuato, Guanajuato, México

Biolistic genetic transformation of plants with viral genes is a method for controlling plant virus diseases; however, optimization of the particle bombardment parameters according to the transformation system is a key factor for an appropiate transgene expression and, therefore, a stronger resistance mechanism in transgenic plants. In order to optimize biolistic parameters, somatic papaya (Carica papaya L.) cv. Maradol embryo masses were bombarded with the CAMBIA 1301 plasmid construction that contains the coat protein gene $(\mathrm{CP})$ of the papaya ringspot virus isolate of Colima, Mexico, driven by the double constitutively CaMV 35S promoter and flanked for the GUS and hygromycin (hpt) resistance genes. Particle bombardment protocol was carried out using the Helios ${ }^{\mathrm{TM}}$ Gene Gun device (BioRad) and the manufacturer's instruction manual. Helium pressure (50, 100, and 150 psi) and gold particle size $(0.6,1.0$, and $1.6 \mu \mathrm{m})$ were evaluated. Five days after bombardment, somatic embryo clusters were used for GUS transient expression and, during 2 months, were selected into 50, 75, and 150 $\mathrm{mg} \cdot \mathrm{L}^{-1}$ hygromycin-containing media to its later CP-PCR detection. Results showed that $50 \mathrm{psi}$ and $1.0 \mu \mathrm{m}$ were the two optimal values for the assayed analyses. This is the first report of genetic transformation of papaya using the Helios ${ }^{\mathrm{TM}}$ Gene Gun device as a new tool compared to conventional PDS-1000/He.

\section{(284) Factors Influencing Somatic Embryogenesis of Proembryonic Mass Suspension Culture in 'Autumn Royal Seedless' Grape}

Yingyos Jittayasothorn*1, Jiang $\mathrm{Lu}^{1}$, Xia Xu${ }^{1}$, Piyada Thipyapong ${ }^{2}$, Nantakorn Boonkerd ${ }^{3}$

${ }^{1}$ Center for Viticulture and Small Fruit Research, CESTA, Florida Agricultural and Mechanical University, Tallahassee, FL, $32317 ;{ }^{2}$ School of Crop Production Technology, Institute of Agricultural Technology, Suranaree University of Technology, Muang District, Nakhon Ratchasima, 30000, Thailand; ${ }^{3}$ School of Biotechnology, Institute of Agricultural Technology, Suranaree University of Technology, Muang District, Nakhon Ratchasima, 30000, Thailand

Biotechnology has great potential for grape genetic improvement. However, successful implementations of grape biotechnologies, such as transformation and in-vitro selection, are based on a high yield productivity of synchronized somatic embryos as well as an efficient single-cell regeneration system. Suspension culture has been known as an ultimate approach to provide those requirements. We recently developed the highly repeatable protocol for PEM suspension culture of 'Autumn Royal Seedless' (Vitis vinifera L.). In a following experiment, three factors, including activated charcoal (AC), darkness, and full- or half-strength MS medium were tested for their impact on grape embryogenesis of PEM suspension cells. All three factors proved to be important for grape somatic embryogenesis. Darkness was the mostinfluenced factor among the three. After 4 weeks on full-strength MS medium plus AC, suspension cells mostly grew friable callus and somatic embryos were rarely observed under 16-h light conditions, whereas numerous somatic embryos were fully developed in darkness. Strength of MS medium and AC also affected grape somatic embyogenesis. In every combination tested, full-strength MS media was all superior to half-strength, which was more obvious under darkness. The AC had a positive effect for promoting of somatic embryogenesis.

\section{(285) Characterization of a Composite Promoter from Genomic Sequences of Grapevine}

Manjul Dutt*, Zhijian T. Li, Sadanand Dhekney, Dennis J. Gray

University of Florida, Mid-Florida Research and Education Center, Apopka, FL, 32703

Genetic transformation of plants necessitates the use of promoters to control transgene expression. Numerous promoters have been isolated from a wide range of organisms for use in plants. However, many of these natural promoters exhibit relatively low activity and/or have limited use. To provide an alternative, we constructed a composite promoter (EP) using a genomic DNA sequence and a $35 \mathrm{bp}$ TATA-containing fragment from the $2 \mathrm{~S}$ albumin $(V v A l b 1)$ gene core promoter of grapevine. The 0.9-kb genomic sequence was identified after TAIL-PCR, based on the presence of several unique $c i s$-acting elements. The sequence showed no homology to any known plant gene, enhancer, and promoter. Two binary vectors, $\mathrm{pEP}-\mathrm{EGFP} / \mathrm{NPT}$ and $\mathrm{pEP}-\mathrm{GUS}$, containing a bifunctional EGFP/NPTII fusion gene and a GUS gene, respectively, were constructed to test transcriptional activity of the composite promoter both qualitatively and quantitatively. Transient GFP expression was observed in somatic embryos (SE) of Vitis vinifera 'Thompson Seedless' after Agrobacterium-mediated transformation using pEP-EGFP/NPT. Quantitative GUS assay of stably transformed SE containing pEP-GUS indicated that the EP composite promoter was capable of producing GUS activity as high as $12 \%$ of that from a doubly enhanced Cauliflower Mosaic Virus 35S promoter or eight times higher than that from a doubly enhanced Cassava Vein Mosaic Virus promoter. In addition, transformation of Arabidopsis with pEP-GUS yielded comparable GUS activity throughout the plant. These data indicate that the EP composite promoter can be used in transformation studies to provide sustained constitutive gene expression in plants.

\section{(286) Identification of Genes in Tomato Roots Induced by Aluminum Stress using Fluorescent cDNA Differential Display}

Tingting Chen*, Suping Zhou, Stephen Smith, Roger Sauve

Tennessee State University, Institute of Agricultural and Environmental Research, Nashville, TN, 37209

The goal of this study was isolate genes that are regulated by Al treatments of tomato roots growing in vitro. For Al treatment, germinating tomato seeds were plated on a MS agar medium supplemented with 0 , 350 , and $1200 \mu \mathrm{M} \mathrm{AlCl} 3$ for 30 days. Total RNA was extracted from root tissues and separated on denature formamide gel to check their quantity and quality. Equal amount of total RNA from treatment and control was treated with DNAse I (Genhunter, TN) to remove genomic DNA contamination. cDNA was obtained by reverse transcription using all the regents in RNA Image Kit (Genhunter, TN). The cDNA was amplified using the fluorescently labeled anchor primers (Oligo dT-A, $\mathrm{C}, \mathrm{G})$ and 16 random primers. Amplification products were separated by electrophoresis in $6 \%$ nondenaturing polyacrylamide gels and DNA bands were observed by scanning the gel on a FMBIOIII scanner. After comparing the band profile on the gel image, fragments of gene that showed changes in intensity compared to control $(0 \mu \mathrm{M}$ AlCl3 $)$ were isolated from the gel manually. These bands were re-amplified with the same pair of primers as the original amplification and cloned onto PCR-Trap cloning vector (Genhunter, TN). After DNA sequence analysis and homology comparison with NCBI database, we have identified clone \# C01HBa0256E08 on L. esculentum chromosome 01, clone \# C10HBa0111D09 on chromosome 10 and clone \# LE_HBa-31H5 on chromosome 4.

\section{Poster Session 26-Nursery Crops 2}

29 July 2006, 12:00-12:45 p.m.

\section{(42) Effects of Photoselective Shadecloths on Potted}

\section{Dracaena and Anthurium Plants}

Kent D. Kobayashi*1, Andrew F. Kawabata ${ }^{2}$, Joanne S Lichty ${ }^{2}$

${ }^{1}$ University of Hawaii at Manoa, Tropical Plant \& Soil Sciences, Honolulu, HI, 96822-2279; ${ }^{2}$ University of Hawaii at Manoa, Tropical Plant \& Soil Sciences, Hilo, HI, 96720-2757

Photoselective shadecloths that manipulate light quality may enable nursery growers to achieve desired plant growth. This ability to manage plant habit could give growers an additional nonchemical tool 
to improve potted plant quality. The objective of this study was to determine growth and flowering responses of potted Dracaena and Anthurium plants to four shadecloths. Dracaena deremensis 'Janet Craig' and Dracaena marginata 'Colorama' cane top-cuttings were placed in $70 \%$ black cinder : $30 \%$ peat moss media. Anthurium 'Lola' liners were transplanted into $100 \%$ black cinder medium. Plants were grown in a greenhouse under $70 \%$ shadecloths: black, gray, red, and blue. Four months after planting, Dracaena 'Janet Craig' had more new leaves under red shadecloth (10.4) compared to other shadecloths (8.9-9.3). Leaf area was less with red shadecloth $\left(340 \mathrm{~cm}^{2}\right)$ than other treatments $\left(380-388 \mathrm{~cm}^{2}\right)$. Plants under the red shadecloth had the lowest grower evaluation scores $(5.4 ; 1=$ poor, $10=$ excellent $)$ than those under other shadecloths (7.2-8.2), but all plants were considered marketable. Dracaena 'Colorama' plants under red shadecloth had the greater plant height increase $(20.1 \mathrm{~cm})$ than those under other shadecloths $(10.1-13.2 \mathrm{~cm})$. Red shadecloth resulted in more new leaves (26.2) compared to other treatments (18.0-21.4). Anthurium 'Lola' flower height 9 months after transplanting was less under red shadecloth $(23.0$ $\mathrm{cm})$ than under black $(33.0 \mathrm{~cm})$. The number of flowers/pot was greater under red shadecloth (3.17) compared to those under other shadecloths $(0.50-1.33)$. Flower size was greater $\left(35.2 \mathrm{~cm}^{2}\right)$ under red shadecloth than under black $\left(20.0 \mathrm{~cm}^{2}\right)$. Photoselective shadecloths may be used to nonchemically manipulate plant growth and improve the quality of potted Dracaena and Anthurium plants.

\section{(43) Salinity Tolerance in Herbaceous Perennials}

Raul I. Cabrera*1, L. Rahman', Genhua Niu², Cynthia McKenney ${ }^{1}$, Wayne Mackay ${ }^{1}$

${ }^{1}$ Texas A\&M University, Horticultural Sciences, Dallas, TX, 75252; ${ }^{2}$ Texas A\&MUniversity, Horticultural Sciences, El Paso, TX, 79927

In this preliminary study, we evaluated the salinity tolerance of selected herbaceous perennials. Liners of Rudbeckia hirta 'Becky Orange', Phloxpaniculata 'John Fanick', Coreopsis grandiflora 'Early Sunrise', Lantana ×hybrida 'New Gold' and Cuphea hyssopifolia 'Allyson' were transplanted to 4-gal plastic containers filled with peat moss : pine bark : sand (3:1:1) medium amended with dolomite, Micromax and Osmocote 18-6-12 (at 2, 0.6, and $6 \mathrm{~kg} \cdot \mathrm{m}^{3}$, respectively). The plants were irrigated for 14 weeks with tap water containing $0,1.5,3,6,12$, and $24 \mathrm{mM}$ of $\mathrm{NaCl}: \mathrm{CaCl}_{2}$ salt mixture (2:1 molar ratio). Increasing salt stress had differential effects on plant growth and quality, with Rudbeckia and Phlox being the most adversely affected even by the lowest salt treatment of $1.5 \mathrm{mM}$, with dry weight reductions of $\sim 25 \%$ compared to the controls. Conversely, Lantana and Cuphea tolerated extremely well salinity up to $12 \mathrm{mM}$, where dry weight reductions were less than $10 \%$ of the nonsalinized controls. The Lantana and Cuphea plants also presented the lowest leaf $\mathrm{Cl}$ accumulation with increasing salinity, whereas Coreopsis showed the highest $\mathrm{Cl}$ accumulations at any salinity level. Plots of leaf $\mathrm{Cl}$ concentration against dry weights showed steeply declining relationships for Rudbeckia and Phlox plants, confirming our observations and assessment that these species are to be considered salt-sensitive. Leaf $\mathrm{Na}$ accumulation is currently being analyzed.

\section{(44) Microscopic and Macroscopic Studies on the Development of Puccinia hemerocallidis in Resistant and Susceptible Daylily Cultivars}

Yonghao Li* ${ }^{* 1}$, Mark T. Windham ${ }^{1}$, Robert N. Trigiano ${ }^{1}$, Donna C. Fare $^{2}$, James M. Spiers 3 , Warren E. Copes ${ }^{3}$

${ }^{1}$ University of Tennessee, Entomology and Plant Pathology, Knoxville, TN, 37996-4560; ${ }^{2}$ USDA/ARS National Arboretum, Floral \& Nursery Plants Research Unit; ${ }^{3}$ USDA/ARS, Small Fruit Research Unit

Infection process of Puccinia hemerocallidis, the causal agent of daylily rust, and resistance responses in eight daylily cultivars, were studied macroscopically and microscopically. After germination of urediniospores, appressoria were formed at the tip of germ tubes and penetrated through stomatal openings. Intercellular hyphae aggregated and formed uredia under the infection sites, and released urediniospores after rupturing the epidermis. In highly resistant cultivars 'Prairie Blue Eyes' and 'Bertie Ferris', intercellular hyphal growth was restricted and uredia were not formed. No macroscopic symptoms of the disease were present on the leaf surface, although a few collapsed cells were observed microscopically. Both resistant and moderately resistant reactions were characterized by necrotic lesions with many collapsed cells under infection sites. The difference between these two reactions was that uredia and urediniospores were observed on the moderately resistant cultivar 'Chicago Apache', but not on resistant cultivars, 'Buttered Popcorn' and 'Stella De Oro'. Sporulation was observed on both moderately susceptible and susceptible cultivars, but latent periods were delayed and the amount of urediniospore production was reduced on moderately susceptible cultivars, 'Mary Todd' and 'Chorus Line', compared to the susceptible cultivar 'Pardon Me'. The results indicate that the hypersensitive cell death is one of the resistance responses to daylily rust, but necrotic lesions on leaf surfaces are associated with the amount of collapsed host cells. The delayed latent periods and reduced sporulation that resulted from restricted intercellular hyphal growth could represent another resistance mechanism in the daylily rust pathosystem.

\section{(45) Root Growth of Three Horticultural Crops Grown in Pine Bark-amended Cotton Gin Compost}

Brian E. Jackson*1, Amy N. Wright ${ }^{2}$, Jeff L. Sibley ${ }^{2}$

${ }^{1}$ Virginia Polytechnic Institute and State University, Horticulture, Blacksburg, VA, 24061; ${ }^{2}$ Auburn University, Horticulture, Auburn, AL, 36849

In the southeastern United States, inconsistent pine bark (PB) supplies and overabundance of cotton gin by-products warrant investigation about the feasibility of replacing PB with cotton gin compost (CGC) for container horticultural plant production. Most research on the use of composted organic substrates for horticultural plant production has focused on shoot growth responses, so there is a need to document the effect of these substrates on root growth. In 2004, 'Blitz' tomato (Lycopersicon esculentum), 'Hot Country' lantana (Lantana camara 'Hot Country'), and weeping fig (Ficus benjamina) were placed in Horhizotrons to evaluate root growth in $100 \%$ PB and three PB:CGC substrates containing, by volume, 60:40 PB:CGC, 40:60 PB:CGC, and 0:100 PB:CGC. Horhizotrons were placed in a greenhouse, and root growth in all substrates was measured for each cultivar. Physical properties (total porosity, water holding capacity, air space, and bulk density) and chemical properties (electrical conductivity and $\mathrm{pH}$ ) were determined for all substrates. Physical properties of $100 \%$ PB were within recommended guidelines and were either within or above recommended ranges for all PB:CGC substrate blends. Chemical properties of all substrates were within or above recommended guidelines. Root growth of all species in substrates containing CGC was similar to or more enhanced than root growth in $100 \% \mathrm{~PB}$.

\section{(46) Response of Container-grown Cotoneaster dammeri to Rates of Dibbled and Pre-incorporated Controlled- release Fertilizer in Three Different Media}

C. Chong*, P. Purvis, G. Lumis, M.Z. Alam, E. Roesler

University of Guelph, Dept. of Plant Agriculture, Guelph, Ontario, N1G 2W1, Canada

Plug-rooted liners of cotoneaster (Cotoneaster dammeri C.K. Schneid. 'Coral Beauty') were grown in 6-L nursery containers filled with three different media: 73 pine bark : 22 peat : 5 pea gravel (Medium 1); 60 pine bark : 25 peat : 15 compost (Medium 2); and 50 pine bark : 50 compost (Medium 3). Plants were fertilized with Polyon (Nutryon) $17-5-12(17 \mathrm{~N}-2 \mathrm{P}-5 \mathrm{~K}) 6$-month controlled-release fertilizer at various rates $\left(0,2.5,4.5,6.5\right.$, and $8.5 \mathrm{~kg} \cdot \mathrm{m}^{-3}$ incorporated or dibbled (placed under the liner at potting). Shoot dry weight of cotoneaster increased with increasing fertilizer rates in all three media, and was consistently higher with dibble (calculated maximum ranges, 269-362 g/plant at $\left.6.1-7.5 \mathrm{~kg} \cdot \mathrm{m}^{-3}\right)$ than with pre-incorporated $(127-263 \mathrm{~g} /$ plant at $6.4-8.5$ $\mathrm{kg} \cdot \mathrm{m}^{-3}$ ) fertilizer. Trends for root dry weight were similar with dibbled fertilizer but nonsignificant with incorporation, while those for shoot : 
root ratio were reversed to those for shoot dry weight. Positive correlations were observed between foliar contents of N, P, and K and shoot dry weight from both dibbled and incorporated treatments, as well as root dry weight from dibbled treatments. With incorporation, however, only foliar K was correlated with root dry weight.

\section{(47) Herbicide Efficacy in Alternative Substrates for Container-grown Nursery Crops}

Diana R. Cochran*1, Charles H. Gilliam', Glenn Fain², Robert D. Wright ${ }^{3}$

${ }^{1}$ Auburn University, Horticulture, Auburn, AL, 36849; ${ }^{2}$ USDA, Southern Horticultura Laboratory; ${ }^{3}$ Virginia Polytechnic Institute and State University, Horticulture, 301 Saunders Hall, Blacksburg, VA, 24061

This study evaluated the effects of nine alternative substrates on herbicide efficacy in container-grown nursery crops: 1) VT (pine wood chips hammer-milled to pass a $0.4-\mathrm{cm}$ screen); 2) USDA (pine wood chips hammer-milled to pass a $0.64-\mathrm{cm}$ screen; 3) AUC (Pinus taeda chipped including needles); 4) AUHM (AUC hammer-milled to pass a 0.48 -cm screen; 5) $1 \mathrm{VT}$ : 1 commercial grade pinebark (v/v); 6) 1 USDA : 1 pinebark (v/v); 7) 1 AUC : 1 pinebark (v/v); 8) 1 AUHM : 1 pinebark (v/v); and 9) 6 pinebark : 1 sand $(\mathrm{v} / \mathrm{v})$. Each substrate was amended with $6.35 \mathrm{~kg}$ of $17-6-12(17 \mathrm{~N}-2.6 \mathrm{P}-10 \mathrm{~K})$ control-release fertilizer, $2.27 \mathrm{~kg}$ of lime, and $0.89 \mathrm{~kg}$ micromax per cubic meter. Containers $(8.3 \mathrm{~cm})$ were filled on 15 June and three herbicides applied the next day: Rout (oxyfluorfen + oryzalin at $2.24+1.12 \mathrm{~kg} \cdot \mathrm{ha}^{-1}$ ), Ronstar (oxadiazon at $4.48 \mathrm{~kg} \cdot \mathrm{ha}^{-1}$ ) and a nontreated control. The next day, containers were overseeded with 25 prostrate spurge seed. Data collected included weed counts 30 and 60 days after treatment (DAT) and weed fresh weights at 60 DAT. Spurge occurred less in the two treatments of $100 \%$ pine wood chips followed by the AUC treatment. With spurge, the least weed fresh weight occurred with the USDA and AUC treatments. For example, at 30 DAT, spurge count was reduced by $33 \%, 40 \%$, and $70 \%$, respectively, when comparing VT, USDA, and AUC to pinebark : sand. Spurge fresh weight at 60 DAT followed a similar trend. With all of the substrates except AUHM, the addition of commercially used pine bark resulted in less weed control. Rout provided superior control followed by Ronstar and the nontreated control These data show that control of prostrate spurge with commonly used preemergent applied herbicides may actually be improved with some of the alternative substrates currently being tested.

\section{(48) Substrate Media and Fertilizer Source Affect Nitrogen and Phosphorus Levels in Leachate from Container-grown Shasta Daisy}

Gladis Zinati*

Rutgers University, Plant Biology and Pathology, New Brunswick, NJ, 08901

Plugs of Leucanthemum × superbum 'Becky'(Chrysanthemum 'Becky', shasta daisy) were grown in \#2 containers using pine bark-peat-sand or vermiculite-peat-sand (40:40:20 by volume). Containers were top dressed with either Osmocote Plus $15 \mathrm{~N}-3.9 \mathrm{P}-9.9 \mathrm{~K}(15-9-12)$ or Nutricote Plus $(18 \mathrm{~N}-2.6 \mathrm{P}-6.6 \mathrm{~K}(18-6-8)$ at five rates $(0,0.5 \times, 1.0 \times$, $1.5 \times$, and $2.0 \times)$ to supply $3.9 \mathrm{~g} \mathrm{~N}$ per container at the recommended level $(1.0 \times)$. Plants were irrigated twice a week using a cyclic irrigation regime consisting of two irrigation applications. Leachates from these containers were collected and evaluated for nitrate and orthophosphate concentrations. Irrespective of the substrate media, Osmocote Plus exhibited a higher rate of nitrogen release at the beginning of the season than Nutricote Plus. Nitrate nitrogen concentration was at least 2.5 times higher in leachates collected from media amended with Osmocote Plus than those with Nutricote Plus. Higher levels of nitrate were found in leachates collected from vermiculite-based media when compared to those from bark-based ones. Phosphate levels in leachates increased as rate of fertilizer increased and were higher in vermiculite-based media than those collected from bark-based media. Plants fertilized with Osmocote Plus were 1.7-fold greater in dry weight than plants fertilized with Nutricote Plus and were 1.2 times greater in vermiculite-based media than those in bark-based media.

\section{(49) Effects of Sowing Time and Tray Size for} Production of Onion

Young-Seok Kwon*, Kwang-Soo Cho, Ju-Seong Im, Eung-Ho Lee, Won-Bae Kim

National Institute of Highland Agriculture, Horticulture, 20, Heonggye, Doam, Pyeongchang, Kangwon, 232-955, Korea

Onions are a major vegetables in Korea. Short-day onions are grown in more than $95 \%$ in southern area of South Korea, and long-day onions are grown above $600-\mathrm{m}$ altitude in the highlands. Onion cultivation in the highland areas has become difficult for farmers to obtain high income but stable production because of higher cost of seed and the intensive labor involved in production. Consequently, onion set culture by inexpensive onion seeds compared with expensive $\mathrm{F}_{1}$ seed has an advantage due to the higher proportion of marketable size bulbs. This study was conducted to find out the suitable sowing time and tray size for onion set culture in the highlands - the earlier the sowing time, the higher the number of onions set. The most appropriate sowing date and 1.6-3.5 g of onion set size was early to middle May, also with the highest distribution percentage. The highest set number $\left(780.8 \mathrm{set} / \mathrm{m}^{2}\right)$ of suitable onion set size (1.6-3.5 g) were harvested from the 288 trays, followed by 770 set from the bed $\left(9 \mathrm{~g} / \mathrm{m}^{2}\right.$ of seed sowed $)$, and $\left(7 / \mathrm{m}^{2}\right.$ of seed sowed) in the 406 tray.

\section{Poster Session 27-Teaching Methods}

29 July 2006, 12:00-12:45 p.m.

\section{(311) Teaching Assistants as a Source of Continuity and Improvement in the Classroom}

Charles L. Rohwer*, Lynette Y. Wong, David C. Zlesak, Jerry D. Cohen

University of Minnesota, Department of Horticultural Science, St. Paul, MN, 55108

It may seem paradoxical that a teaching assistant (TA), whose involvement in a particular class may be limited to a single semester, can provide continuity in the classroom from year to year. Improvement in TA performance from one year to the next also seems difficult to achieve under such circumstances. However, when TAs are encouraged to document classroom activities, specific TA responsibilities, and student concerns, this documentation may be useful in achieving continuity, improved TA performance, and result in a better classroom experience for the students. In addition to the benefit of documentation, TAs, in conjunction with faculty, can together reflect upon how well the objectives of specific laboratories were met. TAs can contribute to generating and documenting ideas that may be implemented to help improve student learning in the future. Each TA comes to the course with a unique collection of horticultural and teaching experiences and has the potential to aid faculty in course refinement and improvement. We explain how TA-directed documentation can provide continuity and year-to-year improvement in horticulture classrooms using our experience with HORT 3005, a required plant physiology laboratory course specifically targeted to horticulture students at the University of Minnesota.

\section{(312) Implementing and Assesing a Bilingual Educational Program for Hispanic Nursery Workers in Ohio}

Alejandra Acuna, Hannah Mathers*, Luke Case

The Ohio State University, Horticulture and Crop Science, Columbus, OH, 43210

Hispanics are becoming the main source of labor in many productiveand service-oriented businesses in the United States, and the nursery industry is one example. Employers invest much time and money into employees, making the employees their biggest investment. However, the educational needs of Hispanic employees have not been adequately addressed, and no formal educational program for Hispanic workers in the nursery industry has been implemented and tested in Ohio. This 
project has two objectives: 1) measure the impact of a bilingual educational program containing instruction in horticulture and instruction in life skills to a Hispanic workforce, and 2) investigate which type of training is more essential to the stabilization of the Hispanic family unit, technical horticultural training, or training in life-skills. Eight nurseries throughout Ohio were selected to participate in this project. At each of the nurseries, an average group size of 15 employees was trained. Only half of this number participated in the social skills lessons to determine differences between the group who received social skills lessons and the group who did not. Three horticultural topics were selected: basic plant structure and development, pruning, and nutrition. Forty-minute lessons in Spanish with key concepts in English were prepared with the topics mentioned. Three social skills topics were selected: meeting your and your family's needs in the United States, social support in your community, and communication. In order to measure the impact of a bilingual educational program, two tests (The Rosenberg Selfeteem and Index of Family Relationship) were applied before and after the program was performed. A course evaluation was completed by each of the participants after the program was completed.

\section{(313) Utilizing Distance Education to Teach Emerging Topics in Horticulture Science: A Report on Four Years of Teaching Introduction to Agricultural Biotechnology}

\section{Kathryn Orvis*}

Purdue University, Horticulture and Landscape Architecture, West Lafayette, IN, 47907

Advances in biotechnology are rapidly changing the way we work and live, but are often met with controversy or raise ethical questions. Approaches that enhance learning and awareness of biotechnology are essential to increasing citizen understanding of these topics. Educators, both formal and informal, need skills to understand the science associated with these technologies, as they may not have been previously exposed to the topics in their training, especially with the rapidly changing science. To address the need for unbiased agricultural biotechnology information, a graduate level internet-based course was developed entitled: "Introduction to Agricultural Biotechnology". This course focuses on agricultural biotechnologies related to horticulture and plant science. Online courses are especially useful for students not able to travel due to various constraints, such as working full-time or being physically distant from campus. The goal is a population better able to understand the science behind rapidly advancing biotechnologies and that is better equipped to make informed decisions regarding those technologies. Course assignments are designed to help students as they teach others about topics associated with biotechnology in both formal and informal settings, such as a high school class or an Extension seminar. In the past 5 years, 54 students (teachers, college instructors, or Extension staff) from across the United States have taken the course. Course ratings have been consistently very good (avg. $4.45)$ on a $1-5$ scale $(1=$ very poor, $5=$ excellent). Former students have indicated that they have a better understanding of biotechnology and would be better able to relate it to others. Students also gained an improved awareness of the resources that are available for teaching agricultural biotechnology.

\section{(314) Creating Videos to Enhance Student and Public Educational Opportunities in Landscape Management}

Sloane M. Scheiber*1, Jennifer Hitchcock ${ }^{1}$, Sudeep Vyapari ${ }^{1}$, Lance Osborne ${ }^{2}$

${ }^{1}$ University of Florida, Environmental Horticulture, Apopka, FL, 32703; ${ }^{2}$ University of Florida, Entomology, Apopka, FL, 32703

A series of video clips and narrated PowerPoints were developed to aid in the presentation of common horticultural techniques. To determine the most effective format for delivery of horticultural subject matter, video clips and PowerPoints were developed for three topic areas and presented to two target audience groups. Target audiences consisted of
Master Gardeners (Orange and Osceola County, Fla.) and future horticulture professionals (UF Environmental Horticulture students enrolled in Landscape Plant Establishment). Upon completion of viewing both media formats, participants were asked to complete a survey. Eightysix percent of participants completed and returned surveys. Data were sorted and analyzed for calculation of mean percent for each response sought. Results of the survey indicated that, depending upon the topic, a higher proportion ( $66 \%$ to $93 \%$ ) of Master Gardeners preferred narrated PowerPoints in comparison to video clips. However, $60 \%$ to $70 \%$ of students preferred video clips to narrated PowerPoints. In reference to the informative nature of both videos and PowerPoints, $>67 \%$ of all respondents rated both media formats between good and excellent; however, most respondents indicated new information gained was less than $40 \%$. Factoring the costs associated with production (about $\$ 1000$ per video vs. essentially no cost for narrated PowerPoints) and participant responses, narrated PowerPoints appear the best option for conveying common horticultural practices.

\section{(315) Learning Style Characteristics of On-line Horticulture Students}

Cynthia McKenney*

Texas Tech University, Plant and Soil Science, Dallas, Texas, 75252

Learning style preferences may impact the success of on-line students in distance education courses. In this study, students from four on-line courses voluntarily completed a modified learning styles assessment instrument. Students attaining a course average of $90 \%$ or greater were considered to have excelled in their respective course. The results from these learners were compared to those of students with lower course averages. It was determined the students that excelled in these on-line courses were visual learners that preferred more images and diagrams than textual references and instructions. This was confirmed by their choice of a map rather than written instructions to a new location when compared to their peers. In addition, they were more likely to prefer a class where they used visual skills rather than auditory skills than their peers. The high-performing students were also more likely to lose points on a timed test due to not reading the written information carefully, while their peers with lower course averages were more likely to run out of time on the test. Recognizing these learning style differences may allow faculty to design courses that better suit their on-line students.

\section{Poster Session 28-Stress Physiology}

29 July 2006, 1:15-2:00 p.m.

\section{(137) High Temperature Increases the Midday Depression of Net Photosynthesis in Oncidium Gower Ramsey}

Yao-Chien Chang*, Hsiao-Wei Chen, Nean Lee

National Taiwan University, Dept. of Horticulture, Taipei, 106, Taiwan

Photosynthetic rate is reduced during midday in some crops; this phenomenon has been termed as midday depression (MD). Oncidium also suffers greatly from MD in the summer, resulting in reduced growth and poor flowering quality. Since high radiation usually accompanies high temperature midday in the summer, it is difficult to figure out the key factor that promotes MD. We investigated the photosynthetic activities of Oncidium Gower Ramsey in the following conditions: environment-controlled and nonenvironment-controlled. In a growth chamber that simulated field growth conditions, photosynthesis declined dramatically when the temperature was higher than $32{ }^{\circ} \mathrm{C}$. Photosynthesis was also reduced when photosynthetically active radiation (PAR) exceeded the saturating point of Oncidium. Gower Ramsey, which is about $250 \mu \mathrm{mol} \cdot \mathrm{m}^{-2} \cdot \mathrm{s}^{-1}$. However, the reduction was slight when PAR was under $500 \mu \mathrm{mol} \cdot \mathrm{m}^{-2} \cdot \mathrm{s}^{-1}$. Daily photosynthetic patterns were changed when Oncidium Gower Ramsey was grown 
under different environments. By regression, we found that MD was not directly associated with PAR within the range of $0-400 \mu \mathrm{mol} \cdot \mathrm{m}$ ${ }^{2} \cdot \mathrm{s}^{-1}$. By contrast, photosynthesis was significantly reduced when temperature was higher than $32{ }^{\circ} \mathrm{C}$. This explains the observation of greater photosynthetic reduction and earlier occurrence of MD when Oncidium Gower Ramsey was grown in rain-shelter rather than in phytotron and growth chamber, since temperature in the rain-shelter was not controlled, while the others were controlled at $25^{\circ} \mathrm{C}$. When Oncidium Gower Ramsey was moved from $35^{\circ} \mathrm{C}$ to $25^{\circ} \mathrm{C}$, the photosynthetic depression was relieved.

\section{(138) Metabolite Profiling in Heat- and Drought- stressed Arabidopsis}

\section{Joel L. Shuman*1, Ron Mittler ${ }^{2}$, Vladimir Shulaev ${ }^{1}$}

${ }^{1}$ Virginia Polytechnic Institute and State University, Virginia Bioinformatics Institute, Bioinformatics, Blacksburg, VA, 24061-0477; ${ }^{2}$ University of Nevada, Reno, Department of Biochemistry and Molecular Biology, Reno, NV, 89557

Drought and heat stress have been extensively studied in plants, but little is known about how the combination of drought and heat impact their physiology and metabolism. The metabolite profile of Arabidopsis subjected to heat, drought, and the combination of heat and drought were analyzed by gas-chromatography-mass spectrometry (GC-MS). Fatty acid retention time standards and the internal standard (IS) ribitol (adonitol) were added to each leaf sample and the polar phase was extracted, methoximated, and derivatized (trimethylsilylated) prior to analysis by GC-MS (Trace DSQ with Combi-PAL autosampler). Compounds were identified based upon retention time (relative to fatty acid standards) and comparison with reference spectra in our custom mass spectral library. Semi-quantitation of compound peak area was done relative to the internal standard. Plants subjected to both heat and drought stress accumulated sucrose and other sugars/sugar alchohols such as maltose, gulose, mannitol. The amino acid proline (Pro) was found in drought-stressed plants, but not found in droughtand heat-stressed plants. Proline has been reported to function as an osmoprotectant in cold-, salt-, and drought-stressed plants, but could be toxic to drought- and heat-stressed plants. We found that growth of heat-stressed Arabidopsis seedlings is inhibited by Pro, but not in drought- and heat-stressed seedlings. These results also indicate that sucrose replaces proline as the major osmoprotectant in heat- and drought-stressed plants. Plants subjected to combined heat and drought also exhibited enhanced respiration, suppressed photosynthesis, and distinct transcriptome expression.

\section{(139) A Capacity for Mannitol Biosynthesis is a Critical Component of Salt Tolerance in Celery}

Wayne H. Loescher*, Paolo Sabbatini, Guo-Qing Song, Kenneth Sink, James Flore

Michigan State University, Horticulture, East Lansing, MI, 48824-1325

Mannitol, a sugar alcohol that appears to serve as an osmoprotectant/ compatible solute to cope with salt stress, is synthesized in celery (Apium graveolens L.) via the action of a NADPH dependent mannose6-phosphate reductase (M6PR). To evaluate the abiotic stress effects of mannitol biosynthesis, we transformed celery with an antisense construct of the celery leaf M6PR gene under control of the CaMV $35 \mathrm{~S}$ promoter. Unlike wild type (WT) celery, independent antisense M6PR transformants did not accumulate significant amounts of mannitol in any tissue, with or without salt stress. In the absence of $\mathrm{NaCl}$, and despite the lack of any significant accumulation of mannitol that is normally the major photosynthetic product, antisense transformants were mostly phenotypically similar to the WT celery. However, in the presence of $\mathrm{NaCl}$, mature antisense transgenic plants were significantly less salt-tolerant, with reduced growth and photosynthetic rates, and some transformant lines were killed at $200 \mathrm{mM} \mathrm{NaCl}$, a concentration that WT celery can normally withstand. Although mannitol biosynthesis is normally enhanced in salt-treated WT celery, no such increase was observed in the antisense transformants. Like our previous gain of function results showing enhanced salt tolerance in Arabidopsis plants transgenic for a sense M6PR construct, these loss of function results, using an antisense construct in celery, demonstrate a major role for mannitol biosynthesis in developing salt-tolerant plants.

\section{(140) Salt Tolerance Assessment of Kentucky Bluegrass Cultivars Selected for Drought Tolerance}

Catherine M. Grieve*1, Stacy A. Bonos ${ }^{2}$, James A. Poss

${ }^{1}$ George E. Brown, Jr., Salinity Laboratory, Plant Science, Riverside, CA, 92507; ${ }^{2}$ Rutgers, The State University of New Jersey, Plant Biology and Pathology, New Brunswick, NJ, 08901

Six selections of Kentucky bluegrass (Poa pratensis L.) cultivars, selected based on their drought tolerance under field and growth chamber conditions in New Brunswick, N.J., were evaluated for salt tolerance based on yield and growth rates at eight soil water salinities [2 (control), 6, 8, 10, 12, 14, 18, and $22 \mathrm{dSm}^{-1}$ ] from Apr. to Sept. 2005 in Riverside, Calif. Cultivars Baron and Brilliant were selected as drought sensitive and 'Cabernet', 'Eagleton', and 'Midnight' were selected as drought tolerant. A Texas $\times$ Kentucky bluegrass (Poa arachnifera $\times$ Poa pratensis) hybrid selection (identified as A01-856) developed for improved drought and heat tolerance was also included. Vegetative clones were established in a randomized complete-block design with three replications, each containing 11 clones. Cumulative biomass and clone diameters were measured over time to evaluate relative yields and growth rates for the six cultivar selections. Based upon maximum absolute biomass production as a function of increasing EC, the order of production was 'Baron' $>$ 'Brilliant' > 'Eagleton' $>$ 'Cabernet' $\geq$ 'Midnight' $>$ A01-856. Yield relative to the non-saline control $\left(2 \mathrm{dSm}^{-1}\right)$ for each cultivar was similar, except that the differences between cultivars were less pronounced, and 'Baron' slightly outperformed 'Brilliant'. Clone area expansion rates were analyzed with a phasic growth model and beta, the intrinsic growth rate of the exponential phase parameter, significantly varied with salinity. Ranking of cultivars, based on expansion rates, was similar to that based on cumulative biomass. Salinity tolerance in this experiment did not appear to be related to the observed ranking for drought tolerance.

\section{(141) Leaf Abscisic Acid Accumulation in Response to Substrate Water Content: Variation Among Acer rubrum L. Genotypes}

William L. Bauerle*, William W. Inman, Jerry B. Dudley

Clemson University, Horticulture, Clemson, SC, 29634

Quantitative differences in leaf abscisic acid $\left(\mathrm{ABA}_{\mathrm{L}}\right)$ among four cultivars of red (Acer rubrum L.) and one Freeman maple (Acer $\times$ freemanii E. Murray) were investigated. This study tested the hypothesis that $\mathrm{ABA}_{\mathrm{L}}$ concentration can be used to compare the effects of water stress on the gas exchange response of five different maple cultivars, including four red maple genotypes, 'Summer Red', 'October Glory', 'Autumn Flame', and 'Franksred' (Red Sunset), as well as one hybridized Freeman maple genotype, 'Jeffersred' (Autumn Blaze). Cloned genotypes of red and Freeman maple were subjected to two treatments: 1) irrigated daily to container capacity or 2) irrigation withheld for one drought and recovery cycle. Leaf abscisic acid concentration, gas exchange, and whole-tree sap flow measurements were conducted under both conditions. Over the course of the drought stress and recovery phase, net photosynthesis $\left(\mathrm{A}_{\mathrm{net}}\right)$, stomatal conductance $\left(\mathrm{g}_{\mathrm{s}}\right)$, and transpiration $(\mathrm{E})$ declined as $\mathrm{ABA}_{\mathrm{L}}$ and instantaneous water use efficiency $\left(\mathrm{A} / \mathrm{g}_{\mathrm{s}}\right)$ increased. This study found that $\mathrm{ABA}$ tracked $\mathrm{g}_{\mathrm{s}}$ and that stomatal responsiveness to substrate moisture deficit is likely mediated by ABA accumulation in leaf tissue. This research demonstrates a leaf-level physiological response to substrate volumetric water content that appears to depend on $\mathrm{ABA}_{\mathrm{L}}$ concentration. In addition, the evidence in this study indicates that $\mathrm{ABA}_{\mathrm{L}}$ may be used as a potential surrogate for the $g_{s}$ response to substrate water stress and could become part of a cultivar drought tolerance selection strategy for red and Freeman maple. 
(142) Hydraulic Resistance: A Determinant of Shortterm Stomatal Conductance Signaling in Disparate Xylem Anatomy of Red Maple (Acer rubrum L.) and Shumard Oak (Quercus shumardii Buckl.)

William W. Inman, William L. Bauerle*

Clemson University, Horticulture, Clemson, SC, 29634

Recent work has shown that stomatal conductance $\left(\mathrm{g}_{\mathrm{s}}\right)$ and net photosynthesis $\left(\mathrm{A}_{\text {net }}\right)$ are responsive to the hydraulic conductance of the soil to leaf pathway $\left(X_{n}\right)$. Two tree species with differing xylem structures were used to study the effect of systematic manipulations in $X_{p}$ that elevated xylem $\square$ hydraulic resistance. Simultaneous measures of $g_{s}$, $A_{\text {net }}$, bulk leaf abscisic acid concentration $\left(\mathrm{ABA}_{\mathrm{L}}\right)$, leaf water potential $\left(\square_{L}\right)$, and whole plant transpiration $\left(E_{w}\right)$ were taken under controlled environment conditions. Quercus shumardii Buckl. (shumard oak), a ring porous species and Acer rubrum L. 'Summer Red' (red maple), a diffuse porous species, were studied to investigate the short-term hydraulic and chemical messenger response to drought. Both species decreased $A_{n e t}, g_{s}, \square_{L}$, and $E_{w}$ in response to an immediate substrate moisture alteration. Relative to initial well-watered values, red maple $A_{n e t}, g_{s}$, and $E_{w}$ declined more than shumard oak. However, $g_{s}$ and $A_{\text {net }}$ vs. whole-plant leaf specific hydraulic resistance was greater in shumard oak. In addition, the larger hydraulic resistance in shumard oak was attributed to higher shoot, as opposed to root, system resistance. The results indicate hydraulic resistance differences that may be attributed to the disparate xylem anatomy between the two species. This study also provides evidence to support the short-term hydraulic signal negative feedback link hypothesis between $\mathrm{g}_{\mathrm{s}}$ and the cavitation threshold, as opposed to chemical signaling via rapid accumulation from root-synthesized ABA.

\section{(143) Drought Acclimation of Leaf Gas Exchange in Jalapeno and Big Chili Pepper}

Frank Williams*1, Alexis Barbarin ${ }^{1}$, Donald Hauber ${ }^{2}$, Harish Ratnayaka ${ }^{1}$

${ }^{1}$ Xavier University of Louisiana, Biology, New Orleans, LA, 70125; ${ }^{2}$ Loyola University of New Orleans, Biologi, New Orleans, LA, 70118

Drought is a major constraint to chili production in a variety of cropping systems worldwide. A greenhouse study was conducted to understand mechanisms underlying drought acclimation of leaf gas exchange in two popular chili cultivars, 'Big Chili' and 'Jalapeno'. Unstressed 'Big Chili' had 27\% greater net photosynthesis $\left(P_{\text {net }}\right), 60 \%$ higher stomatal conductance $\left(g_{\mathrm{w}}\right)$, and $18 \%$ higher transpiration $(E)$, but only $3 \%$ greater intercellular $\mathrm{CO}_{2}$ concentration $\left(C_{\mathrm{i}}\right)$ than 'Jalapeno'. Light compensation point was 43.3 and $31.6 \mu \mathrm{mol} \cdot \mathrm{m}^{-2} \cdot \mathrm{s}^{-1}$ in 'Big Chili' and 'Jalapeno', respectively, although light-saturated assimilation $\left(A_{\max }\right)$ and photosystem II efficiency $\left(F^{\prime} / F^{\prime}\right)$ were the same in the two cultivars. Maximum rubisco-mediated carboxylation, $V_{\text {cmax }}$, was 66.3 and $69.1 \mu \mathrm{mol} \cdot \mathrm{m}^{-2} \cdot \mathrm{s}^{-1}$ in 'Big Chili' and 'Jalapeno', respectively. During drought, $50 \%$ of plants wilted to zero $P_{\text {net }}$ in 5 days in 'Big Chili', and 7 days in 'Jalapeno'. However, at wilting, relative water content was the same at $66 \%$, with $97 \%$ less $g_{w}$ than unstressed plants, in each cultivar. 'Jalapeno' had $9 \%$ greater $F{ }^{\text {, w }} / F$ ' than 'Big Chili', at wilting. Four days after rewatering, $P_{\text {net }}, g_{\mathrm{w}}$ and $F{ }^{\prime}{ }_{\mathrm{v}}^{\mathrm{m}} F$ ' were $27 \%, 47 \%$, and $8 \%$ less in 'Big Chili', but only $11 \%, 19 \%$, and $4 \%$ less in 'Jalapeno', than unstressed plants, respectively. 'Jalapeno' shows greater acclimation of gas exchange to drought than 'Big Chili' through rapid recovery of photosystem II, carbon assimilation and stomatal activity.

\section{(144) Landscape Growth and Aesthetic Quality of Coleus Managed with Irrigation Deficits}

Sloane M. Scheiber*, Richard C. Beeson

University of Florida, Environmental Horticulture, Apopka, FL, 32703

Previous research indicated that bedding plants can be maintained in landscape soils allowed to dry to substantially less than field capacity before irrigation; however, canopy size and aesthetic quality were compromised. Continuing this research, Solenostemon scutellarioides (coleus) were grown in drainage lysimeters in an open-sided clear polyethylene-covered shelter to assess growth characteristics and landscape quality when irrigated at various managed allowable deficits. Using tensiometers, plants were irrigated back to field capacity when $30 \%, 40 \%$, or $50 \%$ of plant available water within a soil was depleted. Deficits were evaluated against a control treatment of 1.25 $\mathrm{cm}$ daily irrigation. Additional plants were grown in a companion open field plot. Growth indices, biomass, irrigation volumes, and landscape quality ratings were recorded. No differences in final height, growth index, shoot or root dry weights, total biomass, or shoot-to-root ratios were found among treatments for either lysimeter or companion field plots. Landscape quality was comparable among treatments. However, total irrigation volume applied was significantly greater for the control treatments than deficit irrigation treatments. On average, irrigation volumes were 4.75 -fold greater for daily irrigation in comparison to other treatments.

\section{(145) Water Relations of Avocado in Response to Changes in Relative Humidity}

Robert L. Heath ${ }^{1}$, Michael V. Mickelbart*2, Mary Lu Arpaia ${ }^{1}$, Claudia Fassio ${ }^{3}$, Ruby Miller ${ }^{1}$

${ }^{1}$ University of California, Department of Botany and Plant Sciences, Riverside, CA, 92521; ${ }^{2}$ Purdue University, Department of Horticulture and Landscape Architecture, West Lafayette, IN, 47907; ${ }^{3}$ Catholic University of Valparaiso, Department of Fruit Crops, Quillota, Chile

Vapor pressure deficit (VPD) is the driving force for plant water loss. However, air relative humidity $(\mathrm{RH})$ can be used as a surrogate for VPD. While plants can adapt to environments with varying $\mathrm{RH}$, little is known about how they respond to sudden shifts in RH. Areas of Southern California can experience drastic shifts in RH, from $60 \%$ or greater to less than $20 \%$ in just a few hours. The effect of these shifts on avocado (Persea americana Mill.) tree productivity is a major concern to growers. We studied the effect of shifts in RH on 'Hass' avocado leaf stomatal conductance $\left(g_{\mathrm{s}}\right)$ and branch sap flow in trees grafted on Duke 7 clonal rootstock. Under many conditions, the avocado assimilation rate is governed by $g_{\mathrm{s}}$. When $g_{\mathrm{s}}$ is high in morning $(>150$ $\left.\mathrm{mmol} \cdot \mathrm{m}^{-2} \cdot \mathrm{s}^{-1}\right)$, the water loss generally leads to some stomatal closure in the afternoon ( $50 \%$ or more). Conversely, low morning $g_{s}$ results in a higher $g_{\mathrm{s}}$ rate in the afternoon ( $10 \%$ to $20 \%$ stomatal closure). This relationship between morning and afternoon $g_{\mathrm{s}}$ is intensified by a shift from high to low RH in the afternoon. Therefore, in a drier atmosphere in the afternoon, the afternoon depression in $g_{\mathrm{s}}$ is greater, leading to an impaired assimilation capacity. We hypothesize that the afternoon decrease in $g_{\mathrm{s}}$ is due to low root/shoot hydraulic conductivity since soil water is readily available. While it is possible that low hydraulic conductivity on $g_{s}$ is exacerbated at the graft union, sap flow of grafted trees in greenhouse studies was nearly equal to trees on their own roots (ungrafted); in fact, often the depression in the afternoon was less on grafted trees. This suggests that while avocado is not suited to areas with low $\mathrm{RH}$, water flow through the roots could be an additional criterion in selecting improved rootstocks.

\section{(146) Minimal Role of Ethylene on Leaf Abscission in Water-stressed Betula papyrifera Marsh.}

Mengmeng Gu*, James Robbins, Curt Rom, Hyun-Sug Choi

University of Arkansas, Horticulture

It has been observed that paper birch (Betula papyrifera Marsh.) has significant leaf abscission under mild to severe water stress. Oneyear-old paper birch seedlings were exposed to water deficit, ethylene, or inhibitors of ethylene action under controlled conditions to study water-stress induced leaf abscission. Exposing well-watered and waterstressed paper birch to $20 \mathrm{ppm}$ of ethylene for 96 hours resulted in more than $50 \%$ leaf abscission regardless of plant water status, while water stress alone did not cause leaf abscission. However, the application of $1 \mathrm{ppm}$ ethylene did not cause leaf abscission. Exposure to $1 \mathrm{ppm}$ 1-methylcyclopropene or treatment with $0.1 \mathrm{mM}$ of silver thiosulfate 
did not affect predawn water potential, gas exchange, and chlorophyll fluorescence. The measured evolved ethylene did not significantly increase in water-stressed paper birch prior to leaf abscission. Based on these observations, ethylene would appear to play a minor role in water-stress induced leaf abscission in paper birch.

\section{(147) Effect of Hypobaria, Oxygen, and Carbon Dioxide on Gas Exchange, Ethylene Evolution, and Growth of Lettuce Plants for NASA Advanced Life Support Systems}

Chuanjiu He ${ }^{1}$, Fred T. Davies*1, Ronald E. Lacey ${ }^{2}$, Sheetal Rao ${ }^{1}$

${ }^{1}$ Texas A\&M University, Horticultural Sciences, College Station, TX, 77843-2133; ${ }^{2}$ Texas A\&M University, Biological and Agricultural Engineering, College Station, TX, 77843

There are engineering and payload advantages in growing plants under hypobaric (reduced atmospheric pressure) conditions in biomass production for extraterrestrial base or spaceflight environments. Objectives of this research were to characterize the influence of hypobaria on growth, gas exchange, and ethylene evolution of lettuce (Lactuca sativa L. cv. Buttercrunch). Elevated levels of the plant hormone, ethylene, occur in enclosed crop production systems and in space-flight environments - leading to adverse plant growth and sterility. Lettuce plants were grown under variable total gas pressures [25 (low) or 101 $\mathrm{kPa}$ (ambient)]. During short growth periods of up to 10 days, growth was comparable between low and ambient pressure plants. Regardless of total pressure, plant growth was reduced at $6 \mathrm{kPa} \mathrm{pO}_{2}$ compared to 12 and $21 \mathrm{kPa} \mathrm{pO}_{2}$. At $6 \mathrm{kPa} \mathrm{pO}$, there was greater growth reduction and stress with ambient $(101 \mathrm{kPa})$ than low $(25 \mathrm{kPa})$ pressure plants. Plants at $25 / 12 \mathrm{kPa} \mathrm{pO}_{2}$ had comparable $\mathrm{CO}_{2}$ assimilation and a $25 \%$ lower dark-period respiration than $101 / 21 \mathrm{kPa} \mathrm{pO}_{2}$ (ambient) plants. Greater efficiency of $\mathrm{CO}_{2}$ assimilation/dark-period respiration occurred with low pressure plants at $6 \mathrm{kPa} \mathrm{pO}_{2}$. Low pressure plants had a reduced $\mathrm{CO}_{2}$ saturation point $\left(100 \mathrm{~Pa} \mathrm{CO}_{2}\right)$ compared with ambient $(150 \mathrm{~Pa} \mathrm{CO} 2)$. Low pO2 lowered $\mathrm{CO} 2$ compensation points for both 25 and $101 \mathrm{kPa}$ plants, i.e., likely due to reduced $\mathrm{O}_{2}$ competing with $\mathrm{CO}_{2}$ for Rubisco. Ethylene was $70 \%$ less under low than ambient pressure. High ethylene decreased $\mathrm{CO}_{2}$ assimilation rate of $101 / 12$ $\mathrm{kPa} \mathrm{O}_{2}$ plants. The higher dark-period respiration rates (higher night consumption of metabolites) of ambient pressure plants could lead to greater growth (biomass production) of low pressure plants during longer crop production cycles.

\section{(148) Effect of Hypobaria on the Expression of Ethylene Biosynthesis Genes in Arabidopsis thaliana}

Sheetal Rao*1, Scott Finlayson ${ }^{2}$, Chuanjiu $\mathrm{He}^{1}$, Ronald Lacey ${ }^{3}$, Raymond Wheeler ${ }^{4}$, Fred T. Davies ${ }^{1}$

${ }^{1}$ Texas A\&M University, Horticultural Sciences; ${ }^{2}$ Texas A\&M University, Soil \& Crop Sciences; ${ }^{3}$ Texas A\&M University, Biological and Agricultural Engineering; ${ }^{4}$ Kennedy Space Center, NASA Biological Sciences Office

The NASAAdvanced Life Support (ALS) System for space habitation will likely operate under reduced atmospheric pressure (hypobaria). There are engineering, safety, and plant growth advantages in growing crops under low pressure. In closed production environments, such as ALS, excessive plant-generated ethylene may negatively impact plant growth. Growth of lettuce (Lactuca sativa) in the Low Pressure Plant Growth (LPPG) system was enhanced under low pressure $(25 \mathrm{kPa})$, due in part to decreased ethylene production. Under reduced $\mathrm{pO}_{2}$, ethylene production decreased under low as well as ambient conditions (He et al., 2003). During hypobaria, the expression of genes encoding ethylene biosynthesis enzymes, namely ACC synthase $(A C S)$ and ACC oxidase $(A C O)$, is not known. The primary objective of this research was to characterize the expression of $A C S$ and $A C O$ genes in response to hypobaria. Three-week-old Arabidopsis was used to determine the effects of hypobaria $(25 \mathrm{kPa})$ and reduced $\mathrm{O}_{2}\left(12 \mathrm{kPa} \mathrm{pO}_{2}\right)$ at the molecular level. Candidate gene expression was tested using quantitative real-time PCR at different times after treatment. Under low pressure, $A C O 1$ expression is induced in the initial 12 hours of treatment, gradually decreasing with increased exposure. At $12 \mathrm{kPa} \mathrm{pO}, A C O 1$ was induced under ambient conditions, suggesting that plants under low pressure may be more tolerant to hypoxic stress. The mechanism for enhanced growth of lettuce under hypobaric conditions will be studied further by analysis of the $A C S$ and $A C O$ gene families, and stress-responsive genes, namely late-embryogenesis abundant (LEA) proteins and dehydrins.

\section{(149) Phytoremediation of Petroleum Hydrocarbons with a Lolium multiflorum-Glomus intraradices- Inorganic Fertilization System: Influence on Plant Growth, Antioxidant Activity, Microbial Respiration, and Hydrocarbon Degradation}

Alejandro Alarcon*1, Frederick T. Davies, Jr. ${ }^{1}$, Robin L. Autenrieth ${ }^{2}$, David Wm. Reed ${ }^{1}$, David A. Zuberer ${ }^{3}$

${ }^{1}$ Texas A\&M University, Department of Horticultural Sciences, College Station, TX, 77843-2133; ${ }^{2}$ Texas A\&M University, Department of Civil Engineering, College Station, TX, 77843-3136; ${ }^{3}$ Texas A\&M University, Soil \& Crop Sciences, College Station, TX, $77843-2474$

A phytoremediation study in a $3 \times 3 \times 2$ factorial experimental design was conducted to determine the effect of Glomus intraradices (AMF) inoculation and inorganic fertilization on the growth and development of Lolium multiflorum cv. Passarel Plus, and on the degradation of total petroleum hydrocarbons (TPH). The 80-day study was done with pots containing sandy soil. Seedlings of L. multiflorum were transplanted to uncontaminated or soil contaminated with Arabian crude oil (ACO) at concentrations of 3000 and $15,000 \mathrm{mg} \cdot \mathrm{kg}^{-1}$. Half of the seedlings were inoculated with 500 spores of AMF. Plants were fertilized with Long Ashton Nutrient Solution (LANS) at $0.5 \times, 1.0 \times$, or $2.0 \times$ strength, modified to supply $30 \mu \mathrm{g} \cdot \mathrm{mL}^{-1} \mathrm{P}$ to maximize the AMF establishment. Total plant dry weight and leaf antioxidant activity were reduced by ACO when compared to control plants. The LANS fertilization enhanced plant growth under ACO-contamination, and allowed similar antioxidant activity in plants exposed to $15,000 \mathrm{mg} \cdot \mathrm{kg}^{-1}$. Soil rhizosphere respiration was increased by LANS, particularly with $15,000 \mathrm{mg} \cdot \mathrm{kg}^{-1}$ ACO. AMF inoculation did not enhance plant growth, antioxidant activity, or microbial respiration. The average root colonization was around $30 \%$ in contaminated and uncontaminated rhizospheres, indicating that the tolerance of AMF symbiosis to ACO. Greater TPH degradation was achieved in non-AMF plants at $3000 \mathrm{mg} \cdot \mathrm{kg}^{-1} \mathrm{ACO}$ in combination with $0.5 \times$ LANS. LANS-fertilization with $1.0 \times$ or $2.0 \times$ did not enhance TPH-degradation when compared to $0.5 \times$ LANS.

\section{(150) Photo, Physical, and Mechanical Pretreatments Reduce Incidence of Blight Diseases in Carrots}

Kathryn Pickle*1, Rajasekaran Lada ${ }^{1}$, Claude Caldwell', Jeffrey Hoyle ${ }^{2}$, Jeffrey Norrie ${ }^{3}$

${ }^{1}$ Nova Scotia Agricultural College, Plant and Animal Sciences, Truro, NS, B2N 5E3, Canada; ${ }^{2}$ Nova Scotia Agricultural College, Environmental Science; ${ }^{3}$ Acadian Sea Plants, NA

Consumer demand for chemically free produce has increased; however, producers have become increasingly dependent on unreliable chemical defenses for control of diseases and pests. These dilemmas, along with the desire to maintain healthy farmland, have led to the research and development of environmentally sound practices. It is hypothesized that predisposing plants to photo, physical, and mechanical (PPM) mechanisms can allow plants to better withstand stress. Plants exposed to one form of PPM mechanism could confer resistance to a range of biotic and abiotic stresses. Such cross-resistance is commonly seen, but not well-understood. In this study, various PPM factors, including UV-C radiation, leaf brushing, and canopy trimming, were applied to field-grown carrots (Daucus carotae L.). The degree of blight and white mold infection was measured. Preliminary analyses showed that UV-C radiation at 4 weeks post-emergence or brushing at 4 or 8 weeks significantly reduced carrot blight and/or white mold. This implies that certain PPM mechanisms may induce plant defenses, allowing the crop to better defend itself against future biotic stress. 


\section{Poster Session 29-}

\section{Consumer Horticulture and Master Gardeners}

29 July 2006, 1:15-2:00 p.m.

\section{(304) Alaska Native Plant Commerical Demand Survey}

Lee Elder, Robert Gorman*

Univ. Alaska Fairbanks, Cooperative Extension Service, Anchorage, AK, 99508

About 333 people in the Anchorage area are involved in landscaping and landscape architecture, while about $18 \%$ of all farms in Alaska are considered greenhouse and nursery farms. These greenhouse and nursery farms account for $\$ 12.7$ million in annual sales and comprise $28 \%$ of total Alaska agricultural sales. Alaskan horticulture producers have little industry knowledge of landscapers' and landscape architects' demand for Alaska native plants. This survey attempted to uncover the amounts of specific native Alaska varieties of shrubs, trees, herbaceous plants, and ferns that landscapers and landscape architects used in 2004, while also asking what types of plants they would like to use if a consistent supply was established. Landscapers' and landscape architects' business activities and perceptions are also evaluated. Surveys were distributed electronically as well as by standard mail to 165 landscapers and landscape architects in the Anchorage area. An overall 12\% response rate provided insight into the commercial demand for Alaska native plant varieties.

\section{(305) Plant Propagation Protocol for Gardeners of Ten Species Native to Southeast Alaska}

\section{Robert F. Gorman*1, Julie Roller ${ }^{2}$}

${ }^{1}$ University of Alaska-Fairbanks, Cooperative Extension Service, Anchorage, AK, 99508; ${ }^{2}$ Pacific Horticulture College, Landscape Horticulture, Victoria, British Columbia, V9E2J7, Canada

Ten plant species native to southeast Alaska and surrounding regions were selected based on their value as ornamentals, food crops, disturbed site revegetation, and traditional Native American uses. Between 2003-05, seeds, cuttings, rhizomes, and bulbs from the 10 native plant species were collected in Sitka, Alaska, and propagated according to existing plant propagation protocol for each species. The most successful propagation method for each species was determined from field trials. This information was provided through workshops and Extension publications to gardeners in southeast Alaska and other parts of Alaska. The purpose of this project was to enhance growing local native plants as ornamentals, food crops, in disturbed site revegetation and for traditional Native American uses, particularly among native elders unable to collect these plants in the wild. A secondary purpose was to create a market for native plants in southeast Alaska and spawn a cadre of local cottage market gardeners to grow native plants for existing small nurseries. The 10 species selected included: Cornus canadensis, C. stolonifera, Empetrum nigrum, Fritillaria camschatcensis, Linnaea borealis, Oplopanax horridus, Rubus chamaemorus, Vaccinium parvifolium, Vaccinium ovalifolium, and Viburnum edule.

\section{(306) Growing Native Plants from Seed in Public Workshops}

\section{Margaret Wolf*}

Utah State University, Extension, Salt Lake City, UT, 84190

Five Utah Native Plant Propagation workshops during Mar. 2005 supplied 100 participants with specialized containers and potting mix, native plant seed, resource booklet, lecture, and instructor supervision during the hands-on workshop portion. Forty-three participants responded to a Sept. 2005 follow-up survey. Seedling survival averaged 6.4 seedlings per tray of 72 cells, or $8.8 \%$. Only $36 \%$ of the participants used the resource booklet after the workshop. Most survey respondents did not cite particular reasons for seedling failure. Seed propagation workshops are challenging due to: 1) wide variance in participants' horticultural experience; 2) limited materials and resources; and 3) inherent inconsistencies in native plant seed viability. Before attending future seed propagation workshops, registrants will receive seedling cultivation information to improve success rates.

\section{(307) Mississippi Master Gardener Training Curriculum Compact Disc: A Multi-Discipline, Two-year Project}

Lelia S. Kelly*, Julie Sexton

${ }^{1}$ Mississippi State University Extension Service, North Mississippi Research and Extension Center, Verona, MS, 38879; ${ }^{2}$ Mississippi State University Extension Service, Department of Human Sciences, Mississippi State, MS, 39759

The Master Gardener program continues to be one of the most popular and effective programs of Extension. Budget cutbacks and an everdecreasing pool of Extension personnel have warranted a reappraisal of how Extension trains these volunteers. The purpose of this project was to develop an up-to-date, complete, and user-friendly training program that could be used by agents or selected Master Gardeners with a minimum of training and advance preparation. Eleven subject matter specialists, 35 Extension agents, hundreds of Master Gardeners, and three curriculum specialists were all involved in this 2-year project. In addition to obvious updating of material, a sampling of objectives that were addressed in the process follows: 1) format the curriculum into a lesson plan with complete step-by-step instructions; 2) remove all questionable copyrighted pictures, graphs, drawings, etc.; 3) align the student manual to the material presented in the PowerPoint lessons; 4) incorporate a resource list of hands-on activities to support each lesson; 5) provide a reference list for each lesson; 6) provide a standardized test with answer key for complete curriculum; and 7) place the entire training curriculum on a compact disc. This project was completed in Summer 2005. Publication and copyrighting of a compact disc that represented the training resources for the Master Gardener program was a first for Mississippi State University Extension Service.

\section{(308) The Mesa County Colorado Irrigation Audit Program}

Curtis E Swift*1, Ardith Blessinger ${ }^{2}$

${ }^{1}$ Colorado State University, Cooperative Extension, Grand Junction, Colorado, 81501; ${ }^{2}$ Mesa County, Cooperative Extension, Grand Junction, Colorado, 81503

Seven and one-half square miles, or 4864 acres, of the Grand Valley in Western Colorado consists of high water-using landscapes. Overirrigation of Grand Valley soils flushes 580,000 tons of salt into the Colorado River each year. These salts negatively impact plant and animal health throughout the Colorado River basin. Proper watering of lawns can significantly reduce this problem. Correcting problems with a sprinkler irrigation system can reduce water use by an average of $40 \%$. If water use on all 4864 acres was reduced by $40 \%$, a savings of 11,187 acre feet, or over 3.6 billion gallons, of water would result. The annual historical evapotranspiration (ET) rate for the Grand Valley of Western is $\approx 61$ inches; the ET rate during the irrigation season (April through October) is $\approx 49$ inches. Since a typical sprinkler system is $\approx 70 \%$ efficient, in order to apply 49 inches of water to the soil, $\approx 70$ inches of water is required. Irrigation system problems such as improperly spaced heads, sunken heads and heads not adjusted are typically responsible for $40 \%$ more water being applied than necessary. In Western Colorado, this equates to an over-application of 28 inches ( 2.3 acre feet) of water being applied each year. The 2005 Western Colorado irrigation audit problem covering 18.7 acres of turf. Assuming the problems noted were all corrected, a water savings of 43 acre feet, or 14,013,797 gallons, of water resulted. The 2006 audit program will continue this educational and water-saving effort. A grant from the Department of the Interior-Bureau of Reclamation will help fund the 2006 Irrigation Audit project. 
(309) Consumer Survey Reveals Poinsettia Cultivar Preferences for 2005

\section{Catanzaro*, S. Bhatti}

Tennessee State University, Institute of Agricultural and Environmental Research, Nashville, TN, 37209

Twenty-one cultivars of poinsettia [Euphorbia pulcherrima Willd. Ex Klotzsch] were evaluated by respondents who voluntarily completed a paper survey $(\mathrm{n}=293)$ at TSU. Rooted cuttings from five major U.S. suppliers were potted and grown during the preceding 4 months according to standard industry practices. Cultivars were displayed without their names for the survey, and respondents were asked to rate each cultivar on a Likert-type scale, where $1=$ strongly dislike and $5=$ strongly like. The top eight rated cultivars (mean > 3.9) were all traditional red forms, which included the new cultivar 'Red Dragon', followed in descending preference by 'Christmas Spirit', 'Freedom Red', 'Cortez Electric Fire', 'Prestige Red', 'Premium Red', 'Novia Red', and 'Candlelight'. For each cultivar, the price respondents indicated they would be willing to pay was highly correlated with the Likert-type scale score. When asked about purchases in the prior year, $89 \%$ of respondents bought at least one red poinsettia. Retail outlets and prices paid varied among respondents. Color was by far the most popular criterion respondents used to determine whether they like or dislike a cultivar, followed by foliage and price. Consistent with recent trends for value-added products, consumers indicated that they would be willing to pay significantly more for a purple-painted plant with glitter than for a white-flowered plant that was otherwise of comparable quality. These results suggest that, while red poinsettias continue to dominate the poinsettia market, niche markets exist for unique flower and foliage traits created through breeding and through enhancements such as paint and glitter.

\section{(310) Mwarmwars and Leis in Guam}

\section{James McConnell*, Louise Q. Naholowaa, Mari Marutani}

University of Guam, College of Agriculture and Life Sciences/Agricultural Experiment Station, Mangilao, GU, 96923

A survey was conducted in Guam to determine the preferred uses and preferred flowers and foliage for leis and mwarmwars. Mwarmwars are a form of lei that is worn on the head. Mwarmwars were introduce to Guam by Carolinians. Lei giving is popular for special occasions to signify honored guests, as a token to loved ones, or given to travelers. In Guam, it is popular to give mwarmwars and leis as gifts to middle school, high school and college students. Preferred characteristics of flowers and foliage are wilt resistance and those that are not fragile. The most popular flowers are orchids, plumeria, mini carnations, baby's breath, bougainvillea, alstromeria, crown flowers, mini daisies, red ginger, spray roses, and sweetheart roses. The most popular foliage are leather leaf fern, polyscias, ti leaf, asparagus fern, and lemon leaves. The majority of the flowers and foliage are imported.

\section{Poster Session 30-Fruit Crop Physiology}

29 July 2006, 1:15 p.m.-2:00 p.m.

\section{(124) The Impact of Nitrogen Application on Nonstructural Carbohydrate Production in Cranberry Leaves}

Justine E. Vanden Heuvel*1, Joan R. Davenport ${ }^{2}$

${ }^{1}$ University of Massachusetts Amherst, Cranberry Station, E. Wareham, MA, 02538; ${ }^{2}$ Washington State University, Irrigated Agriculture Research and Extension Center, Prosser, WA, 99350

Five fertilizer treatments were applied to a 'Stevens' cranberry bed in a 3-way split application (roughneck, 75\% bloom, and 3 weeks after bloom) in Spring 2004 at State Bog in E. Wareham, Mass. Nitrogen rates were $0,22,45,67$, and $90 \mathrm{~kg} / \mathrm{ha}$; $\mathrm{P}$ was applied at $22 \mathrm{~kg} / \mathrm{ha}$, and $\mathrm{K}$ at $44 \mathrm{~kg} / \mathrm{ha}$. At mid-fruit development and again at preharvest, 20 vegetative and 20 fruiting uprights were collected from each plot in mid-morning. The $\mathrm{N}$ concentration per upright increased linearly with increased $\mathrm{N}$ application. Increased upright $\mathrm{N}$ concentration had no effect on soluble carbohydrate (sucrose + glucose + fructose) concentration, but decreased starch concentration, more so in vegetative uprights than in fruiting uprights on both sampling dates. Total nonstructural carbohydrate concentration (TNSC) was negatively impacted by increased $\mathrm{N}$ in vegetative and fruiting uprights at mid-fruit development, but $\mathrm{N}$ did not impact TNSC in either type of upright by harvest. Vegetative uprights contained greater concentrations of $\mathrm{N}$, soluble carbohydrates, starch, and TNSC at both sampling dates, but contained lower concentrations of chlorophyll A and chlorophyll B.

\section{(125) Effect of Organic Residues on Shoot and Root Growth of Apple Tree}

Davide Neri*1, Gianpaolo Mascanzoni², Paolo Sabbatini ${ }^{1}$, Franco Zucconi ${ }^{1}$, James Flore ${ }^{3}$

${ }^{1}$ Universita' Politecnica delle Marche, Energetica, Ancona, AN, 60100, Italy; ${ }^{2}$ Centro Ricerche Produzioni Vegetali, Centro Ricerche Produzioni Vegetali, Cesena, Italy; ${ }^{3}$ Michigan State University, Horticulture, Plant and Soil Science Building, East Lansing, MI, 48824

To simulate soil sickness, 1-year-old trees of 'Golden Delicious' (grafted on M9 and M106) were grown in rhizotrons $(1 \times 1-\mathrm{m}$ and $0.5-\mathrm{m}$ depth $)$ with different plant residues content, at Ravenna, Italy. Sandy loam soil was used as a substrate. Fine-grounded wood from apple and peach residues ( $6 \mathrm{~kg}$ per rhizotron) was mixed to the substrate and considered as main treatment. Mature compost ( $1 \%$ and $2.5 \%$ in volume) was added or not to the substrate with the organic residues and considered as subtreatment. The application of residues was localized either near the soil surface $(0-25 \mathrm{~cm})$ or deeper in the soil profile $(25-50 \mathrm{~cm})$. In each rhizotron, four trees on the same rootstock were planted and each soil treatment was replicated twice. After 2 years, the roots were accurately excavated (washing off the soil with water), and growth was measured. The presence of apple residues near the soil surface induced a $5 \%$ to $20 \%$ reduction of shoot growth. The reduction per plant dry weight was higher when trees were grafted on M106. At root level, the presence of residues increased the root migration in the search for fresh niches, enhancing root crossing and anastomosis. Both these shoot and root conditions are typical of replant diseases symptoms. The localization of apple residues in the lower part of the profile reduced the symptoms and so did the addition of compost. The peach residues did not affect shoot growth when compared to the control, but the shoot-to-root ratio was reduced, indicating a tendency to increase root migration.

\section{(126) Morphology and Physiology of Sugar Transport in Apple Leaves}

Edwin J. Reidel*1, Lailiang Cheng ${ }^{2}$, Robert Turgeon ${ }^{1}$

${ }^{1}$ Cornell University, Plant Biology, Ithaca, NY, 14853-5904; ${ }^{2}$ Cornell University, Horticulture, Ithaca, NY, 14853-5904

Sorbitol is the predominant phloem-translocated carbohydrate in apple. The pathway - either apoplastic or symplastic — of sugar transport from photosynthetic cells to the phloem is not established. Furthermore, the presence of absence of phloem loading has not been tested. This study characterized the morphology and physiology of sugar movement to the phloem in apple leaves. An electron micrographic survey of apple leaf minor vein morphology was performed. Plasmodesmata were abundant and found at the interfaces of each cell type from mesophyll to sieve elements, indicating a symplastic sugar pathway. We also tested for a phloem loading mechanism. First, ${ }^{14} \mathrm{C}$-labeled sorbitol and sucrose were introduced exogenously to leaf discs to determine if they are loaded into veins from the apoplast. Although leaf discs floated on a solution containing either sugar actively accumulated label, the labeling pattern was diffuse, with no accumulation in minor veins. The addition of the sulfhydryl reagent PCMBS to the leaf disc assay inhibited sugar uptake. We also attempted plasmolysis of apple leaf sections to measure the solute concentration difference between photosynthetic mesophyll cells and cells of the minor vein phloem. Apple leaf pieces fixed in a solution containing $1.5 \mathrm{~mol} / \mathrm{kg}$ osmoticum did not plasmolyze. We conclude that although active uptake of both sorbitol and sucrose takes place 
in apple leaves, apoplastic phloem-loading is absent. Considering the high sugar concentration and the symplastic connectivity among leaf cell types, we propose that sugars are instead enter the phloem after moving down — rather than against—a concentration gradient.

\section{(127) Use of Bioregulators to Manipulate Flowering in Apple}

Tory Schmidt*1, Don Elfving ${ }^{1}$, Jim McFerson ${ }^{2}$

${ }^{1}$ Washington State University, Horticulture, Wenatchee, WA, 98801; ${ }^{2}$ Washington Tree Fruit Research Commission, Wenatchee, WA, 98801

In three trials, 2004 crop loads were adjusted at the balloon stage of blossom development on heavily cropped whole apple trees by clipping all flower pedicels within a cluster while leaving the spur intact. Trees were adjusted to $0 \%$ crop (all flowers removed), $50 \%$ crop (half of all clusters removed), or left as $100 \%$ crop (no flowers removed). On 'Cameo'/Bud.9, 400 ppm GA $_{4+7}$ were applied to trees of each crop level at petal fall, $10 \mathrm{~mm}, 20 \mathrm{~mm}$, or left unsprayed. At each crop load, $\mathrm{GA}_{4+7}$ marginally diminished the 2005 return bloom regardless of application timing, but the 2004 crop level was far more influential in 2005 flowering. In a second 'Cameo'/Bud.9 trial, 0, 300, 600, or 900 ppm ethephon were applied to whole trees of each crop level at 45 DAFB. Ethephon generally demonstrated a rate response in improving the 2005 return bloom, but the 2005 flowering was more dramatically influenced by

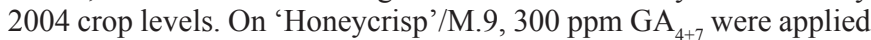
to whole trees of each crop level at $10 \mathrm{~mm}$. $\mathrm{GA}_{4+7}$ diminished 2005 return bloom at the $50 \%$ crop load, but spray effects were not as clear at the extreme 2004 crop levels. These results suggest that commercial floral inhibitors and promoters have difficulty overcoming endogenous effects of heavy or light bloom and crop in severely alternating apple trees. In a fourth trial, lightly cropped organic 'Fuji'/MM.106 trees were sprayed with $0,150,300$, or $450 \mathrm{ppm} \mathrm{GA}_{4}$ at petal fall, $10 \mathrm{~mm}$, or 20 $\mathrm{mm}$ timings in 2004. The 2005 return bloom was inversely correlated with spray rates, with $10 \mathrm{~mm}$ showing more floral inhibition than other timings. Overall, 'Cameo' was less sensitive to GA and ethephon than 'Honeycrisp' or 'Fuji'.

\section{(128) Effect of 2,4-DP Concentration on Fruit Drop Control and Maturation of 'Braeburn' Apples}

Patricia Garriz*, Graciela Colavita, Hugo Alvarez, Valeria Blackhall Comahue National University, Applied Biology Department, Faculty of Agriculture, c.c. 85, Cinco Saltos, Río Negro, 8303, Argentina

Apple fruit abscission shortly before harvest is a frequent, recurring problem, thereby reducing potential yield. The synthetic auxin $2(2,4-$ dichlorophenoxy) propionic acid (2,4-DP) was evaluated for its effect on reducing fruit drop and influencing ripening of 'Braeburn' apples, in the High Valley region of Río Negro, Argentina ( $\left.38^{\circ} 56{ }^{\prime} \mathrm{S}, 67^{\circ} 59^{\prime} \mathrm{W}\right)$. Thirteen-year-old apple trees grafted on MM 111 rootstock were sprayed on 4 Mar. 2005, at 162 days after full bloom (DAFB) with 2,4-DP at doses of $0.05 \%$ and $0.10 \%(\mathrm{v} / \mathrm{v})$, applied with an airblast sprayer, until runoff. Each tree was trained to palmette and planted in a single row from north to south with spacing of 2.3-4.0 m. The following measurements were performed: a) accumulated fruit drop, twice per week and b) maturity indices, weekly. Samples of uniform-size fruits were assessed for maturity ( $\mathrm{n}=20$ per date and treatment), from 167 (commercial harvest) to 195 DAFB. On 23 Mar. (at 181 DAFB), cumulative fruit drop for control treatment was $19.9 \%$, whereas 2,4 -DP significantly reduced it to $4.90 \%$ and $2.94 \%$ at $0.05 \%$ and $0.10 \%(\mathrm{v} / \mathrm{v})$, respectively. Reduction in the drop was also significant later, and 2,4-DP at both doses controlled drop comparably. The synthetic auxin did not affect fruit quality and maturation, based upon flesh firmness, starch degradation, and soluble solids concentration. We conclude that 2,4-DP is an effective drop control compound and it is useful as a management tool to increase yield by reducing fruit abscission and to extend the harvesting window of 'Braeburn' apples, since it does not affect ripening. Delaying harvest may provide flexibility for scheduling of labor, fruit processing and packaging, cold storage, and marketing.

\section{(129) Determining Maturity Indices for Eastern Black Walnut (Juglans nigra L.)}

Scott A. Brawner*1, Michele R. Warmund ${ }^{1}$, Mark V. Coggeshall ${ }^{2}$ ${ }^{1}$ University of Missouri, Division of Plant Sciences, Columbia, MO, 65211; ${ }^{2}$ University of Missouri, Center for Agroforestry, Columbia, MO, 65211

A study was conducted to: 1) evaluate the use of a durometer for determining husk softening and the date of black walnut harvest and 2) elucidate the relationship between husk hardness, kernel color and weight, and date of harvest. Thirty nuts were randomly collected weekly from mature 'Sparrow', 'Emma K', 'Kwik Krop', and 'Football' trees from 1 Sept. to 13 Oct. 2004. Husk denting, hardness, and color measurements were recorded immediately after harvest. Husk denting is the method commonly used by growers to determine the optimum time of harvest. Nuts were then hulled within 48 hours and the in-shell fresh weights were recorded. After drying under natural conditions for 5 weeks, kernel color and weights were assessed. On 15 Sept., 99\% of 'Sparrow' husks dented with a mean durometer value of 54. On 29 Sept., $\geq 99 \%$ of 'Emma K' and 'Kwik Krop' husks dented with mean durometer values of 63 and 68 , respectively. By 13 Oct., $80 \%$ of 'Football' husks dented with a mean durometer value of 74 . From the first harvest date to the time of maximum denting, kernel weight and color ( $\mathrm{L}^{*}$, hue values) of 'Sparrow' and 'Emma K' generally increased. The $\mathrm{L}^{*}$ and hue values of 'Kwik Krop' were inversely related to increased kernel weight over time. Kernel color of 'Football' remained relatively constant as kernel weight increased over time.

\section{(130) Effects of Nitrogen Fertigation on First-year Pecan Seedling Growth}

Patrick Conner*

University of Georgia-Tifton Campus, Horticulture, Tifton, GA, 31793

Pecan seedling rootstocks require several years of growth in the nursery before they are large enough to graft. In this experiment, first-year pecan seedlings were fertigated with varying amounts of calcium nitrate to stimulate growth rates. Pecan seedlings were fertigated every 2 weeks from May through October for a total of 10 applications. Total amounts of nitrogen $(\mathrm{N})$ applied by fertigation were $0,4,10,20$, and $40 \mathrm{~g}$ of $\mathrm{N}$ per seedling. Leaf samples were taken after the fourth and 10th fertigation, and leaf elemental concentration was affected by fertigation rates. Seedling height and caliper were measured monthly. Seedling caliper continued to increase throughout the experiment, while height increase stopped in September. Seedling height and caliper were not affected by $\mathrm{N}$ fertigation except for the $\mathrm{N}$ rate of $40 \mathrm{~g}$, which suppressed seedling growth. These results suggest that the nitrogen needs of the seedlings were met by a preplant application of $56 \mathrm{~kg} \cdot \mathrm{ha}^{-1} \mathrm{~N}$ applied as $10 \mathrm{~N}-10 \mathrm{P}-10 \mathrm{~K}$.

\section{(131) E-beam Irradiation Induced Minor Changes in Phytochemical Content and Antioxidant Capacity of Pecan Kernels}

Jose E. Villarreal*, Leonardo Lombardini, Luis Cisneros-Zevallos Texas A\&M University, Horticultural Sciences, College Station, TX, 77843

Pecans nuts from 'Kanza' and 'Desirable' cultivars were irradiated with $0,1.5$, and $3.0 \mathrm{kGy}$ using electron beam (E-beam) irradiation and stored under accelerated conditions $\left(40{ }^{\circ} \mathrm{C}\right.$ and $55 \%$ to $\left.60 \% \mathrm{RH}\right)$. Antioxidant capacity (AC), phenolic (TP) and condensed tannin (CT) content, HPLC phenolic profile, tocopherol content, peroxide value (PV), and fatty acid profile were evaluated in kernels after $0,7,21,55$, and 134 days of storage. Irradiation had no detrimental effects in AC and TP; however, variation was found throughout storage. Tocopherol content of 1.5 and $3.0 \mathrm{kGy}$ kernels decreased after irradiation, but no further decrease was observed thereafter. Irradiated 'Desirable' samples had greater PV than controls, while 'Kanza' $1.5 \mathrm{kGy}$ samples had increased PV only after 134 days of storage. No change in fatty acid composition was detected for any cultivar. Color modification induced by storage included a decrease in lightness and yellowness and an initial increase 
of redness followed by a decrease after 98 days of storage. No differences in phenolic profile were observed after irradiation. Compounds identified by HPLC in hydrolyzed extracts were gallic and ellagic acid, catechin, and epicatechin. In general, beside the decrease in tocopherol content, no detrimental effects were found in antioxidant composition caused by irradiation treatments. While a faster oxidation rate was seen in irradiated kernels for 'Desirable' cultivar, no other quality attribute was affected by E-beam irradiation.

\section{Poster Session 31-}

Vegetable Crops Management-Cropping Systems 2

29 July 2006, 1:15-2:00 p.m.

\section{(11) How Small Growers Can Help Vegetable Crops Survive Hurricanes: Tips We Didn't Want to Learn}

Nancy E. Roe*1, Darrin M. Parmenter ${ }^{2}$

${ }^{1}$ Farming Systems Research, Grower, Boynton Beach, FL, 33437; ${ }^{2}$ University of Florida, Palm Beach County Extension, West Palm Beach, FL, 33415

The Atlantic hurricane season stretches from June to November, and the vegetable growing season in South Florida begins in August. This means that pre-plant, planting, and early harvesting operations are performed during hurricane season. Three major hurricanes striking our area during two consecutive growing seasons have helped to teach us how to give vegetable crops the best chance of survival. On a 4-ha farm growing diversified vegetable crops, there have been clear differences in crop survival. Tiny seedlings of most crops were generally killed by driving rains and strong winds. However, 7- to $10-\mathrm{cm}$-tall transplants in plastic cell trays survived surprisingly well when placed on the ground in an area that did not flood and was protected from flying debris. During the hurricane with the highest winds, large plants, such as tomatoes and squash, were defoliated. Even plants that survived defoliation and regrew were injured, so they were vulnerable to diseases later in the season. It actually appears to be best not to stake crops in extremely high winds. Staked and tied tomatoes often broke off at the top string. In winds of over 90 knots, unstaked eggplants fared best of any mature crops. They fell over immediately and, lying on the ground, were protected from the high winds. After the storm passed, they were pulled upright, staked and tied, and produced excellent yields. Sweet corn also fell over, but, over a period of a week, gradually returned to about a $45^{\circ}$ angle where it produced about $30 \%$ of the normal yield. Of course, each hurricane has different characteristics; what works in one may not be the best during others. We are, however, hoping not to have a chance to learn more about how crops survive hurricanes.

\section{(12) Influence of Single and Biculture Cover Crops with or without Synthetic Nitrogen on Leaf Area Index and Above Ground Biomass Yields of Sweet Corn}

Wayne F. Whitehead*, Bharat P. Singh

Fort Valley State University, Agricultural Research Station, Fort Valley, GA, 31030-4313

During the 2004-05 growing season, a study was conducted to determine effect of cover crop, their mixture and fertilizer $\mathrm{N}$ rates on above ground biomass (AGB) yields, and Leaf Area Index (LAI) of Bt sweet corn. The following cover crop nitrogen fertility treatments were applied using randomized complete-block design with three replications: 1) fall- $0 \mathrm{~N}$, fallow; spring- $0 \mathrm{~N}, 2$ ) fall- $0 \mathrm{~N}$, abruzzi rye; spring- $0 \mathrm{~N}, 3$ ) fall- $0 \mathrm{~N}$, hairy vetch; spring- $0 \mathrm{~N}, 4$ ) fall- $0 \mathrm{~N}$, abruzzi rye+hairy vetch; spring- $0 \mathrm{~N}$, 5) fall-0 N, fallow; spring-101 kg N/ha, 6) fall- $0 \mathrm{~N}$, abruzzi rye; spring-101 $\mathrm{kg} \mathrm{N} / \mathrm{ha}, 7$ ) fall- $0 \mathrm{~N}$, hairy vetch; spring-101 kg N/ha, 8) fall-0 N, abruzzi rye+hairy vetch; spring-101 $\mathrm{kg} \mathrm{N} / \mathrm{ha}, 9$ ) fall-0 N, fallow; spring-202 $\mathrm{kg} \mathrm{N} / \mathrm{ha}, 10$ ) fall-0 N, abruzzi rye; spring-202 kg N/ha, 11)fall-0 N, hairy vetch; spring-202 kg $\mathrm{N} / \mathrm{ha}$, and 12 ) fall-0 N, abruzzi rye+hairy vetch; spring-202 $\mathrm{kg} \mathrm{N} / \mathrm{ha}$.
In Spring 2005, 'Attribute BSS0977' bi-color (BC) supersweet (sh2) corn seeds were field planted. AGB yields were collected during harvest week while LAI was recorded at tasseling $(6 / 27)$, silking $(7 / 8)$ and one week after harvest (7/25). Hairy vetch; spring-101 kg N/ha produced highest LAI at tasseling (2.18), silking (2.73), and one week after harvest (2.57). Lowest LAI at tasseling (1.12) and silking(1.60) were produced by abruzzi rye; spring- $0 \mathrm{~N}$ with fallow; spring- $0 \mathrm{~N}$ producing lowest LAI (1.40) one week after harvest. Maximum AGB fresh $(40.5 \mathrm{Mg} / \mathrm{ha})$ and dry weight $(12.1 \mathrm{Mg} / \mathrm{ha})$ yields were produced by hairy vetch; spring- $101 \mathrm{~kg} \mathrm{~N} / \mathrm{ha}$, while minimum AGB fresh $(9.6$ $\mathrm{Mg} / \mathrm{ha}$ ) and dry weight (3.6 Mg/ha) yields were produced by abruzzi rye; spring-0 N. Results imply LAI at each growth stage and AGB yields of this $\mathrm{BCsh} 2$ corn variety are best supported by hairy vetch supplemented with $\mathrm{N}$ at $101 \mathrm{~kg} / \mathrm{ha}$.

\section{(13) Pod Cactus (Nopalitos) as a Fresh Vegetable in Sonora, Mexico}

Everardo Zamora*, Santiago Ayala, Cosme Guerrero*, Damian Martínez*, Francisco Rivas*

Universidad de Sonora, Agricultura y Ganadería, Boulevard Luis Encinas y Rosales., Hermosillo, Sonora, 83,000, México

The pod cactus (Opuntia sp.), a tender stem, has been consumed by Mexican people for centuries either as a fresh or boiled vegetable. Traditionally, Southern Mexico people consume this tender pod cactus in several traditional Mexican dishes. During recent years, an increase in nopalitos consumption by Sonoran people has been observed. People interested in a disciplined diet or people troubled with high cholesterol desire this peculiar vegetable. In Hermosillo, Mexico, people buy nopalitos in small plastic bags packages a pound of small cutting of tender pods from local supermarkets and mobile sellers. Usually, a nopalitos bag pound price is a range of $\$ 1.00$ to $\$ 1.2$ U.S. dollars in Hermosillo. Nopalitos production in Sonora, Mexico, is a seasonal. Nopalitos harvesting starts in early April and runs through late October. Because low temperatures start in late October, and continue during the winter season, there is no nopalitos production in Sonora. Hense, Sonoran producers are considerig building high tunnels, to provide more temperature control and to produce nopalitos during the winter. Most growers are low-income people that produce nopalitos in home gardens. This activity allows low-income growers to have nopalitos during most of the year, except during the winter. The current growing area production of 240 acres (170 ha) of tender pod cactus was recorded during 2005 in Sonora, of which a half is cultivated in home gardens. A potential yield production of nopalitos in Sonora is about of 40 tons per acre of tender pod cactus. In comparison to other crops, nopalitos production is a good alternative for small growers.

\section{(14) Establishment of Buckwheat as a Summer Cover Crop after Early Vegetables}

Thomas Björkman*

Cornell University, Horticultural Sciences, Geneva, NY, 14456

Buckwheat has historically been used to suppress weeds and improve soil condition, but many of the tricks to success have been lost to history. Buckwheat is inexpensive and particularly effective in short windows between crops. We are documenting the techniques of existing experts and complementing that with research. We surveyed northeastern vegetable and strawberry growers to identify what information they need in order to feel confident that they could succeed with a buckwheat cover crop. Top questions include seed availability, types of weeds controlled, relation to other cover crops, volunteer management, and herbicide tolerance. One question tested experimentally was how to establish a full stand with minimum cost. We tested the minimum tillage requirement following pea harvest. No-till resulted in good emergence but slow growth, and dominance by weeds. Disk incorporating the pea residue resulted in excellent growth, which was not further enhanced by chisel plowing before disking. Buckwheat seedlings are intolerant of waterlogging, so deeper tillage may be important in wet years. Sowing buckwheat immediately after tillage resulted in emergence of 
$35 \%$, leaving gaps large enough for weeds to grow. Waiting 1 week gave an $80 \%$ stand and complete weed suppression. Waiting 2 weeks also gave an $80 \%$ stand, but weed growth was advanced enough that weed suppression was incomplete. Therefore, a buckwheat cover crop following early vegetables requires light tillage to permit root growth, and up to a week of decomposition. If those provisions are made, complete weed suppression is obtainable.

\section{(15) The Cactus Pear Vegetable (Nopalitos) as an Alternative Crop for Northwest Mexico}

Fabián Robles-Contreras ${ }^{1}$, Rubén Macias-Duarte ${ }^{2}$, Raul Leonel Grijalva-Contreras*3, Manuel de Jesus Valenzuela-Ruiz ${ }^{4}$

${ }^{1}$ INIFAP-Caborca, Alternative Crops, Sonora, México; ${ }^{2}$ INIFAP-Caborca, Soli \& Horticultural, Sonora, México; ${ }^{3}$ INIFAP-Caborca, Protected Horticulture, Sonora, México; ${ }^{4}$ INIFAP-Caborca, Viticulture, Sonora,

The agricultural zones in the Sonoran Desert have great problems of water availability. An alternative that the grower must consider to diminish the negative effects caused by the water shortage is the establishment of crops with low water requirements. One such crop is the cactus pear vegetable (nopalitos). This crop supports and produces in conditions of low water availability and is a product of high demand. The objective was evaluate the potential of production of nopalitos under this condition. We evaluated two cultivars (Opuntia inermis and $O$. Ficus-indica) in a system of furrows with $1 \mathrm{~m}$ of separation between lines and $50 \mathrm{~cm}$ between plants, with a pruninig system of two producing caldodes per plant. The plot was drip-irrigated every 10-15 days. The evaluation was made during Spring 2004, harvesting the nopalitos to commercial size $(17-21 \mathrm{~cm})$ every $3-4$ days. The measured variables were the yield and the weight of the nopalitos. The budbreak and harvest of nopalitos appeared in form of productive cycles, and we evaluated only the first two cycles of harvest (24 Mar. to 20 May). The obtained yields were 45.8 and $42 \mathrm{t} \cdot \mathrm{ha}^{-1}$ in cv. Opuntia inermis and O. ficus-indica, respectively. The weight of nopalitos was $112 \mathrm{~g}$ and $106 \mathrm{~g}$, respectively. We observed an insect attack (Dactylopiidae), and it was necessary to make two applications of a biological soap for pest control. The presence of this pest was almost exclusively in cv. Opuntia inermis, producing yellowish color in some cladodes.

\section{(16) Delayed Harvesting Results in Firmer Fall- sown Onions}

Neel Kamal*, Christopher S. Cramer

New Mexico State University, Plant and Environmental Sciences, Las Cruces, NM, 88003-8003

Onions grown in New Mexico currently are hand-harvested. In order to remain competitive and to lower production costs, growers will need to harvest onions mechanically. The current recommendation for harvest time is when $80 \%$ of onion tops have fallen. The objective of this study was to measure several bulb quality traits when bulbs were harvested at four different stages. Twelve short- and intermediate-day onion cultivars of different maturities were sown during Sept. 2004 in Las Cruces, N.M. Bulbs were harvested at four stages of physiological maturity: $20 \%$ tops down (TD), $80 \%$ TD, 1 week after $80 \%$ TD, and 2 weeks after $80 \%$ TD. After curing, data on harvest date, bulb diameter, height, firmness, number of growing points, average center diameter, fleshy scale number, and thickness were collected. For most traits, no differences existed among the different treatments. For the earliest-maturing cultivars, the maximum bulb firmness and number of scales were observed when bulbs were harvested 2 weeks after $80 \%$ TD. For later-maturing cultivars, the maximum number of scales was observed 1 week after $80 \%$ TD, while the maximum bulb firmness was observed at 2 weeks after $80 \%$ TD. For latest-maturing cultivars, bulbs harvested at 1 week after $80 \%$ TD were firmer than bulbs harvested at other times. For later-maturing cultivars, average scale thickness was greatest when bulbs were harvested 2 weeks after $80 \%$ TD. From this work, a delayed harvest of 1 to 2 weeks after $80 \%$ TD resulted in firmer bulbs with more scales.

\section{(17) Bulb-to-Bulb Transmission of Botrytis allii in} Dry Bulb Onion Production

Brad Geary*1, Deron Beck ${ }^{2}$, Mike Thornton ${ }^{2}$

${ }^{1}$ Brigham Young University, Plant and Animal Sciences, Provo, UT, 84602; ${ }^{2}$ University of Idaho, Plant Soil and Entomological Sciences, Parma Research and Extension Center, Parma, ID, 83660

Botrytis neck rot, caused by Botrytis allii, is a major storage problem in dry bulb onions. This disease has been responsible for losses exceeding $50 \%$, resulting in financial devastation to growers. Botrytis infections likely occur around the last month onions are in the field prior to harvest and before moving into storage. Earlier studies indicated that the spread of this fungus did not occur in storage. More recent studies suggest that bulb-to-bulb transmission in storage is possible, especially when bulbs are handled roughly during harvest. 'Vaquero' dry bulb onions were planted in 2003 and 2004, and in 2005 the cultivar Renegade was used. All bulbs were produced using standard commercial practices. Bulbs were hand-lifted at harvest to reduce the amount of mechanical injury, then cured for 2 weeks. To simulate impact bruising, a 1/4-lb weight was dropped through a 2-ft PVC pipe, striking a healthy bulb on the outer scale. Shatter bruising occurred by dropping healthy bulbs down a 7 -ft column containing seven offset immobile metal bars. To evaluate the interaction of inoculum load with bruise injury on disease spread, healthy bulbs were surface inoculated with botrytis and incubated until visible sporulation. Twelve infected bulbs were added to onion samples immediately after bruising. The treatments were then stored under ambient conditions. In 2004 and 2005, shatter bruising caused significant increases in botrytis infections to the inside and outside of the bulb over impact bruising, and impact bruising caused significantly more infections than the nonbruised check treatments. Adding botrytis infected bulbs increased infections, but only when injury of either type was present. Shatter bruising had the most significant effect on total botrytis infection.

\section{(18) Is Withholding Irrigation during Winter Months Detrimental to Onion Bulb Quality?}

Jagtar Singh*, Christopher S. Cramer

New Mexico State University, Plant \& Environmental Sciences, Las Cruces, NM, 88003

Onion growers in New Mexico often withhold irrigation for overwintered onion varieties during the months of December and January. This study was initiated to determine if this deficit irrigation program is detrimental to onion bulb quality. Twelve short- and intermediate-day onion cultivars, which differed in their maturity, were seeded in Sept. 2004 in Las Cruces, N.M. Once plants were established, 12 plots of each cultivar were not irrigated during the months of December and January (dry treatment), while the same number of plots was irrigated during these months (wet treatment). Once a plot had $80 \%$ of the plants with tops down, all bulbs were harvested, cured, and data on date of harvesting, bulb diameter, bulb height, firmness rating, number of centers, scale number, and scale thickness of first and third fleshy layers were collected. For most of the bulb traits measured, there was no difference between the two irrigation treatments for the cultivars tested. For the earliest-maturing cultivars, bulbs grown in the dry treatment had on average more fleshy scale layers than the bulbs grown in the wet treatment. For later-maturing cultivars, bulbs grown in the dry treatment had more growing points (centers) per bulb than the bulbs grown in the wet treatment. For the latest-maturing cultivars, average fleshy scale layer thickness was greater for bulbs grown in the dry treatment. From this work, a winter deficit irrigation program appears to be detrimental to the percentage of single-center bulbs for later-maturing, autumn-sown onion cultivars.

\section{(19) The Dry Piquin Chili as a Potential and Natural Industry in Sonora, Mexico}

Everardo Zamora*, Santiago Ayala, Cosme Guerrero, Damián Martínez, Francisco Rivas

Universidad de Sonora, Agricultura y Ganadería, Hermosillo, Sonora, Mexico

The piquin chili (Capsicum annuum L.), a type of high-pungency small- 
ball chili fruit, is traditional among Sonoran people and is consumed as paprika and dry fruit in some regional dishes. Also, the high prices obtained in domestic and oversea markets every year, mainly through piquin dry fruit sales, have encouraged this small informal and seasonal industry. In some Sonoran Mountain ranges, where piquin chili plants grow wild, a latent, informal industry has been maintained by people who harvest piquin chilies as fresh and dry fruits for sale. Enough precipitation, good environment conservation, and other conditions maintain the natural preservation of this chili plant, so that the piquin chili industry is maintained without cultivation, and has become a natural and ecological chili industry. During harvest time (September through November), low-income people harvest by hand dry piquin chili fruits for sale in several cities in Sonora. After harvesting, fresh red piquin chili fruits must be dried over several days. The fruit is spread out over a fabric during sunny days and removed at nights, and the small piquin red fruits dry in just a few days. Usually dry piquin chili presentations are sold in liter $(0.25-1 b)$ or kilogram $(2-1 b)$ lots. Throughout the 2005 dry piquin chili harvesting season, sales reached prices close to $\$ 18$ and $\$ 82$ (U.S. dollars) per liter or kilogram, respectively. Although the dry piquin chili is exported to the United States, fresh fruit sales are still limited to the domestic Sonoran market. The piquin chili harvesting season offers temporary employment and represents, in part, an important source of family income.

\section{(20) The Potential of Bacanora Plant Use in Distillation and Ornamental Industries in Sonora, Mexico}

Everardo Zamora*, Santiago Ayala*, Cosme Guerrero*, Damian Martínez*, Francisco Rivas*

Universidad de Sonora, Agricultura y Ganadería, Hermosillo, Sonora, Mexico

In Sonora, Mexico, a new crop is emerging as a potential and alternative crop industry: the bacanora plant (Agave angustifolia Haw). The bacanora plant belongs to the Amaryllidaceous family and is a type of agave with a low water requirements, growing as a wild plant in Sonora, Mexico. It is different from the one used to produce the most famous Mexican liquor in the world - tequila. Some time ago, the bacanora plant had been used to distill and produce a kind of liquor known by Sonoran people as bacanora. However, this activity was prohibited by the Sonoran government during the past century. Now, in order to encourage job growth, the Sonoran government has given permission to producers for new bacanora plantations. To protect the originality of both bacanora plant production and the bacanora distillation industry, the Federal Mexican government issued a law that prohibits all activity for growing bacanora plant and bacanora distillation outside of Sonora, Mexico. The law was approved in 2005 and now, all natural areas where wild plants of bacanora grow are known as "origin denomination," which means that some Sonoran areas are unique locations where the bacanora industry can be legally established for plant production, distillation, refining, and labeling. Currently, there are about 20,000 ha of bacanora plants located in Sonora. Some producers estimate that, in the near future, there will be more than 60,000 ha of bacanora plants. Although bacanora plants are used mainly for producing liquor, they could be considered ornamental plants for establishing home desert gardens together with desert plants, such as cacti.

\section{Poster Session 32-Floriculture}

30 July 2006, 12:00-12:45 p.m.

\section{(74) Winter Greenhouse Performance and Photoperiod Responses of 51 Cultivars of Seed- grown Trailing Petunias}

H. Brent Pemberton*, William R. Roberson

Texas A\&M University, Agricultural Research and Extension Center, Overton, TX, 75684

Long days are known to hasten flowering of Petunia hybrida. However, breeding of modern standard-type petunia cultivars has reduced this response. With the introduction of new genetics involved in the creation of trailing-type petunias, many cultivars have been observed to have a strong photoperiodic response to the point that it is an issue for late winter or early spring flowering cropping cycles. In order to characterize this photoperiodic response in modern seed-grown trailing-type petunia cultivars, seed of 51 cultivars of trailing petunias (Petunia hybrida) were sown in November in 288 plug trays. When established about 4 weeks later, uniform plants were selected and transplanted individually to $15-\mathrm{cm}$ pots. Plants were exposed to either natural days or a 4-hour night interruption using incandescent light from 2200 to 0200 $\mathrm{HR}$ each day until flowering. A minimum night temperature of $17^{\circ} \mathrm{C}$ was maintained. Days to first flower from sowing ranged from 72 to 117 days. Generally, the night interruption treatment hastened flowering. However, the degree of hastening ranged from 4 and 5 days for 'Ramblin' Burgundy Chrome' and 'Ramblin' Lilac Glo', respectively, to 27 and 32 days for 'Tidal Wave Cherry' and 'Tidal Wave Hot Pink', respectively. Effects of night interruption treatment on plant architecture will also be presented.

\section{(75) Sugars and Flower Induction in Poinsettia}

Emilia Orozco-Gaeta ${ }^{1}$, Maria-Teresa Colinas-Leon*1, Luis-Alonso Valdez-Aguilar ${ }^{1}$, Edilberto Avitia-Garcia ${ }^{1}$, Ismael Leon-Rivera ${ }^{2}$

${ }^{1}$ Universidad Autonoma Chapingo, Fitotecnia, Carretera Mexico-Texcoco Km. 38.5, Chapingo, Texcoco, Edo. Mexico,Mexico; ${ }^{2}$ Universidad Autonoma del Estado de Morelos, Cemntro de Investigaciones Quimicas, Av. Universidad 1001, Col. Chamilpa, Cuernavaca, Morelos, Mexico

During Fall 2004, poinsettia plants were grown in a greenhouse (Texcoco, Edo. Mexico, $\left.19^{\circ} 29^{\prime} \mathrm{N}\right)$. The objectives were to: 1 ) evaluate which soluble carbohydrates (mono- and disaccharides) are present in the cultivars Supjibi and Peter Star and their concentrations; 2) study the relationship between sugar content and flower induction; and 3) analyze the relationship between starch content and phenology of the plant. Apical meristems were prepared for microscopy, soluble sugars, and sugars from starch hydrolysis were studied by HPLC. Flower induction in 'Supjibi' took place about 99 days after transplant (DAT), with no artificial short photoperiod. In 'Peter Star', flower induction took place about 137 DAT, 19 days after initiation of short-day photoperiod. Soluble sugars found were: sucrose, maltose, glucose, and fructose (in order of the highest to lowest concentration). Concentration varied from $0.5 \%$ to $2.1 \%$ for 'Supjibi' and from $1.1 \%$ to $2.9 \%$ for 'Peter Star', based on fresh weight. Sucrose content is reduced in root and mature leaf during flower induction, probably sent to young leaves. During flower induction, there is also an increase in glucose in young leaves. Sugars from starch hydrolysis were: fucose, (6-desoxi-L-galactose), fructose, and galactose. Soluble sugars content generated from starch varies in each organ from $2.0 \%$ to $32 \%$ for 'Supjibi', and from $2.0 \%$ to $39 \%$ in 'Peter Star'. During induction, starch content is reduced (between 6\% and $9 \%$ ). After flower induction, there is an increase in leaf area and in starch content (from 32\% to 39\%), during bract development starch seems to be utilized in this plant part.

(76) Photoperiod, Irradiance, and/or Cool Temperature Effects on Mamillopsis senilis, Echinopsis Hybrid, and Trichocereus Hybrid Growth and Flowering

John Erwin*, Esther Gesick, Ben Dill, Charles Rohwer University of Minnesota, Department of Horticultural Science, St. Paul, MN, 55108

The impact of photoperiod, irradiance, and/or cool temperature on flowering and/or dormancy in Mamillopsis senilis and Echinopsis and Trichocereus hybrids was studied. Two- to 3-year-old plants (180 plants of each type) were grown for 4 months under natural daylight (DL) conditions (August-November) in a greenhouse maintained at $26 \pm 2{ }^{\circ} \mathrm{C}$. Plants were then placed in either of two greenhouses: a cool temperature house $\left(5 \pm 2{ }^{\circ} \mathrm{C} ; \mathrm{DL}\right)$, or a lighting treatment house $(22 / 18 \pm$ $1^{\circ} \mathrm{C}$ day/night temperature, respectively). The lighting treatment house 
had eight light environments: 1) short day (SD; 8 h; 0800-1600 HR); 2) $\mathrm{SD}+25-35 \mu \mathrm{mol} \cdot \mathrm{m}^{-2} \cdot \mathrm{s}^{-1}$; 3) $\mathrm{SD}+45-50 \mu \mathrm{mol} \cdot \mathrm{m}^{-2} \cdot \mathrm{s}^{-1}$; 4) $\mathrm{SD}+85-95$ $\mu \mathrm{mol} \cdot \mathrm{m}^{-2} \cdot \mathrm{s}^{-1}$; 5) DL plus night interruption lighting (NI; 2200-0200 $\mathrm{HR} ; 2 \mu \mathrm{mol} \cdot \mathrm{m}^{-2} \cdot \mathrm{s}^{-1}$ from incandescent lamps); 6) $\mathrm{DL}+25-35 \mu \mathrm{mol} \cdot \mathrm{m}$ ${ }^{2} \cdot \mathrm{s}^{-1}$ (lighted from $0800-0200 \mathrm{HR}$ ); 7) DL $+45-50 \mu \mathrm{mol} \cdot \mathrm{m}^{-2} \cdot \mathrm{s}^{-1}$; and 8) $\mathrm{DL}+85-95 \mu \mathrm{mol} \cdot \mathrm{m}^{-2} \cdot \mathrm{s}^{-1}$. Supplemental lighting was provided using high-pressure sodium lamps. Plants were placed in the cool temperature house for $0,4,8$ or 12 weeks before being placed under lighting treatments. All plants received lighting treatments for 6 weeks and were then placed in a finishing greenhouse (DL; $22 \pm 2{ }^{\circ} \mathrm{C}$ ). Data were collected on approximate day when growth resumed, the date when each flower opened (five only), total flower number per plant, and how long each flower stayed open (five only). Whether species exhibited dormancy and what conditions, if any, broke that dormancy was identified. Species were also classified into photoperiodic, irradiance, and vernalization response groups with respect to flowering.

\section{(77) Effects of Photoselective Shadecloths on Flowering of Potted Orchids}

\section{Kent D. Kobayashi*1, Edwin F. Mersino ${ }^{2}$}

${ }^{1}$ University of Hawaii at Manoa, Tropical Plant \& Soil Sciences, Honolulu, HI, 96822-2279; ${ }^{2}$ University of Hawaii at Manoa, Plant \& Environmental Protection Services, Honolulu, HI, 96822-2279

Increasing flower production and manipulating the flowering season of potted ornamental plants would help provide a competitive edge for floriculture producers in Hawaii. Photoselective shadecloths that modify the light spectrum may be an approach to achieve these aims. The objective of this study was to determine the effects of photoselective shadecloths on the flowering of potted orchids. At the University of Hawaii Magoon Facilities (Oahu), two kinds of orchids were grown in a saranhouse in chambers built with PVC pipe covered with the four shadecloths - black (control), gray (diffusive), red, and blue-each providing 30\% shading. With M-10973 Rhv. Herbert Kurihara 'Flori' orchid plants, more buds and flowers were produced under the black and red shadecloths than the other two shadecloths. The black and red shadecloths resulted in similar earlier starting dates of bud appearance (4 Aug.2005) and flower appearance (4 Aug. 2005). Whereas, under the blue shadecloth, bud appearance (18 Aug. 2005) and flower appearance (31 Aug. 2005) were delayed. Under the black and red shadecloths, flowering ended earlier (27 Oct. 2005). When flower production resumed, new spikes were produced earliest under the red shadecloth (1 Dec. 2005). No new spikes were produced under the black shadecloth. For M-10878 Colmanara Sphacetante 'Evelyn' AM/AOS orchid plants, spike formation occurred later than with the M-10973 plants. Spike formation occurred on the same date for all shadecloth treatments (10 Feb. 2006), with similar numbers of spikes. Thus, photoselective shadecloths influenced flowering, but their effects varied with the orchid.

\section{(78) Sheltering Cut Flower Plants to Increase Stem Length}

H. Chris Wien*

Cornell University, Horticulture, Ithaca, NY, 14853

The stems of many flower species used as cut flowers are too short to be commercially useful. Non-chemical techniques are needed to increase the length of the harvested stems without weakening stem strength. Field experiments were conducted that explored the use of black or red shade fabric, used either as a canopy, or as a side curtain, with three species of cut flowers. Trachelium caerulum, Eustoma grandiflorum (Echo Champagne), and Rudbeckia hirta (Prairie Sun) were grown in split-plot experiments in which shade and shelter treatments were applied as main plots, and the flower species formed the subplots. In 2004, shade canopies of $70 \%$ light transmission were compared in black and red ("ChromatiNet") netting, and 50\% red netting. Stem length increased from $51 \mathrm{~cm}$ for unshaded controls to 54, 56, and 59 $\mathrm{cm}$ for $70 \%$ black, red, and $50 \%$ red, respectively. Productivity of the plants was decreased an average of $21 \%$ by shading. In 2005 , shade canopies of $50 \%$ black or red were compared to side curtains of the same materials, and an unsheltered control, growing the same species of flowers. Stem length was increased by $25 \%$ when plants were grown under a shade canopy, and by $14 \%$ in the side curtain plots. Shading treatments reduced stem yield by $31 \%$, whereas side curtains had no significant effect on number of stems per plant. Color of the netting did not affect stem length or stem yield in 2005. In both years, the thickness of harvested stems were increased significantly in the shelter treatments. The three species reacted similarly to the treatments imposed in both years. Shelter treatments can be a practical way of increasing cut flower stem length.

\section{(79) Direct Bulblet Regeneration from Mature Embryo: A Rapid, Efficient and Genotype- independent In Vitro Morphogenesis Pathway for Preservation of Endangered Wild Populations of Fritillaria imperialis and Fritillaria persica}

Manijeh Mohammadi-Dehcheshmeh ${ }^{1}$, Ahmad Khalighi ${ }^{1}$, Esmaeil Ebrahimie*2, Manoochehr Sardari $^{3}$, Rohangiz Naderi ${ }^{1}$

${ }^{1}$ University of Tehran, Horticulture Faculty, Bolvar Ememzade Hasan, Karaj, Tehran, 31587-11167, Iran; ${ }^{2}$ University of Tehran, 3 Department of Agronomy and Plant Breeding, Bolvar Ememzade Hasan, Karaj, Tehran, 31587-11167, Iran; ${ }^{3}$ Chahar Mahal va Bakhtiari, Department of Research Center of Agriculture and Natural Resources, Farokhsahr Road, Shahrekord, Chahar Mahal va Bakhtiari, Iran

Wild populations of Fritillaria sp. have dramatically decreased in Iran because of pest overflow and continual grazing. Previous studies have shown that Fritillaria cannot rapidly and efficiently propagate by traditional methods. In vitro tissue culture techniques have shown high potential for micropropagation of endangered plants. The use of bulb-scale pieces for tissue culture can result in the destruction of the endangered parent plant. Fritillaria is a heterozygous plant in which the genetic content of each embryo is different from others, even on the same plant. In this study, mature embryos of $F$. imperialis and $F$. persica were used as explant for the first time. Embryos were extracted from seeds and cultured on B5 medium supplemented with various combinations of BAP $(0,0.1,1 \mathrm{mg} / \mathrm{L}), \mathrm{NAA}(0,0.4,4 \mathrm{mg} / \mathrm{L})$, and IAA $(0,0.4,4 \mathrm{mg} / \mathrm{L})$. Embryo explant showed low genotype dependency between different heterogenous and heterozygote populations of both $F$. imperialis and F. persica. The best response of bulblet regeneration in both $F$. imperialis and $F$. persica was obtained from $1 \mathrm{mg} / \mathrm{L} \mathrm{BAP}+$ $0.4 \mathrm{mg} / \mathrm{L} \mathrm{NAA}+4 \mathrm{mg} / \mathrm{L}$ IAA and direct organogenesis pathway, with 15 bulblets per explant for $F$. imperialia and 20 for $F$. persica. Because of the large number of embryos in a plant and their different genetic contents, established in vitro propagation by using embryo explant in this study can provide broad genetic resources and variations. As explained above, in vitro protocols can play a major role in rescuing $F$. imperialis and $F$. persica from extinction.

\section{(80) Direct Somatic Embryogenesis from Thin- section Leaf Explant of Phalaenopsis Hybrids}

Jae-Dong Chung ${ }^{1}$, Hong-Yul Kim², Jung-Hae Suh ${ }^{3}$, Oh-Chang Kwon ${ }^{4}$, Chang-kil Kim*5

${ }^{1}$ Kyungpook National University, Horticulture, Daegu, Kyeongbuk, 702-701, Korea; ${ }^{2}$ Catholic University of Daegu, Horticulture, Gyeongsan, Kyeongbuk, 712-702, Korea; ${ }^{3}$ Kyungnam College, Enviromental Landscape Architecture, Pusan, Kyungnam, 617-714, Korea; ${ }^{4}$ Dong-A University, Horticulture, Pusan, Kyungnam, 604-714, Korea; ${ }^{5}$ Sangju National University, Horticulture, Sangju, Kyeongbuk, 742-711, Korea

Somatic embryo formation was observed on thin-sectioned leaf explants within 3 weeks of culture from two Phalaenopsis hybrids-Phalaenopsis Hwafeng Redjewell 'Ching Ruey' Phalaenopsis Chingruey's Giant Ching Ruey’ $(\mathrm{R} \times \mathrm{R})$, and Phalaenopsis Formosa Best Girl Ching Ruey' Depts. Lih Jiang Beauty 'S 566' (WR $\times$ WR). Frequency of somatic embryo formation was higher in hybrid WRxWR than $\mathrm{R} \times \mathrm{R}$ and optimal concentration of TDZ for the induction of somatic embryos was $9.08 \mu \mathrm{M}$. In $(\mathrm{WR} \times \mathrm{WR})$ embryo proliferation was simultaneously observed after transferring the explants with somatic embryo clumps onto PGR-free half-strength MS medium. Six months after initiation, 
the culture plantlets were produced. This is the first report on somatic embryogenesis induced directly from the leaf explants using TDZ in Phalaenopsis.

\section{(81) Effect of Ethephon on Establishment of Herbaceous Ornamentals in a Landscape- Response of Plants During Production Phase}

Sudeep Vyapari*1, Robert Graves ${ }^{1}$, Edmund Thralls ${ }^{2}$

${ }^{1}$ University of Florida, Department of Environmental Horticulture, UF/IFAS-Plant City Campus, Plant City, FL, 33563; ${ }^{2}$ University of Florida, Department of Environmental Horticulture, Mid-Florida REC, Apopka, FL, 32703

Use of growth regulators in ornamental plant production is a common nursery practice. Research conducted in determining landscape establishment of herbaceous plants treated with various concentrations of growth regulators is limited. The first phase of this study was conducted to evaluate response of three herbaceous ornamental species to application of ethephon. Containerized plants of irish moss, scotch moss, and salvia were treated once with FLOREL $^{\circledR}$ (ethephon) at 0 , 250,500 , or 750 ppm 2 weeks after transplanting into \#1 size containers. During the course of the 6-week production period, standard nursery practices of fertigation, pest control, and weed management were followed. Data were collected on growth indices and marketable quality ratings (scale of $1-5$ ) every 2 weeks. Mean initial and final shoot and root dry weights were calculated at the start and end of this phase of the experiment. The experimental design was completely randomized and data analyses were made using the analysis of variance with SAS general linear model procedure. Growth indices $(\mathrm{cm})$ were significantly affected by increasing concentrations of FLOREL ${ }^{\circledR}$. At $750 \mathrm{ppm}$ concentration the mean growth indices were low $(2516 \mathrm{~cm})$ whereas, control $(0 \mathrm{ppm})$ produced the highest mean growth indices $(4317 \mathrm{~cm})$. Significant differences in marketable quality ratings were also observed among the treatments where control $(0 \mathrm{ppm})$ plants had the best mean rating (4.3) as compared with $500 \mathrm{ppm}$ (3.6) or 750 ppm (3.5) concentrations. Salvia produced mean growth indices and mean width of 9106 and $513 \mathrm{~cm}$, respectively. However, irish moss had asignificantly higher mean quality rating (4.4) when compared with either salvia (3.7) or scotch moss (3.3).

\section{(82) Determining Effects of a Uniconazole Drench on Celosia, Petunia, Salvia, and Tagetes}

Erik S. Runkle*, Catherine M. Whitman, Mike Olrich

Michigan State University, Horticulture, East Lansing, MI, 48824

Uniconazole is a plant growth regulator used to inhibit internode elongation on container-grown ornamental plants. Uniconazole is effective on a wide range of plants, but is not commonly used on bedding plants because of concerns about stunting and flowering delay. Our objective was to determine the effectiveness of uniconazole when used as a drench, eliminating the variability inherent in a spray application. Seedlings of Celosia argentea L. var. plumosa L. 'Fresh Look Red', Petunia $\times$ hybrida Vilm.-Andr. 'Prostrate Wave Rose', Salvia splendens Sell ex Roem. \& Schult. 'Vista Red', and Tagetes erecta L. 'Inca II Gold' in 288-cell plug trays were transplanted 2 days after arrival into $10-\mathrm{cm}$ pots filled with a soilless medium containing no bark. Plants were placed in a greenhouse with a setpoint of $20^{\circ} \mathrm{C}$ and under a 16 -h photoperiod provided by high-pressure sodium lamps. A single drench application of $0,0.04,0.07,0.15$, or $0.30 \mathrm{mg}$ active ingredient/pot was made 11 days after transplant. The uniconazole drench inhibited internode elongation in these species and higher rates provided a greater degree of response. At time of flowering, the 0.30 -mg uniconazole drench inhibited shoot length in Celosia, Petunia, Salvia, and Tagetes by $36 \%, 23 \% 26 \%$, and $13 \%$, respectively. Drenches of 0.04 or $0.07 \mathrm{mg}$ provided a desirable degree of height control for Celosia and Salvia. For vigorous species like Petunia or Tagetes, 0.15 to $0.30 \mathrm{mg}$ may be more appropriate. We observed a 1- or 2-day delay in flowering of Salvia and Tagetes plants drenched with $0.30 \mathrm{mg}$, but no delays in Petunia flowering.

\section{(83) Production Systems for Marigold in a Tobacco Transplant Greenhouse}

Carl E. Niedziela, Jr.*, Stephen A. Emerson, Guochen Yang

North Carolina A\&T State University, Natural Resources and Environmental Design, Greensboro, NC, 27411

Plug seedlings of Tagetes erecta L. 'Gold Coin Mix' were planted in four production systems (harvest lugs, lay-flat bags, pots, and polystyrene trays) on 5 May 2005. Production systems were randomized in a Latin-square design with four replications of each system. Each treatment plot was $0.7 \mathrm{~m} \times 1.1 \mathrm{~m}$. Planting density was 31 plants $/ \mathrm{m}^{2}$. The harvest lugs were $55 \mathrm{~cm} \times 37 \mathrm{~cm} \times 16 \mathrm{~cm}$. The lay-flat bags were $114 \mathrm{~cm} \times 30 \mathrm{~cm} \times 3 \mathrm{~cm}$. The pots were $25-\mathrm{cm}$ bulb pans. The polystyrene trays were $67 \times 34 \times 5 \mathrm{~cm}$ and contained 32 square cells. All of the containers were filled with the same tobacco germination media. The plants in the harvest lugs, lay-flat bags, and pots were irrigated on alternate days with $150 \mathrm{mg} \cdot \mathrm{kg}^{-1} \mathrm{~N}$ from $20 \mathrm{~N}-4.4 \mathrm{P}-16.6 \mathrm{~K}$. The plants in the polystyrene trays were floated on a solution of $150 \mathrm{mg} \cdot \mathrm{kg}^{-1} \mathrm{~N}$ from $20 \mathrm{~N}-4.4 \mathrm{P}-16.6 \mathrm{~K}$. Float solutions were monitored and adjusted weekly for volume and fertilizer concentration. Individual stems were harvested at the appropriate stage of development for market. The fresh weight, stem length, and dry weight of individual stems were recorded. The rate of growth and maturation differed between production systems and locations in the greenhouse. Detailed results will be presented.

\section{(84) Producing Cut Flowers in High Tunnels and Open Fields}

\section{H. Chris Wien*}

Cornell University, Horticulture, Ithaca, NY, 14853

Flowering plants grown and marketed locally as cut flowers have become economically important in recent years, concentrating on species that are too delicate to ship long distances. Although the bulk of this production is done outdoors, extending the season at both ends by using high tunnels (unheated greenhouse structures covered with a single layer of polyethylene), has become popular. To determine the advantages and drawbacks of using high tunnels as season extension structures for cut flowers, variety trials of seven and four flower species were conducted in 2004 and 2005, respectively, both in a high tunnel and in an adjacent field. In the cool, rainy 2004 season, plants in the tunnel were ready for harvest 20 days sooner than the same varieties outside. Outside plants had $25 \%$ more stems than tunnel-grown plants, but there was no difference in average stem length. In the dry, warm season of 2005, tunnel-grown plants were 8 days earlier, and had $58 \%$ more stems, which were increased in length by $16 \%$ over field-grown plants. Lisianthus (Eustoma grandiflorum) and snapdragons (Antirrhinum) were grown in both seasons, and gave similar results both times. Tunnel-grown lisianthus showed a $34 \%$ increase in stems per plant, and an $8 \%$ increase in stem length, and the stems could be harvested 8 days earlier. Snapdragons were 9 days earlier in the tunnel both years, but tunnel-grown plants produced $22 \%$ fewer stems. Disease and insect pressures occurred in both locations, but pest species causing problems differed. With careful choice of species to be grown in tunnels, cut flower production in this environment can be optimized.

\section{Poster Session 33-Viticulture}

30 July 2006, 12:00-12:45 p.m.

\section{(117) Grape Cultivar Preference and Organic Control of Japanese Beetles (Popillia japonica)}

Sanjun Gu, Kirk Pomper*

Kentucky State University, Land Grant Program, Frankfort, KY, 40601

Feeding by Japanese beetles (JB) can damage grape leaves and result in a loss of vine leaf area, thus reducing both yield and fruit quality. The objectives of this study were to determine if there was a grape cultivar 
feeding preference by JBs and whether application of organic feeding deterrents to leaves would reduce damage by JBs. Eleven American and hybrid grape cultivars were evaluated in a choice feeding study in cages, where $15 \mathrm{JBs}$ per vine were introduced for 48 hours. The number of leaves damaged by JBs varied by cultivar. 'Chardonel' (43\%) had fewer damaged leaves than 'Seyval' (78\%), 'Edelweiss' (74\%), 'Norton' (63\%), and 'Vignoles' $(63 \%)$. The leaf area lost by feeding varied by cultivar, with 'Lacrosse' $(15 \%)$ showing the least damage and 'Seyval' the most (40\%). In another JB choice feeding study with organic feeding deterrents, Surround (at label rate) and Neemix 4.5 [at high label rate (A) or doubled high label rate (B)] were compared to a water control with 'Chardonel', 'Traminette', and 'Vignoles' grapes. Surround and Neemix 4.5 applied at level A reduced the number of damaged leaves compared to the control; however, Neemix 4.5 at level $\mathrm{B}$ showed similar damage to the control. Loss of leaf area due to feeding of JBs was greatest on vines treated with Neemix 4.5 at level B and least on those treated with Surround, although this loss of leaf area was not significantly different between the two Neemix 4.5 treatments. Vines treated with Surround had the least leaf area loss, followed by the control, Neemix 4.5 at level A, and Neemix 4.5 at level B.

\section{(118) Selection of Pollinators for 'Pam' Muscadine Grape}

Zhongbo Ren*, Jiang Lu*, Xia Xu*

Florida A\&M University, Viticulture Center, Tallahassee, FL, 32317

'Pam' is a popular muscadine grape (Vitis rotundiforia) used for the fresh fruit market. It is characterized with large berry, nice appearance, good texture and flavor, and high disease resistance. This cultivar, however, requires pollinators because it is pistillate. To select a better pollinator for this pistillate cultivar, a 2-year study was conducted at Florida A\&M University in 2003 and 2005. Fresh pollen of muscadine grape 'Alachua', 'Nesbitt', and 'Noble' was used for pollination. 'Nesbitt' pollen resulted in $100 \%$ of the pollinated clusters setting fruits in both years, while pollination with 'Alachua' yielded $70 \%$ (2003) to $87 \%$ (2005) of fruiting clusters, and 'Noble' pollen yielded $72 \%$ (2003) and 97\% (2005) fruiting clusters, respectively. Fruit numbers per fruiting cluster also varied among pollen sources. 'Alachua' pollen resulted in 7.2 (2003) and 8.1 (2005) fruits per cluster, while 'Nesbitt' produced 10.1 (2003) to 10.5 (2005) fruits per cluster, and 'Noble' produced 8.3 (2003) and 9.0 (2005) berries per cluster. Open pollinated 'Pam' had $100 \%$ clusters set fruits, averaging about 11 fruits per cluster in both seasons. No difference of berry size was observed among fruits produced from different pollen sources. Both sugar contents and acids levels were a little bit higher in 2005 than that in 2003. However, no differences of sugar content and acid level were found among the fruits derived from different controlled pollen sources. These data suggested that 'Nesbitt' is a better pollinator than 'Alachua' and 'Noble' for 'Pam' muscadine grape.

\section{(119) Mycorrhizal Effects on Grape Acclimation}

\section{Rhoda Burrows*, Anne Fennell}

South Dakota State University, Horticulture, Forestry, Landscape, \& Parks, Brookings, $\mathrm{SD}, 57007$

Grape growers are interested in production systems that are ecologically sustainable. The positive effect of colonization by arbuscular-mycorrhizal (AM) fungi on water and nutrient uptake, and thereby plant growth, is well-documented, at least in greenhouse studies. However, we have only limited data on how this complex association between grapes and these fungi might affect entry into winter dormancy, a factor crucial to vine survival in the northern great plains. To test this relationship, we rooted cuttings of grape genotypes Vitis riparia and an $\mathrm{F}_{1}$ selection of 'Seyval' $\times V$. riparia in a soil mix containing either inoculum of the AM Glomus intraradices, or a control. These cuttings were then used in growth chamber, greenhouse, and field experiments. The inoculated rooted cuttings were successfully colonized; no significant differences were observed among treatments in initial cutting vigor, budbreak, or leaf number. In the field and greenhouse, periderm development (an indicator of entry into dormancy) occurred earlier in AM-inoculated plants, regardless of genotype. Growth chamber-grown plants did not display differences in the first year, but, after a dormancy cycle, buds from inoculated plants survived lower temperatures in freezing tests compared to controls.

\section{(120) Comparison of Techniques for Whole Plant Sampling in Grape}

Suphasuk Pradubsuk ${ }^{1}$, Joan R. Davenport*1, Robert G. Stevens ${ }^{1}$, Eileen M. Perry ${ }^{2}$

${ }^{1}$ Washington State University, Crop and Soil Sciences, Prosser, WA, 99350; ${ }^{2}$ Washington State University, Center for Precision Ag Systems, Prosser, WA, 99350

Collection and estimation of root material are likely some of the greatest challenges of whole-plant sampling. As with other perennial crops, season of sample collection is also a challenge in grape whole-plant sampling. Our interest is in collecting grape whole-plant samples from an established ( $>25$-year-old) vineyard to study plant nutrient partitioning. Before launching into routine sampling, two techniques were compared for very fine, fine, and coarse root distribution. For very fine and fine root sampling, soil cores were collected in a radial pattern around the vine trunk at eight sample points, each either $20,60,120 \mathrm{~cm}$ from the trunk or 50,100 , and $150 \mathrm{~cm}$ from the trunk. Roots were washed from the soil material, separated into fractions and weighed. For evaluation of techniques for sampling fine and coarse roots, roots were either excavated by tracing them from the trunk in about a $1-\mathrm{m}^{3}$ soil volume or by extracting about the same soil volume using a backhoe and shaking the soil free of the roots. Overall, the more narrow soil core sampling gave a greater total root mass and both the tracing and backhoe methods gave similar results. In addition, pruning weight measurement is also frequently measured in grape research. We compared using the NDVI (Normalized Difference Vegetation Index) device, the "Greenseeker"TM, with pruning mass to determine if this device could be used as a nondestructive measurement for grape pruning weight.

\section{(121) 'Rubaiyat': An Old Cultivar with New Potential}

\section{Eric T. Stafne*}

Oklahoma State University, Department of Horticulture and L.A., Stillwater, OK, 74078

In 2005, 212 ha of grapes were grown in Oklahoma and more than 30 licensed wineries were in operation. With this increase in grape growing and wine making comes the necessity to evaluate commercially appropriate cultivars. 'Rubaiyat' was a cross between Seibel 5437 and 'Bailey' made at Oklahoma State University by Herman Hinrichs in 1952. The overall genetic constitution of 'Rubaiyat' (based on disomic inheritance) is $37.5 \% \mathrm{~V}$. lincecumii, $31.25 \% \mathrm{~V}$. vinifera, $18.75 \%$ V. labrusca, $6.25 \% \mathrm{~V}$. rupestris, and $6.25 \% \mathrm{~V}$. riparia. 'Rubaiyat' is a dark blue-black grape that ripens in mid-August. The berries are medium-sized and round. The clusters are medium in size with a long shoulder. The vine has medium vigor and good to very good disease resistance. The juice is very dark red with about $19 \%$ sugars and tartaric acid levels of $0.63 \%$. The wine is fruity and has good balance. A slight "foxy" flavor from the V. labrusca is sometimes evident in wine made from 'Rubaiyat'. Currently, other hybrid grape cultivars such as 'Chambourcin' are more popular for use as red wine varietals than 'Rubaiyat'. However, in observation trials in Oklahoma, 'Rubaiyat' compares favorably to 'Chambourcin' in quality and may outyield it. Perhaps the greatest potential for 'Rubaiyat' is as a teinturier, since it has the attribute of red flesh derived from its progenitor 'Alicante Bouschet', a parent of 'Alicante Ganzin'. 'Rubaiyat' is not widely grown, but the potential exists for it to become an important cultivar for Oklahoma and surrounding states.

\section{(122) Productivity of 'Superior Seedless' Grafted on Rootstocks Harmony and Freedom for Table Grape}

Manuel de Jesus Valenzuela-Ruiz ${ }^{1}$, Fabián Robles-Contreras², Rubén Macias-Duarte ${ }^{3}$, Raul Leonel Grijalva-Contreras*4

'INIFAP-Caborca, Viticulture, Caborca, Sonora, 83600, México; ${ }^{2}$ INIFAP-Caborca, 
Agroclimatology; ${ }^{3}$ INIFAP-Caborca, Soli\&horticultural; ${ }^{4}$ INIFAP-Caborca, Protected Horticulture

Grapes are one of the more important fruit crops in northwest Mexico, mainly dedicated for the production of table grape, with the most important cultivar being 'Superior Seedless'. The shortage and high cost of extraction of the water, infestation of nematodes, and salinity, are the main problems that limit the production in the region. The objective of the present investigation was to determine the productivity of 'Superior Seedless' grafted on the rootstocks Harmony and Freedom. The present study was carried out in the INIFAP-Caborca Research Station in 2005, and consisted of 15 plants for treatment grafted to each rootstock. We used 'Superior Seedless' in their own foot as control; watering was under a drip-irrigation system, and we used a completely randomized statistical design, where each plant was the experimental unit. Statistical differences were not observed in production among the two rootstocks (Freedom and Harmony), which yielded 2225 and 2112 boxes/ha, respectively (boxes of $10 \mathrm{~kg}$ ) and an average of 1000 boxes/ha over the control. The quality (berry size and cluster weight) of the fruit on both rootstocks was superior to the control. They were no differences in the sugar content and the phonological stages (budbreak, flowering, and harvest time). In both rootstocks, we obtained $100 \%$ nematode control, a $35 \%$ savings of water consumption, and a $40 \%$ savings in fertilizer use.

\section{(123) Performance of Muscadine Grape (Vitis rotundifolia Michx) Cultivars in Mississippi}

Stephen J. Stringer*, Donna A. Marshall, James M. Spiers, Blair J. Sampson

USDA-ARS, Thad Cochran Southern Horticulture Laboratory, Poplarville, MS, 39470

Muscadines are grapes indigenous to the Southeastern United States, and they are highly prized for their unique fruity flavors. Factors including skin color, berry size, skin thickness, flower type, productivity, etc., vary among muscadine grape cultivars, making some cultivars more desirable for fresh market while others are better suited for processing and prodction of juice, jelly, and wine. A muscadine grape research vineyard was established in McNeil, Miss., in 1992 containing 37 named cultivars and numerous breeding lines. Performance of these cultivars was evaluated in 2001-2003 and results of these trials are presented.

\section{Poster Session 34-Seed and Stand Establishment}

\section{July 2006, 12:00-12:45 p.m.}

\section{(204) Optimization of One-step Extraction/ Methylation Method for Analysis of Fatty Acid Composition in Rice and Alday Seeds}

Kyoung-Shim Cho*1, Hyun-Ju Kim¹, Sang-Mi Moon ${ }^{1}$, Hyun-Gu Choi $^{2}$, Young-Sang Lee ${ }^{1}$

Soonchunhyang Univ., Biological Resources and Technology, Shinchang-myon Eupnaeri 646, Asan, Chung-Nam, 336-745, South Korea; ${ }^{2}$ Chungcheon Nam-Do Agricultura Research and Extension Services, Crop Experiment, Sinarm-myon Jongkyung-ri 365, Yesan, Chung-Nam, 340-861, South Korea

Traditionally fatty acid composition used to be analysed by GC and the sample preparation consisted of lipid extraction from sample and subsequent methyl esters preparation, which are time-consuming and cumbersome. As an alternative, simultaneous extraction/methylation methods are being developed for rapid and simplified sample preparation. To optimize one-step extraction/methylation method for analysis of fatty acid composition in brown rice and adlay seeds, various factors, such as sample to reaction solution ratio, reaction time and temperature, and shaking intensity, were altered and resultant fatty acid composition data were evaluated in comparison with previous reports. The ratio of sample weight to reaction solution volume was the most critical factor in that higher sample to reaction solution ratio caused overestimation of palmitic acid and linoleic acid composition, resulting in underestimation of oleic acid. Lower reaction temperature also induced overestimation of linoleic acid and underestimation of oleic acid. Reaction duration and the intensity of shaking prior to and during the reaction, however, induced no significant changes in analysis results. In conclusion, the optimum condition for brown rice was mixing 5 grains (about $0.2 \mathrm{~g}$ ) of brown rice with $680 \mu \mathrm{L}$ of methylating mixture and $400 \mu \mathrm{L}$ of heptane, followed by reaction at $80{ }^{\circ} \mathrm{C}$ for 2 hours.

\section{(205) Germination of Echinacea Species Is Enhanced by ACC}

Laura A. Wood*, Sharon Kester, Robert L. Geneve

University of Kentucky, Horticulture

Echinacea are North American members of the Asteraceae, and all can show some degree of endogenous physiological seed dormancy that is alleviated by chilling stratification. In some species, ethephon has been shown to substitute for chilling stratification to relieve dormancy. The objective of this research was to investigate the effect of ACC on dormancy and germination in five Echinacea species. Germination for each species was $90 \%, 59 \%, 99 \%, 81 \%$, and $21 \%$, respectively. Germination on 5 mM ACC improved germination in E. tennesseensis, E. paradoxa, and E. simulata to $82 \%, 99 \%$, and $82 \%$, respectively, but there was no change for E. purpurea and E. angustifolia. Germination rate was dramatically accelerated in all species in the presence of ACC. On average, there were $57 \%$ more seeds germinated on ACC after 3 days compared to untreated seeds. Exposing E. purpurea and E. tennesseensis seeds to 1 or 2 days of $5 \mathrm{mM} \mathrm{ACC}$ before drying and subsequently re-hydrating the seeds did not have the same effect as continual exposure to ACC. Similarly, there was no clear enhancement of adding ACC during stratification over the improvement gained by chilling stratification alone. Seeds produced more ethylene upon germination following both stratification and ACC treatment. However, significantly more ethylene is produced during germination in ACCtreated seeds. It was clear that ACC-treated seeds showed improvement for enhanced germination speed and in some cases germination percentage. Unfortunately, this enhanced germination was not retained in seeds treated with ACC and dried prior to germination. Additional work is required to develop a commercially viable method of loading $\mathrm{ACC}$ into seeds for germination enhancement.

\section{(206) Carbohydrate Compositions and Peroxidase Activity in Whole Seed, Cotyledon, and Embryo Tissues of Cowpea (Vigna unguiculata L. Walp) Cultivars Grown Under Stress Temperatures}

Shahidul Islam*1, Carmen Rafaela ${ }^{2}$, James Garner ${ }^{1}$

${ }^{1}$ University of Arkansas, Agriculture, Pine Bluff, AR, 71601; ${ }^{2}$ Mississippi State University, Plant Science

Twenty-five cultivars were initially screened for germination at 10 ${ }^{\circ} \mathrm{C}, 30^{\circ} \mathrm{C}$, and $40{ }^{\circ} \mathrm{C}$. Four cultivars were chosen for further study for physiological and biochemical characteristics - namely, 'Texas Cream 40 ' (TC-40), which showed ability to germinate at very high $\left(40^{\circ} \mathrm{C}\right)$ and low $\left(10^{\circ} \mathrm{C}\right)$ temperatures; 'Black Crowder' (BC), which had acceptably high germination at $40^{\circ} \mathrm{C}$, but reduced germination at $10^{\circ} \mathrm{C}$; and 'Mississippi Purple' (MP), which exhibited lower germination at all temperatures tested. The main sugars present in cowpea seed were sucrose, raffinose, and stachyose. Sugar contents were affected by cultivar, type of tissue, and temperature. Sucrose contents were higher in embryo tissue of cultivars with a lower germination percentage, and reduced in the cultivar with a higher germination percentage, suggesting the use of sucrose for germination. Sucrose decreased greatly at $30{ }^{\circ} \mathrm{C}$ and increased again at $40{ }^{\circ} \mathrm{C}$. Sucrose "de novo" synthesis was higher at higher temperature. An accumulation of sucrose was evident in embryo tissues of cultivars with reduced ability to germinate at low temperature. Raffinose and stachyose contents were higher in ungerminated seed. In germinated seed, raffinose and stachyose contents were found only in cotyledon tissues at $10^{\circ} \mathrm{C}$. The peroxidase activity was affected by cultivars, type of tissue, and temperature. The highest peroxidase activity was found at low temperature $\left(10^{\circ} \mathrm{C}\right)$ in embryo 
tissue of the cultivar with the highest germination. The result also suggests that high peroxidase activity was related to ability of seed to germinate at low temperature.

\section{(207) Sensitivity of Two Lettuce Genotypes to Abscisic Acid during Germination}

Jiyoung Hong*, Daniel Cantliffe

University of Florida, Horticultural Science, Gainesville, FL, 32611

In many lettuce (Lactuca sativa L.) cultivars, temperatures above $30{ }^{\circ} \mathrm{C}$ can inhibit germination completely. Lettuce seeds imbibed at supraoptimal temperature for 72 hours or more will not germinate even when the temperature is returned to the optimal range. Sung et al. (1998) reported that thermosensitive 'Dark Green Boston' and thermotolerant 'Everglades' responded to temperature at seed maturation by being able to show greatly enhanced germination at $36^{\circ} \mathrm{C}$ when seeds were matured at $30 / 20^{\circ} \mathrm{C}$. Abscisic acid (ABA) plays an important role relative to both dormancy and germination of many seeds and may contribute to lettuce seed thermodormancy. Therefore, sensitivity of 'Everglades' and 'Dark Green Boston' to ABA of seeds maturated at $30 / 20^{\circ} \mathrm{C}$ and $20 / 10{ }^{\circ} \mathrm{C}$ in light and dark was determined. Seeds were germinated at $20^{\circ} \mathrm{C}$ and 36 ${ }^{\circ} \mathrm{C}$ in light and dark. All seeds of 'Dark Green Boston' and 'Everglades' matured at $30 / 20{ }^{\circ} \mathrm{C}$ and $20 / 10^{\circ} \mathrm{C}$ germinated similarly regardless of maturation temperature and light/dark condition at $20^{\circ} \mathrm{C}$. At $36{ }^{\circ} \mathrm{C}$ in dark, both genotypes matured at $30 / 20{ }^{\circ} \mathrm{C}$ germinated more than those matured at $20 / 10^{\circ} \mathrm{C}$. 'Dark Green Boston' genotypes were more sensitive to $\mathrm{ABA}(0.5,1,10,50,100 \mu \mathrm{M})$ during germination at $36^{\circ} \mathrm{C}$ in dark. When ABA was added, seeds matured at $30 / 20^{\circ} \mathrm{C}$ germinated better than those matured at $20 / 10^{\circ} \mathrm{C}$, regardless of genotype. At $36^{\circ} \mathrm{C}$ in light, $40 \%$ of both genotypes were inhibited at $0.5 \mu \mathrm{M}$ ABA. At 36 ${ }^{\circ} \mathrm{C}$ in dark, germination of all seeds but 'Everglades' matured at 30/20 ${ }^{\circ} \mathrm{C}$ were completely inhibited at all ABA concentrations. Thus, seed maturation temperature has an influence on lettuce seed germination at high temperature and sensitivity to $\mathrm{ABA}$.

\section{(208) Effects of Temperature During Seed Development in Lactuca sativa and Helianthus debilis}

Samuel Contreras ${ }^{1}$, David Tay*2, Mark A. Bennett ${ }^{1}$

${ }^{1}$ The Ohio State University, Department of Horticulture and Crop Science, Columbus, $\mathrm{OH}, 43210 ;{ }^{2}$ The Ohio State University, Ornamental Plant Germplasm Center, Columbus, $\mathrm{OH}, 43210$

Among the factors affecting germinability of a seed lot are the environmental conditions under which the seeds are produced. The objective of this study was to determine the effects of temperature during seed development on seed quality of two Asteraceae species. Seeds of lettuce cv. Tango and Helianthus debilis cv. Vanilla Ice and sp. cucumerifolius were produced in a greenhouse under one of two treatments: i) hot $\left(27,40\right.$, and $20^{\circ} \mathrm{C}$ temperatures average, max, and min, respectively), and ii) $\operatorname{cool}\left(23,33\right.$, and $18^{\circ} \mathrm{C}$ temperatures average, max, and min, respectively). In both species, heavier seeds were produced under the cool conditions and no differences were observed in standard germination. In lettuce, germination percentage and rate were both affected by increased levels of exogenous ABA concentrations and reduced water potential (PEG solutions), and, in both cases, seeds from cool treatments were more affected. Germination at $30{ }^{\circ} \mathrm{C}$ and constant light was higher for seeds from the hot treatment. Lettuce seed showed a strong light requirement for germination. However, seeds from the hot treatment gave better dark germination at 13 and 19 ${ }^{\circ} \mathrm{C}$. Seeds of $H$. debilis did not required light for germination, and the germination percentage and rates were evaluated at 13,21 , and $29^{\circ} \mathrm{C}$. For both lines, seeds from each treatment behave similarly; however, the germination of $\mathrm{H}$. debilis cv. Vanilla Ice at $29^{\circ} \mathrm{C}$ was higher when seeds were produced in the hot conditions. The results showed that temperature during seed development affected aspects of seed quality that are not detectable by the standard germination, but by germination at suboptimal conditions. Within the Asteraceae family, differences varied among and within species.

\section{(209) Development of Germinability and} Desiccation Tolerance in Lettuce Seeds

Roel Rabara ${ }^{1}$, Samuel Contreras ${ }^{1}$, David Tay*2, Mark A. Bennett ${ }^{1}$, Miller B. McDonald ${ }^{1}$

${ }^{1}$ The Ohio State University, Department of Horticulture and Crop Science, Columbus, $\mathrm{OH}, 43210^{2}$ The Ohio State University, Ornamental Plant Germplasm Center, Columbus, $\mathrm{OH}, 43210$

Germinability and desiccation tolerance are important attributes that seeds acquire during their development. The timing in the expression of these characteristics is important to understand how environmental conditions affecting the mother plant influence seed quality. Lettuce plants (cv. Tango) were cultivated in the greenhouse. Seed germination, under light and darkness, was evaluated in fresh and dry seeds at 3, 5, $7,9,11,13,15$, and 17 days after flowering (DAF). Desiccation was performed $\approx 1 \mathrm{~h}$ after harvest by placing the seeds at $25^{\circ} \mathrm{C}$ and $\approx 53 \%$ $\mathrm{RH}$. The seed moisture level after desiccation decreased from $\sim 14 \%$ for $3 \mathrm{DAF}$ seed to $\sim 7 \%$ for $7 \mathrm{DAF}$ seed, and then remained constant until the last sampling. Seeds achieved maximum dry weight (physiological maturity) at $\sim 13$ DAF. Germination of fresh seeds increased from $0 \%$ at $3 \mathrm{DAF}$ to $\sim 80 \%$ at $5 \mathrm{DAF}$, reaching $100 \%$ at $7 \mathrm{DAF}$. Dry seeds did not germinate when they were 3 or 5 DAF. Seeds at 7 DAF had $\sim 10 \%$ germination and at $9 \mathrm{DAF} \sim 100 \%$. When germinated in the dark, an increase in germination from $0 \%$ in fresh seeds at 3 DAF to $50 \%$ germination at $5 \mathrm{DAF}$ was observed. However, seeds at $9 \mathrm{DAF}$ had dark germination values that decreased to $0 \%$ and increased again to $\sim 70 \%$ germination at 13 DAF. Dry seeds had no dark germination until 7 DAF, with variable and low germination (below 20\%) until $11 \mathrm{DAF}$, then germination reached a maximum of $\sim 55 \%$ at $13 \mathrm{DAF}$ and decreased to below $10 \%$ at 17 DAF. According to these results, lettuce seed germinability and desiccation tolerance were reached sooner than physiological maturity. In the dark, germination of fresh seeds presented a curve with two peaks suggesting that, depending on the seed developmental stage, two different physiological mechanisms restrict dark germination.

\section{(210) X-ray-assisted Flower Seed Lot Improvement}

Susan M. Stieve, David Tay*

The Ohio State University, Ornamental Plant Germplasm Center, Columbus, OH, 43210

Storage of quality herbaceous ornamental seeds is a primary concern of the Ornamental Plant Germplasm Center, a USDA National Plant Germplasm System genebank. In Autumn 2005, 30 accessions, including 10 genera of herbaceous ornamentals, were evaluated for initial seed weight and viability using four replications of 50 seeds except for Begonia, which consisted of two replications of 500 seeds due to extremely small seed size. Seed lots were then recleaned using an Oregon Seed Blower; Begonia were cleaned using the rolling paper method where good, round seeds roll off vibrating paper held at an angle and shrunken seed do not. Heavy and light fractions of all seeds were saved, 50-seed weight calculated, and viability tested. Seed cleaning was assisted by Faxitron X-ray technology to identify the quantity of seeds with embryos in each treatment. Seed cleaning statistically increased the weight for 19 accessions including Actea, Antirrhinum, Oenothera, Penstemon, Ranunculus, Rudbeckia, and Talinum, where the heaviest seed were in the heavy fraction of recleaned seed. Seed weight for some Begonia and Tagetes accessions was statistically increased, while weight of no Petunia accessions was increased. Viability was calculated as the percentage of normal and dormant seeds. Seed cleaning statistically increased the viability of 10 accessions including Actea, Oenothera, Petunia, Ranunculus, and Talinum; seed lot viability was statistically increased for some accessions of Antirrhinum, Penstemon, Rudbeckia; no accessions of Begonia or Tagetes had improved viability. Results suggest that recleaning seed lots to improve seed weight and viability may be effective, but differences between genera as well as species within genera exist. 


\section{(211) Moisture Sorption Characteristics of Seeds of} Five Ornamental Species

Roel Rabara*1, Miller McDonald ${ }^{1}$, David Tay ${ }^{2}$, Yael Vodovotz ${ }^{3}$

${ }^{1}$ The Ohio State University, Horticulture and Crop Science, Columbus, OH, 43210; ${ }^{2}$ The Ohio State University, Ornamental Plant Germplasm Center, Columbus, OH, 43210; ${ }^{3}$ The Ohio State University, Food Science and Technology, Columbus, OH, 43210

The moisture sorption characteristics of French marigold 'Boy Golden' (Tagetes patula), upland aster (Aster ptarmicoides), Texas bluebonnet (Lupinus texenensis), impatiens 'Infinity' (Impatiens wallerana), and scarlet sage 'Scarlet Pimpernel' (Salvia splendens) was determined by allowing the seeds to equilibrate at different temperatures and relative humidities. The moisture sorption isotherm of the five ornamental species was determined at four different temperatures; i.e., 5, 15, 25, and $35^{\circ} \mathrm{C}$ using seven different salt solutions (sodium hydroxide, lithium chloride, magnesium chloride, potassium carbonate, sodium bromide, sodium chloride, and potassium nitrate) having relative humidity ranging from $7 \%$ to $96 \%$. The moisture content of the seeds after equilibrium was measured using the gravimetric method. Equilibrium moisture content at $5{ }^{\circ} \mathrm{C}$ ranged between $6.2 \%$ to $31.5 \%, 6.2 \%$ to $32 \%$, $5.7 \%$ to $29.7 \%$, and $6.8 \%$ to $16.1 \%$ for marigold, upland aster, scarlet sage, and Texas bluebonnet, respectively. At the highest temperature; i.e., $35^{\circ} \mathrm{C}$, the equilibrium moisture content observed ranged between $6.1 \%$ to $18.1 \%, 6 \%$ to $21.1 \%, 6.2 \%$ to $20.3 \%$, and $9.1 \%$ to $15.6 \%$ for marigold, upland aster, scarlet sage and Texas bluebonnet, respectively. The rate of desorption was also determined in the imbibed seeds by drying the seeds in dry cabinet, with water loss recorded by a portable computer inside the cabinet. Total lipid content was also measured to correlate with the water content of the seed.

Poster Session 35-Ornamentals/Landscape and Turf 3

30 July 2006, 12:00-12:45 p.m.

\section{(61) Nutrient Management of Common Herbaceous Perennial Plantings in Southern Landscapes}

Yan Chen*, Regina Bracy, Roger Rosendale

LSU AgCenter, Hammond Research Station, Hammond, LA, 70403

While herbaceous perennials continuously gain popularity in southern landscape plantings, the nutrient requirements of many species in this group are still unknown. The business goal of lawn and garden care companies emphasizes aesthetic value of the urban landscape. Improper nutrient management, such as the overapplication of fertilizers, is inefficient and may result in increased pest problems and risks of contaminating ground and surface waters by nutrient runoff. Seven herbaceous perennials (lantana, rudbeckia, purple cone flower, daylily, mexican heather, cigar plant, and guara) were planted in simulated landscape beds. Fertilizers applied included one or two OsmocotePlus 16-8-12 tablets (7.5 g), OsmocotePlus 15-9-12 (5 months) at 0,33, 66, and 131 $\mathrm{g} / \mathrm{m}^{2}$ at planting, or applying OsmocotePlus $15-9-12$ (5 months) $33 \mathrm{~g} / \mathrm{m}^{2}$ or one OsmocotePlus tablet at the time of planting plus another $33 \mathrm{~g} / \mathrm{m}^{2}$ topdressing after flowering. Plant growth of rudbeckis, purple cone flower, and lantana were highest at $131 \mathrm{~g} / \mathrm{m}^{2}$ applied at planting, but resulted in similar overall plant quality as with 33 or $66 \mathrm{~g} / \mathrm{m}^{2}$ treatments. Daylily growth was similar across fertilization treatments, and overall quality decreased at high fertilization rates with more severe daylily rust observed on these plants. Applying one OsmocotePlus 7.5-g tablet resulted in similar plant quality with applying OsmocotePlus 33 and 66 $\mathrm{g} / \mathrm{m}^{2}$, but significantly reduced the amount of fertilizer used. Additional topdressing after flowering did not further increase plant quality in fall, but may affect the overwintering survival of perennial plants.

\section{(62) Salinity and Growing Medium Affected Growth and Morphology of Gaillardia aristata}

Genhua Niu*, Denise S. Rodriguez

Texas A\&M Univ., AREC-El Paso, Dept. of Horticultural Sciences, El Paso, TX, 79927

Gaillardia aristata Foug. is a hardy, drought-tolerant perennial found throughout much of the United States. Little information exists on the salt tolerance of this plant when grown in various growing media. A study was conducted to characterize the response of $G$. aristata to three salinity levels $(0.8,2.0$, or $4.0 \mathrm{dS} / \mathrm{m})$ and four growing media: 1$) 100 \%$ perlite; 2) 1 perlite : 1 Sunshine mix No. 4 (v/v); 3) 100\% Sunshine mix No. 4; or 4) 1 Sunshine mix No. $4: 1$ composted mulch (v/v). The type of medium influenced the dry weight of roots but not shoots, while salinity significantly influenced the dry weight of both shoots and roots. The dry weight of shoots was higher in plants irrigated with tap water $(0.8 \mathrm{dS} / \mathrm{m})$ compared to those irrigated with saline solution at 2.0 or $4.0 \mathrm{dS} / \mathrm{m}$ except for those grown in $100 \%$ Sunshine mix. The ratio of root to shoot dry weight was not influenced by salinity, but was highest in the plants grown in $100 \%$ perlite. Both medium and salinity affected plant height. Elevated salinity reduced plant height. Plants were taller when grown in $100 \%$ perlite and in 1 Sunshine mix : 1 composted mulch. However, plants had fewer lateral shoots when grown in $100 \%$ perlite or 1 Sunshine mix : 1 composted mulch. Some of the flower buds aborted when grown in $100 \%$ Sunshine mix or 1 perlite : 1 Sunshine mix compared to none in plants grown in $100 \%$ perlite or 1 Sunshine mix : 1 composted mulch. These results indicate that growth and morphology of G. aristata were affected by not only salinity, but also the type of medium.

\section{(63) Effect of Fertilization on Growth of Ornamental Lotus in Containers}

Daike Tian*, Ken Tilt, Floyd Woods, Jeff Sibley, Fenny Dane

Auburn University, Horticulture, Auburn, AL, 36849

Little research is reported on container production of ornamental lotus (Nelumbo nucifera Gaertn.). In this study, fertilization has a critical impact on growth index of lotus 'No.7', a numbered clone, in 29 liter (7.5 gallon) containers. Compared to the control treatment (zero fertilization), 1-3 tsp. (4g/tsp.) of 20-10-20 (Pro•Sol) applied every 20 days significantly increased plant height (1.3-1.6 times), fresh biomass (2.4-3.3 times), emerging leaf number (1.9-2.7 times), flower number (2.4-2.7 times), and propagule number (1.3-1.5 times). There was a quadratic response as growth parameters increased with increasing fertilizer rates. Growth indices increased linearly from $0-2$ tsp. and then leveled as fertilizer rates reached 3 tsp. No difference was recorded in flower number and plant height for 1-3 tsp. fertilizer treatments. Absorption of nutrition increased with fertilization concentration, an absorption peak value appeared between 13 July and 2 Aug. For 1-3 tsp. treatments, nitrogen is nearly $100 \%$ absorbed by lotus every 20 days. However, there is some residue for $\mathrm{P}$ and $\mathrm{K}$, especially in 3-tsp. treatment in the earlier and later growth season. Analysis of young leaf tissue indicated that macronutrients $\mathrm{N}, \mathrm{P}, \mathrm{K}$, and dry mass increased, but $\mathrm{Ca}$ decreased with increasing fertilizer rates. In tuber tissue, $\mathrm{K}, \mathrm{Na}$, and dry mass increased, while $\mathrm{Ca}$ and $\mathrm{Fe}$ content decreased. The most efficient rate of fertilizer for 7.5 gallon container production of 'No.7' lotus was 2 tsp. per 20 days. Although soluble fertilizer also stimulated proliferation of algae growth in the early growth stage of lotus, this problem dissipated as emerging leaves shaded the water surface.

\section{(64) Effect of Backfill Composition on Posttransplant Root Growth of Kalmia latifolia $\mathbf{L}$.}

Amy N. Wright*1, Robert D. Wright ${ }^{2}$, Jake F. Browder ${ }^{2}$, Brian E. Jackson ${ }^{2}$

${ }^{1}$ Auburn University, Horticulture, Auburn, AL, 36849; ${ }^{2}$ Virginia Polytechnic Institute and State University, Horticulture, Blacksburg, VA, 24061

Posttransplant root growth is critical for landscape plant establishment. The Horhizotron provides a way to easily measure root growth in a wide range of rhizosphere conditions. Mountain laurel (Kalmia latifolia L.) plants were removed from their containers and planted in Horhizotrons in a greenhouse in Auburn, Ala., and outdoors in Blacksburg, Va. Each Horhizotron contained four glass quadrants extending away from the root ball, and each quadrant within a Horhizotron was filled with a different substrate (treatment): 1) 100\% pine bark (Pinus taeda L., PB), 2) $100 \%$ soil, 3) a mixture of $50 \mathrm{~PB}: 50$ soil (by volume), or 4) $100 \%$ 
soil along the bottom of the quadrant to a depth of $10 \mathrm{~cm}$ (4 inches) and $100 \%$ PB layered $10 \mathrm{~cm}$ (4 inches) deep on top of the soil. Root growth along the glass panes of each quadrant was measured biweekly in Auburn and weekly in Blacksburg. Roots were longer in all treatments containing pine bark than in $100 \%$ soil. When pine bark was layered on top of soil, roots grew into the pine bark but did not grow into the soil. Results suggest that amending soil backfill with pine bark can increase posttransplant root growth of container-grown mountain laurel.

\section{(65) Jasmonate-induced Changes in Polyphenol Oxidase, Peroxidase, and Proteinase Inhibitors in Horticultural Species}

Charles L. Rohwer*, John E. Erwin

University of Minnesota, Department of Horticultural Science, St. Paul, MN, 55108

Jasmonates are a class of plant hormones involved in plant defense and stress responses. For example, jasmonate-induced defense responses in Lycopersicon esculentum include increases in activity of proteinase inhibitors, polyphenol oxidases, and peroxidases. As part of our efforts to reduce or control greenhouse pest infestations, we hypothesized that methyl jasmonate (MeJA) could induce these biochemical changes in common greenhouse crops. We studied Impatiens wallerana 'SuperElfin Pink', L. esculentum 'Big Boy', Petunia $\times$ hybrida 'Bravo Lavendar', Viola $\times$ wittrockiana 'Imperial Beaconsfield', Coleus $\times$ hybridus 'Wizard Jade', Nicotiana alata 'Saratoga Lime', Pelargonium $\times$ hortorum 'Pinto Pink', and Tagetes erecta 'Antigua Primrose'. Polyphenol oxidase and peroxidase activity was studied in the first four species, and proteinase inhibitors were studied in all eight. We sprayed plants with $0,5 \times 10^{-6}$, or $10^{-4}$ molar MeJA and made measurements after 24 hours. We detected a small increase in polyphenol oxidase activity of plants treated with $10^{-4}$ molar MeJA; $5 \times 10^{-6}$ molar had no effect, and L. esculentum had the highest polyphenol oxidase activity. Peroxidase activity was not affected by MeJA. I. wallerana had the highest peroxidase activity, $L$. esculentum and $V$. $\times$ wittrockiana had the lowest. $5 \times 10^{-6}$ molar MeJA increased proteinase inhibitor activity in most species, and $10^{-4}$ molar increased activity in every species except $P$. $\times$ hortorum.

\section{(66) Modeling Lime Reaction in Horticultural Substrates}

Paul R. Fisher ${ }^{1}$, Jinsheng Huang*1, William R. Argo ${ }^{2}$

${ }^{1}$ University of New Hampshire, Plant Biology, Durham, NH, 03824; ${ }^{2}$ Blackmore Co., Belleville, MI, 48111

Limestone is incorporated into horticultural substrates to neutralize substrate acidity, increase $\mathrm{pH}$ buffering capacity, and provide calcium and magnesium. Limestones differ in their rate of $\mathrm{pH}$ change, equilibrium $\mathrm{pH}$, and proportion of unreacted "residual"? lime. In horticulture, lime reactivity is currently measured empirically in batch tests, whereby limestone is incorporated into a batch of substrate and $\mathrm{pH}$ change is measured over time. Our objective was to develop a quantitative model to describe reaction of lime over time. The lime reaction model predicts the substrate-pH based on lime acid neutralizing capacity, lime type (calcitic, dolomitic, or hydrated), lime particle size distribution, application concentration, and the non-limed $\mathrm{pH}$ and neutralizing requirement (buffering) of the substrate. Residual lime is calculated as the proportion of lime remaining following gradual neutralization of the substrate acidity (by subtraction of reacted lime from total applied lime).

\section{Poster Session 36-Vegetable Breeding 2}

30 July 2006, 12:00-12:45 p.m.

\section{(253) 'TAM Ben Villalon' and 'TAM Valley Hot': Two New Pepper Cultivars from the Texas Agricultural Experiment Station at Weslaco}

Kevin Crosby*1, Daniel Leskovar ${ }^{2}$, John Jifon ${ }^{1}$, Kilsun Yoo $^{3}$

${ }^{1}$ Texas A\&M University, Vegetable and Fruit Improvement Center-Department of Horticultural Sciences, Texas Agricultural Experiment Station, Weslaco, TX, 78596; ${ }^{2}$ Texas
A\&M University, Vegetable and Fruit Improvement Center-Department of Horticultural Sciences, Texas Agricultural Experiment Station, Uvalde, TX, 78801; ${ }^{3}$ Texas A\&M University, Vegetable and Fruit Improvement Center-Department of Horticultural Sciences, College Station, TX, 77845

The Texas Agricultural Experiment Station/Texas A\&M University announces the release of two new open-pollinated cultivars of long chile. The first, 'TAM Ben Villalon,'(TBV) is a long green chile/Anaheim type, while the second, 'TAM Valley Hot,' (TVH) is a large cayenne type. Both cultivars have complex pedigrees involving TAES potyvirus resistant germplasm developed by Ben Villalon. Consequently, they exhibit resistance to some strains of tobacco etch virus when mechanically inoculated. In addition, TBV exhibits resistance to several strains of pepper mottle virus. These new cultivars out-yielded their comparable commercial cultivars, 'Sonora,' and 'Mesilla', when grown with drip irrigation at Weslaco and Uvalde, Texas. TBV yielded $16,632 \mathrm{~kg} / \mathrm{ha}$ of green pods, compared to $14,228 \mathrm{~kg} /$ ha for 'Sonora.' Both cultivars had similar capsaicin concentrations of $30-40 \mathrm{ppm}$ on a fresh-weight basis. TBV pods are significantly heavier than those of 'Sonora' due to thicker flesh. It should be useful for the green chile processing and fresh market industries. TBV may also be dried at the red stage to produce chile powder, which is very similar in quality to that of 'NM 6-4.' TVH pods are not significantly different from 'Mesilla' for size or weight, but contain significantly more capsaicin (670 vs. 320 ppm) when grown at Weslaco. TVH should be well-suited to the cayenne mash industry for hot sauce production due to its high heat level. Both cultivars will be distributed through commercial seed companies after receiving approval for Plant Variety Protection Patents.

\section{(254) Genetic Improvement of the Fordhook Lima Bean (Phaseolus lunatus) for Vegetable Processing by Single-seed Decent}

Mathew Wilson*, Jeffrey C. Wong

California Polytechnic State University, Horticulture and Crop Science

The Fordhook lima bean is a large-seeded lima bean grown in California for use by vegetable processors as an ingredient in frozen mixed vegetable packs. California represents one of the largest production regions for this bean because of the temperate climate. Unfortunately, as the population of California grows, the land available for producing this relatively low-valued crop continues to diminish. To overcome the loss of productive lands, we have initiated two projects, both focused on an increase in productivity. The first project is the improvement of current lines used by one processor. Due to the method of production of the seed bean, as well as the age of current lines in use, plant vigor and uniformity within the fordhook lima bean population has decreased over time. By using a modified single-seed descent method within the population, a certain level of improvement of production lines should be realized. Our second objective is in the development of a more heat-tolerant line, which could be grown in the inner valleys of California, where more land is available. Because of the limited availability of heat-tolerant Fordhook lima beans, we are currently investigating the possibility of using chemical mutagenesis to produce a more heat-tolerant variety.

\section{(255) Growth and Salt Tolerance of Grafted Hot Pepper Seedlings}

Hee-Ju Lee*1, Sang-gyu Lee ${ }^{2}$, Changhoo Chun ${ }^{3}$, Jung-Myung Lee ${ }^{4}$ ${ }^{1}$ Rural Development Administration, Farm Management and Information Officer; ${ }^{2}$ Rural Development Administration, Research \& Davelopment Bureau; ${ }^{3}$ Seoul National University, College of Agriculture and Life Science; ${ }^{4}$ Kyung Hee University, Horticulture Biotechnology

Use of grafted seedlings is a practical method to overcome salt accumulation, deterioration of physicochemical properties of soil, and accumulation of soil-borne pathogen that farmers, as well as commercial plug seedling producers, in Korea mainly adapted. Graft-take, subsequent growth, and quality characteristics of grafted hot pepper (Capsicum annuum L.) seedlings composed of three scions and 10 rootstocks were investigated. 'Manita', 'Chungyang', and 'Nokkwang' 
were cultivars of scions used - they are the major hot pepper cultivars in Korea. The ten rootstock cultivars can be categorized into three groups: cultivars specially bred for rootstocks ('Konesian Hot', 'PR-380', 'R-Safe', and 'Tantan'); cultivars recently bred in NHRI, Korea with the potential to be rootstocks ('Wonkwang1' and 'Wonkwang2'); and cultivars originally bred for fruit harvest, but used as rootstocks due to their tolerance to soil-borne pathogens ('Kataguruma', 'PR-Data', 'PR-Gangza', and 'PR-Power'). All the plants were treated with 5 $\mathrm{mg} \cdot \mathrm{L}^{-1}$ diniconazole solution 2 weeks after grafting and were soaked into $1.4 \%$ salt solution for 48 hours about 5 weeks after grafting. All the grafted seedlings showed feasible growth, including normal flowering and fruit set, and any symptoms of phytophthora blight and anthracnose were not found during 17-day-long experiment. Seedlings grafted onto 'Tantan' rootstock showed stronger tolerance to high salt concentration than those grafted onto other rootstocks. Use of some, such as 'Wongang 1', 'PR-Data' and 'Kataguruma', was alleviated the salt-induced growth inhibition.

\section{(256) Investigation into the Poor Seedling Establishment Trait Associated with Compact Phenotype in PI308916 and Possible Relationship to Apical Hook Formation}

Laura Havenga, Kaori Ando*, Rebecca Grumet

Michigan State University, Horticulture, East Lansing, MI, 48824;

Cucumber PI308916 has a compact growth habit (short internodes and main stem length) due to a single recessive gene $c p$. We also observed that this PI has lower incidence of Phytophthora fruit rot, likely due to its upright fruit bearing habit. Previous researchers reported that compact cucumber lines derived from PI308916 exhibited the potential for higher yields due to increased planting density. Despite these potentially beneficial traits, efforts to develop PI308916-derived lines were terminated due to poor seedling establishment. The objective of this research is to determine the relationship between the compact phenotype and poor seedling establishment. Short internodes can be caused by deficiency in gibberellins or brassinosteroids that can also impact germination or apical hook formation, a trait important for seedling emergence from the soil. Germination rate and apical hook angle was recorded for 'Wautoma' (control inbred line that forms normal apical hook), PI308916, and their $\mathrm{F}_{1}, \mathrm{~F}_{2}$, and BC progeny. Germinating 'Wautoma' seeds showed consistent, large apical hook angles (mean 147), while hook angles of PI308916 were broadly distributed from 0 to 180 (mean 96). $\mathrm{F}_{\text {}}$ progeny for the reciprocal crosses had a similar angle (mean 134 and 133) to 'Wautoma'. Segregation ratios for apical hook angle in the $\mathrm{F}_{2}$ and $\mathrm{BC}$ populations were consistent with a single recessive gene. Evaluation of the relationship between the apical hook and compact phenotype, showed an absence of the recombinant class of long internodes and small apical hook angle in the $\mathrm{F}_{2}$ population, suggesting that the two traits may be conferred by a single gene or two tightly linked genes.

\section{(257) Evaluation and Selection of Squash Types and Cultivars for Production of Edible Squash Blossoms}

Darrin Parmenter*1, Russell Nagata ${ }^{2}$, Kent Cushman ${ }^{3}$, Nancy Roe 4

${ }^{1}$ University of Florida, IFAS, West Palm Beach, FL, 33415; ${ }^{2}$ University of Florida, IFAS, Belle Glade, FL, 33430; ${ }^{3}$ University of Florida, IFAS, Immokalee, FL, 34142; ${ }^{4}$ Local Grower, Farming Systems Research, Inc., Boynton Beach, FL, 33474

Recently, an increasing number of restaurants in Palm Beach County, Florida, have been requesting squash (Cucurbita pepo) flowers from local vegetable growers. Typically, current field-grown squash cultivars produce a higher ratio of female to male flowers, with the emphasis on fruit production. However, a market for squash blossoms indicates a need for cultivars that produce higher numbers of consistently developing male flowers throughout the growing season. In order to evaluate male squash blossom production, 10 squash cultivars, including yellow-summer, zucchini, round, and scallop-types, and one compact-type pumpkin, were field-grown during the 2005-06 growing season. The average number of male flowers per plant by week was recorded for 7 weeks, starting when the first male flowers were identified within the entire trial. In addition to blossom counts, flower traits, such as bell height, depth, volume, and weight were also recorded. Preliminary results from the 2005 season indicate that the commercial yellow-summer squash cultivars, Mulitpik and Early Prolific Straightneck, and the zucchini cultivars, Jaguar and Raven, produced fewer male flowers on a week-by-week and total basis. The cultivar, White Bush Scallop, produced significantly more male flowers then any other entry, with an average of 9.8 male flowers per plant per week. Little or no difference was seen in bell height and depth among the 11 cultivars; however, two cultivars, Costa Romanesque and Hybrid Pam (compact pumpkin type) had significantly greater bell volumes and weights, indicating a much larger blossom size.

\section{(258) GreenPack-DG, a Pinkeye-type Southernpea with an Enhanced Persistent Green Seed Phenotype}

Richard L. Fery*

USDA-ARS, U.S. Vegetable Laboratory, Charleston, SC, 29414

The USDA-ARS has released a new pinkeye-type southernpea cultivar named GreenPack-DG. GreenPack-DG is the first pinkeye-type southernpea to be released that has a persistent green seed phenotype conditioned by both the green cotyledon gene (gc) and the green testa (gt) gene. The new cultivar was developed from a cross between Charleston Greenpack (green cotyledon phenotype) and the breeding line USVL 97-296 (green testa phenotype). Except for longer pods, GreenPack-DG is similar in appearance and maturity to Charleston Greenpack. Dry GreenPack-DG seeds have a richer and more-uniform green seed color than dry seeds of Charleston Greenpack. GreenPackDG seeds are much less susceptible to color loss due to blanching when harvest is delayed than are seeds of green-cotyledon cultivars such as Charleston Greenpack. Color loss is a critical problem in production systems where preharvest desiccants are used to facilitate mechanical harvesting operations. The 7-day delay between application of the desiccant and initiation of harvesting operations can result in serious color degradation. Results of 3 years of replicated field tests at Charleston, S.C., indicate that GreenPack-DG yields are comparable to Charleston Greenpack yields. The new cultivar has excellent field resistance to blackeye cowpea mosaic virus and does not produce hard seeds. GreenPack-DG is recommended for trial by the frozen food industry as a replacement for Charleston Greenpack. Protection for GreenPack-DG is being sought under the Plant Variety Protection Act.

\section{(259) TigerPaw-NR, a Root-knot Nematode Resistant, Habanero-type Pepper}

Richard L. Fery*, Judy A. Thies

USDA-ARS, U.S. Vegetable Laboratory, Charleston, SC, 29414

The USDA-ARS has released a new Habanero-type pepper cultivar named TigerPaw-NR. The new cultivar is the product of a conventional recurrent backcross breeding procedure to transfer a dominant root-knot nematode resistance gene from the Scotch Bonnet accession PA-426 into the Habanero-type accession PA-350. TigerPaw-NR was derived from a single $\mathrm{F}_{3} \mathrm{BC}_{4}$ plant grown in 2002. TigerPaw-NR is homozygous for a dominant gene conditioning a high level of resistance to the southern root-knot nematode, the peanut root-knot nematode, and the tropical root-knot nematode. TigerPaw-NR has a compact plant habit and produces attractive lantern-shaped, orange-colored fruit. The results of three replicated field studies conducted at Charleston, S.C., indicate that the fruit and yield characteristics of TigerPaw-NR are comparable to those of currently available Habanero-type cultivars. A typical fruit weighs $7.8 \mathrm{~g}$, is $2.7 \mathrm{~cm}$ wide $\times 4.4 \mathrm{~cm}$ long, and is extremely pungent (348,634 Scoville heat units). Root-knot nematodes are major pests of peppers in the United States, and all Habanero-type cultivars currently available to commercial growers and home gardeners are susceptible. The root-knot nematode resistant TigerPaw-NR is recommended for use by both commercial growers and home gardeners. Protection for TigerPaw-NR is being sought under the Plant Variety Protection Act. 
Poster Session 37-Vegetable Crops Management

30 July 2006, 1:15-2:00 p.m.

\section{(21) Using Compost Sources as an Alternative to Methyl Bromide in Vegetable Production}

Douglas C. Sanders ${ }^{1}$, Luz M. Reyes*1, David W. Monks ${ }^{1}$, Katie M. Jennings ${ }^{1}$, Frank J. Louws ${ }^{2}$, Jim G. Driver ${ }^{2}$

${ }^{1} \mathrm{NCSU}$, Hort. Sci., Kilgore Hall, Raleigh, NC, 27695; ${ }^{\mathrm{NCSU}}$, Plant Pathology, Raleigh, NC, 27695

Compost sources were used to determine long-term influence on common vegetable cropping systems (tomato, pepper, and cucumber). Three sources of Controlled Microbial Compost (CMC) $\left(20 \mathrm{yd}^{3} / \mathrm{A}\right)$ amended with fumigant Telone-C35 (35 gal/A) and Trichoderma-382 [2.5 oz/yd. ${ }^{3}$ (T-382)] were used during 3 consecutive years. Tomato showed statistic differences (1\%) among compost treatments with higher total yields when CMC was combined with Telone-C35 (21\%) and T-382 (8.2\%). All treatments but Bio-Compost and control presented al least $25 \%$ more marketable yield per acre. No differences in fruit size were found for tomato, except for medium-size fruit when Telone C-35 was added. The CMC alone or combined with Telone C-35 and T-382 increased the total plant dry weight at least $18.6 \%$. Pepper crop showed statistic differences with higher number of No. 1 fruit size when CMC was combined with Telone C-35 and T-382. Number of culls per acre decreased for all three compost sources, with no differences from the control. Cucumber yields differed among treatments for total and marketable yields and No. 1 size fruit per acre. Best yields were achieved with CMC and when mixed with Telone C-35 and T-382. The lower numbers of culls per acre were found with Bio-Compost and Lexington sources and $\mathrm{CMC}+\mathrm{T}-382$. Total plant dry weight was increased in at least $24 \%$ when Bio-Compost or CMC compost were used alone or combined with Telone-C35 or T-382. CMC increased root knot nematode soil counts and percentage of root galling, but tended to improve root vigor in cucumbers. It seems that compost sources combined with Telone $\mathrm{C}-35$ or T-382 could improve the cropping management as alternative to methyl bromide. Weed responses will also be discussed.

\section{(22) Effect of Biculture Legume-Cereal Cover Crops on Kernel Weight and Yields of Sweet Corn Grown with or without Synthetic Nitrogen}

Wayne F. Whitehead*, Bharat P. Singh

Fort Valley State University, Agricultural Research Station, Fort Valley, GA, 31030-4313

The goal of this study was to compare the effect of leguminous and non-leguminous cover crops alone or in mixture with fertilizer nitrogen rates on kernel weight, ear number, and yield of Bt sweet corn. The following fall-spring fertility treatments were applied using randomized complete-block design with three replications: 1) fall- $0 \mathrm{~N}$, fallow; spring- $0 \mathrm{~N}, 2$ ) fall- $0 \mathrm{~N}$, abruzzi rye; spring- $0 \mathrm{~N}, 3$ ) fall- $0 \mathrm{~N}$, hairy vetch; spring-0 $\mathrm{N}, 4$ ) fall- $0 \mathrm{~N}$, abruzzi rye+hairy vetch; spring- $0 \mathrm{~N}, 5$ ) fall- 0 $\mathrm{N}$, fallow; spring-101 kg N/ha, 6) fall-0 N, abruzzi rye; spring-101 kg $\mathrm{N} / \mathrm{ha}, 7$ ) fall-0 N, hairy vetch; spring-101 kg N/ha, 8) fall-0 N, abruzzi rye+hairy vetch; spring- $101 \mathrm{~kg} \mathrm{~N} / \mathrm{ha}$, 9) fall- $0 \mathrm{~N}$, fallow; spring- $202 \mathrm{~kg}$ $\mathrm{N} /$ ha, 10) fall- $0 \mathrm{~N}$, abruzzi rye; spring- $202 \mathrm{~kg} \mathrm{~N} / \mathrm{ha}, 11$ ) fall- $0 \mathrm{~N}$, hairy vetch; spring-202 $\mathrm{kg} \mathrm{N} / \mathrm{ha}$, and 12) fall- $0 \mathrm{~N}$, abruzzi rye+hairy vetch; spring-202 kg N/ha. In Spring of 2005, 'Attribute BSS0977' bi-color (BC) supersweet (sh2) corn seeds were field planted. Total unhusked ear yield and ear number were harvested 74 days after planting, while kernel weight was measured from three randomly chosen ears. Maximum kernel fresh weight (111.6 g/ear), ear number (101,773/ha) and total yield (17.3 Mg/ha) were produced by hairy vetch; spring-101 $\mathrm{kg} \mathrm{N} / \mathrm{ha}$. Minimum kernel fresh weight (23.0 g/ear) and ear number $(51,485 /$ ha $)$ were produced by fallow; spring- $0 \mathrm{~N}$, while minimum total yield (2.2 Mg/ha) was produced by abruzzi rye; spring- $0 \mathrm{~N}$. Results indicate that hairy vetch supplemented with $\mathrm{N}$ at $101 \mathrm{~kg} / \mathrm{ha}$ is most effective in supporting kernel fresh weight, ear number and yield of this BCsh2 corn variety.

\section{(23) High Tunnels for High Latitude Snap Bean} Production

Heidi Rader, Meriam Karlsson*

University of Alaska Fairbanks, Department of Plant, Animal and Soil Sciences, Fairbanks, AK, 99775-7200

Two snap bean (Phaseolus vulgaris L.) cultivars, 'Provider' and 'Concesa', were planted successionally in a high tunnel in Fairbanks, Alaska $\left(64^{\circ} 49^{\prime} \mathrm{N}\right.$ and $\left.147^{\circ} 52^{\prime} \mathrm{W}\right)$, from late May to late July. For the entire growing season, air/soil temperatures averaged $1.7^{\circ} \mathrm{C} / 1.1^{\circ} \mathrm{C}$ higher in the tunnel than the field. The temperature differential was, however, largely dependent on amount of high tunnel ventilation. With tunnel ends not yet erected in May, the air temperature difference averaged $0.5^{\circ} \mathrm{C}$ while in September the difference was $2.5^{\circ} \mathrm{C}$ in the enclosed tunnel. On average, both cultivars flowered 4 days earlier in the tunnel compared to the contiguous open field. 'Provider' had high overall yields with no significant difference between the tunnel and the field, although the tunnel did offer protection from an early frost. 'Provider' produced an average of $3454 \mathrm{~g} \cdot \mathrm{m}^{-2}$ in the tunnel and $2860 \mathrm{~g} \cdot \mathrm{m}^{-2}$ in the field. Average yields of 'Concesa' inside the tunnel were significantly greater $(P<0.01)$, with $1719 \mathrm{~g} \cdot \mathrm{m}^{-2}$ compared to $756 \mathrm{~g} \cdot \mathrm{m}^{-2}$ in the open field. 'Provider' pods were larger in diameter and more fibrous than 'Concesa' pods, which we concluded were of improved quality with higher soluble solids content $\left({ }^{\circ}\right.$ Brix refractometer readings). High tunnels could be an important way to provide an advantageous production environment for high quality cultivars without sacrificing the reliability of cold-tolerant cultivars. To consistently produce high quality snap beans to meet local Alaska fresh market demands, cultivars suited for high tunnel production need to be identified.

\section{(24) Non-Pungent Jalapeño Pepper Yields and Preplant-incorporated Herbicides}

Charles L. Webber ${ }^{1}$, Vincent M. Russo ${ }^{1}$, James W. Shrefler*2

'USDA-ARS, So. Central Agric. Research Lab., Lane, Oklahoma, $74555 ;{ }^{2} \mathrm{Oklahoma}$ State University, WWAREC, Lane, Oklahoma, 74555

Non-pungent jalapeño peppers are used for making commercial picante sauces (salsas) and have a potential for outstanding yields in Oklahoma. There is incomplete information on the crop safety of certain herbicides that may not specifically address their use with non-pungent jalapeño peppers. The objective of this research was to determine the weed control efficacy and safety of a combination of preplant incorporated herbicides on transplanted non-pungent jalapeño pepper production. A field study was conducted during the Summer 2005 on $91-\mathrm{cm}-$ wide raised beds at Lane, Okla. The herbicides in the study included napropramide (2.2 kg a.i./ha), clomazone (1.1 kg a.i./ha), bensulide (6.7 kg a.i./ha), and trifluralin (1.1 kg a.i./ha) used separately and in combination with one of the other herbicides. All herbicides were applied preplant-incorporated just prior to transplanting 'Pace 105' nonpungent jalapeño peppers on 6 May 2005. Fruit were harvested on 21 July 2005, 76 days after transplanting. Plants treated with clomazone used by itself produced the greatest yields $(16.4 \mathrm{t} / \mathrm{ha})$ compared to plants treated with the other herbicides used individually, although it was not significantly greater than napropramide, $9.2 \mathrm{t} / \mathrm{ha}$. Four of the five top-yielding herbicide treatments included the use of clomazone. The tank mixture of napropramide and bensulide produced the second greatest yield $(16.2 \mathrm{t} / \mathrm{ha})$. The weed-free treatment produced $17.5 \mathrm{t} / \mathrm{ha}$ compared to $86 \%$ yield reduction for the weedy check. These results demonstrated that clomazone, used individually or in combination with certain other herbicides, can maintain non-pungent jalapeño yields equivalent to weed-free levels.

\section{(25) Effects of Saline Irrigation Timing on the Physiology and Marketable Yield of Bell Peppers Growing in Mulch or Nonmulch Conditions}

Dagobiet Morales*, Katrine A. Stewart

McGill Univ., Dept. of Plant Science, Ste. Anne de Bellevue, Quebec, H9X 3V9, Canada

The effect of applying saline water $\left(2.5 \mathrm{dS} \cdot \mathrm{m}^{-1}\right)$ via a drip irrigation 
system at different growth stages of mulched or nonmulched bell peppers (Capsicum annuum L. var. Red Knight) was investigated under greenhouse conditions. The study $6 \times 2$ factorial was arranged as a randomized complete-block design. The six irrigation treatments were: 1) control-nonsaline water throughout growth; 2) saline irrigation throughout growth; 3 ) saline irrigation from transplanting until formation of the first fruit set; 4) saline irrigation from transplanting until appearance of the first flower and from first harvest to final harvest; 5) saline irrigation from appearance of the first flower until first harvest; and 6) saline irrigation from fruit set until final harvest. A measurement of stomatal conductance $\left(\mathrm{g}_{\mathrm{s}}\right)$, transpiration $(\mathrm{E})$, and photosynthesis (A) rates was performed during vegetative growth, at flowering, at fruit set, and during fruit growth and development. Mulched plants had higher photosynthetic rates than nonmulched plants, although values were only significant for treatments $2,3,5$, and 6 . In addition, nonmulched plants were slower to recover after periods of saline irrigation than mulched plants. Mulched plants had significantly greater yields than nonmulched plants regardless of irrigation treatment. Saline irrigation when applied throughout growth or from fruit formation until harvest reduced marketable yields by $38 \%$ and $45 \%$ compared with the control plants.

\section{(26) Selecting Highly Colored Bell Peppers for Fresh-market Specialty Growers}

William B. Evans*1, Christine E. Coker ${ }^{2}$, Kent E. Cushman ${ }^{3}$, Thomas E. Horgan ${ }^{4}$, Keri L. Paridon ${ }^{1}$

${ }^{1}$ Mississippi State University,Truck Crops Branch Experiment Station, Crystal Springs, MS, 39059-0231; ${ }^{2}$ Mississippi State University, Coastal Research and Extension Center, Biloxi, MS, 39532; ${ }^{3}$ University of Florida, Southwest Florida Research \& Education Center, Immokalee, FL, 34142-9515; ${ }^{4}$ Mississippi State University, North Mississippi Research and Extension Center, Verona, MS, 38879

Three years of trials in Mississippi have led to the naming of a Mississippi Medallion vegetable award winner for 2007, the fourth vegetable winner in the program's history. The Medallion program looks for garden crops that will perform throughout the state of Mississippi and help improve sales of plant materials to gardeners at retail. The Medallion selection process illustrates how growers and marketers, not just gardeners, can select specialty vegetables and cultivars for production and sale. Between 2003 and 2005, the Mississippi Medallion trials evaluated 11 sweet peppers with no green fruit stage for ornamental and yield value. Each site had three or four replications of all cultivars under evaluation annually with four plants per plot set out on raised beds with drip irrigation. Objective evaluation included total yield, marketable yield, fruit size, and days to harvest. Subjective evaluation included crop uniformity, pest tolerance, and appearance of the fruit based on color, uniformity, and shape. After nine trials, four cultivars were among the highest-yielding group in most trials: Mavras, Tequilla, Blushing Beauty, and Gypsy. The Medallion winner, to be announced in Fall 2006, was selected in part because it was within or near the top-yielding group, by least significant difference, in most trials. The perceived attractiveness of the mature fruit to the evaluating team and the perceived potential marketability of the cultivar moved it above the others under consideration. The reasons for not selecting other cultivars as the winner are as important as the reasons for selecting the winning cultivar. In the Medallion pepper case, these were mostly marketability concerns with the other cultivars, not yield issues, relative to that of the winner.

\section{(27) Effect of Plant Stand Density and Pesticide Application Technology on Insect Pests and Diseases of Bell Peppers}

Salvador Vitanza ${ }^{1}$, Celeste Welty ${ }^{1}$, Mark Bennett*2, Sally Miller ${ }^{3}$, Richard Derksen ${ }^{4}$

${ }^{1}$ The Ohio State University, Entomology, Columbus, OH, 43210; ${ }^{2}$ The Ohio State University, Dept of Horticulture and Crop Science, Columbus, OH, 43210; ${ }^{3}$ The Ohio State University, Plant Pathology, Wooster, OH, 44691; ${ }^{4}$ USDA-ARS, Ohio State Univ., Wooster, $\mathrm{OH}, 44691$

The impact of pesticide application technology and crop stand density on bell pepper production was evaluated in a series of field trials, during 2004 and 2005, at the North Central Agricultural Research Station, Fremont, Ohio. In 2004, one trial tested three sprayers, at a speed of 8 and $4 \mathrm{mph}$, using insecticides at half the recommended rate and one treatment at full rate. Sprayers evaluated included an air-assisted electrostatic sprayer, a Cagle sprayer equipped with AI-11005 or AI-110025 nozzles, and an air-blast sprayer with XR-1003-VS or XR-110015-VS nozzles. In 2005, one experiment tested the interaction of two application technologies, three planting distances within row, and single vs. twin rows. Another experiment compared the Cagle sprayer (with TJ60-11003 or AI-110025 nozzles) and the airblast sprayer (with XR-110015-VS nozzles), at a speed of $4 \mathrm{mph}$, and insecticides at half the recommended rate. In 2004, the Cagle sprayer with air-induction nozzle, half rate, at $8 \mathrm{mph}$ obtained the highest fruit yield. There was not significant improvement in European corn borer control by applying insecticides at full rate with the Cagle sprayer and all treatments achieved significantly better bacterial soft rot control than the untreated control. In 2005, the trials were terminated early due to crop destruction by Phytophthora capsici. Red fruit weighed less at high than at medium or low plant stand densities. Clean yield of red fruit was significantly greater in single rows than in twin rows. Marketable yield of green fruit was greater using the TJ60-11003 than using the AI-110025 nozzles.

\section{(28) Productivity and Fruit Quality of Bell Pepper under Greenhouse Conditions in Northwest Mexico}

Raul Leonel Grijalva-Contreras*1, Rubén Macias-Duarte², Fabián Robles-Contreras ${ }^{3}$, Manuel de Jesus Valenzuela-Ruiz ${ }^{4}$

${ }^{1}$ INIFAP-Caborca, Protected Horticulture, Sonora, 83600, México; ${ }^{2}$ INIFAP-Caborca, Soli \& Horticultural, Sonora, 83600, México; ${ }^{3}$ INIFAP-Caborca, Agroclimatology, Sonora, 83600, México; ${ }^{4}$ INIFAP-Caborca, Viticulture, Sonora, 83600, México

Vegetables are important in Mexican agriculture, and production under greenhouse conditions has been increased notably during the past year. The production area is about 3500 ha. The main crop grown in greenhouses is tomatoes, but bell pepper is a potential crop due to high yield and that good quality commands a good price during the winter. The objetive of this research was to evaluate nine bell peppers with high technology for horticultural production in the greenhouse. The experiment was carried out at the Experimental Station (INIFAPCIRNO). The greenhouse conditions are: polyethylene $(8 \mathrm{~mL})$, without temperature control, natural ventilation, and soil condition (electrical conductivity of $1.22 \mathrm{dS} \cdot \mathrm{m}^{-1}$ and $\mathrm{pH}$ 7.96). The planting date was on 26 Oct. 2004. Plant density used was 3.78 plants $/ \mathrm{m}^{2}$. The harvest period ocurred from 3 Mar. to 11 May 2005. In this period, we made six cuttings. There were no differences in the yield among varieties. The varieties with the higher yield were Laroles, Asaia, Far-114 and Cupid, with 65.6, 63.1, 63.1, and 57.4 t $\cdot \mathrm{ha}^{-1}$, respectively. Cadia and Parker had the lowest yield, with 78.5 and $90.0 \mathrm{t} \cdot \mathrm{ha}^{-1}$, respectively. The fruit weight was good in all varieties, however, Far-114 and Asaia had higher fruit weight with 272.5 and $269.5 \mathrm{~g}$, respectively. The main insect pests during this experiment were white fly (Bemissia sp.) and leafminer (Lyriomyza sp.). There were no disease problems during this trial.

\section{(29) Effects of Colored Plastic Mulches on Bell Pepper Yield and Fruit Characteristics}

Maurice Ogutu*

University of Illinois, Extension, Countryside, IL, 60525

Astudy was carried out to compare the effects of different colored plastic mulches (black smooth, red, black embossed, blue, olive, yellow, clear, white, and reflective) and bare ground on bell peppers (Capsicum annum) yield and fruit characteristics. Pepper varieties 'Crusader' (2004 trial) and 'Boynton Bell $\mathrm{F}_{1}$ ' (2005 trial) seeds were planted in flats filled with Jiffy Mix in a greenhouse in late Apr. 2004 and 2005, and the seedlings transplanted in early June 2004 and 2005, respectively. In 2004, pepper fruits were harvested once in early September, and reflective and black embossed plastic mulch treatments had higher U.S. No. 1 fruit weight than other treatments. Pepper fruits harvested 
from reflective plastic mulch treatment were longer and larger than fruits in other treatments. In 2005, pepper fruits were harvested three times in late September to early October, and plants grown in reflective and red plastic mulch treatments had higher Fancy fruit weights while olive and white plastic mulch treatments had higher U.S. No. 1 fruit weights than other treatments. Fruits from reflective and red plastic mulch treatments were longer and larger than fruits from other treatments. The total marketable yield (Fancy and U.S. No. 1 fruit weight combined) was higher in olive, reflective, white, and red plastic mulch treatments. In comparison with black embossed plastic mulch, plants grown in reflective and olive plastic mulches had higher yield in 2004. However, in 2005, yield followed the same trend, with plants grown in olive, white, and reflective plastic mulches having higher yield than other treatments.

\section{(30) Effects of Fungicides and Cultivar Resistance for Phytophthora capsici Control in Bell Pepper Production}

Jamie R. Stieg*1, S. Alan Walters ${ }^{1}$, Jason P. Bond ${ }^{1}$, Mohammad Babadoost $t^{2}$

${ }^{1}$ Southern Illinois University, Plant, Soil, and Ag. Sysytems, Carbondale, IL, 62901-4415; ${ }^{2}$ University of Illinois, Crop Science, Urbana, IL, 61801

Management strategies for Phytophthora blight (caused by Phytophthora capsici) in bell pepper production are limited and there is no single method that will consistently provide adequate control. Twelve bell pepper cultivars (including four marketed as resistant/tolerant to $P$. capsici) were transplanted into a $P$. capsici-infested field and were managed with or without fungicide applications. The fungicide applications consisted of: i) Mefenoxam (Ridomil Gold EC, 1.2 L/ha) at transplant; and ii) a spray application of Dimethomorph (Acrobat, $0.45 \mathrm{~kg} / \mathrm{ha}$ ) + Copper (Tenn-Cop, 3.6 L/ha) alternated with Manganese ethylenebisdithiocarbamate (Maneb, $2.8 \mathrm{~kg} / \mathrm{ha}$ ) + Copper (Tenn-Cop; 3.6 L/ha) at 10- to 14-day intervals. Regardless of cultivar, the standard fungicide program reduced the incidence of Phytophthora blight and resulted in greater yields and farm-gate revenues when compared to the no fungicide program. Across all cultivars, total farm-gate revenues per hectare were $\$ 6,773$ and $\$ 3,674$ for the standard fungicide program and the no fungicide program, respectively. For $P$. capsici-tolerant cultivars, farm-gate revenues improved with the use of the standard fungicide program by $\$ 1,316, \$ 4,427$, and $\$ 5,447$ per hectare for 'Aristotle X3R', 'Revolution', and 'Alliance', respectively, compared to no fungicide applications. Furthermore, farm-gate revenue for $P$. capsici-resistant 'Paladin' was improved by $\$ 3,240$ per hectare when a standard fungicide program was used. Results indicate that although plant resistance is an important component of a $P$. capsici bell pepper management program, the use of recommended fungicides could improve disease control and increase farm-gate revenues.

\section{(31) Growth Response and Fruit Yield of Solanum integrifolium to Growing Medium and Fertility under Reduced Irradiance and Long-day Photoperiod}

Jonathan N. Egilla*

Lincoln University of Missouri, Cooperative Research Program, Jefferson City, MO, 65102-0029

Four-week-old seedlings of Scarlet eggplant (Solanum integrifolium Poir.), a short-day fruiting vegetable, were grown for 20 weeks in a greenhouse $(\mathrm{G} / \mathrm{H})$ from 14 Mar. to 2 Aug. 2005. Mean daily photosynthetic photon flux in the $\mathrm{G} / \mathrm{H}$ was about 480,349 and $71 \mu \mathrm{mol} \cdot \mathrm{m}^{-2} \cdot \mathrm{s}^{-1}$ above-, within canopy; and at pot level, respectively in July. Seedlings were grown either in Turface ${ }^{\circledR}$ (fritted clay) or fine sand. Fertilizer treatment consisted of $5 \mathrm{~g}$ Osmocote ${ }^{\circledR}\left(18 \% \mathrm{~N}-6 \% \mathrm{P}_{2} \mathrm{O}_{5}-12 \% \mathrm{~K}_{2} \mathrm{O}\right)$ per pot, plus $100 \mathrm{~mL}$ of Peat-lite ${ }^{\circledR}\left(15 \% \mathrm{~N}-16 \% \mathrm{P}_{2} \mathrm{O}_{5}-17 \% \mathrm{~K}_{2} \mathrm{O}\right)$ solution at $200 \mathrm{mg} \cdot \mathrm{L}^{-1}$ of $\mathrm{N}$ twice weekly, or Peat-lite only. Seedling growth (plant height, leaf number) during the first 12 weeks in both growing media was similar regardless of fertilizer treatment. The number of lateral shoots (not fruit number, FRN) increased from early fruit set (week 14) until termination (week 20), but there were no significant $(P=0.05)$ growing media or fertilizer treatment effects. While root dry mass was similar in both growing media, shoot dry mass was significantly $(P<0.0001)$ increased in fritted clay. Conversely, FRN and fruit dry mass (FDM) were, respectively, 8- and 11-fold greater in sand compared with fritted clay. Fertilizer treatment had no significant $(P=0.05)$ effect on both FRN and FDM either in fritted clay or sand. These trends indicate that $S$. integrifolium can produce limited amounts of fruit under the long daylength conditions of the summer at reduced irradiance, but factors determining shoot growth may have significant influence on fruit yield under this condition.

\section{(32) Changes in Functional Phytochemicals in Response to Altered Light Environments}

Nihal Rajapakse*

Clemson University, Horticulture, Clemson, SC, 29631

Numerous recent epidemiological studies have reconfirmed the old wisdom that consumption of fruits and vegetables play an important role in maintaining a healthy life. As a result, the role of fruits and vegetables in preventing the onset of chronic diseases is being established in the wake of epidemic-level health problems. The majority of evidence links various antioxidant phytochemicals in fruits and vegetables to the reduction in chronic diseases. Various methods are being investigated to enhance functional phytochemicals in fruits and vegetables, but, our knowledge on how these methods affect functionally important phytochemicals is relatively limited at this point. Environmental factors have been shown to affect certain phytochemicals and we are investigating if changing the spectral irradiance and composition in the growing environment can improve functional phytochemicals in food crops. In the present work, we investigated the role of irradiance on functionally important phytochemicals in selected lettuce (green and red) and tomato cultivars. Preliminary results show that in lettuce, high irradiance (500 vs. $\left.250 \mu \mathrm{mol} \cdot \mathrm{m}^{-2} \cdot \mathrm{s}^{-1}\right)$ increased total phenolic content, anthocyanin content, red coloration, and over all antioxidant capacity. Irradiance levels used in this study did not affect functional phytochemical levels in tomato fruit. High irradiance decreased the B-carotene content in lettuce cultivars, but lycopene levels in tomato were not affected by irradiance.

\section{(33) Evaluation of Salad Crop Growth under Environmental Conditions for Space Exploration using Mixed Crop Versus Monoculture Hydroponic Systems}

Sharon L. Edney*1, Jeffrey T. Richards ${ }^{1}$, Matthew D. Sisko ${ }^{1}$, Neil C. Yorio $^{1}$, Gary W. Stutte ${ }^{1}$, Raymond M. Wheeler ${ }^{2}$

${ }^{1}$ Dynamac Corporation, Food and Crop Systems, Kennedy Space Center, FL, 32899; ${ }^{2}$ NASA Biological Sciences Office, Kennedy Space Center, FL, 32899

The development of a crop production system that can be used on the International Space Station, long-duration transit missions, and lunar or Mars habitats, has been a part of NASA's Advanced Life Support (ALS) research efforts. Crops that can be grown under environmental conditions that might be encountered in the open cabin of a space vehicle would be an advantageous choice. The production efficiency of the system would be enhanced by growing these crops in a mixedcrop arrangement. This would also increase the variety of fresh foods available for the crew's dietary supplementation. Three candidate ALS salad crops, radish (Raphanus sativus L. cv. Cherry Bomb II), lettuce (Lactuca sativa L. cv. Flandria), and bunching onion (Allium fistulosum L.cv. Kinka) were grown hydroponically as either monoculture (control) or mixed-crop within a walk-in growth chamber with baseline environments maintained at $22{ }^{\circ} \mathrm{C}, 50 \% \mathrm{RH}, 17.2 \mathrm{~mol} \cdot \mathrm{m}^{-2} \cdot \mathrm{d}^{-1}$ light intensity and a 16-h light/8-h dark photoperiod under cool-white fluorescent lamps. Tests were carried out at three different $\mathrm{CO}_{2}$ concentrations: 400, 1200 , and $4000 \mu \mathrm{mol} \cdot \mathrm{mol}^{-1}$. Weekly time-course harvests were taken over 28 days of growth, and fresh mass, dry mass, and harvest index 
were determined. Results showed that none of the species experienced negative effects when grown together under mixed-crop conditions compared to monoculture growth conditions under the range of environmental conditions tested.

\section{(34) Energy and Capital Costs of High Tunnel Construction}

Michael K. Bomford*, Anthony Silvernail

Kentucky State University, Community Research Service, Frankfort, KY, 40601

Commercial vegetable growers in Kentucky have used high tunnels for year-round production for the past decade. They suggest it is a more energy-efficient and economical means of supplying off-season vegetables to the region than trucking field-grown produce from warmer regions. In 2005, we erected a $9 \times 12-\mathrm{m}$ high tunnel, designed to comply with National Organic Program standards, at the Kentucky State University Research Farm. We recorded the retail cost of each component, and estimated its embodied energy using published figures for common building materials. The materials used for construction were valued at $\$ 2830$, and contained 59 GJ of embodied energy. The frame and plastic cladding accounted for $36 \%$ and $24 \%$ of the total capital cost, and $28 \%$ and $37 \%$ of the embodied energy, respectively, with other components accounting for the remainder. Assuming that the frame, plastic cladding and other components last 20,4, and 10 years, respectively, the average cost of the tunnel is $\$ 328 /$ year, and the average energy input is $8 \mathrm{GJ} /$ year. The plastic cladding accounts for $50 \%$ of the annual amortized cost, and $66 \%$ of the embodied energy. If the structure is used to grow 2000 heads of lettuce each winter, and $450 \mathrm{~kg}$ of early market tomatoes each spring, it could generate sufficient income to recover the total cost of construction materials in its first year. Trucking this amount of produce from California to Kentucky would consume approximately 8 GJ. We conclude that there is an economic incentive for growers to adopt this technology, but no energy efficiency advantage to society. Longer tunnels, such as the $9 \times$ 29-m models more commonly used by commercial vegetable growers in Kentucky, will be more energy- and capital-efficient.

\section{Poster Session 38-Plant Biotechnolgy 2}

30 July 2006, 1:15-2:00 p.m.

\section{(287) Factors Affecting In Vitro Proliferation and Regeneration of Birch Species}

Wenhao Dai*, Cielo Castillo, Victoria Magnusson

North Dakota State University, Department of Plant Sciences, Fargo, ND, 58105

In vitro shoot cultures for two birch species, Asian white birch (Betula platyphylla) and paper birch (Betula papyrifera), were initiated from shoot tips of mature trees and maintained in MS (Murashige and Skoog) medium containing $3 \%$ sucrose and $5-10 \mu \mathrm{M}$ (micromolar) benzyladenine (BA). The effect of such factors as genotype, basal medium, and plant growth regulator (PGR) on proliferation was investigated. Shoots were proliferated in both MS and woody plant medium (WPM) supplemented with different concentrations of thidiazuron (TDZ), BA, and kinetin (Kin). Two birch species responded differently to these factors. In general, more shoots were proliferated in WPM than in MS medium. The maximum proliferation rate of Asian white birch was achieved by being cultured in WPM containing 4-8 $\mu \mathrm{M}$ TDZ, while paper birch gave rise to the maximum proliferation rate in WPM supplemented with $20 \mu \mathrm{M}$ BA. Interactions between genotype and medium or cytokinin were found. Shoots produced on media with TDZ had thick stems and small, dark green leaves. Microshoots can be rooted both in vitro and ex vitro with or without IBA treatment. Plants were regenerated from leaf tissues of Asian white birch. Adventitious shoots regenerated when in vitro leaves were cultured on WPM supplemented with 10-20 $\mu \mathrm{M}$ BA with 2-week dark treatment. The effect of genotype, PGR, and culture condition on in vitro regeneration of birch species is being tested.

\section{(288) Determination of Genetic Stability of In Vitro-} derived Birch Plants

Wenhao Dai*, Victoria Magnusson, Andrea Swanberg

North Dakota State University, Department of Plant Sciences, Fargo, ND, 58105

Many woody plants, including some birch species, can be cloned using such in vitro techniques as pre-existing meristem culture, organogenesis, and embryogenesis. However, clonal fidelity of in vitro-derived plants is always a big concern because somaclonal variations may be induced during the entire in vitro process. To address this issue, we used random amplified polymorphic DNA(RAPD) markers to determine the genetic stability of in vitro-propagated plants of Betula platyphylla 'Fargo'. Forty-two greenhouse-grown birch plants derived from a 10 -year shoot tip culture (shoot-derived) and 42 in vitro plants regenerated from leaf tissues (regenerated) were randomly selected and evaluated for their genetic fidelity by RAPD. To date, 20 primers (C1-C20, Operon Technologies) were screened for all 84 plants. Only strong bands that are conservative were scored. Each primer generated a unique set of amplification products. Most of scoreable bands are ranged from 350 to $1800 \mathrm{bp}$. A total of 3696 fragments were amplified from 42 shootderived plants by all 20 primers with an average of 4.4 bands per primer, in which 6 primers produced polymorphic bands, indicating some genetic variations within shoot-derived plants. Nineteen out of 20 primers yielded 2772 clear and reproducible bands (an average of 3.47 per primer) from 42 regenerated plants with no significant variations being detected. Our preliminary results showed that in vitro regenerated plants are genetically uniform. However, a long-term tissue culture might result in a few genetic variations of birch species.

\section{(289) Development of a Technique to Screen for Transgenic Guayule}

William J. Liesenbein*, Dennis T. Ray

University of Arizona, Plant Sciences, Tucson, AZ, 85721

Guayule is a desert shrub that has been researched extensively for the purpose of developing it into a commercially viable source of high quality, hypoallergenic latex and rubber. Traditional breeding techniques have dramatically increased rubber yields, but genetic engineering techniques have the potential to increase rubber concentration in each plant while accelerating the development time of high-yielding guayule lines. Development of techniques to measure the flow of pollen from transgenic to non-transgenic plants is necessary to learn how to limit potential contamination of the environment due to transgene escape. Thus, the purpose of this work was to develop the methodology to quickly screen for transgenic seedlings. Guayule lines AZ 101, AZ-2, and N6-5, which were transformed with plasmids containing the NPTII gene that confers kanamycin resistance, were planted in a field surrounded by border rows and satellite plots of non-transgenic guayule. Seeds of known transgenic and non-transgenic guayule (controls) and seed collected from the non-transgenic plants were germinated and treated with an aerosol solution containing kanamycin at concentrations of 200,300 , and $400 \mathrm{mg} \cdot \mathrm{L}^{-1}$. Kanamycin caused seedlings to develop blotchy yellow leaves at all concentrations. Kanamycin at $300 \mathrm{mg} \cdot \mathrm{L}^{-1}$ was determined to be ideal for its time-to-symptom development and its lack of symptom severity found when treated at $400 \mathrm{mg} \cdot \mathrm{L}^{-1}$. Plants showing kanamycin resistance or kanamycin damage were confirmed using PCR.

\section{(290) Analysis of Genetic Diversity in Selected Cornus Species Using SSR Markers}

Xinwang Wang*1, Robert N. Trigiano*1, Mark T. Windham ${ }^{1}$, Renae DeVries $^{1}$, Timothy A. Rinehart ${ }^{2}$, James M. Spiers ${ }^{2}$, Brain Scheffler ${ }^{3}$

${ }^{1}$ The University of Tennessee, Entomology and Plant Pathology, Knoxville, TN, 37996; ${ }^{2}$ USDA-ARS MSA Small Fruits Research Station, Poplaville, MS, 39470; ${ }^{3}$ USDA-ARS MSA Genomics Laboratory, Stoneville, MS, 38776

The genus Cornus consists of many species, of which $C$. florida, $C$. kousa, C. mas, and C. stolonifera are four main ornamental species in North America, Asia, and Europe. For example, over 200 cultivars of 
C. florida alone have been developed for the nursery industry. Microsatellite loci, or SSR, are useful markers for studying genetic diversity and for creating linkage maps of the various species. The objective of this study was to investigate the genetic diversity between these four Cornus species and eight hybrids. Evaulation of the diversity will be useful in assessing the selection pressure of breeders and/or genetic drift of these dogwood cultivars/lines. Fifteen SSR primer pairs were selected to examine 56 Cornus cultivars and/or lines of the four species and hybrids. The study included 28 C. florida cultivars and lines, $15 C$. kousa cultivars and lines, four C. stolonifera cultivars, one cultivar of $C$. mass and eight hybrids between various Cornus species. An exceptionally high level of diversity was detected among the 56 entries in both the number and size range of SSR alleles. A total of 95 alleles with an average of 7.8 alleles per loci were detected among these 56 genotypes. These selected Cornus cultivars and/or lines could be clustered into four to six subgroups. Some Cornus species were integrated into other species groups, suggesting gene flow between species via the breeding or evolution. SSR markers can contribute to the exploitation of genetic diversity for existing Cornus germplasm. For further study, examination of more SSR loci could explain more completely the diversity among these Cornus cultivars and lines.

\section{(291) Plant Regeneration through Direct Somatic Embryogenesis in Homalomena 'Emerald Gem'}

\author{
Qian Zhang, Jianjun Chen*, Richard J. Henny
}

University of Florida, Mid-Florida Research and Education Center, Apopka, FL, 32703

Homalomena 'Emerald Gem' is an important ornamental foliage plant and widely used for interior plantscaping. Current propagation of this cultivar has been primarily carried out through in vitro culture by organogenesis; regeneration through somatic embryogenesis has not been documented. This report describes successful plant regeneration via direct somatic embryogenesis from explants of different organs. Somatic embryos formed at and around the cut surface of petiole, spathe, and peduncle explants. Embryos also appeared at the base between expanded ovaries of the spadix segment, and around midrib of leaf explants. The optimal treatments for somatic embryo occurrence from petiole, spathe, and peduncle explants were MS medium containing 0.2 $\mathrm{mg} / \mathrm{L} \mathrm{NAA}$ or $0.5 \mathrm{mg} / \mathrm{L} \mathrm{2,} \mathrm{4-D} \mathrm{with} 2.0 \mathrm{mg} / \mathrm{L} \mathrm{CPPU}$, and for spadix explants were MS medium with $0.5 \mathrm{mg} / \mathrm{L}$ PAA and $2.5 \mathrm{mg} / \mathrm{L} \mathrm{TDZ}$. Somatic embryos appeared 6 to 8 weeks after culture and formed large embryo clumps in 3 to 4 months. Somatic embryos produced more secondary embryos and geminated on induction medium. Multiple shoot development and plant regeneration occurred from somatic embryo clusters on MS medium without hormone or with $2 \mathrm{mg} / \mathrm{L} \mathrm{BA}$ and 0.2 $\mathrm{mg} / \mathrm{LNAA}$. The regenerated plants grew vigorously after transplanting to a soilless container substrate in a shaded greenhouse.

\section{(292) The Effect of Darkness and Sucrose Concentrations on the Production of Rosmarinic Acid in the Callus of Five Rosemary Genotypes}

Hany M. El-Naggar*1, Paul E. Read ${ }^{1}$, Susan L. Cuppett ${ }^{2}$

${ }^{1}$ University of Nebraska-Lincoln, Agronomy and Horticulture Dept., Lincoln, NE, 68503; ${ }^{2}$ University of Nebraska-Lincoln, Food Science and Technology, Lincoln, NE, 68583

Rosemary Rosmarinus officinalis is a member of the Lamiaceae. Rosmarinic acid (RA) is a very strong antioxidant produced in the chloroplast, and used to protect plant tissues against oxidative stress. A number of investigations showed that the sucrose concentration in the callus growing medium greatly influenced the production of secondary metabolites of the phenylpropanoid pathway such as RA. The aim of this study was to test the effect of elevated sucrose concentrations $(2 \%, 3 \%, 4 \%, 5 \%$, and $6 \%$ sucrose) and the effect of light and dark treatments on the production of RA in the callus of five different genotypes. The genotypes were Majorca, Rosmarinus officinalis, Pine Scented, Madeline Hill, and APR. It was found that the dark treatment produces more RA than the light treatment in all genotypes, and in all sucrose concentrations. The RA concentration increased with increasing the sucrose concentration from $2 \%$-reaching the highest concentration at $4 \%$ and $5 \%$ in most genotypes. The RA concentration declined again at $6 \%$ sucrose in all genotypes. We concluded that for the extraction of RA from rosemary callus it is preferred to be produced in the dark - this will save energy and will produce more RA than the light treatment. Also it is preferred to use sucrose concentration at $4 \%$ for genotypes Rosmarinus officinalis, Pine Scented, and APR; and 3\% sucrose for genotype Madeline Hill in the dark condition. While for the light condition, it is preferred to use $5 \%$ sucrose with genotypes Majorca, Rosmarinus officinalis, Pine Scented, and Madeline Hill; and $4 \%$ sucrose for genotype APR.

\section{(293) The PAL Gene Activity in Five Rosemary Genotypes and Its Effect on the Production of Rosmarinic Acid}

Hany M. El-Naggar*1, Paul E. Read ${ }^{1}$, Ayed Al-Abdallat ${ }^{2}$

${ }^{1}$ University of Nebraska-Lincoln, Agronomy and Horticulture Dept., Lincoln, NE, 68503; ${ }^{2}$ University of Nebraska-Lincoln, School of Biological Science, Lincoln, NE, 68588-0118

Phenylalanine ammonia-lyase (PAL) enzyme is the most extensively studied enzyme in the phenylpropanoid pathway. Studies on the biosynthesis of rosmarinic acid (RA) showed that the PAL enzyme catalyzes the initial step of the phenylpropanoid pathway. The increase in RA content in plant tissues in vitro coincided with the increase in PAL activity. The aim of this study was to investigate the activity of the gene responsible for the production of the PAL enzyme in the five rosemary genotypes; this will give more understanding about the accumulation of rosmarinic acid in the five rosemary genotypes. The genotypes were Majorca, Rosmarinus officinalis, Pine Scented, Madeline Hill and APR. Northern blot hybridization between the PAL gene primer and the five genotypes' cDNA showed bands at $300 \mathrm{bp}$ in all the five genotypes for the PAL gene. The expression of the PAL gene was high in genotypes Majorca, Rosmarinus officinalis, and Madeline Hill, while the expression was low in genotypes Pine Scented and APR. It was expected that the genotypes having the highest PAL gene expression will produce the highest amount of RA, but the highest genotype in PAL gene expression Madeline Hill had the lowest RA production in their leaves. This could occur due to the tissue specific regulation inside plant tissues. Inside the callus tissues, where the specific tissue regulation no longer exists, the RA was produced in repetitively large amounts in genotypes with high PAL gene expression.

\section{(294) The Effect of Heavy Metal Cadmium on Transgenic and Nontransgenic Petunia Plants}

Pranitha Patil*1, Sung Park ${ }^{2}$

${ }^{1}$ College Station Middle School, College Station, TX, 77845; ${ }^{2}$ Texas A\&M University, Vegetable and Fruit Improvement Center, Horticultural Sciences, College Station, TX, 77845

Heavy metal contamination in the ground and its effects on human health has been a major concern. The objective of this experiment is to determine how cadmium affects transgenic and nontransgenic (control) petunia plants. Initially, the petunia seed germination medium (SGM) was prepared, and petunia seeds were sterilized and cultured on the SGM medium. During the actual experiment, using 8-day-old germinated petunia, the SGM-Cd media containing four different concentrations $(0$, $50,100$, and $200 \mu \mathrm{M})$ of $\mathrm{CdCl}_{2}$ were prepared. Plant growth and survival rates in four concentrations of SGM-Cd media were recorded. Over 20 days of observations, the plants showed two distinct differences: color and growth. For the first few days, all of the plants grew very slowly, but the plants showed marked differences in growth and color at later days. On the final day, 22 Jan., the control plants on $0 \mu \mathrm{M}$ of $\mathrm{CdCl}_{2}$ grew $4.2 \mathrm{~cm}$, while the transgenic plant grew $2.4 \mathrm{~cm}$ and showed a dark shade of green color. The control plants on $50 \mu \mathrm{M}$ grew $1.38 \mathrm{~cm}$, while the transgenic plants grew $2.2 \mathrm{~cm}$. The control plants on $100 \mu \mathrm{M}$ grew $1.14 \mathrm{~cm}$, while the transgenic plants grew a total of $1.7 \mathrm{~cm}$. Both control and transgenic plants on $200 \mu \mathrm{M}$ had similar growth of 0.94 $\mathrm{cm}$ and showed very light shade of green color. The hypothesis in this 
experiment was confirmed because $\mathrm{CdCl}_{2}$ impacted the growth of the control and transgenic plants by stunting the growth of the plant and changing its color. It is also demonstrated here that transgenic plants containing the heavy metal transport (HMT) gene can grow better than control because of the specific HMT gene that allowed the plant to uptake more $\mathrm{CdCl}_{2}$ into the central vacuole.

\section{(295) Relationship Between Macromolecule and Metal Ion Accumulation in Two Salt-stressed Cultivars of Sweetpotato under In Vitro Conditions}

Devi Prasad V. Potluri*

Chicago State University, Biol. Sciences,Chicago, IL, 60628

Two cultivars of sweetpotato [Ipomoea batatas (L.) Lam.], Commensal and Salyboro, were subjected to salt stress using axillary bud cultures. The salt levels ranged from $0-150 \mathrm{mM}$. After 10 weeks of growth, plantlet shoot height, dry weight, number of nodes, levels of proline, soluble carbohydrate, and protein; and metal ions sodium, potassium, magnesium, and calcium, were measured. In both cultivars, proline accumulation was higher in the shoot. There was a positive correlation between the increase in soluble carbohydrates and proteins in 'Commnesal', but not in 'Salyboro'. More sodium accumulated in the shoots of 'Salyboro' compared to 'Commensal'. The accumulation of sodium reduced the calcium and potassium, but not magnesium levels. Increase in sodium levels correlated with the increase in soluble carbohydrate levels is 'Salyboro', but not in 'Commensal'. A similar trend was evident with praline and sodium accumulation. Based on these and previous results, the cultivar 'Salyboro' appears to be more susceptible to salt stress.

\section{(296) Genetic and Molecular Characterization of Putative Ethylene Mutants in Antirrhinum majus}

Leslie Heffron*1, Emily Jordan², Jackie Nugent ${ }^{2}$, Schuyler Korban

${ }^{1}$ University of Illinois, Department of Natural Resources and Environmental Sciences, Urbana, IL, 61801; ${ }^{2}$ National University of Ireland Maynooth, Department of Biology, Maynooth, Co. Kildare, Ireland

Sixteen putative ethylene mutant Antirrhinum majus (snapdragon) lines, derived from 1-aminocyclopropane-1-carboxylic acid (ACC) screening, were crossed in a full diallel that included the wild-type line to determine allelism/complementation groups. Seeds from these crosses were screened on a tissue culture medium containing $5 \mu \mathrm{M}$ ACC to elucidate the response to exogenous ethylene treatment. Additionally, five of the mutant lines along with an inbred control, from which the mutants were derived, were analyzed using RT-PCR to determine regulation of gene expression in vegetative (roots, shoots, leaves, and sepals) and floral (six stages of flowering, from green bud to post-pollination) tissues using six different ACC synthase (ACS) cDNA clones and two different ethylene receptor (ETR) cDNA clones, all derived from Antirrhinum majus, as probes. Differential regulation of gene expression for ACS and ETR were observed in some tissues and at different stages of floral development.

\section{(297) Expression Analysis of a Peach-1,3- glucanase Gene, $P p G n s 1$, in Response to Various Phytohormones and Chemical Elicitors}

\section{Scott Schaefer*, Ksenija Gasic, Schuyler Korban}

University of Illinois, Department of Natural Resources and Environmental Sciences, Urbana, IL, 61801

Peach shoots were grown in vitro for $0,6,12,24$, and $48 \mathrm{~h}$ on a basal medium containing one of several phytohormones or chemical elicitors, including abscisic acid (ABA), indolebutyric acid (IBA), indoleacetic acid (IAA), kinetin, gibberellic acid (GA), aminocyclopropane-1-carboxylic acid (ACC), methyl jasmonate (MeJ), and salicylic acid (SA). Northern blot analysis was conducted using the 3' end of a peach-1,3glucanase gene, $P p G n s 1$, used as a probe. Variations in levels of $P p G n s 1$ expression patterns were observed for each of the treatments. Shoots treated with ABA displayed high levels of transcripts at 12 and $24 \mathrm{~h}$, followed by a sharp decline at $48 \mathrm{~h}$. Shoots treated with ACC displayed a steady increase in transcripts throughout the $48 \mathrm{~h}$ period. The synthetic auxin IBA displayed a steady increase in mRNA accumulation for the first $24 \mathrm{~h}$ followed by a sharp decline at $48 \mathrm{~h}$. Shoots treated with kinetin displayed low levels of transcripts after $24 \mathrm{~h}$, while $\mathrm{GA}_{3}$ did not induce any accumulation of PpGns 1 transcripts. Both SA and MeJA induced steady mRNA accumulation in peach shoots over the entire 48-h period. Induction of $P p G n s 1$ in response to SA, MeJ, and ACC also resulted in observed necrotic lesions on peach shoots, thus suggesting a different defense mechanism response.

\section{Poster Session 39-Organic Production}

30 July 2006, 1:15-2:00 p.m.

\section{(151) Effect of Glucose Application on Tomato Plant Growth in a Saline Soil}

Alejandra Guadalupe Zamora-Solís, Marcelino Bazan-Tene, Javier Farias-Larios, Jose Gerardo López-Aguirre*, Jaime Molina-Ochoa

Universidad de Colima, Facultad de Ciencias Biológicas y Agropecuarias, Autopista ColimaManzanillo KM 40, Crucero de Tecomán, Tecomán, Colima, 28100, México;

Distribution of salinity and sodicity through the world is around 80 thousand million $\mathrm{km}^{2}$. To this quantity, we must add 10 million ha of irrigated lands that are abandoned each year due to such adverse effects on irrigation as salinity and/or alkalinity. Easily available substrates, such as glucose, increase the microbial activity to imprpove soils; for example, $\mathrm{pH}$ decreases because of a high production of some metabolites, such as carboxylic acids and hydro phenolics group. We carried out a study to evaluate the effect of glucose application on tomato plant (Lycopersicum esculentum Mill.) growth in saline soil. The experiment was done under greenhouse conditions. Soil samples were taken from 0-20-cm depth at the "El Chococo" ranch (lat. $18^{\circ} 47$ 'N; long. 103 ${ }^{\circ} 55^{\prime} \mathrm{W}$ ). Treatments imposed were: $2 \%$ (T1), 4\% (T2), and 6\% (T3) glucose and a control without glucose (T0). Soil with treatments was incubated at ambient temperature for 40 days. Tomato seeds were germinated for 30 days and later transplanted to plastic bags that contained treatments. After transplant, tomato plants were grown for 40 days and then evaluated for plant height, dry and fresh weight, aerial and radicular biomass, and foliar area. Treatments were distributed under randomized design, and Tukey's $(0.05)$ separation means were done. When the glucose percentage was increased, the soil $\mathrm{pH}$ decreased 8.50, 8.0, 7.70, and 7.60 in $\mathrm{T} 0, \mathrm{~T} 1, \mathrm{~T} 2$, and $\mathrm{T} 3$, respectively, but electrical conductivity increased. The highest values of parameters evaluated in plants were measured in treatment $\mathrm{T} 3$, and all the plants died in treatment $(0)$.

\section{(152) Application of Lemon Industrial Waste and the Effect on Tomato Plant Growth in a Saline Soil}

Orlando Javier Torres-Meza ${ }^{1}$, Marcelino Bazan-Tene ${ }^{1}$,

Javier Farias-Larios ${ }^{1}$, Jose Gerardo Lopez-Aguirre*2, Jaime Molina-Ochoa ${ }^{1}$

${ }^{1}$ Universidad de Colima, Facultad de Ciencias Biológicas y Agropecuarias, Autopista Colima-Manzanillo KM 40, Crucero de Tecoman, Tecomán, Colima, 28100, México; ${ }^{2}$ Universidad de Colima, Autopista Colima-Manzanillo KM 40, Crucero de Tecoman, Tecomán, Colima, 28100, México

Low organic matter in soil is a large problem in crop production around the world because it affects physical, chemical, microbiological, and morphological properties. On the other hand, regions with agro-industry generally generate waste that can cause some level of contamination. Therefore, it is necessary to find some use for this kind of waste. This study was done to evaluate the effect of lemon industrial waste on tomato (Lycopersicum esculentum Mill.), growth in a saline soil. The experiment was conducted under greenhouse conditions. Soil samples were taken from 0 - to 20-cm depths at the El Chococo ranch, located at $18^{\circ} 47^{\prime} \mathrm{N}$ and $103^{\circ} 55^{\prime} \mathrm{W}$. Four treatments were imposed: $0(0), 600$ (1), 1200 (2), and $1800(3) \mathrm{m}^{3} / \mathrm{ha}$. Soil in treatments was incubated at ambient temperature for 40 days. Tomato seeds were germinated for 
30 days and later transplanted to plastic bags containing treatments. After transplant, tomato plants were grown during 40 days, after which was measured: high plant, dry and fresh weight, aerial, and radicular biomass and foliar area. Treatments were distributed under randomized design, and Tukey's (0.05) separation means was performed. Organic matter, $\mathrm{pH}$, and $\mathrm{CE}$ in soil before treatment application was $1.01 \%$, 8.5 , and $7.6 \mathrm{dS} / \mathrm{m}$ respectively (in 1:5 soil : water ratio). After application, $\mathrm{OM}$ increased until $3.7 \%$ in treatment $3 . \mathrm{pH}$ and $\mathrm{CE}$ decreased to 5.5 in treatment 2 , and $1.57 \mathrm{dS} / \mathrm{m}$ in treatment 0 . All data measured in plants had the highest values in treatment 1 , and all plants died in treatment 0 . We believe that is necessary to do this experiment in the field to obtain additional data.

\section{(153) Impact of Variety and Production Method on Yield and Quality of Organically Grown Watermelon}

Angela R. Davis*, Charles L. Webber III, Penelope Perkins-Veazie, Julie Collins, Vincent M. Russo

USDA-ARS, South Central Agricultural Research Laboratory, Lane, OK, 74555;

Cultural practices have been reported to affect quality and phytonutrient content of watermelon. Knowing which varieties perform best under various production systems, and how these systems affect quality, yield, and phytonutrient content, is imperative to ensure high quality and yield. There is limited information on how watermelon [Citrullus lanatus var. lanatus (Thunb.) Matsum. \& Nakai] varieties perform when grown with organic practices. Production characteristics of six watermelon varieties from certified organic seed sources were compared under high- (black plastic and mechanical cultivation for weed control) and low-input (no-till) organic culture. The high-input method utilized black plastic mulch and mechanical cultivation for weed control. The low-input utilized no-till planting. 'Triple Star' was the most productive seedless variety in terms of number of fruit and marketable yield when data were combined across locations. 'Early Moonbeam' produced the largest number of fruit, and the smallest fruit, of the seeded varieties. 'Allsweet', a seeded variety, had the best marketable yield due to its larger size. 'Triple Star' had the best quality (lycopene and ${ }^{\circ}$ Brix content) when data were combined across locations. Among the seeded varieties, 'Allsweet' had the best quality at both locations; however, average lycopene content on a per-fruit basis under low input production was not significantly different when compared to 'Sugar Baby'. High-input production methods almost doubled the number of fruit produced for all varieties, producing greater yields, and heavier average fruit weights, but lower ${ }^{\circ}$ Brix and lycopene content compared to the low-input production method.

\section{(154) Alternatives for Pest Management in a Tropical Organic Watermelon Production System}

Annette L. Wszelaki*, Bryan Brunner

University of Puerto Rico, Horticulture, Mayaguez, PR, 00681

While much research has been conducted in organic farming, little has focused on tropical systems. Tropical, versus temperate, systems present additional challenges for organic producers, including differences in soils, temperature, daylength, rainfall, and humidity. Pest management in tropical organic systems can be particularly demanding due to the year-round pest pressure and optimal environment for pest proliferation. Weed management is essential for the production of high-quality watermelons, but can be difficult when herbicides are not permitted. Weeds also serve as a source of inoculum for disease organisms and a habitat for insects, both beneficial and detrimental. Many products have been advertised for pest control in organic farming systems, most of which have not been adequately evaluated in independent, replicated trials. Here we investigated alternatives to pesticides for the control of weeds, insects, and diseases in 'Crimson Sweet' watermelons. A split plot on a RCBD with four replications per treatment was used, with weed treatment ( \pm paper-grass mulch) as the main plot and 12 insect and disease control alternatives as subplots. The alternatives for insect and disease control included traditional copper-based fungicides, biological control agents, potassium bicarbonate, hydrogen dioxide, milk, and commercial formulations of essential oils. Weed abundance (percentage cover), disease severity (percentage disease), and insect damage (percentage foliar damage) were evaluated weekly using a modified Horsfall-Barratt scale. Yield and quality were measured at harvest on five plants from each replication. While none of the products should be relied upon as the sole means of managing pests, those with efficacy could be integrated into organic management programs.

\section{(155) Hybrids Versus Heirlooms: A Comparison Study in Garden Productivity and Marketability for Small-scale Commercial Growers}

Leah Grunzke*1, David Baumbauer ${ }^{2}$, Tracy Dougher ${ }^{1}$

${ }^{1}$ Montana State University, Plant Sciences and Plant Pathology, Bozeman, MT, 597173140; ${ }^{2}$ Montana State University, College of Agriculture, Bozeman, MT, 59717

This project investigated the apparent consumer trend in recent years toward increasing popularity of heirloom vegetable varieties, and its significance in regard to growers that market their produce on a local or regional scale. Growing heirloom and hybrid varieties of tomatoes, carrots, eggplants, and sweet corn side by side provided insight on different varieties from a small-scale producer's perspective, including information on garden performance, productivity, and ease of production (including germination, growth habit, yields, maturation, harvest timing, and longevity). Feedback from consumers was gathered while selling the produce at a local farmer's market. Finally, a local chef and deli manager provided professional insight into the potential uses and marketability of the products. From a grower's perspective, there was no distinct pattern of advantages or disadvantages to either hybrids or heirlooms, as the varieties varied widely in terms of field performance. Consumer acceptance of unusual or unique varieties (in terms of appearance and recognition) varied with each crop. The chef evaluation, with taste preferences evenly split between hybrid and heirloom varieties, tended to favor those with an unusual or nontraditional appearance.

\section{(156) Improved Cover Crop Establishment and Growth Is Related to Planting Date in Organic Concord Grape Production}

Kyle E. Bair*, Robert G. Stevens, Joan R. Davenport

Washington State University, Crop and Soil Science, Prosser, WA, 99350

Concord grape (Vitis labrusca L.) accounts for a majority of juice grapes produced in Washington State. Because synthetic nutrients are not permissible in USDA organically-certified production systems, legume cover crops are used to supply nitrogen $(\mathrm{N})$ to the crop. In order to supply a sufficient amount of $\mathrm{N}$, the cover crop must successfully establish and produce large quantities of biomass. This study evaluates how the planting date influences emergence and biomass production of hairy vetch (Vicia villosa subsp. villosa L.) and yellow sweet clover [Melilotus officinalis (L.) Lam.] when used as legume green manures. The research was conducted on a commercial vineyard and a research vineyard from 2003-05. Treatments for the study consisted of yellow sweet clover and hairy vetch planted in both the spring and fall. Plots receiving soluble $\mathrm{N}$ sources were planted with wheat (Triticum aestivum L.) or rye (Secale cereale L.). Because of the large relative seed sizes of rye, wheat, and hairy vetch compared to yellow sweet clover, these treatments established faster with good stands in 2004. In 2005, clover plots had high emergence and biomass production because of water management modifications. Biomass data from the commercial vineyard in May 2005 indicates that fall-planted vetch produced more biomass than spring-planted vetch. Fall-planted hairy vetch and yellow sweet clover in the research vineyard showed higher biomass production than spring- and fall-planted hairy vetch and yellow sweet clover. When hairy vetch and yellow sweet clover are planted in the fall, they generally have better seedling emergence and biomass production due to the heightened aggressiveness exhibited by competing weed species during late spring and summer. 
Poster Session 40-Produce Quality, Safety, and Health

30 July 2006, 1:15-2:00 p.m.

\section{(167) Carotenoid Accumulation Among the Diploid} and Amphidiploid Brassica Species

Dean A. Kopsell*1, Scott McElroy ${ }^{1}$, Carl Sams ${ }^{1}$, David Kopsell ${ }^{2}$

${ }^{1}$ The University of Tennessee, Plant Sciences, Knoxville, TN, 37996; ${ }^{2}$ The University of Wisconsin-Platteville, School of Agriculture, Platteville, WI, 53818

Vegetable crops can be significant sources of nutritionally important dietary carotenoids and Brassica vegetables are sources that also exhibit antioxidant and anticarcinogenic activity. The family Brassicaceae contains a diverse group of plant species commercially important in many parts of the world. The six economically important Brassica species are closely related genetically. Three diploid species ( $B$. nigra, $B$. rapa, and $B$. oleracea) are the natural progenitors of the allotetraploid species (B. juncea, B. napus, and B. carinata). The objective of this study was to characterize the accumulation of important dietary carotenoid pigments among the genetically related Brassica species. The HPLC quantification revealed significant differences in carotenoid and chlorophyll pigment accumulation among the Brassica species. Brassica nigra accumulated the highest concentrations of lutein, 5,6epoxy lutein, violaxanthin, and neoxanthin. The highest concentrations of beta-carotene and total chlorophyll were found in B. juncea. Brassica rapa accumulated the highest concentrations of zeaxanthin and antheraxanthin. For each of the pigments analyzed, the diploid Brassica species accumulated higher concentrations, on average, than the amphidiploid species. Brassicas convey unique health attributes when consumed in the diet. Identification of genetic relationships among the Brassica species would be beneficial information for improvement programs designed to increase carotenoid values.

\section{(168) Phospholipase D $\alpha$ and Lipoxygenase Gene Expression in Fruit, Floral, and Vegetative Tissues of 'Honey Brew' Hybrid Honeydew Melon}

Bruce D. Whitaker' ${ }^{1}$ Gene E. Lester*2

${ }^{1}$ USDA-ARS Beltsville Agricultural Research Center, Produce Quality \& Safety Laboratory, Beltsville, MD, 20705-2350; ${ }^{2}$ USDA, Agricultural Research Service, Kika de la Garza Subtropical Agricultural Research Center, Weslaco, TX, 78596

Increases in phospholipase D (PLD) and lipoxygenase (LOX) activities are thought to play a key role in senescence of mesocarp tissues in muskmelon fruit. We have cloned and characterized two full-length cDNAs, CmPLD $\alpha$ and CmLOX1, encoding PLD $\alpha$ and LOX proteins in honeydew melon (Cucumis melo L. Inodorus Group). Levels of expression of the corresponding genes were determined by semi-quantitative RT-PCR in developing and mature fruit mesocarp tissues (20-60 d after pollination; DAP), and in roots, leaves, and stems from 4-week-old and flowers from 6-week-old plants. The coding regions of CmPLD $\alpha 1$ and CmLOX1 cDNAs are, respectively, 2427 and 2634 nucleotides long, encoding proteins 808 and 877 amino acids in length. CmPLD $\alpha 1$ is most similar to PLD $\alpha$ genes in castor bean, cowpea, strawberry, and tomato (77\% nucleotide identity), and is the first cucurbit PLD gene cloned. CmLOX1 has 94\% nucleotide identity to a cucumber LOX gene expressed in roots and $80 \%$ identity to cucumber cotyledon lipid body LOX. Transcript of CmPLD $\alpha 1$ was much more abundant than that of CmLOX1, but relative levels of transcript in the various organs and tissues were similar for the two genes. Expression was highest in roots, flowers, and fruit mesocarp tissues. CmPLD $\alpha 1$ expression in fruit was high throughout development, although maximum levels occurred at 50 and 55 DAP, respectively, in middle and hypodermal mesocarp. CmLOX1 expression was generally higher in middle than in hypodermal mesocarp with maximum transcript levels at 55 and 50 DAP, respectively. Overall, the patterns of expression of CmPLD $\alpha 1$ and CmLOX1 are consistent with a model in which their encoded enzymes act in tandem to promote or accelerate senescence in fruit mesocarp tissues.
(169) Antioxidant Levels in Frozen and Processed Lingonberries and Bog Blueberries

Patricia S. Holloway*1, Roxie Rodgers Dinstel ${ }^{2}$

${ }^{1}$ Univ. of Alaska Fairbanks, Dept. of Plant, Animal \& Soil Sciences, Fairbanks, AK, 99775; ${ }^{2}$ Univ. of Alaska Fairbanks, Cooperative Extension Service, Fairbanks, AK, 99775

Frozen lingonberries (Vaccinium vitis-idaea subsp. minus) and bog blueberries ( $V$. uliginosum) were processed using recipes of the Alaska Cooperative Extension Service. Overall antioxidant activity (H-ORAC) was $71 \mu \mathrm{mol} \cdot \mathrm{g}^{-1}$ of TE for frozen bog blueberries and for lingonberries, $160-165 \mu \mathrm{mol} \cdot \mathrm{g}^{-1}$ of TE. Processing into fruit leather and drying increased levels in bog blueberries to $260-430 \mu \mathrm{mol} \cdot \mathrm{g}^{-1}$ of $\mathrm{TE}$ and lingonberries to $457-939 \mu \mathrm{mol} \cdot \mathrm{g}^{-1}$ of TE. Leathers and dried fruit had significantly higher levels of total anthocyanins (frozen bog blueberries: $2.1 \mu \mathrm{g} \cdot \mathrm{g}^{-1}$, leather: $8.0 \mu \mathrm{g} \cdot \mathrm{g}^{-1}$, dried: $9.8 \mu \mathrm{g} \cdot \mathrm{g}^{-1}$; frozen lingonberries $1.4 \mu \mathrm{g} \cdot \mathrm{g}^{-1}$, leather: $4 \mu \mathrm{g} \cdot \mathrm{g}^{-1}$, dried: $\left.5.2 \mu \mathrm{g} \cdot \mathrm{g}^{-1}\right)$; total phenolics (frozen bog blueberries: $4.8 \mu \mathrm{g} \cdot \mathrm{g}^{-1}$, leather: $19 \mu \mathrm{g} \cdot \mathrm{g}^{-1}$, dried: $26 \mu \mathrm{g} \cdot \mathrm{g}^{-1}$; frozen lingonberries $7.7 \mu \mathrm{g} \cdot \mathrm{g}^{-1}$, leather $24 \mu \mathrm{g} \cdot \mathrm{g}^{-1}$, dried: $38 \mu \mathrm{g} \cdot \mathrm{g}^{-1}$ ); and quercetin (frozen bog blueberries: $6.7 \mu \mathrm{g} \cdot \mathrm{g}^{-1}$, leather: $86 \mu \mathrm{g} \cdot \mathrm{g}^{-1}$, dried: $150 \mu \mathrm{g} \cdot \mathrm{g}^{-1}$; frozen lingonberries $7.7 \mu \mathrm{g} \cdot \mathrm{g}^{-1}$, leather $110 \mu \mathrm{g} \cdot \mathrm{g}^{-1}$, dried: $\left.430 \mu \mathrm{g} \cdot \mathrm{g}^{-1}\right)$. Bog blueberries did not have detectible levels of p-coumeric acid or benzoic acid, but lingonberries showed a significant increase in dried fruit and leather (frozen fruit p-coumeric: $0.18 \mu \mathrm{g} \cdot \mathrm{g}^{-1} \mathrm{~g}$, leather: $0.45 \mu \mathrm{g} \cdot \mathrm{g}^{-1}$, dried: $1.4 \mu \mathrm{g} \cdot \mathrm{g}^{-1}$; frozen fruit benzoic: $0.41 \mu \mathrm{g} \cdot \mathrm{g}^{-1}$, leather: $0.84 \mu \mathrm{g} \cdot \mathrm{g}^{-1}$, dried: 0.71 $\left.\mu \mathrm{g} \cdot \mathrm{g}^{-1}\right)$. Frozen and processed lingonberries had little or no vitamin C. Bog blueberries had detectible levels in all treatments [highest in leather $\left(440 \mu \mathrm{g} \cdot \mathrm{g}^{-1}\right)$, frozen berries $\left.\left(220 \mu \mathrm{g} \cdot \mathrm{g}^{-1}\right)\right]$. ORAC, total anthocyanins, total phenolics, and quercetin were detected in all other processing methods (canned fruit, syrup, canned juice, jam, sauce, frozen $\mathrm{j}$ uice, and freezer jam). Levels were similar to or lower than frozen fruit.

\section{(170) Reduction of Natural Microbial Population with Antimicrobial Agents and Subsequent Washing Treatments of Fresh-cut Vegetables}

\section{Hidemi Izumi*, Takeshi Yamashita, Maki Inada}

Kinki University, School of Biology-Oriented Science and Technolgy, 930 Nishimitani, Kinokawa, Wakayama, 649-6493, Japan

Ferulic acid agent (2\% of ferulic acid), fumaric acid agent $(20 \%$ of fumaric acid), mustard extract agent (10\% of allyl isothiocyanate), and calcined calcium agent (91\% of calcium) were assessed for reduction of endogenous microbial population on fresh-cut lettuce, cabbage, and cucumber in the preliminary study. In seeking effective minimum concentration, a $0.5 \%$ ferulic acid agent or $1.0 \%$ fumaric acid agent applied on lettuce, $0.1 \%$ mustard extract agent on cabbage, and $0.05 \%$ calcined calcium agent on cucumber reduced mesophilic aerobic bacteria (MAB) and coliform group (coliforms) by about 0.5 to $1.5 \operatorname{logs}$ relative to water-dipped control. The efficacy of these antimicrobial agents with subsequent washing treatments with electrolyzed water (13 ppm of available chlorine) or ozonated water (5 ppm of ozone) on endogenous microorganism were evaluated with fresh-cut vegetables stored in MA package for 4 days at 10 ${ }^{\circ} \mathrm{C}$. With lettuce, the fumaric acid agent followed by electrolyzed water treatment was the most effective in reducing counts of MAB, coliforms, and psychrotrophic aerobic bacteria (PAB) for the first 2 days of storage. This treatment eliminated gram-positive bacteria such as the genus Curtobacterium and gram-negative bacteria such as the genus Stenotrophomonas. With cucumber, fumaric acid agent or calcined calcium agent with sequential washing with electrolyzed water reduced counts of $\mathrm{MAB}$, coliforms, $\mathrm{PAB}$ and lactic acid bacteria during 4 days of storage, with the reduction being greater with fumaric acid agent than with calcined calcium agent. With cabbage, the combinations of the agents and washing treatments had no pronounced effect when compared with water treatment. 


\section{(171) Blueberry Leaf Inhibits Hepatitis C Virus RNA Replication}

Ena Akamatsu*1, Takanori Kai², Hideaki Hirabaru², Chizuko Yukizaki ${ }^{3}$, Miho Sakai ${ }^{4}$, Hirofumi Uto ${ }^{5}$,

Hirohito Tsubouchi ${ }^{6}$, Hisato Kunitake ${ }^{7}$

${ }^{1}$ Miyazaki Prefectural Industrial Support Foundation, Research Promotion Bureau for Collaboration of Regional Entities, 16500-2, Higashi-kaminaka. Sadowara-cho, Miyazaki City, Miyazaki, 880-0303, Japan; ${ }^{2}$ Unkai Shuzo Co., Ltd., Research \& Development, 1800-5, Aza mameshinkai, Oaza Minamimata. Aya-cho, Higashimorokata-gun, Miyazaki, 880-1303, Japan; ${ }^{3}$ Miyazaki Prefectural Food Research \& Development Center, Food Development Department, 16500-2, Higashi-kaminaka. Sadowara-cho, Miyazaki City, Miyazaki, 880-0303, Japan; ${ }^{4}$ Miyazaki Prefectural Food Research \& Development Center, Food Development Dept.; ${ }^{5}$ Faculty of Medicine, University of Miyazaki, Dept. of Internal Medicine 2, 5200 Oaza Kihara, Kiyotake-cho, Miyazaki-gun, Miyazaki, 889-1692, Japan; ${ }^{6}$ Kagoshima University Grasuate School of Medical \& Dental Sciences, Dept. of Digestive and Life-style Related Disease, 8-35-1, Sakragaoka, Kagoshima City, Kagoshima, 890-8520, Japan; ${ }^{7}$ Faculty of Agriculture, University of Miyazaki, Dept. of Biochemistry \& Applied Biosciences, 1-1, Nishi, Gakuenkibanadai, Miyazaki City, Miyazaki, 889-2192, Japan

Blueberry (Vaccinium sp.) fruits contain high concentrations of polyphenols such as anthocyanin. It is well known that polyphenols have antioxidant activity, so it is likely that the fruit has a possible preventative effect against several diseases like cancer. However, only a few reports so far have studied the human health benefits of the leaves. In this study, the antioxidant activity and antiviral effects of blueberry leaves were investigated. The leaves of three groups of blueberry, northern highbush blueberry (NHB), southern highbush blueberry (SHB), and rabbiteye blueberry (REB), were examined. These leaves were harvested in July and extracted with $80 \%$ ethanol. Samples were analyzed for antioxidant activity (DPPH radical scavenging activity) and antiviral activity against hepatitis $\mathrm{C}$ virus using the replicon cell assay (Lomann et al., 1999). The antioxidant activity showed significant variability between cultivars and species, with REB having about two times the activity of NHB and SHB. Antiviral activity was observed in the extracts of the leaves and the fruit, and the activity of the leaves was higher than that of the fruit. Among the cultivars and species evaluated, the antiviral activity of REB was higher than that of NHB and SHB. In addition, we discovered a positive correlation $(r=0.68)$ between the antioxidant activity and the antiviral activity, using the leaves of hybrid seedlings of REB. Therefore, it is possible to speculate that the antiviral activity bears some relation to the antioxidant activity.

\section{(172) Strawberries Inhibit Cancer Cell Proliferation}

Shiow Wang*1, Kimberly Lewers ${ }^{1}$, Linda Bowman ${ }^{2}$, Min Ding ${ }^{2}$

${ }^{1}$ U.S. Department of Agriculture, Fruit Laboratory, Beltsville, MD, 20705-2350; ${ }^{2}$ Center for Disease Control and Prevention, Health Effects Laboratory Division, Morgantown, WV, 26505-2888

Representatives of three species of strawberries (Fragaria virginiana, $F$. chiloensis and $F$. $\times$ ananassa) were evaluated for antioxidant capacity, scavenging capacity for reactive oxygen species ( $\mathrm{ROO}, \mathrm{OH},{ }^{1} \mathrm{O}_{2}$ and $\mathrm{O}_{2}{ }^{-}$), and inhibitory effect on proliferation of A549 human lung epithelial cancer cells. Differences among the strawberry genotypes were observed for all three qualities. High antioxidant and scavenging capacities were found in 'CFRA 0982', 'JP 95-1-1', NC 95-19-1 and RH 30. Lowest antioxidant and scavenging capacities were found in 'Allstar'. There was also a relationship between scavenging capacity and the inhibition of cancer cell proliferation. The correlations $\left(R^{2}\right)$ between the scavenging capacities for the reactive oxygen species and the inhibition of cancer cell proliferation were $0.8074,0.8279,0.7862$ and 0.7761 for $\mathrm{ROO}, \mathrm{OH},{ }^{1} \mathrm{O}_{2}$ and $\mathrm{O}_{2} \cdot-$, respectively. These results suggest that antioxidants, specifically their scavenging capacities, may play an important role in the antiproliferative activity of strawberries. This study also identified strawberry germplasm of value in developing cultivars useful for cancer prevention.

(173) Phytonutrient Accumulation and Antioxidant Capacity at Eight Developmental Stages of Black Raspberry Fruit

Mustafa Ozgen ${ }^{1}$, Artemio Z. Tulio, Jr.', Ann M. Chanon²,
Nithya Janakiraman ${ }^{3}$, R. Neil Reese ${ }^{4}$, A. Raymond Miller ${ }^{2}$, Joseph C. Scheerens*2

${ }^{1}$ Gaziosmanpasa University, Horticulture, Tasliciftlik, Tokat, 60240, Turkey; ${ }^{2}$ The Ohio State University, Horticulture and Crop Science, Ohio Agricultural Research and Development Center, Wooster, OH, 44691; ${ }^{3}$ The Ohio State University, School of Environment and Natural Resources, Ohio Agricultural Research and Development Center, Wooster, OH, 44691; ${ }^{4}$ South Dakota State University, Biology and Microbiology, Brookings, SD, 57007

To investigate phytonutrient accumulation in black raspberries, fruits of 'Jewel' and 'MacBlack' were harvested at stages from the onset of color development (S1) to ripe fruit (S7). S1-S7 samples were characterized for color reflectance and then frozen at $-28{ }^{\circ} \mathrm{C}$ within an hour of harvest. Additional ripe fruit were maintained at $20^{\circ} \mathrm{C}$ for 3 days to overripen (S8) before freezing. After storage, samples were analyzed for dry weight (DW), total soluble solids (TSS), fructose (FRU), glucose (GLU), and organic acid (ORG) contents; total phenolic (PHE) and anthocyanin (ACY) contents; individual cyanidin glycoside levels (ICG); and antioxidant capacity (FRAP and ABTS) by standard methodology. 'Jewel' and 'MacBlack' ripened similarly. Chroma values and DW percentage decreased while TSS levels, sugar contents (FRU+GLU), PHE, ACY, the ACY : PHE ratio, and ICG increased with progressive ripening stages (S1-S7). Values of PHE, ACY, and ICG were highly correlated $(r<+0.95)$ with FRAP and ABTS values. ACY levels in S6 fruit were $18 \%$ to $23 \%$ less than those of S7; lower S6 ACY levels were associated with reduced antioxidant capacity in 'MacBlack', but not 'Jewel'. Overripened fruit (S8) exhibited increased DW (11\% to 25\%) and decreased sugar contents (16\% to $17 \%$ ), consistent with moisture and respiratory losses after harvest. After correction for these losses, S7 and S8 levels of PHE, ACY, FRAP, and ABTS were similar in 'MacBlack'. However, as 'Jewel' overripened, ACY levels and antioxidant activity increased $44 \%$ and $22 \%$ to $26 \%$, respectively. Our data suggests that significant changes in the antioxidant behavior of black raspberries can occur during the periods surrounding peak ripeness.

\section{(174) Determination of Fatty Acid Composition in 120 Korean Native Rice Cultivars}

Kyoung-Shim Cho*1, Hyun-Ju Kim¹, Jae-Ho Lee', Jung-Hoon Kang ${ }^{2}$, Young-Sang Lee ${ }^{1}$

${ }^{1}$ Soonchunhyang University, Biological Resources and Technology, Shinchang-myon Eupnae-ri 646, Asan, Chung-Nam, 336-745, South Korea; ${ }^{2}$ National Institute of Agricultural Biotechnology, RDA, Information Network, Genebank, 225 Seodundong, Kwonseonku, Suwon, Kyonggi-do, 441-707, South Korea

Fatty acid is known as a physiologically active compound, and its composition in rice may affect human health in countries where rice is the major diet. The fatty acid composition in brown rice of 120 Korean native cultivars was determined by one-step extraction/methylation method and GC. The average composition of 9 detectable fatty acids in tested rice cultivars were as followings: myristic acid; $0.6 \%$, palmitic acid; $21.2 \%$, stearic acid; $1.8 \%$, oleic acid; $36.5 \%$, linoleic acid; $36.3 \%$, linolenic acid; $1.7 \%$, arachidic acid; $0.5 \%$, behenic acid; $0.4 \%$, and lignoceric acid; $0.9 \%$. Major fatty acids were palmitic, oleic and linoleic acid, which composed around $94 \%$. The rice cultivar with the highest linolenic acid was cv. Jonajo (2.1\%), and cvs. Pochoenjangmebye and Sandudo showed the highest composition of palmitic $(23.4 \%)$ and oleic acid (44.8\%), respectively. Cultivar Pochuenjangmebye exhitibed the highest composition of saturated fatty acid (28.1\%), while cvs. Sandudo and Modo showed the highest mono-unsaturated (44.8\%) and poly-unsaturated (42.4\%) fatty acid composition, respectively. The oleic acid showed negative correlation with palmitic and linoleic acid, while positive correlation between behenic and lignoceric acids was observed.

\section{(175) Variety- and Cultivation Place-dependent Variations in Capsaicinoid Content of Red Peppers Produced in Cheongyang Area}

Jae-Ho Lee*, Hyun-Il Cha, Sang-Mi Moon, Kyoung-Shim Cho, Young-Sang Lee

Soonchunhyang Univ., Biological Resources and Technology, Shinchang-myon Eupnae-ri 646, Asan, Chung-Nam, 336-745, South Korea; 
Red pepper, as an ingredient of Kimchi, is an important horticultural crop in Korea, and capsaicinoid content is a major factor determining the pungent quality of red pepper. To clarify the factors affecting capsaicinoid content, 122 red pepper samples of 24 varieties were collected from 21 cultivation sites in Cheongyang area, South Korea, and their nordihydrocapsaicin (NDC), capsaicin (CAP), and dihydrocapsaicin (DHC) contents were evaluated by using an HPLC. The average content of NDC, CAP, and DHC were 4.8, 74.2, and $26.5 \mathrm{mg} / 100 \mathrm{~g}$, respectively, and its relative composition ratios were slightly affected by variety or cultivation places. In most cultivation places, capsaicinoid contents showed significant dependence upon variety, in that cv. WangJangKum $(225.5 \mathrm{mg} / 100 \mathrm{~g})$ exhibited 6.2-fold higher total capsaicinoid contents when compared to cv. ChonHaTongIl (36.2 mg/100 g). Even the same cultivar (e.g., WangDaeGum) exhibited almost 2-fold variations according to cultivation places, indicating the dependence of capsaicinoid content of red peppers upon the cultivation sites. Analysis of variance revealed significant variety-cultivation place interactions in CAP, DHC, and total capsaicinoid contents, but not in NDC. This data suggests the necessity of more-careful selection of variety and cultivation place corresponding to the expected pungency of harvested red peppers.

\section{(176) Yield Data from 2005 and Instrumental and Sensory Evaluation of Tomato Fruits from Plants Grown in High Tunnels at Beltsville, Md., or Obtained from Commercial Sources}

Donald Krizek*1, Robert Saftner ${ }^{2}$, Eunhee Park², Judith Abbott ${ }^{3}$, Mary Camp ${ }^{4}$, David Clark ${ }^{1}$

'USDA-ARS, ANRI, Sustainable Agric. Systems Lab., BARC-West, Beltsville, MD, 20705-2350; ${ }^{2}$ USDA-ARS, PSI, Produce Quality \& Safety Lab., BARC-West, Beltsville, MD, 20705-2350; ${ }^{3}$ USDA-ARS, ANRI, Produce Quality \& Safety Lab., BARC-West, Beltsville, MD, 20705-2350; ${ }^{4}$ USDA-ARS, BA, Biometrical Consulting Services, BARCWest, Beltsville, MD, 20705-2350

A study of tomato (Lycopersicon esculentum Mill.) production and quality in high tunnels was conducted. Seedlings of 'Oregon Spring' and 'Red Sun' were transplanted weekly to two high tunnels at Beltsville, Md., from 23 Mar. to 13 Apr. 2005. Data were recorded on the date of anthesis, leaf expansion, and marketable yields of tomato fruits for each cultivar and transplant group under UV-transmitting (+UV) and UV-blocking (-UV) covering materials. Instrumental and sensory quality characteristics of fruit obtained from 'Oregon Spring' and 'Red Sun' in the two high tunnels were compared with field- and hydroponic greenhouse-grown fruit obtained from a wholesale warehouse. 'Oregon Spring' plants flowered in 16-17 days from transplanting vs. 25 days for 'Red Sun'. 'Red Sun' produced $3 \times$ as much leaf area as did 'Oregon Spring'. The fresh weight of 'Red Sun' tomatoes in the +UV and-UV high tunnel was $60 \%$ and $22 \%$ greater, respectively, than that of 'Oregon Spring'. Intact fruit or extracts were used for measurements of firmness, titratable acidity (TA), soluble solids content (SSC), and aromatic volatile concentration. The SSC of high tunnel-grown tomatoes was higher than that of commercially grown fruit. Field-grown tomatoes had the highest firmness and hydroponically-grown tomatoes had the highest concentration of volatiles. 'Red Sun' fruit from plants grown under-UV had a higher SSC than corresponding fruit grown under+UV. High tunnel-grown tomatoes had higher sensory scores for sweetness, flavor, and for acceptability of texture, taste and overall eating quality than commercially grown fruit. These results are the first to show that high tunnel-grown tomatoes generally have better consumer acceptance than those grown commercially.

\section{(177) Open Column Chromatographic Separation of Health-promoting Bioactive Citrus Limonoids}

Clark Wilson*, G.K. Jayaprakasha, Bhimanagouda Patil

Texas A\&M University, Vegetable and Fruit Improvement Center, Department of Horticultural Sciences, College Station, TX, 77845

Open column chromatography is an effective and common technique for the separation and purification of chemical constituents. Limonoids are found in significant quantities in citrus fruits. Citrus limonoids have documented anti-cancer activity in several types of cancer, such as breast, colon, skin, and neuroblastoma in animal models and in vitro cell culture studies. Furthermore, limonoids have shown anti-inflammatory properties and inhibitory effects on bone resorption. In addition to many potential health benefits, limonoids have also shown antifungal and insect anti-feedant properties. To meet the large demand of limonoids for bioactivity studies, defatted grapefruit seeds were extracted using acetone and concentrated under vacuum. The dried extract was loaded onto a silica gel column and eluted with mixtures of dichloromethane and ethyl acetate with increasing polarity to obtain three compounds. The purity of the compounds (1-3) have been analyzed by HPLC and the structures have been identified by using NMR spectra and mass spectra as nomilin, limonin, and deacetylnomilin, in respective order of elution. The results will be presented in greater detail on the poster. This project is based upon work supported by the USDA-CSREES underAgreement USDAIFAFS \#200152102 02294 and USDA\#200534402-14401 "Designing Foods for Health" through the Vegetable \& Fruit Improvement Center.

\section{(178) Ultraviolet Radiation Influences Grapefruit Juice Bioactive Furocoumarins}

Sara Simpkins*, Basavaraj Girennavar, G.K. Jayaprakasha, Bhimanagouda S. Patil

Texas A\&M Univ., Vegetable \& Fruit Improvement Center, College Station, TX, 77845

Irradiation of fruit and vegetables can potentially be used by industry as a quarantine method to contain insect pests, microorganisms, and to extend shelf life. Gamma, electron beam, and ultraviolet radiation are the most frequently used radiation techniques. These radiation treatments have an effect on bioactive compounds. Grapefruit juice contains bioactive compounds such as limonoids, flavonoids, and furocoumarins. Bioactive furocoumarins in grapefruit juice have been found to increase the bioavailability of many drugs. Bergamottin, dihydroxybergamottin, and paradisin A are major furocoumarins that are shown to inhibit the activity ofCYP P4503A4 and P-gylcoprotein, which are involved in the first pass metabolism of drugs in the gut. This results in a dose-dependent increase of the drug beyond what is intended. Furocoumarins are photoreactive compounds and will readily react to ultraviolet radiation. The effect of various doses of ultraviolet radiation was investigated on 'Rio Red' and 'Marsh White' grapefruit. Grapefruit juice $(50 \mathrm{~mL})$ was irradiated with Ultraviolet A, B, and C radiation for either 5 or $10 \mathrm{~min}$. Treated and control juice was extracted with 100,50 , and 50 $\mathrm{mL}$ of ethyl acetate. The extract was then dried and reconstituted with methanol and filtered through a $0.4-\mu \mathrm{m}$ PTFE membrane filter. The methanol extracts were analyzed by HPLC and the concentrations of bergamottin, dihydroxybergamottin, and paradisin A were compared for UVA, UVB, UVC, and control. This project is based upon work supported by the USDA-CSREES under Agreement USDA IFAFS \# 20015210202294 and USDA \# 2005-34402-14401 "Designing Foods for Health" through the Vegetable \& Fruit Improvement Center.

Poster Session 41-Nutrition

30 July 2006, 1:15-2:00 p.m.

\section{(212) Influence of Mineral Nutrient Source in NFT} System and Temperature on the Yield of Cos Lettuce 'Cimmaron'

Jonathan N. Egilla*, Isabelle Nyirakabibi

Lincoln University, Cooperative Research Program, Jefferson City, MO, 65102-0029

Two-week-old seedlings of cos lettuce (Lactuca sativa L. var. longifolia) 'Cimmaron' were transferred into NFT hydroponic troughs in July and Sept. 2005. The crop was grown either in a polyethylene or polycarbonate greenhouse. Mean July temperature and maximum relative humidity $(\mathrm{RH})$ in the two greenhouses were 30.5 and $27.7^{\circ} \mathrm{C}$ $\pm 0.32{ }^{\circ} \mathrm{C} ; 81.3 \%$ and $84.7 \%$, respectively. In September, the mean 
temperature and $\mathrm{RH}$ in the same greenhouses were $22.6^{\circ} \mathrm{C}$ and 21.9 ${ }^{\circ} \mathrm{C} \pm 0.30{ }^{\circ} \mathrm{C} ; 95.6 \%$ and $99.2 \%$, respectively. Lettuce crop grown with Peters Excel ${ }^{\circledR}\left[15 \mathrm{~N}-5 \mathrm{P}_{2} \mathrm{O}_{5}-15 \mathrm{~K}_{2} \mathrm{O}\right.$; (Excel)], had higher fresh mass (FM) and dry mass (DM) compared with either Peat-lite ${ }^{\mathbb{R}}$; $\left[15 \mathrm{~N}-16 \mathrm{P}_{2} \mathrm{O}_{5}\right.$ $17 \mathrm{~K}_{2} \mathrm{O}$; (Peat-lite) $]$ or All-Purpose Hydroponic Fertilizer ${ }^{\mathbb{B}}\left[9 \mathrm{~N}-4 \mathrm{P}_{2} \mathrm{O}_{5}-15\right.$ $\mathrm{K}_{2} \mathrm{O}$; (All-Purpose)], but lower DM/FM. At harvest, the crop had good market quality, regardless of mineral nutrient source (MNS). MNS significantly $(P \leq 0.05)$ influenced yield (FM and DM) in September, regardless of greenhouse type. However, in July only Peat-lite caused significant $(P<0.0252)$ increase in DM, under the higher temperature condition of greenhouse I. This trend suggests that good quality lettuce and sustained yield can be obtained with the soluble fertilizers Excel and Peat-lite, which are not formulated for hydroponic crop production. Furthermore, 'Cimmaron' can produce satisfactory yield under relatively high temperature conditions. However, taste panel evaluation and nutrient content analysis of lettuce produced with these various fertilizers are necessary to determine consumer satisfaction.

\section{(213) Establishing Minimum Critical Nutrient Standards for Herbaceous Perennials}

Allison L. Byrd, Velva A. Groover, Holly L. Scoggins*

Virginia Polytechnic Institute and State University, Horticulture, Blacksburg, VA, 24061

Herbaceous perennials comprise one of the fastest-growing segments of floriculture crop production. Little information has been published regarding their mineral nutrition requirements, specifically nutrient foliar standards and nutrient deficiency symptoms. Our research documents visual symptoms of nutrient deficiencies in the chronological order in which they appear from incipient to advanced stages, and establishes foliar analysis standards by correlating nutrient levels with initial and advanced stages of symptoms for nitrogen, phosphorus, potassium, calcium, magnesium, sulfur, iron, copper, zinc, manganese, molybdenum, and boron. Rooted cuttings were grown for as many as 12 weeks in a hydroponic system with modified Hoagland's solution minus the element of interest, along with complete nutrient solution controls. Taxa selected for study were representative of commonly grown varieties and of differing families; Verbena canadensis 'Homestead Purple' (clump verbena), Heliopsis helianthoides 'Bressingham Doubloon' (false sunflower) and Veronica $\times$ 'Goodness Grows' (speedwell). Days to incipient deficiency symptoms ranged from 5 to 60 . Chronological order of appearance was consistent with $\mathrm{Fe}$ and $\mathrm{Ca}$ symptoms appearing within 10 days for all three taxa. Other deficiency symptoms varied both by taxa and in chronology. Root and shoot dry weights were closely and positively correlated with time to incipient deficiency.

\section{(214) Adult Pear Response to Integrated Nitrogen Fertigation and Drip Irrigation System}

Xinhua Yin*, Clark Seavert, Jinhe Bai

Oregon State University, Mid-Columbia Agricultural Research and Extension Center, Hood River, OR, 97031-9512

Responses of adult pear to the integrated $\mathrm{N}$ fertigation and drip irrigation system have not been documented in Oregon. Afield trial was conducted on adult pear at the Mid-Columbia Agricultural Research and Extension
Center, Hood River, Ore., in 2005. Two N and water management systems (integrated $\mathrm{N}$ fertigation and drip irrigation system; and broadcast application of dry $\mathrm{N}$ fertilizer to the soil surface and microsprinkler irrigation system) were compared on pear cultivars of Bartlett and Golden Russet Bosc, and rootstocks of $\mathrm{OH} \times \mathrm{F} 97$ and $\mathrm{OH} \times \mathrm{F} 87$. The responses of these cultivars and rootstocks to the integrated $\mathrm{N}$ fertigation and drip irrigation system were similar. The integrated $\mathrm{N}$ fertigation and drip irrigation system consumed $1450 \mathrm{~m}^{3} \cdot \mathrm{ha}^{-1}$ of irrigation water during the entire season from May to September, reducing irrigation water use by $73 \%$ compared with $5297 \mathrm{~m}^{3} \cdot \mathrm{ha}^{-1}$ under the current system - broadcast application of dry $\mathrm{N}$ fertilizer to the soil surface and microsprinkler irrigation system averaged over the four cultivar and rootstock combinations. The fruit yield was statistically similar for the integrated $\mathrm{N}$ fertigation and drip irrigation system and the broadcast application of dry $\mathrm{N}$ fertilizer and microsprinkler irrigation system on the average of the four cultivars and rootstocks. Differences in fruit size and color were negligible between the two $\mathrm{N}$ and irrigation management systems. Overall, our results suggest that adopting the integrated $\mathrm{N}$ fertigation and drip irrigation system does not cause significant reduction in yield or quality of adult pear; the integrated $\mathrm{N}$ fertigation and drip irrigation system could be a profitable and environmentally sound management alternative for pear production.

\section{(215) Effects of Groundcover and Drip Irrigation on Mineral Nutrition and Productivity of Sweet Cherry}

Xinhua Yin*, Clark Seavert, Jinhe Bai

Oregon State University, Mid-Columbia Agricultural Research and Extension Center, Hood River, OR, 97031-9512

The effects of in-row groundcover and drip irrigation on mineral nutrition and productivity of sweet cherry are largely unknown in the Pacific Northwest. A field experiment was initialized on the Mel Omeg orchard at The Dalles, Ore., in 2005. This orchard had been managed under microsprinkler irrigation and in-row herbicide application since its establishment in 1998. Two irrigation systems (drip irrigation, microsprinkler irrigation) and four in-row ground management systems (straw mulch, white fabric cover, black fabric cover, and no cover with herbicide applications) were evaluated in a split-plot design with four replicates. Drip irrigation reduced irrigation water consumption by $74 \%$ relative to microsprinkler during the entire season from May to September. Compared with no cover, black fabric lowered water use by $8 \%$, and straw mulch and white fabric had a $1 \%$ to $3 \%$ reduction in water use. Fruit yield was similar for drip irrigation and microsprinkler. There was a trend of yield increase with groundcovers relative to no cover. Fruit firmness, size, and sugar content did not differ regardless of irrigation or groundcover systems. Drip irrigation increased marketable fruits by $5 \%$ (absolute value) via reducing fruit surface pitting compared with microsprinkler. Differences in soil-available N, P, K, Ca, Mg, S, $\mathrm{B}, \mathrm{Zn}, \mathrm{Mn}, \mathrm{Cu}, \mathrm{pH}$, and organic matter were negligible between the two irrigation systems and among the four groundcover treatments. However, drip irrigation resulted in slightly lower concentrations of $\mathrm{N}, \mathrm{P}, \mathrm{K}, \mathrm{Ca}, \mathrm{B}$, and $\mathrm{Mn}$ in leaf than microsprinkler. Overall, our results suggest that in-row straw mulch and fabric covers and drip irrigation could be feasible management alternatives for sweet cherry production in the Pacific Northwest. 